\title{
1 Coral indicators of past sea-level change: a global repository of U-series dated benchmarks
}

3 Fiona D. Hibbert (a,b), Eelco J. Rohling (a,b), Andrea Dutton (c), Felicity H. Williams (b), Peter M.

4 Chutcharavan (c), Cheng Zhao (b), Mark E. Tamisiea (d)

6 a. Research School of Earth Sciences, The Australian National University, Canberra, ACT 2601,

7 Australia (fiona.hibbert@anu.edu.au)

8 b. Ocean and Earth Sciences, University of Southampton, National Oceanography Centre,

9 Southampton, SO14 3ZH, UK

10 c. Department of Geological Sciences, University of Florida, Gainesville, Florida, USA.

11 d. National Oceanography Centre, 6 Brownlow Street, Liverpool, L3 5DA, UK

\section{Abstract}

15 Fossil corals provide valuable data for reconstructing past sea levels, as they are often well 16 preserved in the fossil record and can be dated with U-series methods. Here we present a global and 17 internally consistent database of U-Th dated fossil coral sea-level indicators, including full 18 consideration of all (known) associated uncertainties (both vertical and chronological). We include 19 carefully determined taxon-specific depth distributions, rather than blanket depth uncertainty terms 20 as used in most previous work. This is based on a synthesis of extensive modern ecological 21 information on depth ranges. These ranges are found to be spatially variable (between ocean basins, 22 between regions, and on sub-regional scales) because depth itself is not limiting - instead, depth 23 distributions arise from complex physical, chemical, and biological interactions with coral-reef 24 growth, distribution, and composition. One of the main causes for recognition of the greater depthvariability of coral taxa has been the routine inclusion of deep-diving and ROV surveys in coral ecological studies over the past few decades, which has broken through the "shallow-water" bias of early surveys by adding frequent observations on deeper occurrences (although more are needed). It is also clear from our assessment that coral habitat-depth distributions must be determined on the species level to reduce uncertainties in reconstructions of past sea levels, and that application to sea-level studies then requires these studies also to identify fossil corals to the species level. Most existing data were determined only to the genus level, which gives rise to wide uncertainties in habitat depth and, hence, sea level. Our database contains extensive metadata to assist evaluations

33 of dating quality, as well as geomorphic and stratigraphic metadata. We demonstrate with examples 34 how such metadata can help to evaluate sea-level reconstructions, for example by identifying outlier 
35 points. One example discusses the Last Interglacial (LIG), where we use the available data with their 36 uncertainties to assess probabilistically the time at which local sea levels exceed that of the present, 37 which yields a mean age of 124.6 ka with $95 \%$ probability bounds at 118.5 and $129.5 \mathrm{ka}$. We 38 conclude with identification of key outstanding issues relating to: (i) current incomplete 39 understanding of tectonic setting (including the current lack of independent verification of 40 uplift/subsidence rates and reliance of somewhat unsatisfactory, and circular, use of the elevation of 41 Last Interglacial deposits); (ii) the depth-distributions of coral taxa and; (iii) the complete 42 documentation of stratigraphic, geomorphological information and other contextual information, 43 with suggestions for strategies to address these issues. 
Fossil corals have provided valuable insights into past changes in sea level, from the early studies that tested Milankovitch pacing of glacial-interglacial cycles (e.g., Broecker et al., 1968; Mesolella et al., 1969), to more recent work on detailed, high-resolution reconstructions of past sea levels (e.g. Deschamps et al., 2012) that provide constraints for investigations of past ice-sheet dynamics (e.g. Clark et al., 2002; Stanford et al., 2011; Lambeck et al., 2014).

Fossil corals offer distinct advantages for reconstructing past sea levels, principally their good preservation potential, and the potential for obtaining precise, numerical ages using U-series dating. They also have a wide distribution in the topical/subtropical regions and many of these sites are farfield (i.e. far away from the centres of the former ice sheets), where glacio-isostatic adjustment (GIA) influences are minimised (e.g. Clark et al., 2002; Bassett et al., 2005). However, the coral data distribution is heterogeneous in space and time; i.e., they are limited to tropical/subtropical regions and represent periods of reef construction, and provide discrete data points rather than continuous sea-level records. In addition, taphonomic and diagenetic factors influence coral preservation, and the relationship between the present elevation of the fossil coral and former sea levels often remains insufficiently constrained. In this paper, we first review modern ecological studies of the main controls on coral growth, and formulate from this a comprehensive assessment of depthdistributions. Thereafter, we present and discuss a new compilation of U-series dated fossil coral data, which is quality-checked and internally consistent, includes relevant contextual metadata, and gives full consideration of uncertainties.

\section{PRINCIPAL CONTROLS ON REEF DEVELOPMENT AND DISTRIBUTION}

Sceleractinian ('hard') corals are composed of polyps that secrete an aragonitic skeleton using calcium and carbonate ions precipitated from seawater. Zooxanthellate sceleractinian corals have endosymbiotic photosynthetic algae. Scleractinian corals may take various growth forms (branching, massive, encrusting, solitary, free-living i.e. not attached to the substrate etc.) and in this review we concentrate on the reef-forming (hermatypic) corals.

Coral reefs are complex structures that consist of both primary (skeletogenesis) and secondary (e.g., marine (re)cementation) structures with a potential for significant biomineralisation (e.g., Barnes and Devereux, 1984). The exact mechanisms of calcification and the role of symbionts remain debated, and - despite considerable progress in recent decades (e.g., Cohen and McConnaughey, 
81 aragonite remains incomplete (Allemand et al., 2004, 2011). The principal components required for 82 coral growth are: light, carbon dioxide and inorganic nutrients for photosynthesis; organic food for 83 organic tissue and organic matrix synthesis; and calcium and carbonate ions for skeleton formation.

85 Coral reefs can be separated into three main geomorphological zones: (i) the back-reef and reef flat 86 zone; (ii) the reef crest, and (iii) the fore-reef (which includes the reef slope), within which different 87 benthic assemblages make statistically distinct contributions to reef framework construction (e.g., Hopley et al., 2007; Woodroffe and Webster, 2014). The back-reef zone is a low-energy zone with lagoons featuring sea-grass beds, patch reefs and sand plains. The reef flat and reef crest (or algal ridge where encrusting coralline algae replace corals in the highest wave-energy settings) is formed from consolidated calcareous material, corals, and coralline algae. This is a high-energy zone with potential for breakage, desiccation through exposure at low tide, and ultra violet (UV) light stress.

93 The fore-reef continues seaward of the reef crest to depth. This lower-energy zone has steep 94 gradients in light and temperature, with the greatest coral diversity typically at intermediate depths of 15 to 30 m (e.g., Burns, 1985; Huston, 1985; Cornell and Karlson, 2000) and decreasing with increasing depth. We refer the reader to Woodroffe and Webster (2014), Kennedy and Woodroffe (2002) and Montaggioni and Braithwaite (2009) for detailed considerations of reef morphology.

The interplay of physical, biological and chemical factors (e.g., substrate, incidence of severe storms, predation, disease, etc.) determines the structure and composition of coral reefs, including their growth form, taxonomic composition, distribution, and their preservation potential within the fossil record. These factors operate on a variety of geographic scales: some affect the global distribution of reefs; others control the dimensions and geometry of individual reefs; yet other factors influence - at the ecosystem level - the community composition, zonation, and habitat availability (including the distribution and abundance of populations/taxa); and, finally, several factors combine to affect corals at the individual level, through recruitment, growth rates, size, form, reproduction, and mortality.

In this section we review the main influences on coral growth (Figure 1), with a focus on the ecological and hydrological factors.

\section{2.1. Temperature}

113 Sea surface temperature is a major determinant in the growth and distribution of modern coral reefs 114 (Macintyre and Pilkey, 1969; Andrews and Gentien, 1982; Johannes et al., 1983; Veron and Minchin, 
115 1992), influencing the composition and structure of reef communities, and regulating the aragonite

116 saturation state of the surface waters (growth is optimal in warm waters that are super-saturated

117 with respect to aragonite; Kleypas, 1997; Kleypas et al., 1999). Temperature also exerts a control on

118 the latitudinal extent (geographical range) of species, and comparison between fossil and modern

119 coral ranges suggests a substantial poleward expansion of the range of many coral taxa during the

120 Last Interglacial (LIG) relative to the present as a result of increased temperatures, although

121 equatorial diversity was reduced (Kiessling et al., 2012). Most modern coral reef growth is limited to

122 waters with temperatures between $\sim 18$ and $31{ }^{\circ} \mathrm{C}$ for most of the year (Hubbard, 1997; Kleypas et

123 al., 2008), but some reef corals are able to tolerate temperatures as low as $11^{\circ} \mathrm{C}$ (Veron, 2000).

124 Prolonged exposure to temperatures outside this range may lead to reduced photosynthesis, coral

125 bleaching, and mortality.

127 Coral reef growth is generally confined to tropical latitudes, although warm surface currents can 128 enable growth outside the tropical latitudes (e.g., Kuroshio, Leeuwin, and Agulhas Currents). In 129 addition, thermal gradients within basins, such as the Red Sea, may determine local/regional coral 130 reef distribution and diversity (Veron, 1995, 2000). Changes in these local or regional conditions or 131 currents and their associated temperature regimes can influence coral distributions resulting in 132 expansion or contraction of the latitudinal range of coral species (e.g., Roberts et al., 1982; Veron, 133 1992; Abram et al., 2001). For example, Greenstein and Pandolfi (2008) demonstrate a contraction 134 in geographic range and a change in assemblage composition within modern reefs compared to 135 fossil Last Interglacial reefs of Western Australia, in response to decreased temperatures from a 136 weakened Leeuwin Current, given that this current brings warm equatorial waters to higher 137 southern latitudes. Similarly, Muhs et al., (2002a, b, 2006) use molluscs and corals as part of the 138 wider reef assemblage, to infer changing thermal and ocean current changes (for California, Hawaii 139 and Bermuda).

\subsection{Salinity}

142 Corals are generally thought to be tolerant of salinity variations, generally growing within a range of 14330 to $38 \mathrm{psu}$ with some species tolerating salinities of $\sim 40 \mathrm{psu}$. Extended exposure to low-salinity 144 waters may reduce growth rates, reproductive success, photosynthesis, and respiration (Coles and 145 Jokiel, 1992; Muthiga and Szmant, 1987; Richmond, 1993; Moberg et al., 1997; Porter et al., 1999; 146 Lirman et al., 2003) although the effects are often species dependent. Past changes in sea surface 147 salinities (e.g., due to altered precipitation regimes associated with changing monsoon dynamics) 
148 are relatively poorly constrained, but salinity changes since the Last Glacial Maximum (LGM) are not

149 thought to have been a limiting factor on subsequent coral reef development (Montaggioni, 2005).

\subsection{Nutrient Availability}

152 Coral reefs are often found in what are considered to be nutrient-poor regions where an increase in nutrient availability can increase macro-algal growth, which increases competition for space within the reef system. In addition, the often-associated phytoplankton blooms increase water turbidity and decrease light penetration (Hallock, 1988; Hallock and Schlager, 1986; Chazottes et al., 2002; Sanders and Baron-Szabo, 2005).

In detail, the situation is more nuanced: coral reefs span a wide range of nutrient levels (Kleypas et al., 1999, Atkinson et al., 1995), and nutrient flux affects coral zonation in multiple ways. Upwelling as well as terrestrial and riverine inputs affect coral distribution via the transport of nutrients to sites (e.g., Maxwell and Swinchatt, 1970; Andrews and Gentien, 1982; D'Elia and Wiebe, 1990; Leichter et al., 2003). Increased nutrient supply can be beneficial (promoting reef growth or enhancing calcification) as well as deleterious - reducing rates of skeletogenesis (Marubini and Davies, 1996), and/or increasing bioerosion (Hallock, 1988; Hallock and Schlager, 1986), and/or increasing the incidence and severity of coral disease (Bruno et al., 2003, 2007). Overall, the resulting changes in coral distribution reflect changing community structures as a whole due to several factors (turbidity, light availability, etc.), rather than just changing nutrient availability (Szmant, 2002).

\subsection{Turbidity}

170 Fluctuations in turbidity regimes can occur at the local and/or regional scale, with turbid 171 environments 'compressing' the habitable vertical range of corals to a few metres (Veron, 1995). 172 High inputs of sediment can have detrimental effects on reef frameworks, in part through the 173 reduction in light penetration. High sediment environments are often associated with fewer coral 174 species, reduced live cover and growth rates, decreased calcification and net productivity, and 175 reduced rates of reef accumulation (Rogers, 1990). Increased turbidity often coincides with elevated 176 nutrient levels, which result in a further decrease in light penetration (see section 2.5 for impacts of 177 irradiance levels). High sediment inputs also affect reef frameworks through abrasion and particle 178 deposition. This results in changes in reef zonation, growth forms, and rates of mass mortality, 179 through smothering or burial (Loya, 1976; Acevedo et al., 1989; Rogers, 1990; Shin 2000; 180 Montaggioni, 2005). However, some coral species and communities can tolerate a wide range of 181 turbidity and light levels, forming sites of relatively high diversity (Veron, 1995), for example in 
182 Jamaica (Mallela and Perry, 2007) and in nearshore turbid zones of the Great Barrier Reef (Woolfe

183 and Larcombe, 1998; Larcombe et al., 2001; DeVantier, et al., 2006; Browne et al., 2012). Thus, some

184 communities can become established and persist in environments dominated by persistent fine-

185 grained sediment deposition (Perry et al., 2008). Coral polyps themselves can be effective in

186 removing clays and silts (e.g., through ciliary currents, tissue expansion, direct tentacle manipulation

187 and pulsed partial contraction of the polyp; Stafford-Smith and Ormond, 1992). Waves and current

188 action provide an additional means of removing suspended and settled material.

Experiments suggest that some symbiotic corals can alter their balance between autotrophy and heterotrophy, making heterotrophic carbon a significant source of energy when photosynthetic carbon is unavailable due to bleaching events or in deep and/or turbid waters. This allows corals to broaden their ecological niche and tolerate turbid conditions (Anthony and Fabricius, 2000; Antony and Connolly, 2004). In addition, so-called phenotypic (shape) plasticity enables corals to regulate light capture across a large spectrum of light conditions (Anthony et al., 2005).

Turbidity increases have been implicated as a major factor in the demise of coral reefs in the geological record (e.g., Lighty et al., 1978; Kleypas, 1996), although changing sediment regimes may be only one of a multitude of related influences that led to cessations of reef formation (e.g., Perry and Smithers, 2011).

\subsection{Irradiance Levels}

203 The amount of light received by corals varies spatially and temporally, and is influenced by cloud 204 cover, turbidity, tidal changes, reef topography, and depth. The depth of light penetration varies 205 with latitude and distance from the shore (Kleypas et al., 1999), with many coastal reefs receiving reduced light levels due to high turbidity. For example, in the most turbid regions of the Great Barrier Reef, corals are found only within the upper 3 to $4 \mathrm{~m}$ of the water column, while on the outer shelf, corals are found to depths up to $100 \mathrm{~m}$ (van Woesik and Done 1997, Hopley, 1994, Cooper et al., 2007). At some mid-ocean Pacific atolls, irradiance levels can be compatible with coral growth even at $160 \mathrm{~m}$ depth (Montaggioni, 2005).

212 Irradiance and coral growth are often positively correlated, with a strong link to calcification in many 213 scleractinian corals (Goreau, 1959; Chalker, 1981; Marubini et al., 2001; Reynaud et al., 2004; 214 Schlacher et al., 2007; Schutter et al., 2008). As stated by Veron (1995), "light, not temperature, is by 215 far the most ecologically limiting of all physical-environmental parameters". As light intensity and 
216 penetration depth decrease, the habitable depth range of many corals becomes compressed and

217 there is a decrease in the depth at which reef building ceases (Hallock and Schlager, 1986, Veron

218 1995). For corals with symbiotic algae, production of photosynthates is reduced when irradiance

219 levels are low (Titlyanov et al., 2001), and a decrease in internal pH may develop due to reduced

220 photosynthesis, which in turn may lead to less favourable conditions for calcification (Schneider and

221 Erez, 2006). Similarly, the increased energy required to repair light damage may exceed the increase

222 in photosynthetic energy received at high irradiance levels (photoinhibition; Iglesias-Prieto et al.,

223 1992). Corals may adapt to changing light levels by altering their growth form (e.g., from mounds to

224 plates in order to maximise exposure of photoreceptors (Hubbard, 1997), altering the density of

225 zooxanthellae (endosymbionts) or pigment (Titlyanov et al., 2001), or altering the composition of

226 pigment according to the spectrum of the available light (Dustan, 1982). In light-limited conditions,

227 corals will rely on heterotrophy for their energy needs, to compensate for reduced photosynthetic

228 activity (Anthony and Fabricius, 2000; Antony, 2006).

229

230

\subsection{Substrate availability and antecedent topography}

231 The availability of suitable substrate is "the most biogeographically limiting of all physical-

232 environmental parameters" (Veron, 1995). The eastward attenuation of coral species richness across

233 the Pacific is considered to be primarily due to substrate availability coupled with the survival and

234 dispersal capacity of recruits (Veron, 1995). Substrate type can also influence coral distributions,

235 with colonisation occurring preferentially on karst or rough lava flows, whereas unconsolidated or

236 smooth surfaces are less favoured sites for coral growth (Cabioch et al., 1995). Additionally, highly

237 reflective substrates such as carbonate-rich sands amplify light intensity surrounding coral colonies

238 and increase stress levels, particularly during bleaching events (Oztiz et al., 2009).

239

240 Coral recolonisation (e.g., during high sea levels after episodes of low sea level) may be inhibited by

241 the contraction or absence of suitable nurseries (shelf edges, banks, seamounts etc.). These provide

242 potential refugia and centres of dispersal once ocean circulation is conducive to larval transport,

243 e.g., after episodes of lowered sea levels (Montaggioni and Braithwaite, 2009). Topographic highs or

244 other elevated regions offer advantages to coral reef formation, for example by optimising larval

245 recruitment (Hubbard, 1997); the general distribution of such highs can directly constrain reef

246 locations; e.g., for Florida see Lidz et al. (1997), for Belize see Purdy (1974), Gischler and Hudson

247 (2004), and for Palau Islands see Kayanne et al. (2002). However, topographic lows, such as those

248 found in some Hawaiian locations (e.g., a drowned stream valley within a morphologically complex

249 antecedent substrate), provided a refuge for Holocene reef growth in a region of high wave energy 
that would otherwise limit most Holocene reef growth to a generally thin veneer (Grigg, 1998;

251 Grossman and Fletcher, 2004).

\subsection{Hydrodynamics (waves, tides and disturbances)}

254 Wave energy and tidal regimes exert a control on the ecological zonation, habitat availability and 255 morphology of modern reefs (Veron, 2000; Rasser and Riegl, 2002), with disturbances (sometimes 256 catastrophic; e.g., storms, cyclones, hurricanes/typhoons, or tsunamis) altering sedimentary inputs, 257 temperatures, salinity, and hydrodynamic patterns that result in breakage and redistribution of coral debris, in effect remodelling the reef surface.

Waves can promote the exchange of nutrients, larvae, and particulate food (Pineda, 1991). In highenergy environments, the enhanced circulation of nutrients and/or the removal of metabolic waste products can promote coral growth (Atkinson and Bilger, 1992; Atkinson et al., 1994; Hearn et al., 2001), but at higher energy levels, community structure can change toward more stress-tolerant growth forms (e.g., encrusting or massive corals) to compensate for the increased mechanical erosion (Done, 2011). For example, the community structure of modern reefs in Hawaii is primarily a function of wave energy and depth: in wave-exposed environments, coral growth is frequently disturbed by wave-induced breakage, scour, and abrasion, which results in frequent turnover and regrowth of fragmented colonies that are rarely thicker than a single living community (Grigg, 1998).

Tidal regimes impact corals over a wide range of habitats, not just those within the intertidal zone. For example, the reduced tidal range of the open ocean, relative to continental margins, often results in fewer inter-tidal habitats, whereas high tidal ranges generally result in a wider range of habitats and maximise the area available for coral growth (Veron, 2000). Within the tidal zone, there is a potential for periodic subaerial exposure of reefs, strong wave action, large temperature fluctuations, and high solar irradiation, as well as the tidal modulation of currents and waves. However, the reef crest is one of the most biologically productive parts of a coral reef (Chisholm, 2003) and accounts for more than half the species richness (Karlson et al., 2004), which indicates that such extremes in environmental conditions are generally within the tolerance of modern corals (Anthony and Kerswell, 2007). Extreme low tides may, however, lead to coral mortality, particularly when coupled with high irradiance levels (Anthony and Kerswell, 2007). This is not necessarily detrimental, as it helps to maintain high species diversity due to periodic removal of competitive taxa, as also occurs with storm-induced coral mortality (Connell, 1978; Rogers, 1993). 
284 Pulsed upwelling can promote coral growth and diversity (e.g., Leichter and Genovese, 2006;

285 Schmidt et al., 2012). However, in regions of strong upwelling, these positive effects may be

286 counteracted by low temperatures, low $\mathrm{pH}$, and high nutrient loading, which favour algal rather than

287 coral growth (McCook et al., 2001).

289 The effect of hydrodynamics on coral distribution and diversity may be local (e.g., wave scour 290 producing resistant reef spurs orientated towards high-energy coastlines; Shinn, 1966), and may 291 extend to the reef/regional scale, with ecological zones dependent upon wave exposure (Geister, 292 1977) and the tendency for reefs to become more developed on windward as opposed to leeward 293 island aspects (Grigg, 1998; Veron, 2000; Yamano et al., 2001). Storms and/or hurricanes can also 294 change sea surface temperatures and turbidity regimes (potentially leading to coral mortality), or cause clearing of reef surfaces that then become available for re-colonisation (e.g., Scoffin, 1993).

296 Finally, changing hydrodynamics can alter the accommodation space available for reef growth 297 (Grossman and Fletcher, 2004).

299 Within the geological record, one of the most important hydrodynamic influences is breakage and 300 redistribution of debris due to permanent wave agitation (Hughes 1999) and major storms, with 301 potential implications for stratigraphic integrity of the fossil reef (Scoffin, 1993). Such events may 302 result in severe modification of the reef by mechanical destruction and reforming surface 303 morphology, displacement of blocks downslope, and/or landward redistribution of sediments from 304 reef margins (i.e., accelerating the process of backreef infilling) (Hubbard, 1992; Scoffin, 1993; 305 Blanchon et al., 1997; Braithwaite et al., 2000; Macintyre et al., 2001; Yamano et al., 2001; Rasser 306 and Riegl, 2002). Reef rubble may accumulate as talus on steep slopes and cause the displacement 307 of material to depth, while on gentle slopes this displacement may result in onshore transport and 308 formation of large piles of rubble (Rasser and Reigl, 2002). Within the geological record, such 309 disturbance events may be recognised by a change in lithology (Dunham, 1962; Insalaco, 1998), 310 although there may be a permanent cycle of destruction and regeneration of coral leading to a 311 constantly reworked substrate (Blanchon et al., 1997) and reef interiors that are "more garbage pile 312 than an in-place assemblage of corals, cemented together into a rigid framework" (Hubbard et al., 313 1990).

315 Storms or other hydrodynamic disturbances may be evident within the fossil record. For example, an 316 'extreme wave event', probably as a result of a tropical cyclone or tsunami, is thought to be 317 responsible for the abrupt infilling of the Paraoir reef (Philippines) by reef rubble and bioclastics 
318 (Gong et al., 2013). Recognition of such acute disturbances within the geological records can only be

319 achieved by thorough examination of stratigraphic (i.e., consistency within each stratigraphic unit),

320 geomorphic, lithologic, and geochemical (i.e., petrography of the reef structure) information (for a

321 review, see Scoffin, 1993), as well as detailed consideration of the coral assemblages themselves. For

322 example, some Pleistocene terraces of Barbados contain distinct $\sim 2 \mathrm{~m}$ high in-situ Montastraea

323 annularis colonies separated by piles of Acropora debris. Although the coeval growth of both species

324 on the reef is possible, growth considerations suggest that Acropora only existed for a relatively

325 short period time, or else the massive $M$. annularis forms would have been unable to reach their

326 large dimensions due to shading effects (Scoffin, 1993). More extreme hydrodynamic origins (a

327 tsunami or large wave) have been controversially suggested for the elevated (at $\sim+20 \mathrm{~m}$ ) boulders

328 of Eleuthera Island (Bahamas) (Hearty, 1997), although these may also have resulted from cliff

329 erosion or be relict features associated with karst towers (Panuska et al., 2002; Mylroie, 2007).

330 Tsunami or giant wave origins have also been suggested for deposits on Hawaii ( +190 m deposits

331 of coral and coralline algae fragments) (Moore and Moore, 1984, 1988), but again there are

332 alternative explanations for the origin of these deposits (e.g., lithospheric deformation) (Keating and

333 Helsley, 2002).

\subsection{Population dynamics, predation, competition and disease}

336 Coral reproduction may occur through broadcast or brooding behaviour. Broadcast spawning

337 releases eggs and sperm in mass spawning events and fertilisation occurs within the water column.

338 The gametes may remain within the water column for several weeks and can distribute offspring

339 over a wide geographic area (Veron, 2000). In coral brooding reproduction, fertilisation and

340 embryogenesis occur internally and the larvae may be ready for settlement immediately. Once

341 settled on a suitable substrate, coral growth is rapid in order to avoid overgrowth by algae or burial

342 by sedimentation (Barnes and Hughes, 1999). Reproduction may also occur asexually through

343 budding (i.e., division into clones; Sumich, 1996) and fragmentation, where such fragments may

344 attach and develop into new colonies.

346 Larval recruitment influences both distribution and diversity of coral populations, reflecting 347 variations in stock size, larval survival, and settlement behaviour (Hughes and Tanner, 2000; Hughes 348 et al., 2003). Macroalgae and cyanobacteria (Kuffner et al., 2006) can have a detrimental impact on 349 coral recruitment and survival of juvenile corals (Tanner, 1995; Jompa and McCook, 2002,), as well 350 as on the growth, reproduction, and survival of established corals (Kuffner et al., 2006, Burkepile and 351 Hay 2006, 2008; Carpenter, 1986, Williams and Polunin, 2001; Hughes et al., 2007), and on the 
352 prevalence of coral disease (Nugues et al., 2004). Along with availability of suitable substrates, limits 353 on survival and dispersal capacities are thought to account for the eastward attenuation of coral 354 species diversity across the Pacific (Veron, 2000; Montaggioni, 2005).

Biological interactions govern the population density of coral species (Montaggioni and Braithwaite, 2009). Examples include: (a) grazing influences on the diversity and growth of coral (Burkepile and Hay, 2010; Bellwood et al., 2004), and on the establishment and maintenance of coral-dominated communities by removing competitively 'superior' marcoalgae (Birkeland, 1977; McClanahan and Muthiga, 1988; Burkepile and Hay, 2006); (b) bioerosion controls on reef dynamics by reshaping reef topography and/or weakening colony structures of live branching corals (Hutchings, 1986, Sammarco, 1996); (c) predation impacts on coral fitness and rates of coral decline (Knowlton et al., 1990; Rotjan et al., 2006), and on coral colony growth and survival (including reproductive potential) (Veghel and Bak, 1994; Rotjan, 2007; Rotjan and Lewis, 2008); and (d) coral disease, which can change the community structure of a reef (Willis et al., 2004; Page and Willis, 2008; Haapkyla et al., 2011). Stress factors, such as increased temperature, nutrient inputs, etc., may both increase the prevalence of coral pathogens, and weaken coral resistance to disease (Aronson and Precht, 2001). Increased ocean temperature is thought to be a main driver of the incidence of coral disease (Harvell et al., 2002, 2007; Rosenberg and Ben-Haim, 2002; Bruno et al., 2003, 2007; Miller et al., 2009). Coral disease may impair zooxanthellae cell division (e.g., yellow band disease), result in tissue necrosis and/or depression of the colony surface (e.g., dark spot disease) (Cervino et al., 2001), and cause weakening of skeletons (Aronson and Precht, 2001).

\subsection{Depth}

375 Most species of zooxanthellate corals are generalists; they can occupy a wide range of habitats, reef

376 and non-reef, with vertical ranges from sub-tidal to substantial depths (Veron, 1995). The influence

377 of biotic factors on reef zonation is highly complex, and there is no simple relationship with 378 bathymetry (Perrin et al., 1995). There is relatively little published research on the direct relationship 379 between coral distribution and depth; instead coral diversity and/or distributions are assessed in 380 terms of factors such as light, temperature, and nutrient availability, for which depth may often 381 serve as a (rough) proxy.

383 The literature suggests that corals are "depth-generalists" that occur in both shallow and deep 384 water, with most species occurring within very shallow to $-40 \mathrm{~m}$ water depth (Carpenter et al., 385 2008). Indeed, based on the International Union for the Conservation of Nature (IUCN) Red List data 
386 (currently the most comprehensive global compilation of the depth distribution of coral species), the 387 maximum global coral species occurrence was at mean depth of $-27 \pm 17 \mathrm{~m}$ (Carpenter et al., 2008). 388 Coral diversity generally peaks at intermediate depth (-15 to $-30 \mathrm{~m}$ ) (Burns, 1985; Huston, 1985; 389 Cornell and Karlson, 2000). Most studies, however, do not directly investigate coral distribution and 390 depth. Surveys are generally undertaken to monitor/ascertain coral reef 'health' in terms of 391 community composition, and any change through time. Typically, such surveys are undertaken by 392 divers, although in recent years there has been an increasing use of autonomous underwater 393 vehicles, which - coupled with technological improvements in diving - have allowed greater depths 394 to be reached (approx.. -150 m depth; Hinderstein et al., 2010). This has enabled more extensive investigation and documentation of deeper-living coral species, including a burgeoning literature on mesophotic reefs. These are defined as deep fore-reef communities that occur in low-light habitats and are composed of zooxanthellate and azooxanthellate scleractinian corals, macroalgae and sponge communities (Lesser et al., 2009). They typically have a depth range of -30 to $-40 \mathrm{~m}$, and can extend to over $-150 \mathrm{~m}$ in tropical and subtropical regions, depending on water quality, light penetration, etc. (Hinderstein et al., 2010; Kahng et al., 2010). Mesophotic reefs are considered extensions of shallow reef ecosystems (with biological, physical and chemical connectivity with these reefs and communities; e.g., Bongaerts et al., 2010; Bridge et al., 2012), although they have coral assemblages that are generally of lower diversity (Liddell et al., 1997; Jarrett et al., 2005; Armstrong et al., 2006; Hinderstein et al., 2010). The genetic and ecological linkages between shallow and deeper reefs remain unclear (Van Oppen et al., 2011). Mesophotic reefs are thought to have acted as refuges during past instances of environmental disturbance (e.g., Bongaerts et al., 2010), but they are poorly documented within the fossil record and potentially difficult to recognise without precise dating and a comprehensive assemblage approach (e.g., Abbey et al., 2013).

Technological advancements are extending the maximum documented depth for many species of zooxanthellate corals. For example: Agaricia grahamae was documented at -119 m in the Caribbean 412 (Reed, 1985), Leptoseris fragilis at -145 m in the Red Sea (Fricke et al., 1987), and Leptoseris sp. at >$413100 \mathrm{~m}$ in the Indo-Pacific (e.g., Kahng and Kelley 2007; Maragos and Jokiel 1986; Fricke et al., 1987), 414 with observations of the latter reaching $153 \mathrm{~m}$ in Hawaii (Kahng and Maragos, 2006) and including 415 abundant cover at $-90 \mathrm{~m}$ depth on the Great Barrier Reef (GBR; Hopley et al., 2007). Also notable is 416 the documentation of coralline algae at $-268 \mathrm{~m}$ in the Bahamas (Littler at al., 1985, 1986), given that 417 association of coralline algae with corals is increasingly being used in sea-level reconstructions 418 (Cabioch et al., 1999b; Iryu et al., 2010; Camoin et al., 2012; Descamps et al., 2012). 
420 The vertical ecological zonation of corals is well documented (e.g., for the Atlantic see Goreau, 1959;

421 Mesolella 1967; Lighty et al., 1982; for the Pacific see Maragos, 1974; for the Indian Ocean see Loya, 422 1972) and is a function of intrinsic and extrinsic factors, and their interactions. In addition, 423 morphological variation can occur across a depth range. Again this variation is correlated with 424 environmental conditions (light depth, wave energy, etc.) rather than depth sensu stricto (Veron, 425 1995). Such community structure and species diversity can be retained in the fossil record (e.g., 426 Mesolella 1967; Lighty et al., 1982; Edinger et al., 2001; Pandolfi and Jackson, 2006), although the 427 accuracy and resolution of fossil corals for sea-level reconstructions may be limited by time428 averaging (i.e., temporal mixing of different coral cohorts within the fossil coral assemblage; see section 1.1.12 for further discussion) (Edinger et al., 2007).

431 Changes in accommodation space (the vertical and lateral space available for coral reef growth) 432 occur through processes such as tectonic movements (uplift/subsidence, etc.) and sea-level changes 433 that alter the water depth above a reef. With an increase in accommodation space, reef growth may 434 fill the space (i.e., 'keep up' or 'catch up' depending upon the rate of relative sea-level rise; 435 Neumann and Macintyre, 1985), but local processes (e.g., larval supply and survival, hydrodynamics, 436 sediment supply) may prevent reef growth from filling any additional space (e.g., the high wave 437 energy settings of Hawaii; Grigg, 1998). A modern example from Heron Island, Australia, 438 demonstrates the ability of coral reefs to respond to changes in accommodation space in response 439 to rising sea levels and other, coincident hydrodynamic factors (Scopélitis et al., 2009). Reef growth 440 may also 'turn off' when the increase in accommodation space ceases and vertical accumulation 441 reaches dynamic equilibrium with other factors (wave energy, disturbances, etc.). In some instances, 442 growth may be arrested and 'drowning' occurs as vertical accretion can no longer track the 443 increasing water depth and concomitant decrease in light, temperature, etc. (i.e., 'give up' response, 444 cf. Neumann and Macintyre, 1985).

446 These different responses to changing accommodation space have been identified within the fossil 447 record. For example, Holocene sea-level stillstands have been inferred from the elevation of upper 448 (dead) surfaces of micro-atolls (e.g., Smithers and Woodroffe, 2001; Kench et al., 2009; Yu et al, 449 2009), while instances of 'keep up' reef growth and limited aggradation due to accommodation450 space reduction (e.g., Strasser et al., 1992; Braithwaite et al.; 2000; Grossman and Fletcher 2004), as 451 well as reef 'drowning' (e.g., Ludwig et al., 1991; Blanchon and Shaw 1995; Webster et al., 2009) 452 have been inferred from changes in sedimentary facies and benthic communities. Rather than 453 relating to depth per se, the effect on coral growth and diversity reflects instead the changing 
physio-chemical conditions brought about by external factors (sea-level change, tectonic subsidence, etc.). The following sections (2.10 and 2.11) present further discussion of the impacts of sea-level change and tectonics.

\subsection{Sea-level change}

459 High species diversity within the central Indo-Pacific is thought, in part, to be due to the interaction 460 of long-term tectonic activity and changes in sea level. Bathymetry of this region was such that, even 461 though reefs were repeatedly aerially exposed during Pleistocene sea-level lowstands, the complex coastline and creation of diverse shallow habitats in close proximity to deep ( $>150 \mathrm{~m}$ ) waters meant that there was minimal broad-scale species dislocation during intervals of rapid sea-level change (Veron et al., 2009).

Changes in sea level may lead to severe (or catastrophic) ecological disruption; e.g., via changing sedimentary regimes, loss of accommodation space (a lack of accommodation space being a limiting factor for reef growth in some instances, Kennedy and Woodroffe, 2002), and disruption of coral dispersal due to changing oceanographic patterns. In addition, the rate of sea-level change may affect the composition of coral reefs; Neumann and Macintyre (1985) suggest that reef growth is a balance between rate of sea-level rise and the ability of the reef to keep pace. The differing responses proposed ("keep-up", "catch-up and "give-up") should be recognisable within the fossil record: (i) "keep-up", where reefs maintain crests at or close to sea level, are preserved as shallowwater growth forms; (ii) "catch-up" - where reef growth initially occurs in deeper water as the rate of sea-level rise exceeds the rate of growth and where reefs later caught up, often due to a decrease in the rate of sea-level rise - produces a successive change from deeper to shallower water assemblages; and finally (iii) the "give-up" scenario, where there is a sudden cessation in growth possibly due to a sudden rise in sea level or a sudden change in environmental or oceanographic conditions and accretion can no longer keep pace, 'drowning' the reef.

In the fossil record, the successive highstand reefs of the Huon Peninsula (Papua New Guinea) were

482 found to have similar coral taxonomic composition and species richness, and it was also noted that 483 the spatial differences in community composition within reefs of the same age were greater than 484 between reefs of different ages (Pandolfi, 1996, 1999). In contrast, the lowstand species 485 compositions of the Huon Peninsula reefs look significantly different. This has been ascribed to 486 changes in the relative influence of ecological processes between the highstands and lowstands, or 487 community response to changed environmental conditions (Tager et al., 2010). 


\subsection{Tectonics}

490 The tectonic history of a region may have a profound influence on the diversity and distribution of

491 modern coral species. This may occur through: subsidence (e.g., Darwin, 1874); folding and faulting

492 (e.g., Purdy et al., 2003); crustal rifting, differential tilting and uplift of tectonic blocks (e.g., Plaziat et

493 al., 1998; Dullo and Montaggioni, 1998); coseismic uplift (e.g., Ota et al., 1993; Ota and Chappell

494 1996; Tudhope et al., 2000; Sieh et al., 2008) and earthquake-related displacement of reef rubble

495 (Rasser and Riegl, 2002; Zachariasen et al., 1999); thermal subsidence of mid-plate hot-spot

496 volcanoes (e.g., Moore and Campbell 1987; Moore and Clague 1992); and flexure forebulges

resulting from localised landmass loading (e.g., Faichney et al., 2010).

In tectonically unstable regions, coral reefs may suffer repeated environmental perturbations, which can create a variety of coral habitats and high species diversity (Pandolfi, 1992; Veron, 1995; Wilson and Rosen, 1998; Veron et al., 2009). Tectonic uplift (subsidence) can also decrease (increase) the accommodation space available for coral growth (see section 1.1.9). The very high species diversity of the "coral triangle" (a region of the western Pacific stretching from the Philippines to the Solomon Islands in which over 600 species of reef-building coral species have been recorded) is the product of interplay between repeated tectonic and environmental disturbance, and sea-level variations (e.g., Keith et al., 2013). Specifically, proximity of deep refugia and complex island shorelines meant that a diversity of habitats was available for recolonisation, and ensured minimal dislocation during rapid sea-level change, thus forming a geographic location that promotes larval recruitment and favourable environmental conditions (Veron et al., 2009).

Exposure of fossil reef material to enhanced diagenetic effects may occur through tectonic uplift

512 (i.e., exposure of the uplifted coral terrace to percolating waters; e.g., Hamelin et al., 1991,

513 Henderson et al., 1993), with sustained and prolonged uplift further increasing the potential for

514 diagenetic alteration. These diagenetic effects are further discussed below (section 2.12).

\subsection{Taphonomy and Diagenesis of coral reefs}

517 The fossil record represents past reef communities after significant modifications. The two main

518 issues to be considered are potential non-preservation, and selective removal or alteration of 519 material by physical, chemical, or biological processes. 
521 Reefs are complex systems that comprise primary and secondary growth frameworks, marine 522 cementation, mechanical and biological erosion, and post-depositional diagenesis. Their complex 523 structure may result in differing susceptibility of the coral reef and individuals within the reef to 524 diagenesis, time averaging and transport of material, and the potential for preferential preservation 525 of certain species or adults/size classes within species. For example, dense fine-grained coral 526 skeletons are most physically durable (Chave, 1962; Brett, 1990), and corals with a branching linear 527 growth form such as Acropora cervicornis are more susceptible to storm damage than massive head corals such as Montastraea annularis (Scoffin, 1992).

Fossil coral reef frameworks typically comprise in situ corals and coral rubble bound by calcareous encrusters and cements. Skeletons are frequently reworked in reef settings, with selective destruction of certain growth forms, individuals and age-classes, as well as a mixing of successive generations (also known as time averaging) (Scoffin, 1992; Pandolfi and Greenstein, 1997a;

534 Greenstein and Pandolfi, 2003). Ecological time averaging is the spatial or temporal mixing of 535 organisms that occupied the same location at different times into a single deposit (Kowalewski and 536 Bambach, 2003; Kidwell and Holland, 2002; Kidwell and Flessa, 1995; Kowalewski 1996). This 537 accumulation and mixing of successive cohorts (Scoffin, 1992; Edinger et al., 2001) directly 538 constrains the temporal resolution achievable from fossil coral reef records, especially given that geological sections rarely provide full 3-dimensional information of coral reef structure. Moreover, the fossil record may not be a faithful representation of the living coral assemblage

542 (Pandolfi and Michin, 1995; Greenstein and Pandolfi, 2003). For example, rare or slow-growing corals may be under-represented in the fossil record due to dilution by other fast-growing taxa or rubble inherited from the death assemblage. This loss in fidelity was highlighted by comparison of raised Pleistocene reefs with their modern counterparts in Barbados, which indicated that the fossil corals confirmed to be in growth position represented less than a quarter of the primary reef framework visible in their modern equivalents (Stearn et al., 1977; Scoffin et al., 1980).

Finally, post-depositional alteration can significantly alter the chemical characteristics of the fossil coral (e.g. the replacement of aragonite with calcite by subaerial weathering, freshwater leaching or percolation through the reef of waters supersaturated with $\mathrm{CaCO}_{3}$ ). For example, exposed fossil reefs (e.g., uplifted coral terraces) are prone to diagenesis and loss of sample integrity through contact with meteoric waters. The rate of alteration is dependent upon: the composition of the interstitial waters; the permeability of the framework; and the potential for complex interplay 
555 between meteoric, vadose, and phreatic waters with mixing of fresh- and seawater. The latter is

556 governed by inter alia: permeability; oxidation of organic matter; and surface and subsurface

557 hydrogeology. These effects are not necessarily confined to exposed corals and long-term

558 submergence is not a guarantee against alteration or dissolution (e.g., Sherman et al., 1999;

559 Montaggioni and Braithwaite, 2009).

560

561

\subsection{Summary and implications}

562 Within coral reefs, the interactions between physical, chemical and biological factors are numerous 563 and complex, which can hinder the identification of straightforward cause and effect relationships.

564 Coupled with the fact that most coral species are generalists (i.e., they can occupy a wide range of 565 diverse habitats and vertical ranges; Veron, 1995), this leads to heterogeneous reef structures and spatial variations in their distribution and composition (Figure 2).

These complications can be compounded in the fossil record, where additional processes (taphonomy and diagenesis, etc.) along with a limited 2-dimensional (section) or 1-dimensional (drill-core) perspective may render physical, chemical, and biological relationships virtually indistinguishable from one another. That is they fail to fully capture the heterogeneous reef structure evident in most modern coral reefs.

When reconstructing past sea levels from fossil coral reefs, the relationship between sample elevation and the position of sea level at the time of growth is a fundamental parameter. Unfortunately, modern ecological studies suggest that there is no direct relationship between coral growth and depth per se. Instead, depth can be considered a proxy for a multitude of factors that determine both species diversity and distribution. Sea-level reconstructions commonly also assume that the modern depth distribution is stable/constant through time. Given the spatial and temporal variability evident in modern coral communities, this assumption requires further testing.

\section{CORAL DISTRIBUTION AND DIVERSITY}

583 Variations in coral communities between different geographic regions (e.g., variations in coral 584 diversity, growth forms, species composition, spatial coverage, etc.) result in local and regional coral585 community zonation. These zones result from factors discussed in the preceding sections, which 586 induce variations 'within species' (i.e., morphological changes, often in response to environmental

587 gradients and which can lead to the emergence of geographic subspecies), and 'between species' 588 (e.g., presence/absence of species, or lack of common species between regions) (Veron, 1995). 
589 These variations in coral communities reflect, in the broadest sense: (i) the degree of geographic 590 separation (e.g., the evolutionary history and degree of genetic connectivity, as well as changes in 591 oceanic circulatory regimes, or the degree of dispersal success by coral species); (ii) latitude-

592 correlated environmental changes (e.g., temperature gradients); and (iii) the degree of isolation and 593 size of each distinct region (Veron, 1995). Additionally, the generalist nature of most corals means:

594 (a) that a species commonly found in one type of habitat in one region may be absent from similar 595 habitats in another, or found in completely different habitats; and/or (b) that species that in one 596 region occupy a wide range of habitats may be confined to just one particular habitat type elsewhere (Veron, 1995).

Attempts to delineate modern faunal distributions (Wallace, 1863; Wells, 1954; Stehli and Wells, 1971; Veron 1993, 1995) have resulted in a variety of biogeographic maps. A recent update of these yields a comprehensive evaluation of species distribution (Veron, 2000; Veron et al., 2009), in which 141 coral 'ecoregions' were defined (Figure 3). Below, we discuss relevant aspects for key regions covered by our coral sea-level database.

604

\subsection{Caribbean}

606 In high to moderate wave-energy settings, robust, branching Acropora palmata is the primary 607 framework builder (reef-crest and upper-reef zones), while Acropora cervicornis dominates in more 608 protected environments (fore- and back-reef settings) (Montaggioni and Braithwaite, 2009). The 609 table- and plate-forms of Acropora palmata in the Caribbean are particularly well suited to rapid

610 exploitation of a wide range of environments as growth rate, substrate coverage, and exposure to 611 sunlight are maximised (Veron, 1995). Montastraea annularis is the third of the principal species; it 612 exhibits a high degree of phenotypic plasticity and a wide depth distribution (Knowlton and Jackson, 613 1994).

615 The biogeographic distribution of corals in the Caribbean is fairly uniform relative to that in the Indo616 Pacific, which may reflect good connections between locations and generally uniform environmental 617 conditions (e.g., generally low terrigenous inputs) (Veron 1995), although local variations are evident 618 in the ecoregions identified by Veron et al. (2009). From comparison with Pleistocene reefs, the 619 structure of Caribbean coral communities appears, in general, to have changed little through the 620 Plio-Pleistocene (e.g. Budd et al., 1994, 1996; Mesolella, 1967, 1968; Jackson, 1992; Budd, 2000), 621 with only five species becoming extinct in the Caribbean during the past 1.5 million years (Budd et 622 al., 1994). Notable examples are the once common and widely distributed Pocillopora cf. palmata 
623 and Montastraea nancyi. M. nancyi was once as abundant and as widely distributed throughout the

624 Caribbean region as other species of the M. annularis complex for the half a million years before its

625 extinction at ca. 82 ka (Pandolfi et al., 2001; Pandolfi 2007). The general similarity of Caribbean

626 Pleistocene reef communities suggests a degree of community stasis despite repeated sea-level 627 oscillations (Hunter and Jones, 1996; Greenstein et al., 1998a, b; Pandolfi and Jackson, 2007).

\subsection{Indo-Pacific}

630 Species diversity is approximately an order of magnitude greater in the Indo-Pacific than in the

631 Caribbean (Veron, 2000). However, reef growth and carbonate production are similar between the two regions (Dullo, 2005), which highlights that diversity is not a control on reef growth. Latitudinal attenuations in species distributions are evident along the coastline of east Africa, both eastern and western Australia, northward along the Japanese coast, and northeast towards Hawaii (Figure 3). In high-latitude areas, species composition is primarily controlled by boundary currents, which determine the thermal regimes and create a 'one-way genetic connectivity' with upstream (tropical) communities (Veron, 1995).

Within the Indian Ocean, species diversity is fairly uniform with distinct longitudinal variations only in the eastern Indo-Pacific region. The central equatorial Indo-Pacific exhibits the highest species diversity and has been named the 'coral triangle' (605 zooxanthellate coral species, representing approx. $76 \%$ of the global complement; Veron et al., 2009). Reasons for this high species diversity include the complex interplay between repeated environmental perturbations, habitat complexity (and assumed evolutionary change) created by the unstable tectonics of the region, and the influence of repeated Pleistocene sea-level changes, as well as patterns of coral larval dispersion and oceanographic regimes (Veron et al., 2009). In contrast, the Hawaiian and far eastern Pacific are somewhat peripheral regions of species diversity. Persistence of taxa and coral community composition also characterise the fossil coral communities of the Pacific (Pandolfi, 1996, 1999; Webster and Davies, 2003). As mentioned in section 2.10, Pandolfi (1996) demonstrated greater diversity within fossil coral sites of the same age from the Huon Peninsula, than between reefs of different ages, which suggests that local environmental conditions exert a greater influence on diversity than differences in global factors such as sea level and atmospheric $\mathrm{CO}_{2}$ concentrations between successive highstands (Pandolfi, 1999). 
Here, we compile a comprehensive fossil coral database, to facilitate evaluation of the data in a 'holistic' manner that spans all major geological and ecological aspects that affect the use of coral benchmarks in studies of past sea level. Thus, the benchmarks possess well-expressed and substantiated uncertainties.

661

662 This effort is needed to address current problems within Quaternary science (e.g. the relationship 663 between sea level, ice sheets and changes in climate; the variability, rates and magnitude of sealevel change; the evidence and implications of a potential two-stage highstand during the last interglacial), which cannot be thoroughly addressed by looking at a single study, or a handful of studies, in isolation. Note that when this database is used, the contributions of the original authors should also be given due credit (e.g., Düsterhus et al., 2016).

Our overall aim is to create one harmonised (i.e., all data treated in a similar way) resource that serves not only to support sea-level reconstructions, but also highlights the state of the art and the remaining challenges, and so foster in-depth discussions about strategies to address the challenges. To achieve this, our specific objectives are:

1. to facilitate assessment of available $\mathrm{U}$-series dated coral sea-level markers within their

688 The latter term is critically important for refining sea-level reconstructions, in addition to properly 689 accounting for all (known) uncertainties. However, the relationship between the modern 690 distribution of corals and the depths at which they occur is far from straightforward. As seen in 
691 section 2, modern ecological studies suggest that depth by itself exerts little direct control on the 692 distribution of coral taxa. Instead, other biotic and abiotic factors influence modern coral 693 distributions, and some of these factors vary with depth. Furthermore, the depth relationships vary 694 spatially, and possibly also temporally. Nonetheless, information on the depth-distribution of the 695 fossil coral taxa is fundamental to the calculation of past sea levels and their uncertainties. We 696 therefore identify from modern census studies the species-level (where possible) depth distributions 697 for use in our sea-level calculations. We thus assess the available geological data within a welldocumented modern biological/ecological context.

We ensure that all appropriate fields within the database are 'harmonised' (i.e., treated the same throughout), so that they are internally consistent. Examples of such harmonisation are: (1) the single approach applied to all locations (where possible) for deriving the appropriate regional uplift term (any exceptions are clearly indicated); and (2) the recalculation of radiometric ages using the same decay constants for all samples, while also noting the originally determined values in the database. Although we inspect the degree of coherence in reconstructed sea-level records between sites (within uncertainties), we refrain from making glacio-isostatic adjustments (this is not a trivial exercise, and is being addressed in a separate study).

Section 4.2 briefly outlines the main parameters within the fossil coral database. It builds upon the compilations of Dutton and Lambeck (2012) and Medina-Elizalde (2012), and currently contains $>2,500$ data points (a greater than three-fold increase on both compilations) from 37 locations (Figure 4). Data from the sources involved in these previous compilations are incorporated in our database, but we have recalculated: the ages; corrected coral position $\left(Z_{c p}\right)$; and the reconstructed relative sea-level probabilities $\left(P_{R S L}\right)$ following our harmonisation. Our $P_{R S L}$ reconstructions include the re-evaluated taxon-specific habitat-depth distributions from section 4.2.4. We highlight that comparison of U-Th ages for a given sample between the three databases (i.e.,

718 Dutton and Lambeck, 2012; Medina-Elizade, 2012; this study) may reveal some age differences. Also, 719 ages in the databases may not be the same as those originally reported in the primary source. These 720 discrepancies arise for two reasons: (1) the use of different decay constants for ${ }^{230} \mathrm{Th}$ and ${ }^{234} \mathrm{U}$; and 721 (2) the consideration (or lack thereof) of the method of spike calibration during recalculation of the 722 ages. Differences between this study and the Dutton and Lambeck (2012) compilation can be 723 attributed solely to the current application of updated decay constants for ${ }^{230} \mathrm{Th}$ and ${ }^{234} \mathrm{U}$ by Cheng 724 et al. (2013) versus previous use of earlier decay constants after Cheng et al. (2000). The difference 
725 in absolute value of these decay constants is very small and in many cases has a negligible effect on

726 age, but the precision is greatly improved in the most recent generation of decay constants (Cheng 727 et al., 2013). Differences between the Medina-Elizade (2012) and Dutton and Lambeck (2012) 728 compilations arise because the method of spike calibration was not considered by Medina-Elizade 729 (2012). This has an effect on isotope activity ratios, and hence calculated age, when a gravimetric 730 standard was used to calibrate the isotopic spike. Our recalculated ages also include the decay constant error within the final age uncertainty.

733 As a rule, we use only published information to compile our database (to date, only data published 734 prior to January 2014 are included). We include only information readily available within the 735 published literature and include the following studies within the database: Andersen et al., 2008, 736 2010a,b; Ayling et al., 2006; Bard et al., 1990a, b, c, 1996a, b, 2010; Blanchon and Eisenhauer, 2001; 737 Blanchon et al., 2002, 2009; Bruckner and Radtke, 1989; Cabioch et al., 2003, 2008; Camoin et al., 738 1997, 2001, 2004; Chappell et al., 1996; Chen et al., 1991; Chiu et al., 2005; Cobb et al., 2003a; 739 Collins et al., 2003, 2006; Colonna et al., 1996; Coyne et al., 2006; Cutler et al., 2003, 2004; Delanghe 740 et al., 2002; Deschamps et al., 2012; Dia et al., 1992, 1997; Edwards et al., 1987b, 1993, 1997; 741 Eisenhauer et al., 1993, 1996; Esat and Yokoyama, 2006; Esat et al., 1999; Fairbanks et al., 2005; 742 Frank et al., 2006; Fruijtier et al., 2000; Galewky et al., 1996; Gallup et al., 1994, 2003; Grün et 743 al.,1992; Hamelin et al., 1991; Hearty et al., 1999, 2002, 2007a; Israelson and Wohlfarth, 1999; 744 Kennedy et al., 2012; Ludwig et al., 1996; McCulloch and Mortimer, 2008; McMurty et al., 2010; 745 Montaggioni and Hoang, 1988; Muhs et al., 2002a,b, 2006, 2011, 2012a,b; Multer et al., 2002; Nunn 746 et al., 2002; O'Leary et al., 2008a,b, 2013; Peltier and Fairbanks, 2006; Pirazzoli et al., 1993; Potter et 747 al., 2004; Riker-Coleman et al., 2006; Schellmann et al., 2004; Scholz et al., 2009; Sherman et al., 748 1999; Speed and Cheng, 2004; Stein et al., 1993; Stirling, 1996; Stirling et al., 1995, 1998, 2001; Sun 749 et al., 2005; Szabo et al., 1994; Thomas et al., 2009, 2012; Thompson and Goldstein, 2005; 750 Thompson et al., 2003, 2011; Toscano and Lundberg, 1999; Toscano et al., 2012; Vezina et al., 1999; 751 Walter et al., 2000; White et al., 2001; Yokoyama et al., 2001; Zazo et al., 2007; Zhao and Yu, 2002; 752 Zhu et al., 1993.

754 Most of the data within our fossil coral database are from the last deglacial interval ( 20\%) and the 755 last interglacial ( 30\%). Obtaining reliable age determinations becomes increasingly difficult the 756 further back in time, due to the lack of well-preserved specimens and the influence of diagenetic 757 processes. Theoretically, the U-Th method enables age determinations of up to 600 ka but in 758 practice there are few coral data older than about $200 \mathrm{ka}$. Improvements in analytical techniques (in 
759 particular the increased precision and accuracy offered by TIMS and MC-ICP-MS techniques over $\alpha$ -

760 counting techniques) have enabled local sea-level reconstructions on millennial rather than just 761 orbital timescales. Uncertainties increase with increasing age, so that in older periods, millennial762 scale sea-level reconstructions are not possible for comparison with those of the last deglaciation. 763 However, the older data remain valuable, for example, for the distinction of older interglacial 764 periods.

This presents a first step toward a comprehensive database of all coral U-Th data generated on mass spectrometers (excluding alpha-counting data) that both legacy data and future data can be added to. Alpha analyses tend to have larger uncertainties and are not included in the current version of the database but are nonetheless valuable and will be incorporated into future versions. The database presented here incorporates all available metadata (e.g., contextual information on geomorphology, taxonomy and stratigraphy of the sample) to enable users to assess the reliability of each sample for reconstructing past sea level. In section 4.3 , we evaluate some of the major implications of the collated information in more detail.

\subsection{Principal database parameters}

\subsubsection{Sample identifiers and location}

Each data point has been assigned a unique identifier within the database, along with the original sample identifier by which it was first published. Sample locations are as originally reported, with the proviso that many of the original publications lack detailed sample location information so that latitude and longitude are estimated.

\subsubsection{Tectonic setting (and uplift/subsidence rate)}

783 We initially intended to find independent estimates of uplift/subsidence rates for each location that 784 requires a tectonic correction. Unfortunately, it was not possible to obtain such independent 785 estimates for the vast majority of sites. One way to perform this correction would be to obtain a GIA 786 prediction of relative sea level at each site in the database for the LIG and use this value in 787 combination with the age and elevation of peak sea level for each site to calculate an uplift rate 788 (e.g., Creveling et al., 2015). In the absence of GIA modelling in this paper, we use a simple approach 789 using the age and elevation of the LIG terrace, which is less desirable as it is both circular and it 790 ignores that geographic variability in sea level that is due, in part, to GIA effects. We recalculated all 791 regional uplift/subsidence rates using the maximum elevation given for the LIG terrace at each site, and assuming a LIG sea level of $6.6 \pm 2 \mathrm{~m}$ (Kopp et al., 2009, 2013) and an age of $125 \pm 5$ ka (equation 

presented in the original publication (while ensuring that a consistent value is used for all data from such a site) (Table 1 ). We calculate uplift rates (in $\mathrm{m} / \mathrm{ka}$ ) as follows:

where

This approach assumes that uplift/subsidence has been linear through time, although we recognise that this assumption may not hold for all locations or time periods (cf. Schellman and Radtke, 2004). Additonally, although internally consistent, our procedure remains open to considerable uncertainties (cf. Creveling et al., 2015) and introduces additional uncertainties to any sea level reconstruction. It does, however, enable a first-order estimation of sea-level but it is an unsatisfactory approach for studies that wish to precisely constrain the position of sea levels

811 through time. Little or no independent information exists to verify the uplift/subsidence rates - this remains one of the most important parameters to require further attention.

\subsubsection{Sample elevation and stratigraphic context}

815 We record the method that was used to determine the present elevation of the sample (GPS,

816 levelling, or interpolation from map contours), and assign elevation uncertainty where none was

817 specified in the original publication; for example, all drill-core samples are assigned a $1 \mathrm{~m}$ elevation

818 uncertainty. We could not correct elevations to any specific datum (e.g., mean high water) because

819 there commonly is insufficient information to do so (i.e., no information on the datum relative to 820 which elevation was measured). Also, we could not (yet) confidently determine past tidal ranges at 821 each location. To date, only few models offer estimates of local or regional variations in palaeo-tidal 822 range (e.g., Hinton 1996; Uehera et al., 2006; Hill et al., 2011). Instead, we provide (modern) 823 indicative ranges (Table 2 ) from a global tidal model.

825 Geological and geomorphological context details were obtained from source publications, when reported (e.g., facies information, details of whether the sample is in situ or displaced, etc.). Terrace 
827 designation is that of the original authors (where reported) with any subsequent reanalysis or

828 change in accepted local nomenclature also noted. Incorporating these metadata allows assessment

829 of the stratigraphic integrity of sample series. For example, it allows evaluation of whether sample

830 ages obtained from within a stratigraphic unit are consistent with each other (including data from

831 multiple studies). However, note that - unlike sediment layers - coral reefs grow in 3-dimensions, so

832 that a prograding reef may contain a wide range of ages along the same elevation (or terrace). Such

833 age structure has been reported, for example, for Holocene growth on the Great Barrier Reef

834 (Marshall and Davies, 1982). The implication is that data should not be rejected where multiple ages

835 are observed for a single elevation. Likewise, age inversions that are identified on the basis of age

836 and elevation data alone should not be rejected out of hand because such relationships may be

837 entirely consistent with 3-dimensional development of the reef.

\subsubsection{Taxonomic identification and depth distribution}

840 The identification of coral is as given in the original papers; identification to species level is available

841 in $\sim 60 \%$ of the total fossil data, while $\sim 34 \%$ is identified to genus level only, and $6 \%$ is unidentified.

843 Many previous studies tended to assume a $6 \mathrm{~m}$ depth habitat for many species (e.g., Lighty et al., 844 1982; Toscano and Macintyre, 2003; Gischler and Hudson, 2003; Peltier and Fairbanks, 2006;

845 Medina-Elizalde, 2012). Some studies use a local modern analogue (i.e., incorporating the 846 characteristics of the modern coral assemblage at a site) to constrain the depth preference of fossil

847 corals (e.g., Montaggioni et al., 1997; Cabioch et al., 1999, Webster et al., 2009; Deschamps et al.,

848 2012). Apart from such local studies, however, there is sparse published research on the direct 849 relationship between coral distribution and depth. As discussed in section 2, corals are "depth850 generalists", with most species occurring within very shallow waters down to depths of as much as $85140 \mathrm{~m}$ (Carpenter et al., 2008). Other controls such as temperature, salinity, nutrients, predation, and 852 local environmental and substrate conditions, were found to exert a greater influence on the depth 853 limit of species than irradiance levels or depth per se (section 2). In addition, depth zonations for 854 coral taxa are less well defined in the Indo-Pacific than in the Caribbean (Woodroffe and Webster, 855 2014). In the Indo-Pacific, coral assemblages and associated coralline algae assemblages may give 856 better indicators of depth (Pandolfi, 1996; Montaggioni and Braithwaite, 2009).

858 It is therefore difficult to justify a blanket assumption that past sea level stood $6 \mathrm{~m}$ above the 859 elevation of the coral for all taxa at all locations. This is reflected in the increasing use of coral or 860 coral/coralline-algal assemblages (cf. Cabioch et al., 1999; Pandolfi and Jackson, 2001; Webster and 
861 Davies, 2003; Webster et al., 2004; Abbey et al., 2011; Deschamps et al., 2012) to refine depth 862 relationships.

864 Here we use data from modern ecological studies to assign modern depth relationships to each 865 fossil coral sample identified to genus or species level. Specifically, we use information from the 866 Ocean Biogeographical Information System (OBIS) (OBIS, 2014; a full list of extracted data and 867 references can be found in online supplementary material) and assign a median depth habitat and 868 uncertainties based on the modern depth distributions of each genus and species, respectively. The modern ecological data within OBIS are derived from credible and authoritative biological research initiatives and have passed internal quality control measures prior to release (e.g., verification of species name). The database contains over 700 datasets and more than 22 million records of marine life. For this study, we have extracted only coral depth data for species currently included in the fossil sea-level database (the exercise may be expanded for any new species added to the reconstructions). The modern studies include information from both shallow and deep (diver/automated underwater vehicle) surveys, often spanning several years.

876

We use only direct observations with a vertical precision $\leq 0.25 \mathrm{~m}$ in our analyses. Examples of the modern depth distributions of the main coral taxa used in sea-level reconstructions are given in Figure 5. The depth distributions are clearly variable, and tend toward skewed distributions (i.e., a

880 long tail to greater depths). There are significant differences between species, with some resembling 881 a lognormal distribution while others exhibit bi- or multi-modal distributions (e.g., Montastraea 882 annularis). For each species, we derive an estimate of the median water depth in which the species 883 lives using all locations available. We have chosen the median rather than the mean because the 884 depth distributions are not Gaussian or symmetrical (Figure 5), and because the mean is more 885 sensitive to outliers. The lower and upper bounds of the 95 and $68 \%$ confidence intervals were also 886 determined using the 2.5, 97.5, 16 and 84 percentiles, respectively (Table 3, depth distributions can 887 be found in the online supplementary material).

889 For some species, no or very limited observational data were available. In these instances, we have 890 used the genus relationship (e.g., Acropora danai, Favia speciosa, Pocillopora guadalupensis) 891 (marked with an asterisk in Table 3). However, the number of fossil corals from these groups is small 892 in our database. We highlight in Table 3 those depth relationships that are based on relatively few 893 (<300) observations (e.g., Alveopora sp., Gardinerosis planulata), and we recommend increased 894 caution when using these in sea-level reconstructions. For Oculina sp. and Oulophyllia sp., there 
895 were insufficient observational data to determine a robust depth relationship (33 and 183

896 observations, respectively). In these two instances only, we relaxed the acceptable depth precision

897 of the modern observations to $\leq 5 \mathrm{~m}$ and included data derived from museum specimens (this

898 increased the number of data to 287 and 240 for Oculina sp. and Oulophyllia sp., respectively). There

899 are no direct observations and only few museum specimens available for the solitary coral

900 Balanophyllia elegans $(n=88)$ and we therefore use data from the study of Gerrodette (1979) for

901 this species. It should be noted that most $B$. elegans specimens are from Californian emerged,

902 erosional terraces (e.g. Muhs et al., 2002b, 2006, 2012b) and are are not in growth position, which

903 results in spurious relationships between fossil elevation and former sea levels (and so this depth

904 distribution is not use in our reconstructions). The authors use shoreline angles etc. to constrain the

905 vertical position of past sea levels for these locations (see sections 5.1.2 and 5.3.1 for further

906 discussion).

907

908 Using our synthesis of modern, ecologically derived, and species-specific depth distributions, we 909 have evaluated the relationship between each modern coral taxon and its modern habitat-depth

910 distribution. For example, species of the genus Acropora have been observed in water depths

911 ranging from 0 to $-91 \mathrm{~m}$ : A. cytherea was observed at a depth of $-91 \mathrm{~m}$ in the Pacific (CRED Rapid

912 Ecological Assessments of Coral Population in the Pacific Ocean 2007-2010) and down to depths of -

91355 to $-60 \mathrm{~m}$ on the Great Barrier Reef (Bridge et al., 2012; Abbey et al., 2013). Our analysis suggests

914 that most (95\% probability) Acropora sp. live between -0.5 and -16.4 m (Figure 5, Table 3). Within

915 the genus, Acropora cervicornis has a wider depth range (-0.2 to $-48 \mathrm{~m}$ ) (Figure 5, Table 3): it was

916 observed at $-48 \mathrm{~m}$ in Puerto Rico (La Parguera, Puerto Rico Benthic Composition and Monitoring

917 Data, 2002 - Present); at -35 m in St Croix (St. Croix, USVI Benthic Composition and Monitoring Data,

9182002 - Present) and at -21 m in Cuba (Atlantic and Gulf Rapid Reef Assessment - Benthic; Marks,

919 2007). Acropora palmata is generally found between -0.35 and -9.4 meters water depth (95\%

920 confidence limits) (Figure 5, Table 3)), with a maximum observed depth of $-22 \mathrm{~m}$ at St Croix, US

921 Virgin Islands (St. Croix, USVI Benthic Composition and Monitoring Data, 2002 - Present), but this

922 increases to a maximum of $-41 \mathrm{~m}$ at this location if we allow depth precision of the observations

$923 \geq 0.25 \mathrm{~m}$ (St. Croix, USVI Benthic Composition and Monitoring Data, 2002 - Present). This accords

924 with the compilation in Lighty et al. (1982), which suggested a narrow range of $<-1 \mathrm{~m}$ to $-5 \mathrm{~m}$ for this

925 species in the Caribbean (note that most studies used in Lighty et al. (1982) occurred prior to the

926 advent of routine deep-water surveys), and with the range of -0.1 to $-40 \mathrm{~m}$ from the more recent

927 IUCN Red List (Carpenter et al., 2008) (Table 3). Comparisons of our depth relationships with 
928 previous assessments (e.g., Carpenter et al., 2008; Bridge et al., 2013) are shown in Figure 6 and 929 Table 3.

931 Most of the depth distributions (this study and Carpenter et al., 2008, Figures 5 and 6, Table 3) 932 corroborate the "depth generalist" tendency of most coral species, with the majority confined to the 933 upper $\sim 20 \mathrm{~m}$ water depth, and a few species extending to depths of $>50 \mathrm{~m}$ (e.g., Siderastrea 934 radians). This has implications for the sea-level precision achievable from fossil corals. For example, 935 use of a fossil Acropora palmata sample, which has a vertical range of $\sim 9 \mathrm{~m}$ (95\% probability range 936 from -0.4 to $-9.4 \mathrm{~m}$, median depth of $-1.5 \mathrm{~m}$ ), will result in smaller uncertainties than use of 937 Montastraea annularis, which has a $16 \mathrm{~m}$ range (95\% range from -1.1 to $-17 \mathrm{~m}$, median depth -9.7 $938 \mathrm{~m})$. This is not a new finding, but it is here more precisely quantified by synthesis of the - as yet 939 most complete biological/ecological database. Also, our synthesis emphasises that depth ranges are 940 much wider and more complex than commonly assumed in fossil coral-based sea-level studies.

942 Some species are not well constrained by modern observations (e.g. Oculina sp.) and caution should 943 be used when using these corals for sea level reconstructions. Oculina includes both zooxanthellate 944 and azooxanthellate species, but the two groups are not morphologically distinct (Veron, 1995). 945 Three species of Oculina are considered to be facultative symbiont bearers (Cairns, 1999). In Florida, 946 Oculina reefs have been identified at depths of -50 to $-60 \mathrm{~m}$ (Reed, 2002, 2006) and O. varicosa was 947 observed at -50 to $-152 \mathrm{~m}$ (Reed, 1980, 2006). On the Flower Garden Banks (Gulf of Mexico), $O$. 948 diffusa has been observed at $-95 \mathrm{~m}$ (Sammarco et al., 2014). The present lack of depth constraints 949 for this species (given its wide depth distribution), in conjunction with the lack of distinguishable 950 morphological feature for the facultative species (Veron, 1995), implies that Oculina is unsuitable for 951 precise relative sea level (RSL) reconstructions from fossil corals.

952

953 Our synthesis gives a 'maximum' species depth preference that applies when considering points 954 without further context; the vertical uncertainties may be reduced where stratigraphic, geomorphic, 955 or other biological information exists. For example, a fossil coral sample that can be firmly 956 associated with reef crest facies will have a much narrower vertical range than a coral of the same 957 species without a reef facies context. Unfortunately, records within our modern synthesis (and many 958 fossil records) have not differentiated between the different reef environments/facies.

960 Starting from section 4.3, we apply the new depth-distributions and their uncertainties in sea-level 961 reconstructions. This includes further assessment of habitat-depth complexities, in particular the 
962 substantial habitat-depth differences that appear to exist within single taxa on a variety of local

963 (reef), regional, and inter-oceanic scales. Prior to such applications, however, we must highlight 964 some caveats to our assessment of habitat-depth preferences. First, the information is limited to 965 regions where modern ecological surveys have been undertaken, and which have been included in 966 the OBIS database. Second, we are constrained by survey-methodologies included in the OBIS 967 database, many of which remain strongly focussed on the uppermost water column. Third, there are 968 limited observations in OBIS for some species (for example, there are no observations of the solitary 969 coral Balanophyllia elegans within the OBIS database, although it is an important species in fossil 970 studies, represented by 274 samples in our database, although the majority of these are not in 971 growth position, see section 5.1.2 for further discussion of the utility of these fossils for sea level reconstructions). Finally, we note that results may be refined as further information becomes available in OBIS, or through the addition of other studies, but care must be taken to avoid duplication when combining other studies along with the OBIS compilation, as that would bias the statistics.

976

\subsubsection{Sample age}

978 Comprehensive reviews of U-Th dating systematics in corals are available elsewhere (Edwards et al., 979 2003a; Stirling and Andersen, 2009; Dutton, 2015). All U-Th geochemical data reported in the initial 980 publications are included in the database, including ${ }^{238} \mathrm{U}$ and ${ }^{232} \mathrm{Th}$ concentrations, ${ }^{230} \mathrm{Th} /{ }^{232} \mathrm{Th}$ activity 981 or atomic ratios, and activity ratios of ${ }^{230} \mathrm{Th} /{ }^{238} \mathrm{U}$ (or ${ }^{230} \mathrm{Th} /{ }^{234} \mathrm{U}$ ) and ${ }^{234} \mathrm{U} /{ }^{238} \mathrm{U}$. Uncertainties are 982 included where possible. We record the instrument used for analysis, decay constants used, and 983 method of spike calibration. Where available, we also note the calcite content and the methodology 984 used for this determination. Wherever possible, missing data not included in the initial publications 985 were obtained from the original authors.

987 Activity ratios were recalculated using the Cheng et al. (2013) decay constants for ${ }^{234} \mathrm{U}$ and ${ }^{230} \mathrm{Th}$ in 988 cases where we were able to establish that the spike was calibrated gravimetrically. All ages and 989 initial $\delta^{234} U$ values were recalculated using Isoplot version 3.5 (Ludwig, 2003) assuming closed990 system behaviour and using the decay constants of Cheng et al. (2013). The reported uncertainties 991 include the error associated with the decay constants.

992

$9931-\left[\frac{{ }^{230} T h}{{ }^{238} U}\right]_{a c t}=e^{-\lambda_{230} T}-\left(\frac{\delta^{234} U_{(\text {meas })}}{1000}\right)\left(\frac{\lambda_{230}}{\lambda_{230}-\lambda_{234}}\right)\left(1-e^{\left(\lambda_{234}-\lambda_{230}\right) T}\right)$ (Equation 2)

994 where

$$
\left[{ }^{230} \mathrm{Th} /{ }^{238} \mathrm{U}\right] \text { act } \text { is the }{ }^{230} \mathrm{Th} /{ }^{238} \mathrm{U} \text { activity ratio; }
$$


1006

1007

1008

1009

1010

1011

1012

1013

1014

1015

1016

1017

1018

1019

1020

1021

1022

1023

1024

1025

1026

1027

1028

1029

$\lambda_{238}, \lambda_{234}, \lambda_{230}$ are the decay constants of ${ }^{238} \mathrm{U},{ }^{234} \mathrm{U}$ and ${ }^{230} \mathrm{Th}$ respectively (Cheng et al., 2000, 2013);

$\delta^{234} \mathrm{U}_{\text {(meas) }}$ is the measured value of the activity ratio of ${ }^{234} \mathrm{U} /{ }^{238} \mathrm{U}$ relative to secular equilibrium in per mille $\left(\delta^{234} U=\left(\left[{ }^{234} U /{ }^{238} U\right]-1\right) \times 1000\right)$; and

$T$ is the age of the sample in years.

The initial value of ${ }^{234} \mathrm{U}$ at the time that the coral grew is calculated by:

$$
\delta^{234} U_{\text {initial }}=\left(\delta^{234} U_{\text {measured }}\right) e^{\left(\lambda_{234} T\right)}
$$

(Equation 3)

We include ages reported in the original sources for comparison, as well as the originally reported isotope ratios and associated geochemical data, to enable users to perform their own calculations, if desired. The potential for open-system behaviour (i.e., remobilisation of nuclides) is recognised as a major limitation of the U-series dating method with the accuracy of ages limited to a greater degree by diagenetic effects than by analytical precision (Bard et al., 1992; Stirling et al., 1995). The potential for open-system behaviour increases with age (e.g., with exposure), but has been recognised even in younger samples that appear to be well preserved at the macro- and microscopic level (e.g. Henderson et al., 1993; Anderson et al., 2008). Diagenetic alteration may be episodic or occur over a prolonged period; it can occur upon deposition or at some interval later (e.g. upon exposure) with potentially multiple and differing modes of alteration (post-depositional gain and/or loss of $U$ and or Th) even within the same fossil coral (e.g., Scholz et al., 2009) (Figure 7).

Methods have been proposed to correct for open-system behaviour (e.g., Thompson et al., 2003; Villemant and Feuillet, 2003; Scholz et al., 2004). However, there is debate within the community regarding how and when such models may be appropriately applied to fossil coral U-Th data (e.g., Stirling and Andersen, 2009). The ages listed in the database are all closed-system ages. However, some of these corals have experienced open-system behaviour of the $U$ and/or Th isotopes. To detect and remove samples which have been altered, a variety of screening criteria can be used (Section 5). The disadvantage of screening out these altered data is that it produces a much smaller pool of samples from which to make interpretations. Another approach would be to evaluate the open-system behaviour of corals study by study (site by site) and use an open-system model such as that of Thompson et al. (2003) to make corrections to a subset of the data in cases where it is appropriate. 
1031 There are at least two pre-requisites to applying an open-system model to correct U-Th ages 1032 (Dutton, 2015). The first of these is whether the coral(s) have been modified in a way that is 1033 consistent with the geochemical array precdicted by the the open-system model (compare 1034 diagenetic trends in Thompson et al., 2011 with Scholz et al., 2009). If subsamples of the coral or 1035 multiple corals from the same outcrop display an array of ${ }^{230} \mathrm{Th}^{234} \mathrm{U}-{ }^{238} \mathrm{U}$ compositions that are consistent with the pattern predicted by the open-system model, this would provide some justification for an open-system modelling approach. In contrast, applications of the model to isolated data points (e.g., single analyses of corals or where the digenetic pattern has not been established) are dubious and become misleading for corals that have been altered along a different diagenetic pathway. The second pre-requisite is that the initial value of seawater $\delta^{234} \mathrm{U}$ is known (for

1041 the time when the coral grew); as this seawater value is an input parameter that defines the point at

1042 which the model 'stops' and calculates an age, the accuracy of the seawater value will directly

1043 translate into the accuracy of the interpreted age.

1044

1045 In reality, determining whether application of an open-system model is even more complicated. For 1046 example, there are cases where the geochemical array of data produced be comparing the $U$ and Th 1047 isotope compositions between coral heads follows the slope predicted by an alpha-recoil 1048 mechanism such as that of the Thompson et al. (2003) model, but the array of subsamples within 1049 each coral does not (e.g., Thompson et al., 2011). It is not clear that averaging the subsamples from 1050 each coral and then applying the model is appropriate if each individual data subsample has been 1051 affected differently. Also, rates and mechanisms of open-system alteration will be a function of 1052 climate hydrology, lithology, taxon (and related porosity and thickness of skeletal elements), as well 1053 as other site- or sample-specific factors. The overall implication is that a one-size-fits all open1054 system model is unlikely to capture all the observed modes of open system alteration in corals. For 1055 this reason, we explicitly discourage any attempt to apply an open-system model to the database as 1056 a whole.

\subsubsection{Reconstructed sea level and uncertainties}

1059 In the above, we ensured consistency of the four principal parameters by: (1) assigning appropriate 1060 uncertainties to the modern elevation of each sample; (2) applying empirically derived species1061 specific depth-distributions and their associated uncertainties (note, we use only the taxon-specific 1062 depth-distributions not palaeo-water depths derived from, for example, assemblage information); 1063 (3) determining uplift/subsidence rates for each geographical region using the same assumptions; 
1064

1065

1066

1067

1068

1069

1070

1071

1072

1073

1074

1075

1076

1077

1078

1079

1080

1081

1082

1083

1084

1085

1086

1087

1088

1089

1090

1091

1092

1093

1094

1095

1096

1097

and (4) recalculated all ages using the same procedure and decay constants. This allows us to recalculate both a corrected coral position $\left(Z_{c p}\right)$ and past sea levels with full consideration of the associated uncertainties.

In order to reconstruct past sea levels, we must consider the relationship between the position of the coral and the position of sea level at the time of coral growth. Without this, we only have a (tectonically) corrected coral position $\left(\mathrm{Z}_{\mathrm{cp}}\right)$ and associated uncertainties.

$Z_{c p}=H_{s a m}-(\Delta H / \Delta t)^{*} t_{s a m}$

(Equation 4)

where

$\mathrm{Z}_{\mathrm{cp}}$ is corrected coral position (in $\mathrm{m}$, negative values are below sea level);

$\mathrm{H}_{\text {sam }}$ is the modern elevation of the sample (in $\mathrm{m}$, positive is above and negative values are below sea level);

$\Delta \mathrm{H} / \Delta \mathrm{t}$ is the recalculated (equation 1 ) uplift/subsidence rate (in $\mathrm{m} / \mathrm{ka}$, increasing positive ages in kilo-years before present); and

$t_{\text {sam }}$ is the recalculated conventional age of the sample (in ka, increasing positive ages in kiloyears before present).

To reconstruct past sea level, we must also consider the relationship between the position of the coral and the position of sea level at the time of coral growth (i.e., where the coral was living the the water column). In order to do this, we need to change the frame of reference from mean sea level (i.e. the modern elevation at which the coral is measured with respect to mean sea level) to the position of the fossil coral (i.e., we know the present elevation of the coral but want to determine past sea levels) (Figure 8). For example, a living Acropora palmata coral occurs at a depth of $-1.5 \mathrm{~m}$ below present mean sea level (i.e., we know the depth of the coral relative to sea level), so that sea level is $+1.5 \mathrm{~m}$ above the position of the coral. In the fossil record, we know the elevation of the coral (corrected for any tectonic change), but we do not know the position of sea level at the time of its growth. Instead we can reconstruct the probability of sea level at the time the coral was living $\left(P_{R S L}\right)$ by assuming that the coral occurs at the median depth (i.e., that the elevation of the coral, $Z_{c p}$, occurs at the median of the modern depth distribution) and combining the corrected coral position $\left(Z_{c p}\right)$ uncertainties with the inverted depth probability distribution (Figure 8$)$. We combine these using a Monte Carlo approach of 350,000 simulations to derive a probability maximum $\left(\mathrm{P}_{\mathrm{RSL}}\right)$ associated with each coral position $\left(Z_{c p}\right)$ and an uncertainty distribution around that point. For each 
1098 coral, we obtain a set of randomly sampled values from the corrected coral position $\left(Z_{c p}\right)$ 1099 uncertainty, and a set of randomly sampled values from the modern taxon depth distribution and 1100 sum across the two errors. For each individual coral, we then have multiple instances across a 1101 combined error distribution. From this set we can generate the probability distribution, and extract a 1102 probability maximum and the (usually asymmetrical) associated 1-, 2- and 3- sigma equivalent levels 1103 (68\%, 95\%, and 99\% probability intervals).

1105 The result is a probability distribution of relative sea level $\left(\mathrm{P}_{\mathrm{RSL}}\right)$ for each coral, which represents the 1106 local sea level position and comprises both a eustatic and local glacio-isostatic component. As we 1107 include a more comprehensive suite of input uncertainties (most notably the depth-distribution 1108 ranges as derived from modern studies), our new $\mathrm{P}_{\mathrm{RSL}}$ calculations come with increased total vertical 1109 uncertainties relative to those in previous compilations (cf. Dutton and Lambeck 2012; Medina1110 Elizalde 2012). Our calculation of $\mathrm{P}_{\mathrm{RSL}}$ results in a probability distribution of past sea level (through 1111 which a line can be drawn); this is in contrast to all previous calculations where the depth1112 distribution term was not included (i.e., the output was in terms of tectonically corrected elevations, 1113 and the position of former sea levels was estimated to be above these).

1115 The inclusion of detailed metadata in our database allows users to assess for themselves the 'most 1116 reliable' age determination and sea-level reconstructions. It also facilitates an assessment of the 1117 available U-series dated corals within both their geological and ecological settings, and a first order 1118 assessment of the degree of coherence of reconstructed sea levels within a site, as well as between 1119 sites. Again, we emphasise that we have not incorporated GIA-corrections (e.g., Farrell and Clark, 1120 1976; Milne and Mitrovica, 1998; Lambeck and Chappell, 2001; Mitrovica and Milne, 2003; Peltier, 1121 2004) in the database. This means that the data should not be expected to directly overlap, since 1122 GIA effects will cause site-specific sea-level data to depart from the eustatic signal. In the remainder

1123 of this paper, we briefly explore the general features of RSL variations in the database, and assess its 1124 utility for interrogating data relative to one another to highlight some outstanding (and solvable) 1125 limitations to sea-level reconstructions.

\section{INTERPRETATION AND SCREENING OF DATA}

1128 Obtaining a reliable and precise RSL reconstruction from the numerous fossil samples requires 1129 choices by the user (i.e. what screening criteria are most appropriate to the question they wish to 1130 investigate). For example, for regional RSL it may be more appropriate to use regional subsets rather 1131 than the global dataset (and there will also be fewer GIA concerns), whereas a global dataset is 
1132 needed for eustatic sea level (ESL) estimation, where GIA corrections become more important.

1133 Other considerations include: how well constrained the tectonic history of a site is; the sensitivity of 1134 sites, especially in the near-field, to glacio-isostatic processes (with uncertainties); the reliability of 1135 age determinations; how well constrained the modern coral depth-distribution is for the location(s) 1136 studied; and whether metadata such as facies or stratigraphic constraints can inform screening choices. The following section outlines such criteria and their impacts upon the data.

\subsection{Location: tectonic and depositional setting}

$1140 \quad$ 5.1.1 Tectonic setting and uplift rate constraints

1141 In regions of high uplift/subsidence, the record of changing sea levels becomes expanded in the 1142 vertical, which facilitates high-resolution studies. On stable margins, no correction for uplift is 1143 required, but stable margins present a superimposition of successive sea level variations and coastal 1144 processes (e.g. erosion and post-depositional diagenesis) that complicates interpretation.

1146 The tectonic setting of many sites is complex and often imperfectly described. For example, the 1147 islands of Vanuatu are the product of island-arc volcanism with a complex uplift history. Tasmaloum 1148 has experienced subsidence $(-4 \mathrm{~mm} / \mathrm{yr}$ for 220 to $130 \mathrm{ka}$ ) followed by uplift $(3 \mathrm{~mm} / \mathrm{yr})$, while 1149 Urelapa has been uplifting at a mean rate of $1.9 \mathrm{~mm} / \mathrm{yr}$ since $130 \mathrm{ka}$ (Taylor et al., 2005 and 1150 references therein). These phases of uplift and subsidence have been attributed to pinning of 1151 submarine features during subduction (Taylor et al., 2005). Similarly, Barbados (where $85 \%$ of the 1152 island is covered by a Pleistocene coral reef limestone cap) evolved as an accretionary prism. 1153 Anticline warping and episodic uplift (i.e., non-uniform rates of uplift) have been documented (e.g. 1154 Donovan and Harper, 2005), leading to locally different uplift rates (Schellmann and Radtke, 2004;

1155 Radtke and Schellmann, 2006). Any such uncertainties in our (and all preceding) assumptions for 1156 calculating uplift rates for the various locations would lead to vertical inaccuracies in RSL. Complex 1157 tectonic histories are not limited to uplifting or subsiding sites: tectonic warping has been 1158 documented for the Perth and Carnarvon Basins of Western Australia (e.g. Hocking et al., 1987; 1159 Whitney and Hengesh, 2015). Coseismic events (e.g. Ota et al., 1993; Ota and Chappell 1996; 1160 Tudhope et al., 2000; Sieh et al., 2008) are also problematic for palaeo-RSL reconstructions.

1162 One distinct advantage afforded by sites that are rapidly uplifting or subsiding is that the spacing and 1163 ages of individual terraces may provide the potential to identify short-term sea-level oscillations that 1164 are not well-expressed on stable coastlines due to overprinting and lack of accommodation space. 1165 Unfortunately, tectonically affected sites are not well suited for reconstructing the absolute position 
1166 of sea level in the past. Due to a lack of independent estimates of uplift/subsidence, we have 1167 recalculated rates using the highest elevation of the regional LIG terrace and assumed LIG age and 1168 eustatic sea level values (equation 1). Although this offers a consistent application of 1169 uplift/subsidence rates for each site, it remains distinctly unsatisfactory: the values for both the age 1170 and LIG eustatic component are ill defined (and most likely incorrect), partly due to spatial and 1171 temporal variability between sites arising from site-specific GIA effects. Additionally, there is an 1172 inherent circularity to using the elevation of the LIG corals to determine an uplift rate that is 1173 subsequently used to calculate $\mathrm{P}_{\mathrm{RSL}}$. The advantage of this approach is that it allows for an 1174 approximation of relative sea-level changes from tectonically affected sites, though the uncertainty 1175 may be significantly larger than quoted in the database. In addition, the pragmatic but unlikely 1176 assumption that uplift/subsidence rates were constant through time (cf. Schellmann and Radtke, 1177 2004; Taylor et al., 2005; Radtke and Schellmann, 2006) further complicates any tectonic correction 1178 required for reconstructing past sea levels (Creveling et al., 2015). Clearly there is an urgent need for 1179 independent verification of uplift/subsidence rates, especially because age determinations and their 1180 uncertainties interact with uplift/subsidence rates and their uncertainties, to produce complex RSL 1181 reconstructions.

\section{$1183 \quad 5.1 .2$ Constructional versus erosional marine terraces}

1184 Fossil corals contained within emergent, primarily erosional, marine terraces have been used to 1185 provide information on past sea levels. These environments, such as the coasts of California (e.g., 1186 Muhs et al., 2006, 2012), Bermuda (e.g., Vacher and Hearty, 1989; Ludwig et al., 1996; Muhs et al., 1187 2002a; Rowe and Bristow, 2015), Japan (e.g., Radtke et al., 1996), and the Mediterranean region 1188 (e.g., Brancaccio et al., 1978; Poole et al., 1990; Leeder et al., 2003; Muhs et al., 2014, 2015), are 1189 generally high energy environments and, in contrast to many constructional reefs, the terraces are 1190 formed by erosional processes. The fossils within these deposits are generally poorly sorted and are 1191 rarely in growth position; consequently they cannot, in themselves, provide information on past sea 1192 levels. Rather, they provide information on the age of the deposit, and past environmental 1193 conditions (i.e. from their faunal composition). Former sea levels can be reconstructed from these 1194 environments only with additional information, such as the elevation of the terrace shoreline angle 1195 or other such feature, where a sound relationship to sea level can be established. Where no such 1196 information is available, the corrected elevation $\left(Z_{c p}\right)$ of the fossil provides a minimum estimate of 1197 former sea levels (i.e., sea level must have been at, or above $Z_{c p}$ ). 
1199 Constructional and abrasional terraces may both be present in the landscape. For example, Speed 1200 and Cheng (2004) emphasised the role of marine erosion in the deposition of carbonates in 1201 Barbados. In Japan, emerged marine terraces were found to be of both erosive and biological 1202 construction (Ota et al., 1983). In Hawaii, Muhs et al (2002a) highlight that for some locations, reef 1203 facies are absent and replaced by coral-basalt conglomerate resting on shore platforms cut into

1204 Tertiary basalt. Hence, thorough and complete documentation of the sample context is essential in establishing the fidelity of the fossil record for reconstructing past sea levels.

\section{Emerged marine terraces of California}

1208 In California, flights of emerged marine terraces are preserved (e.g., Alexander, 1953, Vedder and 1209 Norris, 1963), documenting past sea levels superimposed on tectonic uplift. These erosional 1210 landforms develop in high energy environments and usually retain a veneer of marine sands and 1211 gravels that often contains molluscs and solitary corals (e.g. Balanophyllia elegans), which can be 1212 used to date the deposit (and constrain the timing of past sea level fluctuations; e.g., Muhs and 1213 Szabo, 1982; Stein et al., 1991; Muhs et al., 1994, 2002a, 2012). These fossil corals cannot be used to 1214 reconstruct sea levels as few, if any, remain in growth position, so that the relationship between 1215 coral elevation and sea level is 'lost'. Instead, the elevation of past sea levels can be derived from the 1216 elevation of shoreline angles, or other such geomorphological features (e.g. Muhs et al., 2012b).

\section{Emerged marine deposits of Bermuda}

1219 The surficial deposits of Bermuda consist of Quaternary carbonates, mostly eolianite with isolated 1220 sublittoral marine and beach deposits (e.g., Vacher et al., 1989). Hermatypic corals are presently 1221 found, due to the influence of the Gulf Stream, but only limited emergent fossil patch reefs have 1222 been documented (e.g., Harmon et al., 1983) and "their existence has subsequently been difficult to 1223 verify" (Rowe et al., 2014). The higher than present fossil corals contained in the marine littoral 1224 deposits from the high energy, south shore environment (e.g., Fort St Catherine) sparked 1225 considerable debate regarding the processes governing their formation, with implications for their 1226 utility for reconstructing former sea levels. Both storm processes (e.g., Harmon et al., 1983) and 1227 higher than present sea levels (e.g., Vacher and Hearty, 1989; Ludwig et al., 1996) have been 1228 invoked. The first naturally renders these fossils unusable for reconstructing past sea levels. The 1229 relatively few, in situ patch reefs and lack of in growth position fossils coupled with the modern high 1230 energy environment suggest that the poorly sorted marine fossils of Bermudan sublittoral deposits 1231 are useful for temporal constraints and palaeozoogeography, but less useful for reconstructing sea 1232 levels. However, additional geomorphological evidence (tidal notches, shoreline angles etc.) with a 
1233 clear relationship to sea level, would enable past sea levels to be reconstructed. In the absence of

1234 such a clear relationship between the fossil/feature and sea level, the information remains limited.

\subsection{Determining reliable ages - chemical screening}

1237 The effect of diagenesis can be significant, resulting in erroneous age and hence, RSL 1238 reconstructions. There are several screening criteria often applied to identify corals that have been 1239 geochemically altered and to additionally identify those that suffer from contaminating effects of 1240 detrital Th $\left({ }^{232} \mathrm{Th}\right)$. Geochemical alteration, also referred to in the U-series literature as open-system behaviour, can be recognised by: (1) conversion of coralline aragonite to calcite; (2) anomalous ${ }^{238} \mathrm{U}$ concentration (or other trace elements that indicate partial conversion to calcite such as $\mathrm{Sr} / \mathrm{Ca}$ or $\mathrm{Mg} / \mathrm{Ca}$ ratios), and; (3) $\delta^{234} \mathrm{U}_{\text {initial, }}$ which is back-calculated from the measured $\delta^{234} \mathrm{U}$ ratio and the age

1244 of the coral to determine the $\delta^{234} \mathrm{U}$ value of the coral at the time it grew (Equation 3). Anomalous

$1245{ }^{230} \mathrm{Th}$ concentrations may also be an indicator of open-system behaviour; expected ${ }^{230} \mathrm{Th}$ 1246 concentrations are a function of prior knowledge of age of the sample, and; Th is less mobile in 1247 oxidising solutions such as groundwater or seawater, so is considered unlikely to experience 1248 significant loss or gain in the way that the more soluble $U$ may behave. To monitor for the 1249 contaminating effects of initial ${ }^{230} \mathrm{Th}$ in the coral, ${ }^{232} \mathrm{Th}$ concentration is also typically measured when $1250 \mathrm{U}$-series measurements are made. Pa-Th dating is another cross-check that can be used to 1251 determine the age of the coral, but is less commonly applied owing to the more difficult laboratory 1252 procedures involved. Here we explore the basis for each of these criteria and discuss issues involved 1253 with applying them to a dataset. We also refer the reader to several in-depth reviews of the 1254 systematics of U-series dating of corals (Edwards et al., 2003a; Edwards et al., 2003b; Stirling and 1255 Andersen, 2009; Dutton, 2015).

\subsubsection{Mineralogy}

1258 Coralline aragonite is metastable and hence prone to conversion to calcite over time. This 1259 conversion will be a function of the water/rock ratio, the porosity of the coral taxa, temperature, 1260 exposure history, as well as other factors. During conversion to calcite, some of the primary U-Th 1261 geochemistry may be altered. For this reason, it is good practice to screen all coral samples for even 1262 trace amounts of calcite that may bias the calculated U-Th age of a sample. Recently, X-ray 1263 diffraction (XRD) techniques have been applied with increasing resolution and detection limits for 1264 trace amounts of calcite (e.g., Sepulchre et al., 2009) to screen corals prior to radiometric dating. 1265 Calcite conversion is also associated with changes in $\mathrm{Sr} / \mathrm{Ca}$ (lower) and $\mathrm{Mg} / \mathrm{Ca}$ (higher) (e.g., 
1266 McGregor and Gagan, 2003) but has been less commonly applied to screen corals prior to U-series 1267 measurements.

\subsubsection{Anomalous ${ }^{238} \mathrm{U}$ concentration}

1270 The measured concentration of uranium $\left(\left[{ }^{238} \mathrm{U}\right]\right)$ in a fossil can be used as an additional age reliability screening criterion (cf. Broecker and Thuber, 1965; Thompson et al., 2003; Scholz and Mangini, 2007). In principle, the addition/loss of uranium since the time of formation may be detected by comparing the concentration of uranium in a fossil coral to its modern counterpart (i.e., if there has been no addition/loss of uranium, then the uranium concentration of the fossil should be similar to that in modern corals of the same species). In modern corals, the concentration of uranium is species dependent (e.g., Cross and Cross, 1983) and its distribution is heterogeneous within the coral skeletal structure (e.g., Schroeder et al., 1970; Robinson et al., 2006). The incorporation of uranium into the skeleton may also vary seasonally as $\mathrm{U} / \mathrm{Ca}$ is correlated with sea surface temperatures. For example, concentrations of uranium within a single coral can vary by around $20 \%$ (e.g., Shen and Dunbar, 1995; Min et al., 1995). ${ }^{238} \mathrm{U}$ concentration is routinely measured during U-

1281 series measurements, but this parameter is not always used for screening purposes. There are 1282 relatively few studies that report the uranium concentration of modern corals (data for modern and 1283 young ( $<1 \mathrm{ka}$ ) fossil corals is compiled in Table 4). We recommend the use of modern uranium 1284 concentration data as an additional screening criterion, although we recognise that the data on 1285 modern corals is limited at present and should be addressed by the community.

\subsubsection{Initial uranium isotope composition ( $\left.\delta^{234} U_{\text {initial }}\right)$}

1288 Corals are thought to precipitate their skeletons with no fractionation of ${ }^{234} \mathrm{U}$ relative to ${ }^{238} \mathrm{U}$, and

1289 hence should record the same $\delta^{234} \mathrm{U}$ value as that of ambient seawater at the time of growth (e.g., 1290 Edwards et al., 2003a). In contrast, corals that have behaved as open-systems tend to display 1291 elevated values of $\delta^{234} \mathrm{U}$ and anomalously old ages (e.g., Bard et al., 1991, Hamelin et al., 1991, 1292 Henderson et al., 1993). This pattern was systematically described by Gallup et al. (1994), although 1293 other forms of open-system behaviour may produce different geochemical arrays and even 1294 anomalously low $\delta^{234} U$ values (see discussion in Stirling and Andersen, 2009). Laser ablation mass

1296 the $\delta^{234} U_{\text {initial }}$ of a sample may be determined rapidly, Spooner et al., 2016). However, the precision 1297 and accuracy of this method are currently lower than for conventional TIMS or MC-ICPMS methods, 1298 (e.g., Eggins et al., 2005; Hoffmann et al., 2009; McGregor et al., 2011). 
1300 As seawater $\delta^{234} \mathrm{U}(\sim 147 \%)$ was thought to be homogenous in the open ocean and relatively 1301 invariant across the timescales relevant to $U$-series dating, the $\delta^{234} U_{\text {initial }}$ value of corals became 1302 widely used as a screening parameter to reject altered corals if the value was significantly different 1303 from that of modern seawater. We note that the accepted value for seawater $\delta^{234} U$ has been 1304 revised several times, in part related to the revision of the decay constant of ${ }^{234} \mathrm{U}$ (Cheng et al., 2000; 1305 Cheng et al., 2013). The most recent, and most precise, determination of seawater $\delta^{234} U$ was 1306 performed by Andersen et al. (2010b), who reported a seawater value of $146.8 \pm 0.1 \%$ ( $2 \sigma)$. As 1307 these data were calculated relative to a secular equilibrium standard, the seawater $\delta^{234} U$ does not 1308 need to be revised, despite subsequent revision of the ${ }^{234} \mathrm{U}$ decay constant (Cheng et al., 2013). 1309 Using this benchmark, coral U-series data are often screened for compliance with a $\delta^{234} U_{\text {initial }}$ value of $1310147 \%$ (i.e. within the range of values consistent with modern seawater and living corals), though 1311 the tolerance for the magnitude of departure from the seawater value varies between publications.

1313 One potential complication of this approach is the assumption that seawater composition has 1314 remained the same over the last several 100,000 years. It has been proposed that seawater $\delta^{234} \mathrm{U}$ 1315 may vary on glacial-interglacial timescales (on the order of $10-15 \%$, Henderson, 2002; Robinson et 1316 al., 2004; Esat and Yokoyama, 2006), with lower than modern values (by 7 to $10 \%$ ) during the last 1317 glacial (Culter et al., 2004; Esat and Yokoyama, 2006; Durand et al., 2013) meaning that screening of 1318 corals using a narrow range around modern seawater may reject some high quality data, if seawater $1319 \delta^{234} \mathrm{U}$ has indeed varied in the past. On the other hand, using a range that is too wide will increase 1320 the inclusion of altered samples that will bias the analysis. One option is to use a scheme similar to 1321 that developed by the radiocarbon IntCal working group, which has defined a seawater $\delta^{234} \mathrm{U}$ 1322 screening value for the last glacial period that is lower (142 $\pm 8 \%$, Reimer et al., 2013) and use a 1323 value more similar to the modern value of $147 \%$ for the interglacial periods. If $\delta^{234} U$ has varied on 1324 glacial-interglacial timescales, it would be inappropriate to apply a constant value for screening the 1325 data if the seawater composition is temporally variable. Unfortunately, the precise evolution of 1326 seawater $\delta^{234} \mathrm{U}$ and the magnitude of the possible changes are still debated, making it difficult to 1327 derive a robust screening approach that would capture such variability.

\subsubsection{Detrital Th $\left(^{232} T h\right)$}

1330 The use of detrital Th as a screening criterion relies on the fact that ${ }^{232} \mathrm{Th}$ is virtually absent from 1331 seawater, but is sometimes found in very small concentrations within coral skeletons during growth 1332 if there is detrital contamination (Edwards et al., 1987; Chen et al., 1991). As all isotopes of Th have 1333 identical chemical properties, if ${ }^{232} \mathrm{Th}$ is present, then some amount of ${ }^{230} \mathrm{Th}$ is likely to have also 
1334 been introduced. The amount of this ${ }^{230} \mathrm{Th}$ contamination is a function both of the concentration of ${ }^{232} \mathrm{Th}$ and the ${ }^{230} \mathrm{Th} /{ }^{232} \mathrm{Th}$ composition of the contaminating source. This allows an assessment of the initial ${ }^{230} \mathrm{Th}$ of the sample, as the assumption of ingrowth of ${ }^{230} \mathrm{Th}$ is the basis for the U-Th dating method. Most modern corals have low to negligible initial ${ }^{230}$ Th concentrations (e.g., Edwards et al., 1987; Cobb et al., 2003a) although values up to $7 \mathrm{ppb}$ have been reported for modern corals from the Bahamas (Robinson et al., 2004) and Sumatra (Zachariasen et al., 1999). During diagenesis, voids within the coral skeleton may be filled with detrital material, thereby adding extraneous ${ }^{230} \mathrm{Th},{ }^{234} \mathrm{U}$, ${ }^{238} \mathrm{U}$ and ${ }^{232} \mathrm{Th}$ to the coral system.

Initial ${ }^{230} \mathrm{Th}$ can have a significant effect on the age determination of young corals, but less impact on samples older than a few thousand years. For example, coral samples with a ${ }^{232} \mathrm{Th}$ concentration of 1 ppb (and assuming a bulk crustal value for ${ }^{230} \mathrm{Th} /{ }^{232} \mathrm{Th}$ of $2.0 \times 10^{-5}$ ) would require an adjustment of up to 40 years, which is significant for very young corals, but only a $<1 \%$ error for a 5,000-year old coral (Cobb et al., 2003a). In previous studies, low ${ }^{232}$ Th concentrations such as $<2 \mathrm{ppb}$ is considered acceptable (cf. Dutton and Lambeck, 2012) due to the relatively small error this introduces when dating corals older than a few thousand years. The ${ }^{232} \mathrm{Th}$ concentration, however, is not always reported so this criterion cannot always be applied. We note that it is preferable to use the ${ }^{230} \mathrm{Th} /{ }^{232} \mathrm{Th}$ activity ratio, as this parameter can be better applied to screen out samples with ${ }^{232} \mathrm{Th}$ contamination where the influence of this contamination is effectively scaled to its age (the ${ }^{230} \mathrm{Th}$

1353 activity). In this way, corals with a similar ${ }^{230} \mathrm{Th} /{ }^{232} \mathrm{Th}$ activity ratio can be considered to have a more 1354 comparable influence on the age of the sample, even across a dataset with corals that have a wide 1355 range of ages. This parameter, however, is even less frequently reported than ${ }^{232} \mathrm{Th}$. In our compiled 1356 database, we have back-calculated the ${ }^{230} \mathrm{Th} /{ }^{232} \mathrm{Th}$ activity ratio wherever possible so that this 1357 parameter can be used to screen for detrital Th contamination in the future instead of ${ }^{232} \mathrm{Th}$ 1358 concentration. As this parameter is not reported as often ( $<25 \%$ of samples in the database report 1359 this parameter whereas $\sim 87 \%$ of samples have reported ${ }^{232}$ Th concentration), a well-defined, 1360 accepted value to use for screening the corals is currently lacking. However, we note that lower 1361 values of ${ }^{230} \mathrm{Th} /{ }^{232} \mathrm{Th}$ represent more significant age biases introduced by detrital Th contamination.

\subsubsection{Pa-Th dating}

1364 Another method for detection of post-depositional alteration combines U-Th dating with ${ }^{231} \mathrm{~Pa} /{ }^{235} \mathrm{U}$ 1365 dating, which is based on the decay of ${ }^{235} \mathrm{U}$ to ${ }^{231} \mathrm{~Pa}$ assuming, (i) the initial ${ }^{231} \mathrm{~Pa} /{ }^{235} \mathrm{U}$ ratio is zero 1366 and, (ii) that the changes in the ${ }^{231} \mathrm{~Pa} /{ }^{235} \mathrm{U}$ ratio occurs only through radioactive ingrowth and decay. 1367 If the system has remained closed since the time of formation, combining ${ }^{231} \mathrm{~Pa} /{ }^{235} \mathrm{U}$ and $\mathrm{U}-\mathrm{Th}$ 
1368 methods, the ages obtained by each technique should agree within analytical precision (as both 1369 methods rely upon the assumption of changes in the ratio results only from radioactive ingrowth 1370 and decay). In addition, using concordia plots enables some constraints on the nature of diagenetic 1371 process and the possibility of obtaining the 'true' age (e.g., Rosholt, 1967; Szabo and Vedder, 1971; 1372 Edwards et al., 1997; Gallup et al., 2002; Cutler et al., 2003). The combination of the two methods is 1373 perhaps the most robust method for assessing if the system has remained closed since the time of 1374 formation. However, practically, the ${ }^{233} \mathrm{~Pa}$ spike required for ${ }^{231} \mathrm{~Pa} /{ }^{235} \mathrm{U}$ dating is more difficult to 1375 handle and to calibrate.

\subsubsection{Implications of chemical screening choice}

1378 Although these screening criteria may successfully remove a subset of altered samples from further consideration, the signature of carbonate diagenesis may be subtle and not fully captured by this approach. In particular, the $\delta^{234} U_{\text {initial }}$ value appears to be a more sensitive indicator of open-system

1381 behaviour than $\mathrm{X}$-ray diffraction assessments of mineralogy (\% calcite) or other geochemical 1382 indicators of carbonate diagenesis. As such, this parameter has been heavily relied upon to screen 1383 out altered coral samples. However, corals may undergo subtle diagenetic alteration that results in 1384 erroneous ages without apparent disturbance to the $\delta^{234} U_{\text {initial }}$ ratio, or undergo variable degrees of 1385 alteration (causing shifts to both lower and higher $\delta^{234} U_{\text {initial }}$ within the same sample; Henderson et 1386 al., 1993, Scholz et al., 2009).

1387

1388 The choice of screening criteria has a large effect upon the number of samples available for further 1389 analysis (Dutton and Lambeck, 2012; Medina-Elizalde, 2012) (Figure 9). Placing tight limits on the 1390 acceptable $\delta^{234} U_{\text {initial }}$ values is effective only if there is sufficient precision in the measurement of $1391 \delta^{234} U$. Modern corals display some variability around the mean open-ocean seawater value, so that 1392 overly tight screening may reject high-quality data. In addition, if seawater $\delta^{234} U$ has varied through 1393 time, use of a constant range of 'acceptable' values may exclude samples that are 'reliable' (i.e., 1394 have not experienced open system behaviour or post depositional diagenesis).

1396 Hence, screening data will successfully remove some, but not all, of the altered samples. This is 1397 where additional criteria can help, such as reproducibility of measurements for corals that have 1398 been measured multiple times or stratigraphic relationships that can be used to evaluate relative 1399 ages (see discussion in Dutton, 2015). Users of the database may assess the data with respect to 1400 the replication of analyses within a coral, where replicate analyses that are consistent in terms of 1401 both their calculated age and their calculated $\delta^{234} U_{\text {initial }}$ values are considered most reliable. 


\subsubsection{Replicate age determinations}

1404 Ages that have been affected by open-system remobilisation of $U$ and/or Th isotopes can have a significant impact on subsequent sea-level reconstructions. For example, a large proportion of the Scholz et al. (2009) report data from Barbados based on multiple dates from the same coral specimen, as well as from multiple short cores in close proximity to one another from the same stratigraphic unit. The authors demonstrate the effects of U-redistribution within these samples, even though they would pass a screening criteria of $\delta^{234} U_{\text {initial }}$ within $5 \%$ of modern, $\leq 2 \%$ calcite and

${ }^{232} \mathrm{Th}$ concentrations $\leq 2 \mathrm{ppb}$ and similar screening criteria employed by Dutton and Lambeck (2012)

1411 and Medina-Elizalde (2012). Of the 54 samples dated in this study, 15 would even pass a stricter 1412 criteria $\left(\delta^{234} U_{\text {initial }}=147 \pm 1 \%\right.$ and $\leq 2 \%$ calcite $)$, and these samples also have ${ }^{232}$ Th concentrations $1413<2 \mathrm{ppb}$, similar to those found in some modern corals; cf. Chen et al., 1986; Muhs et al., 2002a; 1414 Robinson et al., 2004; Stirling and Andersen, 2009). The screened data appear as a linear trend in the 1415 reconstructed Barbados $\mathrm{P}_{\mathrm{RSL}}$ record (Figure 10), even though all are from the same stratigraphic unit, 1416 the Last Interglacial/Rendezvous Hill Terrace (some separated by only $30 \mathrm{~cm}$ ). The expectation 1417 would be that ages for each coral from within this single unit (and especially the replicates of single 1418 coral specimens) yield closely replicating U-Th ages and hence a close cluster of tectonically 1419 corrected coral positions $\left(Z_{c p}\right)$ after multiplication with the site's uplift rate. However, the samples 1420 instead show a spread of ages, which through multiplication with the site's uplift rate result in a 1421 linear trend of tectonically corrected coral positions $\left(Z_{c p}\right)$ (Equation 4). Averaging all the 1422 measurements for one coral head would be one way to overcome this, but is not warranted if the 1423 initial measurements are not within analytical error of each other. Another reason that averaging 1424 the data is not recommended is that the average of a diagenetic trend may represent the average 1425 composition of alteration whereas one end member is more likely to be a better indication of the 1426 primary geochemistry.

1428 Where many replicates are available, outlier analysis can be undertaken and an average age 1429 provided (e.g., ADU-3, xA4-2 and BB02-5-1; Figure 10). Unfortunately, this is not an appropriate 1430 procedure for most of the replicate analyses in the database, especially when only a few 'survive' 1431 the initial geochemical screening (only a few repeat analyses are consistent i.e., with some overlap 1432 of their $2 \sigma$ ranges). Where only two replicates pass the initial screening, both should be excluded if 1433 age and $\delta^{234} \mathrm{U}_{\text {initial }}$ are inconsistent (at a $4 \sigma$ distance) because one, or both, of the ages are clearly 1434 incorrect but we cannot determine which one. Further refinements of past sea-level records from 1435 fossil corals may be achieved through agreement on a statistically sound method for dealing with 
1436 replicates to reduce the instances of several (different) $P_{R S L}$ values for the same sample, and 1437 eliminate the spurious linear trends from the plots. Clearly, meticulous inclusion of contextual 1438 metadata is essential.

\subsubsection{Example of chemical screening approach}

1441 Here we introduce an example application of how the database can be screened, as described in the

1442 following, but emphasise that this is an example only and that there are multiple ways to screen the 1443 data as previously discussed. The data were screened for reliability using the commonly applied $1444 \delta^{234} \mathrm{U}_{\text {initial, }} \%$ calcite, and ${ }^{232} \mathrm{Th}$ concentration criteria. As noted previously, it would be preferable to 1445 also include a screening criterion for ${ }^{238} \mathrm{U}$ concentration, which may be a tractable solution for a site1446 specific study with a limited number of taxa with known modern ${ }^{238} \mathrm{U}$ baselines, but was not feasible 1447 in this example. We do not exclude data from our analysis on the basis of ${ }^{238} \mathrm{U}$, rather we highlight 1448 (circled in the figures) samples that have uranium concentrations outside the modern range of 1449 modern corals of the three genera with the most modern $\left[{ }^{238} \mathrm{U}\right]$ determinations: 2 to 4 ppm for 1450 Acropora sp., 2 to $3.5 \mathrm{ppm}$ for Montastraea sp. and, 2 to $4 \mathrm{ppm}$ for Porites sp. As previously 1451 mentioned, use of the ${ }^{230} \mathrm{Th} /{ }^{232} \mathrm{Th}$ activity ratio is probably preferable to use of the ${ }^{232} \mathrm{Th}$ 1452 concentration, which is now possible using the back-calculated ${ }^{230} \mathrm{Th} /{ }^{232} \mathrm{Th}$ values provided in the 1453 database. We opted to use three different $\delta^{234} \mathrm{U}_{\text {initial }}$ screening criteria to account for the possibility 1454 of variations in seawater composition on glacial-interglacial timescales. For interglacials, we use the 1455 modern $\delta^{234} U_{\text {initial }}$ value of $147 \pm 5 \%$, and for glacial intervals we follow the IntCal Working Group 1456 (Reimer et al., 2013) recommendation of $\delta^{234} U_{\text {initial }}$ values of $142 \pm 8 \%$. The IntCal Working Group 1457 (Reimer et al., 2013) use this lower value for samples older than 17 ka but do not define an older age 1458 limit (because the radiocarbon timescale does not extend past the last glacial period). We use the 1459 LR04 (Lisiecki and Raymo, 2005) age of the transition from Marine Isotope Stage (MIS) 5 to MIS 4 (71 $1460 \mathrm{ka}$ ) as the transition between glacial and interglacial screening criteria (i.e. between 71 and $130 \mathrm{ka}$, a 1461 screening criterion of $147 \pm 5 \%$ is used). For samples older than 130 ka (age of the transition from

1462 MIS 6 to 5 defined in LR04; Lisiecki and Raymo, 2005), we use a value of $147+5 /-10 \%$ in order to account for possible variations in seawater (Figure 9).

1465 Further to this, we opted to exclude data with a reported calcite percentage $>2 \%$ or when this 1466 information has not been reported. This particular cut off has been used is some previous studies 1467 either due to detection limits (where \% <2 could not be evaluated) or because more outliers appear 1468 when values above $2 \%$ are used. In theory, there is no percentage of calcite that is "ideal". The 1469 effect of recrystallization on the age will depend on many site-specific factors, including the age of 
1470 the coral, so a $5 \%$ calcite coral may have an age that is as robust as a $1 \%$ coral at another location.

1471 We also chose to exclude data where the ${ }^{232} \mathrm{Th}$ concentration is $>2 \mathrm{ppb}$ or where this has not been 1472 reported. Despite these screening criteria, we emphasise that multiple diagenetic episodes, such as 1473 the exposure of uplifted reef terraces to meteoric waters (with potentially varying effects; i.e., the 1474 addition or loss of nuclides) may not necessarily be recognisable using the $\delta^{234} U_{\text {initial }}$ and percentage 1475 calcite screening criteria (Scholz et al., 2009). We have used our screening criteria in such a way as to 1476 retain samples with most likely reliable ages, while also retaining a reasonable number of samples 1477 for further analysis; this resulted in a $70 \%$ reduction in the number of samples relative to the full 1478 database.

1480 After screening $\left(\delta^{234} \mathrm{U}_{\text {initial, }}\right.$, calcite $\leq 2 \%,{ }^{232} \mathrm{Th}$ concentration $\left.\leq 2 \mathrm{ppb}\right) \sim 750$ samples remain from the 1481 original database (for which we can calculate $Z_{C p}$ and $P_{R S L}$ ) representing 31 locations, both near-field 1482 sites (proximal to former ice sheets, where influence of glacio-isostatic adjustment (GIA) processes 1483 on RSL records is large) and far-field sites (far from former ice sheets and where GIA influences are 1484 smaller): Bahamas (Chen et al., 1991); Barbados (Edwards et al., 1987; Gallup et al., 1994, 2002;

1485 Cutler et al., 2003; Thompson et al., 2003; Bard et al., 1990a,b,c; Hamelin et al., 1991; Blanchon and 1486 Eisenhauer, 2001; Peltier and Fairbanks, 2006; Fairbanks et al., 2005; Potter et al., 2004; Scholz et 1487 al., 2007; Andersen et al., 2010); Bermuda (Ludwig et al., 1996; Muhs et al., 2002a); southern China 1488 (Zhao and Yu, 2002); Comoro Islands (Camoin et al., 2004); Curacao (Muhs et al., 2012a); Mururoa 1489 atoll, French Polynesia (Camoin et al., 2001); Tahiti (Thomas et al., 2009; Yokoyama et al., 2001; 1490 Deschamps et al., 2012; Bard et al., 1996b); Haiti (Bard et al., 1990a); Sumba Island, Indonesia (Bard 1491 et al., 1996a); Madagascar (Camoin et al., 2004); Yucatan Peninsula (Blanchon et al., 2009); Huon 1492 Peninsula, Papua New Guinea (Yokoyama et al., 2001; Esat and Yokoyama, 2006; Cutler et al., 2004; 1493 Bard et al., 1996b; Cutler et al., 2003; Stein et al., 1993); Henderson Island (Pitcairn Islands) 1494 (Anderson et al., 2010; Stirling et al., 2001); Seychelles (Israelson and Wolfarth, 1999; Camoin et al., 1495 2004); Hawaii (Muhs et al., 2002; Szabo et al., 1994); Vanuatu (Edwards et al., 1987b; Taylor et al., 1496 1985; Cutler et al., 2004); and Western Australia (Stirling et al., 1995, 1998, 2001; Zhu et al., 1993; 1497 Eisenhauer et al., 1996; O'Leary et al., 2008; Collins et al., 2006) (Figure 11). Only these data are 1498 used in subsequent analyses. Most data are concentrated within the last deglacial and the LIG 1499 periods, with relatively few samples older than $>200$ ka passing our screening (note that the choice 1500 of screening criteria has a dramatic influence upon the number of samples available for subsequent 1501 analysis, Figure 9).

1502

1503 5.2.9. Overview of reconstructed sea levels using screened data 
1504 Despite some degree of scatter in the data, the various records provide, in general, a consistent (i.e., 1505 within 95\% bounds of one another) picture of sea level during the last deglacial and interglacial 1506 periods (see also, for subsets of the data: Stanford et al., 2011; Medina-Elizalde, 2012; Dutton and 1507 Lambeck, 2012) (Figure 11). The principal difference between our compilation and previous efforts is 1508 the greater vertical uncertainty associated with the sea-level reconstructions, which in our case are based on a synthesis of extensive modern ecological surveys.

1511 While there is general agreement between $\mathrm{P}_{\mathrm{RSL}}$ records from the various sites, some significant 1512 differences are also evident. For example, data from the far-field site Mururoa atoll (French 1513 Polynesia; Camoin et al., 2001) between 15.5 and 18 ka appear 'anomalously' low, relative to other 1514 records for this interval, although the youngest Mururoa samples overlap with the Tahiti dataset 1515 within their respective vertical uncertainties (Figure 11). The $P_{\text {RSL }}$ values from both Vanuatu and 1516 Tahiti agree well (within uncertainties) with $\mathrm{P}_{\mathrm{RSL}}$ values from Barbados in this time interval even 1517 without incorporating corrections for GIA effects at each site. These differences will reflect in part 1518 GIA influences (cf., Dutton and Lambeck, 2012), but the magnitude of the observed differences 1519 (Figure 11) is often greater than the size (and uncertainty) of typical GIA corrections (Figure 12). 1520 Figure 12 was generated using a version of the ICE-5G ice history (Peltier, 2004) extended to cover 1521 two glacial cycles with a 4 ka duration interglacial at near present day ice volume, and a VM2-like 1522 earth model. We model sea level in multiple locations using a GIA model based on principles 1523 detailed in Kendall et al., (2005), which incorporate variations in sea-level resulting from changes to 1524 the Earth's rotation vector, and time dependent shorelines. These are plotted with reference to a 1525 global mean sea level. These should not be interpreted as "the" glacial isostatic correction for these 1526 points in time, but they serve to illustrate the variability in local relative sea levels that is possible.

1528 For the Holocene, values of $\mathrm{P}_{\mathrm{RSL}}$ sit a few metres ( +1.5 for Western Australia and $+0.7 \mathrm{~m}$ for New 1529 Caledonia) above $0 \mathrm{~m}$ (Figure 11). This can be accounted for by: (i) the tidal component of RSL at 1530 each location - as the modern elevation of the sample was measured to mean sea level (see Table 2 1531 for estimated ranges for these sites) - and; (ii) glacio-isostatic processes (where the correction is on 1532 the order of 1 to $2 \mathrm{~m}$ ).

1534 A striking difference between the corrected coral position $\left(Z_{c p}\right)$ and our reconstructed sea level 1535 probabilities are the large vertical uncertainties associated with the latter (compare Figures 11a, c 1536 with Figures $11 \mathrm{~b}, \mathrm{~d})$. The majority of this vertical uncertainty derives from our updated taxon1537 specific depth distributions. 
1539 Aside from habitat-depth uncertainties and GIA effects, vertical uncertainties and differences in RSL 1540 reconstructions between sites may result from an incomplete understanding of influences such as 1541 local and regional tectonic histories, and from insufficient application of contextual information from 1542 geology, stratigraphy, and geomorphology. There also remain considerable dating uncertainties in 1543 many cases, and these affect $Z_{c p}$ and $P_{R S L}$ through interaction with uplift/subsidence rates. Important 1544 improvements in the vertical resolution of sea-level reconstructions may be achieved by 1545 comprehensively addressing these issues. The following sections use examples from the database to 1546 illustrate the extent and importance of these issues.

\subsection{Stratigraphic and sedimentological constraints}

1549 In addition to age, the facies and stratigraphic context of samples provides vital information for RSL assessments. Our fossil coral database incorporates fields that indicate whether the original authors assessed the sample to be in growth position and/or in situ. Coral fragments and rubble are included in the database and can provide bounding ages on deposits but unlike the in situ samples, they are not, in themselves, reliable indicators for past sea level. Regardless, they can provide valuable information where additional, complementary data, such as the elevation of shoreline angle associated with these deposits is available (section 5.1.2). Stratigraphic constraints can also help reduce the vertical uncertainty that applies to sea-level trends reconstructed for sites that are stratigraphically coherent (section 5.2.4).

\subsubsection{In situ samples}

1560 A simple means for refining RSL records could be to include only in situ or in growth data. Classically, 1561 in situ relates to material found in the geological unit in which they formed or were deposited 1562 whereas in growth means that the fossil coral as remained in the same position as it was in life. An in 1563 growth designation means the fossil coral is in situ but in situ does not necessarily mean that the 1564 fossil is in growth position. For reefs, these are complicated issues. Reefs are complex structures that 1565 comprise both primary growth frameworks and coral rubble, with variable degrees of reworking 1566 (section 2.12). Ascertaining if a fossil coral remained in the same position as at the time of growth 1567 (e.g., by a lack of severe surface abrasion/rounding; orientation of well-preserved corallites; 1568 orientation of branches; orientation of encrusting algae on the upper surface of the coral; geopetals 1569 or other 'way up' structures) is key for establishing if a faithful record of elevation has been retained, 1570 which is required for reconstructing $Z_{c p}$ and $P_{R S L}$. However, in some erosional settings/high wave 1571 energy settings such as the marine terraces of California and Bermuda, fossil corals rarely remain in 
1572 life or growth position but they are still in situ, i.e., they are found within the unit formed at the time 1573 of their growth and death. The nature of these deposits renders the fossil coral elevation unreliable 1574 and additional sources of information are needed to reconstruct past sea levels (section 5.1.2), but 1575 as they are in situ, ages derived from these fossils provide temporal constraints. In growth position 1576 designation therefore provides further clarification on the stratigraphic integrity of the fossil coral. It 1577 should be noted that this distinction is not always made the literature (in situ and in growth position 1578 have been used interchangeably). Within the database, we have noted both in situ and in growth 1579 position designations and, for primarily constructional reef environments, assumed that these are 1580 synonymous (note, a sample is labelled as in situ or in growth only where this was explicitly stated 1581 by the original authors).

1582

\subsubsection{Samples from the reef crest (or close to)}

1584 Some studies explicitly state that they targeted (close to) the reef crest during sampling (e.g. Dodge 1585 et al., 1983; Chen et al., 1991; Gallup et al., 1994; Potter et al., 2004. However, in some cases 1586 apparent contradictions between the reconstructed coral position $\left(Z_{c p}\right)$ and this stratigraphic 1587 constraint are evident. For example, reef-crest samples from Barbados of similar age have $Z_{c p}$ values 1588 (coloured symbols; Figure 13a) that are separated vertically by approximately $30 \mathrm{~m}$ at $\sim 104 \mathrm{ka}$. The 1589 samples concern different taxa; those with $Z_{c p}$ of -15 to $-23 \mathrm{~m}$ are A. palmata, except for one 1590 Montastraea sp. sample. The samples at -43 to $-53 \mathrm{~m}$ are Montastraea sp., which has a much wider 1591 modern depth distribution than A. palmata. Interestingly, the samples have overlapping 1592 reconstructed $\mathrm{P}_{\mathrm{RSL}}$ values (within uncertainty) (Figure 13b). This suggests that: (i) the Montastraea 1593 sp. samples were misdiagnosed as reef crest, given that identification was to genus level only, and 1594 that no other assemblage information was given; (ii) there is an artefact due to reef heterogeneity; 1595 (iii) the samples are not in situ (only the A. palmata samples from Barbados were confidently 1596 determined as in situ by the original authors); (iv) the ages of the samples are incorrect, which 1597 results in erroneous reconstructions due to the age-dependent uplift correction; or (v) a 1598 combination of some or all of these.

\subsubsection{Other stratigraphic constraints: Drill cores and vertically coherent sections}

1601 Vertically coherent stratigraphic sequences (e.g. sections, vertical transects or drill cores) allow the 1602 age-elevation relationship of a set of samples to be interrogated. For example, one can test whether, 1603 for the same stratigraphic unit, all ages and reconstructed sea levels are consistent. However, note 1604 that ages from a single stratigraphic unit may reflect variability within the reef structure as well as 1605 changes in prevailing environmental (including sea-level) conditions. Coral reefs do not grow as 
1606 continuous horizontal layers; they have 3-dimensional structures. Hence, a given elevation is not 1607 indicative of a certain age. Caution is therefore needed, as reversals in the age-depth relationships 1608 may occur due to: (i) erroneous age determinations; (ii) inherent complexity of a reef structure and 1609 the multitude of factors influencing coral zonation and formation; (iii) taphonomic processes (e.g. 1610 vertical/time averaging etc.; section 2.12); or (iv) a combination of some or all of these. . In 1611 summary, age reversals within a core do not invalidate the data, because of the 3-dimensional 1612 structure of reefs. Hence, age-elevation relationships can only be used where there is evidence that 1613 one coral nucleated directly on top of another.

1615 Several key RSL records were obtained by drilling (e.g., Barbados: Bard et al., 1990a, c; Fairbanks et 1616 al., 2005; Peltier and Fairbanks, 2006; Chiu et al., 2005. Tahiti: Bard et al., 1990b, 2010; Thomas et 1617 al., 2009, 2012; Deschamps et al., 2012) and the inherent stratigraphic constraints offer valuable 1618 information for refining RSL records. However, while drill cores provide useful stratigraphic ordering, 1619 they may lack other contextual information. For example, it may be difficult to assess if the samples 1620 are in situor in growth position, and the restricted dimensions of cores can also make palaeo1621 assemblage and facies description more difficult. In addition, there are potential difficulties in 1622 resolving notoriously complex reef structures using drill cores (and even using 2-dimensional 1623 sections), particularly when drilling is at an angle, or where backstepping reef architecture 1624 dominates.

1625

1626 Stratigraphic information has the potential to provide valuable constraints on the vertical 1627 uncertainties associated with reconstructed $\mathrm{P}_{\mathrm{RSL}}$, especially in a relative sense between consecutive 1628 samples. The stochastic component of the $P_{R S L}$ uncertainty, in particular the depth-distributions, can 1629 be modified by such contextual constraints. Unfortunately, information on the stratigraphic ordering 1630 of samples is not available for all samples (and all sites), and - as yet - inclusion and subsequent 1631 modification of the vertical error terms would therefore introduce undue bias between the various 1632 sites in the database. We invite authors to submit to us scans of contextual field notes for inclusion 1633 into the database.

1635 As yet, drill-core results offer the best examples of stratigraphic constraints to larger numbers of 1636 samples. For the last deglaciation, a large proportion of the data derives from Barbados and Tahiti 1637 drill cores. When identified by core, the Barbados data (Figure 14) are remarkably consistent both 1638 within each core and between cores, and a coherent temporal evolution is evident. For Tahiti, the $1639 \mathrm{P}_{\mathrm{RSL}}$ records are highly consistent within cores between 14 and 9 ka (cores P6 to P9, Figure 15). For 
1640 the older portion of the Tahiti records, some discrepancies appear between the various cores, but 1641 robust $P_{R S L}$ inflections seem to be visible in the sequences of several cores between 16 and $14 \mathrm{ka}$.

1642 Offsets between the different cores reflect changes in assemblages and the depth-distributions of 1643 the various taxa (Deschamps et al., 2012). Discrepancies may also have arisen from variable 1644 hydrodynamic and oceanographic conditions between the southwestern and northeastern sides of 1645 the island, due to different levels of turbidity and seawater chemistry) (Abbey et al., 2011), and/or 1646 progressive flooding of the shelf and increasing accommodation space (i.e. the sequential drowning 1647 of corals in cores from the outer to the inner reefs) (Camoin et al., 2012). Figure 15(c) reveals a 'line' 1648 of maximum probability, and a 'ghost maximum' above it. This 'ghost' is directly caused by the use of 1649 many observations that are identified only to the genus-level, which leads to bimodal habitat-depth 1650 distributions. For the Tahiti data presented here, detailed coral assemblage information is available, 1651 which allowed the authors to provide a palaeowater depth estimates based on modern analogues 1652 (resulting in uncertainties that are much smaller than those plotted here). This example is intended 1653 only to show the result of using depth distributions strictly limited to taxonomic identification of the 1654 coral (without consideration of assemblage or stratigraphic information), which in some cases is only 1655 to the genus level. This example is not intended to be a new reinterpretation of the Tahiti dataset. 1656

1657 Identification of corals to species level as well as inclusion of site-specific depth-distributions (e.g. 1658 from modern assemblage studies) would help to reduce uncertainties around the main 1659 reconstructed level. Where possible, $\mathrm{P}_{\mathrm{RSL}}$ reconstructions need to include not only the data and 1660 uncertainties, but also the more qualitative of contextual constraints. Going forward, statistical 1661 treatment of the data will also need to deal with such more qualitative knowledge.

\section{$1663 \quad 5.4$ Palaeodepth}

1664 The vertical resolution and precision achievable in determining past relative sea level from fossil 1665 corals depends upon several conditions. Foremost among these is the need for identification to 1666 species level and the application of appropriate depth-habitat ranges. For example, the median 1667 depth of growth for a taxon with genus-only identification is inevitably a reflection of many different 1668 species (e.g. Acropora sp. has a median depth of $-2.4 \mathrm{~m}$, whilst A. palmata and A. cervicornis have 1669 median depths of $-1.5 \mathrm{~m}$ and $-4.6 \mathrm{~m}$ respectively). Similarly, at the genus level, the total depth1670 distribution incorporates species with narrow and large depth ranges (e.g. Acropora sp. has a depth 1671 range of 0 to $-18 \mathrm{~m}$, whilst $A$. palmata and $A$. humulis have ranges of -0.4 to $-9.4 \mathrm{~m}$ and 0 to $-40 \mathrm{~m}$ 1672 respectively). Hence, using habitat-depth data for exactly the right species will increase both 1673 accuracy and precision of the calculated RSL. 
1675 Additional constraints to the depth-habitat values used can come from modern assemblage 1676 analogues that can be derived, for example: from the composition and vertical zonation of corals, 1677 corals and coralline algae (coralgal associations), and foraminifera; or from the presence/absence of 1678 indicator taxa (for example, vermetid gastropods: Morton and Chalis, 1969; Safriel, 1974; Antonioli 1679 et al., 1999; Cabioch et al., 1999a,b; Schiparelli et al., 2008). It requires an adequate assemblage 1680 description of the fossil record, which may be difficult given sampling constraints, such as drill cores, 1681 or limited exposures. Unfortunately, relatively few studies in the database undertook a local, 1682 modern assemblage survey at their study location but some considered palaeo-depth of samples by 1683 applying local and/or regional (i.e., from the same ocean basin) modern analogues to their palaeo1684 assemblage, zonation, or species (e.g. Bard et al., 1996b, 2010; Yokoyama et al., 2001; Deschamps et 1685 al., 2012).

1687 Given the current paucity of local modern analogue studies, we have adopted a uniform approach of 1688 describing the depth-distribution of the commonly used taxa from a synthesis of modern data (OBIS, 1689 2014; for a full list of extracted data and references, see online supplementary material). As noted in 1690 section 4.2.4, there are gaps in the spatial coverage (e.g., Western Australia) and possibly also with 1691 depth due to methodological limitations and focus on the upper water column. As yet, this precludes 1692 the incorporation of the well-documented variations in coral composition and distribution both 1693 within and between ocean basins (see section 5.3.2), as well as variations on local scales that arise 1694 from differences in sediment load, temperature, etc. However, as further modern ecological 1695 information becomes available, our 'global' depth-distributions will likely change, and regional 1696 and/or local depth ranges will eventually become available for all sites and species found in the fossil 1697 database. Of course, the use of local, modern assemblage data is preferable, as these generally best 1698 describe the modern vertical zonation of the reef under consideration. One caveat to this is recent 1699 human influence; in Barbados the modern fringing reefs (Tomascik and Sander, 1987) are dominated 1700 by Porites astreoides, with very little Acropora palmata cover $(<1 \%)$, even though branching 1701 Acropora corals dominated the tropical western Atlantic for the last 500 ka (Geister, 1977; Pandolfi 1702 and Jackson, 2006). Recent human influence has changed the coral community structure of 1703 Barbados reefs in ways that have not been observed in the last 200 ka (Pandolfi and Jackson, 1704 2006). 
1706 In the following sections we consider examples of how our ecologically derived depth-distributions

1707 compare with those accounting for assemblage information, and how this may offer improvements 1708 to RSL calculations.

\subsubsection{Comparison of the ecologically derived depth distributions with assemblage palaeo-depths:}

1711 A. palmata is the most frequent taxon within the fossil database (accounting for $\sim 20 \%$ of all 1712 samples). This species is highly characteristic of reef environments in the Caribbean with a common 1713 depth range of -0.5 to $-5 \mathrm{~m}$ (Goreau and Wells, 1967; Lighty et al., 1982), but it is also found at 1714 depths up to $-40 \mathrm{~m}$ (Carpenter et al., 2008). Our synthesis of ecological (depth) data gives similar 1715 values with $68 \%$ of OBIS observational data (OBIS, 2014) between -0.7 and $-3 \mathrm{~m}$ (95\% between -0.4 1716 and $-9.4 \mathrm{~m}$ ) (Figure 5a). The increase in the reported vertical range of $A$. palmata between older 1717 surveys and more recent work reflects methodological developments, with ROV and diving 1718 improvements extending depths at which observations have been made.

1720 For Porites sp., our synthesis of depth distributions indicates that most specimens are found in the 1721 uppermost water column (Figure 5) but that there is a significant proportion of observations at 1722 depth as well (median depth $-4 \mathrm{~m} ; 68 \%$ between 0 and $-45 \mathrm{~m}, 95 \%$ between 0 and $-71 \mathrm{~m}$ ). Carpenter 1723 et al (2008) give a range of 0 to $-50 \mathrm{~m}$, but the depth range of some species remains unknown. 1724 Studies within the fossil database report a variety of palaeodepths for this genus, including: $<5 \mathrm{~m}$ 1725 (Comoro Islands; Camoin et al., 2004); 0 to $-35 \mathrm{~m}$ (with 'most likely' 0 to $-20 \mathrm{~m}$, Mururoa Atoll; 1726 Camoin et al., 2001); >-20 m, 0 to $-25 \mathrm{~m}$ and 0 to $-6 \mathrm{~m}$ depending upon assemblage (Tahiti: Thomas 1727 et al., 2009, with palaeodepths derived from Montaggioni, 2005); -2 to $-5 \mathrm{~m}$, or 0 to $-15 \mathrm{~m}$ (Huon

1728 Peninsula: Chappell et al., 1996; Yokoyama et al., 2001 citing Pandolfi and Chappell, 1994). The most 1729 recent Tahiti dataset (Deschamps et al., 2012) assigns a palaeodepth to Porites sp. of -5 to $-25 \mathrm{~m}, 0$ 1730 to $-20 \mathrm{~m}$ and -5 to $-15 \mathrm{~m}$ dependent upon coralgal assemblage. Fossil assemblages used were after 1731 Camoin et al. (2007), Abbey et al. (2011), and Camoin et al. (2012), with depositional environments 1732 inferred from modern studies from Tahiti (Sugihara et al., 2006; Montaggioni et al., 1997; Camoin et 1733 al., 1999; Cabioch et al., 1999a) and other Indo-Pacific reefs (Camoin et al., 1997, 2004; Montaggioni 1734 and Faure, 1997; Cabioch et al., 1999; Sagawa et al., 2001).

1736 Our depth distributions - which do not take into account the assemblage information, and which are 1737 based on global data - adequately capture the majority of assigned palaeodepths within the 1738 literature, albeit with larger vertical uncertainties. As Porites sp. is determined only to the genus 1739 level, the median depth and vertical uncertainties are increased relative to other assessments (cf., 
1740 Deschamps et al., 2012). These vertical uncertainties may be substantially reduced if new 1741 identifications could reduce it to the species level (Figure 5), and if stratigraphic ordering of samples 1742 is taken into account (section 5.2.4). Still, the somewhat narrow depth-distribution uncertainties 1743 allowed in some of the cited palaeo-studies seem to be at odds with the wide range of depth 1744 habitats for Porites sp. in modern ecological data.

1746 The third most common species in the fossil database is Montastraea annularis ( $9 \%$ of all 1747 samples). Unfortunately few of the original studies included consideration of the modern (or palaeo) 1748 depth range for this species (e.g., Shinn et al., 1989; Muhs et al., 2011). Other studies calculated RSL 1749 for these specimens with only a 'generic' depth uncertainty applied, if at all, and should therefore 1750 be treated with caution. Our recalculation specifically accounts for the depth-distribution within both the calculated $\mathrm{P}_{\mathrm{RSL}}$ and the vertical uncertainties.

1752

\subsubsection{Global, regional, and local variations in depth habitat}

1754 Modern coral distributions (e.g. 'ecoregions' of Veron 2000, Veron et al., 2009) vary at both the 1755 inter- and intra- ocean basin scales. Hence, we might expect differences in both the regional and 1756 local drivers of species diversity and distribution between locations to be reflected in the depth1757 distribution of each coral species (see Figure 3, section 3). In this section, we evaluate this 1758 expectation.

\section{Variation at the genus level: an example from the Pacific}

1761 Differences in coral community composition and zonation result from the complex interplay of

1762 biological and environmental factors (section 3). These modern faunal distributions (cf. Veron et al., 1763 2009) reflect the generalist nature of most corals; for example, a species may occupy a wide range of 1764 habitats in one region, and be confined to a specific habitat elsewhere, or be absent entirely (Veron, 1765 1995). From detailed scrutiny of modern depth ranges, we observe that the depth-distribution of 1766 single taxa can differ between ocean basins. For example, on a global scale, Porites sp. observations 1767 are concentrated within the uppermost few metres for all species (except $P$. asteroides for which a 1768 greater range of depths is observed), although the maximum depth reaches nearly $-100 \mathrm{~m}$. In the 1769 Pacific alone, most Porites observations are in the top metre, but there is a considerable peak also 1770 between -30 and $-55 \mathrm{~m}$ (median depth virtually $0 \mathrm{~m}, 95 \%$ range of 0 to $-71 \mathrm{~m}$ ). In the Atlantic Ocean, 1771 however, Porites is found at a median depth of $-7.3 \mathrm{~m}$, with a 95\% range of $-0.8 \mathrm{~m}$ to $-21 \mathrm{~m}$ (Figure 1772 16b). 
1774 In addition to global differences between ocean basins, taxa also show regional differences in their 1775 depth distribution. To gauge the potential impacts on RSL reconstructions, we use our synthesis of 1776 modern ecological data to identify any regional variations in the depth distribution of two genera 1777 that are commonly used in sea-level reconstructions (Acropora sp. and Porites sp.). We focus on the 1778 Pacific, since there are generally good records within the modern coral database for that basin, for each of these taxa. Specifically, we examine regional depth distributions for the Great Barrier Reef, the 'NW Pacific' and three 'central' Pacific regions (1-3) (Figures 16 and 17).

The genus Acropora shows strikingly different depth distributions between the NW Pacific (multimodal with large numbers close to the surface and at $\sim 40 \mathrm{~m}$ ), the Great Barrier Reef (skewed distribution with a long tail to greater depths), and three central Pacific regions (similar to NW Pacific but with fewer observations at depth) (Figure 17). Even within the central Pacific, there are distinct differences between the three sub-regions, with the most southerly region 3 (Figure 17) possessing a substantial number of Acropora observations at depths of $-50 \mathrm{~m}$. We observe similar variability in the depth distributions of Porites (Figure 16). There are very few recorded observations for Acropora sp. and Porites sp. below about -11 to $-15 \mathrm{~m}$ on the Great Barrier Reef (Figures 16b and 17b).

1792 The observed differences may be due to different species compositions within each genus at the 1793 various sites (which is why a strict species-specific approach would be vital), but it may also include a

1794 component of truly contrasting depth preferences of individual species between sites. To test this, 1795 we investigate the sub-regional depth-distribution variability within a single species at an even finer 1796 (sub-regional) scale.

1797

\section{Variation at the sub-regional scale: a species-specific example from the Caribbean}

1799 Intra-species variation is well illustrated by the modern depth distribution of A. palmata within the 1800 wider Caribbean (including Florida and Gulf of Mexico). We assigned the modern synthesis data to 1801 one of ten geographic regions (Figure 18) and determined A. palmata depth preferences for each 1802 separate sub-region. $A$. palmata is found within the upper $3 \mathrm{~m}$ in the Caribbean region (excluding 1803 the Gulf of Mexico and Florida regions; median depth of $-1.5 \mathrm{~m} ; 95 \%$ range of -0.35 to $-9.4 \mathrm{~m}$ ) which 1804 accords with Lighty et al. $(1978,1982)$. Around Florida, A. palmata is not recorded in the upper 2.5 $1805 \mathrm{~m}$, but is mostly confined to the 0 to $-4 \mathrm{~m}$ depth. The Gulf of Mexico is represented by too few 1806 observations in our modern synthesis to make a significant case $(n=12)$. The Bahamas and Cuba 1807 share similar depth profiles, with most A. palmata within the upper $5 \mathrm{~m}$ of the water column and 
1808 with limited numbers at -5 to $-15 \mathrm{~m}$ (median depths of -1.5 and $-1 \mathrm{~m}$ respectively) (Figure 18). This

1809 contrasts with the Cayman Islands and the Puerto Rico to Virgin Islands sub-regions, where $A$.

1810 palmata tends towards greater depths (median depths of $-7 \mathrm{~m}$ and $-4 \mathrm{~m}$ respectively).

1812 Such local variations in the depth distribution of a single species (A. palmata) could cause bias of the 1813 order of several metres when applied to fossil coral-based $P_{\text {RSL }}$ reconstructions (Figures 18 and 19).

1814 In Figure 19, we investigate how calculated $P_{\text {RSL }}$ values (and uncertainties) would change if such sub1815 regional (or local) depth-distributions were used rather than global depth-distribution. For the 1816 Bahamas and Yucatan Peninsula (Chen et al., 1991 and Blanchon et al., 2009 respectively), using the 1817 sub-regional depth distribution does not alter calculated $\mathrm{P}_{\mathrm{RSL}}$ values, but it does alter the size of the 1818 vertical uncertainties (95\% bounds). These 'offsets' in $\mathrm{P}_{\mathrm{RSL}}$ uncertainties are not trivial, and the 1819 complexity of reconstructed $\mathrm{P}_{\mathrm{RSL}}$ is best highlighted when full consideration of the modern depth1820 distribution is incorporated into our $\mathrm{P}_{\mathrm{RSL}}$ reconstructions (Figure 19). Still, we have not been able to 1821 systematically apply such sub-regional depth-habitat corrections in the fossil coral database, 1822 because modern habitat constraints remain insufficiently documented for many areas.

1823

1824

\subsubsection{Palaeodepth summary}

1825 Using a few key examples, we have found that there is excellent scope for improving RSL 1826 reconstructions by further documentation of modern species-specific depth distributions at regional

1827 to sub-regional scales. To avoid "shallow-water" bias, such new ecological survey work should 1828 include deep-diving and ROV surveys.

1829

1830 Unfortunately, there is a more fundamental hurdle to overcome for coral-based RSL reconstructions 1831 than regional depth-preference variability within single species. This obstacle relates to the 1832 identification of corals to the species level: many taxonomic determinations in fossil coral-based sea1833 level studies remain limited to the genus level. Genus-level assessment of the modern distribution 1834 data yields much broader depth distributions than species-specific assessment, and genus-level 1835 results may become skewed by particular species that may or may not be present at all sites (also, 1836 there is scope for sampling bias when some areas have fewer observations than others). So, while 1837 improved modern species-level depth-habitat assessments will undoubtedly help to minimise 1838 uncertainties in past RSL reconstructions, this can only be effectively applied in sea-level studies if 1839 those follow a similarly strict species-specific approach. 
1841 We find that improvements in RSL reconstructions may be achieved by: (1) using identifications to 1842 the species level; (2) using coral depth-distributions and an assemblage approach that are location1843 specific; (3) inclusion of a greater number of cores/sections to more fully assess the complex reef 1844 geometry; and (4) optimisation of the use of stratigraphic constraints within the calculations.

\section{EXAMPLE APPLICATION OF THE FOSSIL CORAL DATABASE}

1847 Here we provide an example of how the database can be used, in this case to assess the age range of samples in our database where local sea level exceeds present during the LIG period. This age range may not be equivalent to the actual timing of the global mean sea level highstand, due primarily to the influence of GIA effects at each of the sites and also due to biases in the sample collections represented in the database (e.g., Dutton and Lambeck, 2012).

1853 Using ages and uncertainties from the screened fossil coral database $\left(\delta^{234} U_{\text {initial }}=147 \pm 5 \%, \leq 2 \%\right.$ 1854 calcite and ${ }^{232} \mathrm{Th}$ concentration $\leq 2 \mathrm{ppb}$ ), we can approximate in a Monte-Carlo approach the median 1855 age and 95\% confidence bounds for the last interglacial (LIG) (Figure 20). For the purposes of this 1856 exercise we define the LIG as being where local sea levels are at or above $0 \mathrm{~m}$, which is significantly 1857 different to a LIG defined by global ice volume or global mean sea level. We acknowledge that the 1858 duration of the last interglacial may be amplified or reduced by isostatic influences depending on the 1859 locations that the sample data are taken from (cf. Dutton and Lambeck, 2012; Figure 12), hence our 1860 estimates relate only to a definition of a local interglacial period, defined by local relative sea levels 1861 being above $0 \mathrm{~m}$. Additionally, any statistical analysis of the dataset will be to some degree affected 1862 by sampling biases, for example where only particular portions of the reef were sampled due to 1863 access/exposure/recovery issues.

1865 The analysis further illustrates the impact of screening choices, not only on the data available but 1866 also the outcome. We consider only data with a reconstructed $\mathrm{P}_{\mathrm{RSL}} \geq 0 \mathrm{~m}$. First, we use samples that 1867 pass our screening criteria from tectonically stable locations ( $n=51$ : Chen et al. 1991; Muhs et al. 1868 2002a; Blanchon et al. 2009; Stirling et al 1995; Stirling et al. 1998; Zhu et al. 1993; Eisenhauer et al. 1869 1996; O'Leary et al. 2008) and use a Monte-Carlo style (350,000 simulations per coral sample) 1870 approach to account for age and vertical (elevation measurement uncertainties and taxon-specific 1871 depth distributions) uncertainties to produce an estimate of periods of time where it is more likely 1872 than not (probability $>50 \%$ ) that relative (i.e. local) sea level $\left(\mathrm{P}_{\mathrm{RSL}}\right)$ exceeds $0 \mathrm{~m}$ (Figure 20a). This 1873 exercise suggests a median LIG age (i.e. $P_{\text {RSL }} \geq 0 \mathrm{~m}$ ) of $125.3 \mathrm{ka}$ with $95 \%$ bounds of $113.2 \mathrm{ka}$ and $1874138.1 \mathrm{ka}$. For comparison, we repeated the exercise using all data passing the 'chemical' screening 
$1875\left(\delta^{234} \mathrm{U}_{\text {initial }}=147 \pm 5 \%\right.$ o, $\leq 2 \%$ calcite and ${ }^{232} \mathrm{Th}$ concentration $\left.\leq 2 \mathrm{ppb}\right)$ with the additional constraint

1876 that samples must have been described as in situ or in growth position in the original publications, 1877 and relaxing the stable tectonic criterion ( $n=57$ : Chen et al. 1991; Muhs et al. 2002a; Blanchon et al. 1878 2009; Stirling et al 1995; Stirling et al. 1998; Zhu et al. 1993; Eisenhauer et al. 1996; O'Leary et al. 1879 2008). In this instance, we also account for the time varying tectonic correction of each uplifting or 1880 subsiding sample. Note that these adjusted criteria exclude some data from the Yucatan Peninsula 1881 (Blanchon et al., 2009) and Bermuda (Muhs et al. 2002a), with significant impact upon our analysis, 1882 effectively removing the tails of the distribution and producing a median LIG age of $124.0 \mathrm{ka}$ and 95 1883 \% bounds at $118.1 \mathrm{ka}$ and $130.3 \mathrm{ka}$ (Figure 20b). This again highlights that the use of data from our 1884 database in subsequent analysis is highly sensitive to the screening criteria that are applied. Hence, 1885 this illustrates the need for clear and transparent description of the definitions, selection criteria, 1886 and procedures used in interpretations.

1887

1888

\section{OUTSTANDING ISSUES AND WAYS FORWARD}

1889 The compilation of U-series dated fossil coral indicators presented here enables an evaluation of the

1890 fossil coral sea-level index points within their proper uncertainties via: harmonisation of the fossil 1891 coral data; a thorough assessment of all uncertainties; and inclusion of full metadata. There remain, 1892 however, outstanding issues that limit the ability of these data to provide robust sea-level 1893 reconstructions aside from issues expected due to glacio-isostatic adjustments. Principal among 1894 these are the relatively large vertical uncertainties that are driven especially by the application of 1895 our new ecology-based taxon-specific depth-distributions, and by the fact that many fossil coral data 1896 points have been identified only to the genus level. While these vertical uncertainties are large, they 1897 derive from extensive biological/ecological surveys, and we therefore consider them be a more 1898 realistic (if conservative) representation of the errors associated with $\mathrm{P}_{\mathrm{RSL}}$ reconstructions from fossil 1899 corals. The current database combines data with little to no prior information about palaeodepth 1900 with data that contains more detailed palaeodepth information. Going forward, reconstructions may 1901 be refined by designing methods for objectively implementing a more structural use of diverse 1902 palaeodepth information.

1904 Significant advances (e.g., technological advances increasing the precision of age determinations, 1905 accuracy of elevation measurements etc.) have been made in the last few decades that have 1906 facilitated millennial-scale sea-level reconstructions for several locations (e.g., Barbados and Tahiti). 1907 There remain, however, three principal outstanding issues that currently hamper our ability to 1908 reconstruct precise and accurate past sea levels from fossil corals. 
1910 The first issue concerns the frequently incomplete understanding of the (often complex) vertical

1911 displacement (tectonic or otherwise) of many sites. This comprises: (a) current inability to

1912 adequately describe the often complex tectonic history of many sites; (b) use of the dated corals

1913 themselves to derive uplift/subsidence rates, coupled with assumptions regarding the age of the last

1914 interglacial and its sea-level position to calculate uplift rates; (c) the assumption of constancy of

1915 those uplift/subsidence rates through time (e.g., Schellmann and Radtke, 2004); and (d)

1916 insufficiently quantified effects of dynamic topography that become more important with increasing

1917 age (Moucha et al., 2008). These need to be revisited as a matter of priority, through independent

1918 verifications of uplift and subsidence rates.

1919

1920 The second outstanding obstacle to obtaining precise sea-level reconstructions concerns the vertical

1921 uncertainties associated with species- and region-specific depth relationships. RSL reconstructions

1922 rely upon understanding of the relationship between the elevation of the fossil coral and sea level at

1923 the time at which the coral was growing. Thus, robust estimates of these species-specific depth

1924 relations are a prerequisite for coral reconstructions of sea level. Significant progress has been made

1925 (e.g., the use of modern, local biological assemblages and the association with vermetid gastropods

1926 and coralline algae), and this study seeks to extend this progress by evaluating fossil data within the

1927 context of modern ecological studies. On that basis, we recommend: (1) the use of modern,

1928 ecologically derived depth distributions in palaeo-sea-level reconstructions; (2) that these are

1929 applied at the species level rather than the often used genus level; (3) that (sub-) regional ecological

1930 surveys are conducted to determine accurate depth-distributions for the appropriate specific species

1931 in the vicinity each fossil coral site; (4) that the surveys mentioned in (3) include extensive deep-

1932 diving and ROV deployments to avoid "shallow-water bias" in the modern habitat characterisations;

1933 and (5) optimisation of the promising approach of using assemblages of reef biota (e.g., coral,

1934 coralline algae, vermetid gastropods, and encrusting foraminifera) and use of coral micro-atoll data

1935 to obtain independent constraints on growth position relative to sea level. As suggested by Camoin

1936 and Webster (2014), additional novel approaches to provide tighter constraints on palaeowater

1937 depth should also be pursued (e.g., endolithic microborers or carbon isotopes).

1939 These five key measures to improve the base-information that goes into RSL reconstructions can be 1940 further strengthened by addressing the third outstanding issue mentioned above. This concerns the 1941 need for complete and routine inclusion of stratigraphic and geomorphological (reef architecture) 1942 data including pictures and outcrop or drill-core descriptions (see also Medina-Elizalde, 2012). This 
1943 context, when provided, is extremely important in making interpretations about sea-level behaviour 1944 (e.g., Speed and Cheng, 2004; Blanchon et al., 2009). Given the importance of these metadata, we 1945 have added this information into the fossil database, so that users may assess the coherency of 1946 samples from the same stratigraphic unit, identify those samples explicitly identified as in situ, etc. A 1947 remaining limitation is that geological sections and drill cores rarely provide the complete desired 31948 dimensional information of coral reef structure. This could be addressed by obtaining a greater number of drillcores/sections to more fully describe reef architecture.

\section{DATABASE RECOMMENDATIONS AND MANAGEMENT}

1952 At present, there is no centralised online repository for the combination of data assembled here, 1953 though preliminary steps are underway to develop a means of archiving both the geochronological 1954 data as well as the associated sample metadata. This will be achieved, in part, through existing openaccess, online data repositories that operate under the umbrella organization of Integrated Earth Data Applications (IEDA, http://www.iedadata.org/). EarthChem, and eventually GeoChron, will be able to archive the $\mathrm{U}$-series geochronological data, provided that all samples are given an International GeoSample Number (IGSN) through the System for Earth Sample Registration (SESAR, http://www.geosamples.org/). Software is presently being developed to recalculate ages from archived data, as well as to develop publication- quality tables and plots such as evolution diagrams. What remains to be developed in terms of the cyberinfrastructure is a way to integrate these

1962 archived data with the sample metadata required to make sea-level interpretations, as well as a means to incorporate other types of sea-level proxies into the database.

1964

1965 The incomplete reporting of data, and a lack of standardised practices for the reporting of data,

1966 hinder syntheses of data such as that shown here. We provide a brief summary of the minimum

1967 suggested data requirements that will facilitate future incorporation of data into the database and 1968 improve the quality and longevity of the data.

With respect to the U-series data, all geochemical parameters measured should be reported with their associated uncertainties (i.e., ${ }^{238} \mathrm{U}$ and ${ }^{232} \mathrm{Th}$ concentration, ${ }^{230} \mathrm{Th} /{ }^{238} \mathrm{U}$ and ${ }^{234} \mathrm{U} /{ }^{238} \mathrm{U}$ activity or molar ratios), including the decay constants used, the method of spike calibration, instrumentation and analytical methodology. In particular we note that it is critical to report both isotope ratios (i.e., ${ }^{230} \mathrm{Th} /{ }^{238} \mathrm{U}$ (or ${ }^{230} \mathrm{Th} /{ }^{234} \mathrm{U}$ ) and ${ }^{234} \mathrm{U} /{ }^{238} \mathrm{U}$ ) so that ages can be calculated (and re-calculated) and assessed for open-system behaviour based on the back-calculated initial $\delta^{234} U$ value. 
1977 Reported elevations should also include uncertainty and a description of the methodology used for

1978 surveying as well as the method used to tie the measurements to a tidal benchmark. All samples

1979 should be assigned an IGSN identifier available through SESAR to ease online cataloguing of 1980 geochemical data and associated metadata.

1981

1982 Complete descriptions of sample location and context within the reef and/or drill core are also 1983 strongly recommended to improve the level of interpretations that can be made, including species1984 level identification and reef biota assemblage information, if possible.

1985

1986 This database will be maintained and periodically updated by FDH (updates accessible on 1987 http://www.highstand.org/erohling/ejrhome.htm via the link "CORAL SEA-LEVEL DATA". The version 1988 of the database used in this paper is archived by British Oceanographic Data Centre (BODC; 1989 www.bodc.ac.uk) doi: xxx. To contribute data, please contact FDH to discuss format requirements 1990 and release information - note that the underlying philosophy is one of complete open access. 1991 Updates will be released periodically.

\section{Acknowledgements}

1994 We thank the editors at QSR for inviting this review, Dan Muhs and Anthony Dosseto for their 1995 thoughtful reviews that improved the manuscript, Belinda Dechnik for the photographs (Figure 2) 1996 and colleagues for fruitful discussions at PALSEA2 conferences. This work was supported by NERC 1997 Consortium Grant iGlass: Using Interglacials to Assess Future Sea Level Scenarios (NE/I009906/1) and 19982012 Australian Laureate Fellowship FL120100050 to EJR, and NSF grant 1443037 to AD.

1999 
Figure 1: Principal influences on coral reef distribution and development (adapted from Harriott and Banks, 2002; Montaggioni and Braithwaite 2009)

Figure 2: Variation of Isopora (highlighted by red boxes) coral morphology from One Tree Reef, One Tree Island (southern Great Barrier Reef): (a) encrusting losopra from the windward, shallow slope ( $2 \mathrm{~m}$ water depth) (very high energy margin); (b) columnar, low branching Isopora from the shallow leeward slope ( $2 \mathrm{~m}$ water depth) (low energy margin); (c) robust, branching Isopora from the deep leeward slope (9 $\mathrm{m}$ water depth) (low energy, deeper environment). Photographs courtesy of Belinda Dechnik, Geocoastal Research Group, The University of Sydney.

Figure 3: Spatial distribution of zooxanthellate coral species richness (after Veron et al., 2009).

Figure 4: Map of fossil coral locations contained in the fossil database.

Figure 5: (a) Modern depth distributions for the 8 most frequently identified coral taxa within the fossil database. See Table 3 for the modern depth range, median depth, and $95 \%$ and $68 \%$ confidence intervals. (b) Cumulative distribution functions for the 8 most frequently identified coral taxa within the fossil database.

Figure 6: Ecologically derived coral depth ranges (blue is this study, red is the ICUN Red List; Carpenter et al., 2008) Blue squares give the median depth of coral growth, and vertical error bars mark the 95\% confidence intervals for each taxon. From right to left: (1) Acropora sp., (2) Acropora abrotanoides, (3) Acropora cervicornis, (4) Acropora danai, (5) Acropora gr. danai-robusta, (6) Acropora humilis, (7) Acropora hyacinthus, (8) Acropora palmata, (9) Acropora pharaonis, (10) Acropora robusta, (11) Agaricia sp., (12) Agaricia agaricites, (13) Alveopora spp., (14) Astreopora sp., (15) Balanophyllia elegans, (16) Colpophyllia sp., (17) Colpophyllia natans, (18) Cyphastrea sp., (19) Cyphastrea chalcidium, (20) Cyphastrea serailia, (21) Diploastrea sp., (22) Diploastrea heliopora, (23) Diploria spp., (24) Diploria clivosa, (25) Diploria strigosa, (26) Echinopora sp., (27) Echinopora gemmacea, (28) Favia sp., (29) Favia pallida, (30) Favia speciosa, (31) Favia stelligera, (32) Faviidae (family), (33) Favites sp., (34) Fungia sp., (35) Galaxea sp., (36) Galaxea fascicularis, (37) Gardineroseris sp., (38) Gardineroseris planulata, (39) Goniastrea sp., (40) Goniastrea parvistella, (41) Goniastrea pectinata, (42) Goniastrea retiformis, (43) Goniopora sp., (44) Goniopora lobata, (45) Hydnophora sp., (46) Hydnophora exesa, (47) Hydnophora microconos, (48) Leptastrea sp., (49) Leptoria sp., (50) Leptoria phrygia, (51) Leptoseris sp., (52) Lobophyllia sp., (53) Lobophyllia corymbosa, (54) Millepora sp., (55) Montastraea sp., (56) Montastraea annularis, (57) Montastraea cavernosa, (58) Montastraea annuligera, (59) Montipora sp., (60) Oculina sp., (61) Oulophyllia sp., (62) Oulophyllia crispa, (63) Pachyseris sp., (64) Pachyseris foliosa, (65) Pavona sp., (66) Pavona clavus, (67) Platygyra sp., (68) Platygyra daedalea, (69) Platygyra lamellina, (70) Platygyra sinensis, (71) Plesiastrea sp., (72) Plesiastrea curta., (73) Pocillopora sp., (74) Pocillopora eydouxi, (75) Pocillopora guadalupensis, (76) Pocillopora meandrina, (77) Pocillopora verrucosa, (78) Porites sp., (79) Porites asteroides, (80) Porites brighami, (81) Porites lobata, (82) Porites lutea, (83) Porites nigrescens, (84) Porites solida, (85) Porites solida lobata, (86) Pseudosiderastrea sp., (87) 2044 Pseudosiderastrea tayami, (88) Siderastrea sp., (89) Siderastrea radians, (90) Siderastrea siderea, (91) Stylophora sp., (92) Symphyllia sp., (93) Symphyllia mobilis, (94) Turbinaria sp.

Figure 7: Schematic for the effects of the main diagenetic processes on the isotopic composition of fossil corals (after Scholz et al., 2009). 
Figure 8: schematic of relationship between, and uncertainty propagation for, corrected coral position $\left(\mathrm{Z}_{\mathrm{cp}}\right)$ and $\mathrm{RSL}$ probability $\left(\mathrm{P}_{\mathrm{RSL}}\right)$.

Figure 9: Effect of screening criteria upon the number of samples available for subsequent analysis. Shaded boxes denote the range of acceptable $\delta^{234} U_{\text {initial }}$ values used, grey crosses are all unscreened data in the database ( 0 to $350 \mathrm{ka}$ ), blue filled squares are samples passing all screening criteria (i.e. acceptable $\delta^{234} \mathrm{U}_{\text {initial, }} \%$ calcite and ${ }^{232} \mathrm{Th}$ concentrations); yellow box - 'interglacial' screening of $\delta^{234} U_{\text {initial }}=147 \pm 5 \%$ (ages $>17 \mathrm{ka}$ and 71 to $130 \mathrm{ka}$ ); blue box - 'glacial' screening of $\delta^{234} \mathrm{U}_{\text {initial }}=142$ $\pm 8 \%$ o (ages 17 to $71 \mathrm{ka}$ ) and; grey box - 'older than $130 \mathrm{ka}$ ' screening of $\delta^{234} \mathrm{U}_{\text {initial }}=147+5 /-10 \%$ (ages $>130 \mathrm{ka}$ ). Red dashed line is the modern $\delta^{234} \mathrm{U}_{\text {initial }}$ of $147 \%$.

Figure 10: (a) Samples that pass our initial chemical screening (grey crosses) and replicate analyses (blue dots). Yellow dots are the consistent multiple analyses from core BB02-5-1 (Barbados, Scholz et al., 2009).

Figure 11: Reconstructed relative sea levels for fossil corals, without GIA correction, from both near and far-field locations that pass an initial screening $\left(\delta^{234} \mathrm{U}_{\text {initial }}\right.$, calcite $\leq 2 \%$ and ${ }^{232}$ Th concentration $\leq$ $2 \mathrm{ppb}$ ) with their respective uncertainties intervals (95\%). Age and RSL recalculated from data contained in the following studies: Bahamas (Chen et al., 1991), Barbados (Gallup et al., 1994; 2002; Cutler et al., 2003; Thompson et al., 2003; Bard et al., 1990a; Hamelin et al., 1991; Blanchon and Eisenhauer, 2001; Peltier and Fairbanks, 2006; Fairbanks et al., 2005; Potter et al., 2004; Bard et al., 1990b,c; Scholz et al., 2009) Bermuda (Muhs et al., 2002), southern China (Zhao and Yu, 2002), Comoro Islands (Camoin et al., 2004), Curacao (Muhs et al., 2012a; Vezina et al 1999), Mururoa atoll (French Polynesia) (Camoin et al., 2001), Tahiti (Thomas et al., 2009; Yokoyama et al., 2001; Deschamps et al., 2012; Bard et al., 1996b), Indonesia (Sumba Island) (Bard et al., 1996a), Madagascar (Camoin et al., 2004), Yucatan Peninsula (Blanchon et al., 2009), Huon Peninsula (Papua New Guinea) (Yokoyama et al., 2001; Esat and Yokoyama, 2006; Cutler et al., 2004; Bard et al., 1996b; Cutler et al., 2003; Stein et al., 1993), Henderson Island (Pitcairn Islands) (Anderson et al., 2010; Stirling et al., 2001), Seychelles (Israelson and Wolfarth, 1999; Camoin et al., 2004), Hawaii (Muhs et al., 2002; Szabo et al., 1994), Vanuatu (Edwards et al., 1987; Taylor et al., 1985; Cutler et al., 2004) and Western Australia (Stirling et al., 1995, 1998, 2001; Zhu et al., 1993; Eisenhauer et al., 1996; O'Leary et al., 2008; Collins et al., 2006)

2084

2085

2086

2087

2088

2089

2090

2091

2092

2093

2094

2095

2096

2097

2098

2099

2100

Figure 12: A demonstration of the geospatial variability of relative sea-level (RSL) predictions with global mean (eustatic) for (a) the last deglacial and (b) the last interglacial periods for an ice history incorporating a $4 \mathrm{ka}$ interglacial period, using one earth model. For any ice history, the choice of earth model affects both the timing and the amplitude of a sea-level peak, highstand or low stand.

Figure 13: (a) Reconstructed corrected coral position $\left(\mathrm{Z}_{\mathrm{cp}}\right)$ for Barbados samples that pass our initial chemical screening (grey crosses), and those with reef-crest designations (coloured). Age and vertical uncertainties are plotted at the $2 \sigma(95 \%)$ interval. (b) As (a) but reconstructed $\mathrm{P}_{\mathrm{RSL}}$ (with their $95 \%$ uncertainties).

Figure 14: (a) Reconstructed corrected coral position $\left(Z_{c p}\right)$ for drill-core samples from Barbados that pass our initial chemical screening. Age and vertical uncertainties are plotted at the $2 \sigma(95 \%)$ interval. (b) As (a) but reconstructed $\mathrm{P}_{\mathrm{RSL}}$ (with their $95 \%$ uncertainties). (c) Reconstructed $\mathrm{P}_{\mathrm{RSL}}$ for the last deglaciation using Monte-Carlo style simulation of samples. Coloured shading indicates the $99^{\text {th }}$ (pale blue), $95^{\text {th }}$ (yellow), $85^{\text {th }}$ (orange), $70^{\text {th }}$ (red) and $50^{\text {th }}$ (black) percentiles. 
Figure 15: (a) Reconstructed corrected coral position $\left(Z_{c p}\right)$ for drill-core samples from Tahiti that pass our initial chemical screening. Note, we have also plotted the Papeete Harbour samples for comparison, although no ${ }^{232} \mathrm{Th}$ data are available for these samples (and these therefore do not strictly meet our screening criteria). Age and vertical uncertainties are plotted at the $2 \sigma(95 \%)$ interval. (b) As (a) but reconstructed $\mathrm{P}_{\mathrm{RSL}}$ (with their 95\% uncertainties) calculated using only taxanomic depth distributions derived (Note, assemblage derived palaeowater depths estimates are available and that this example is intended only to show the result of using depth distributions strictly limited to taxonomic identification of the coral) (c) Reconstructed $\mathrm{P}_{\mathrm{RSL}}$ for the last deglaciation using Monte-Carlo style simulation of samples (excluding the Papeete Harbour samples) using only the taxanomic depth distributions (not original palaeo-water depth estimates). Coloured shading indicates the $99^{\text {th }}$ (pale blue), $95^{\text {th }}$ (yellow), $85^{\text {th }}$ (orange), $70^{\text {th }}$ (red) and $50^{\text {th }}$ (black)

Figure 16: (a) Map of Porites sp. observations from the Pacific and the Atlantic (OBIS, 2014; see online supplementary material for references and datasets used). (b) Histograms of the depth distributions for: all OBIS observations ('Porites sp. - ALL'); the Atlantic and Pacific basins; and regional subsets of the Pacific.

Figure 17: (a) Map of Acropora sp. observations from the Pacific and the Atlantic (OBIS, 2014; see nline supplementary material for references and datasets used). (b) Histograms of the depth distributions for: the Atlantic; a subset of Caribbean data and Florida data; the Pacific basin; and regional subsets of the Pacific.

Figure 18: (a) Map, histogram and cumulative frequency distribution of Acropora palmata in the Caribbean (OBIS, 2014; see Appendix A for references and datasets used). (b) Histograms of $A$. palmata depth-habitat distributions in Caribbean sub-regions. (c) Cumulative frequency distributions of $A$. palmata depth-habitat distributions in Caribbean sub-regions.

Figure 19: Example of the effect of applying sub-regional, taxon-specific depth distribution to calculate $P_{\text {RSL }}$ (Chen et al., 1991; Blanchon et al., 2009 using the depth distributions derived for $A$. palmata for the Caribbean (i.e. 'global') , Bahamas and Yucatan Peninsula regions) (a) reconstructed coral position $\left(\mathrm{Z}_{\mathrm{cp}}\right)$ with $2 \sigma$ uncertainties (b) $\mathrm{P}_{\mathrm{RSL}}$ calculated using the $A$. palmata depth-distributions. (i) using the 'global' depth-distribution (ii) as in (i), but $P_{R S L}$ calculated using sub-regional (Bahamas and Yucatan Peninsula) depth-distributions. Note the smaller vertical uncertainties for the Bahamas samples (vertical uncertainties are plotted at the $2 \sigma(95 \%)$ interval). (iii) calculation of $P_{\text {RSL }}$ using a Monte-Carlo style simulation of the same samples. Coloured shading (red, Bahamas; blue, Yucatan Peninsula) indicates the $99^{\text {th }}, 95^{\text {th }}, 85^{\text {th }}, 70^{\text {th }}$ and $50^{\text {th }}$ percentiles. All data plotted pass our initial chemical screening.

Figure 20: Monte-Carlo style simulation (350,000 simulations per coral sample) estimate of periods of time where it is more likely than not (probability $>50 \%$ ) that relative (i.e. local) sea level $\left(\mathrm{P}_{\mathrm{RSL}}\right)$ exceeds $0 \mathrm{~m}$ (a) histogram for data from stable regions only $(n=51)(b)$ as in (a) but with additional constraint that samples must be in situ or in growth position and the tectonically stable location criterion relaxed $(n=57)$. All data plotted pass the initial interglacial screening criteria. 
Table captions:

2147

2148

2149

2150

2151

2152

2153

2154

2155

2156

2157

2158

2159

2160

2161

2162

2163

2164

2165
Table 1: Recalculated uplift/subsidence rates used in the fossil database. Uplift/subsidence rates were recalculated assuming a LIG sea level of $6.6 \pm 2 \mathrm{~m}$ (Kopp et al., 2009, 2013) and an age of $125 \pm$ $5 \mathrm{ka}$.

Table 2: The modern tidal range for sites in the fossil database (for simplicity the minimum and maximum tidal ranges for a location are listed here). The modern tidal range was estimated from a global tidal model (i.e. the difference between the maximum and minimum tides predicted from the location).

Table 3: Summary of empirically derived global depth distributions for coral in the fossil coral database. Only modern observational data with a depth precision $\leq 0.25 \mathrm{~m}$ were used to derive the depth-habitat distributions (OBIS, 2014; a full list of datasets and references can be found in the online supplementary material).

Table 4: Compilation of modern (and fossils $<1 \mathrm{ka}$ ) ${ }^{238} \mathrm{U}$ concentrations from the literature. 
Abbey, E., Webster, J.M., Braga, J.C., Jacobsen, G.E., Thorogood, G., Thomas, A.L., Camoin, G., Reimer, P.J., Potts, D.C. 2013. Deglacial mesophotic reef demise on the Great Barrier Reef. Palaeogeography, Palaeoclimatology, Palaeoecology 392: 473-494.

Abbey, E., Webster, J.M., Braga, J.C., Sugihara, K., Wallace, C., Iryu, Y., Potts, D., Done, T., Camoin, G., significance: IODP Expedition 310, "Tahiti Sea Level". Global and Planetary Change 76: 1-15.

Abram, N.J., Webster, J.M., Davies, P.J., Dullo, W.C. 2001. Biological response of coral reefs to sea surface temperature variation: Evidence from the raised Holocene reefs of Kikaijima (Ryukyu Islands, Japan). Coral Reefs 20: 221-234.

Abu-Hilal, 1994. Effect of depositional environment and sources of pollution on uranium concentration in sediment, coral, algae and seagrass species from the Gulf of Aqaba (Red Sea). Marine Pollution Bulletin 28(20): 81-88.

Acevedo, R., Morelock, J., \& Olivieri, R. A. 1989. Modification of coral reef zonation by terrigenous sediment stress. Palaios 4: 92-100.

Allemand, D., Tambutté, E., Zuccola, D., Tambutté, S. 2011. Coral calcification, cells to reefs. In Dubinsky, Z. and Stambler, N. (Eds.) Coral reefs: an ecosystem in transition. Springer, pp.119-150.

Allemand, D., Ferrier-Pagès, C., Furla, P., Houlbrèque, F., Puverel, S., Reynaud, S., Tambutté, E., Tambutté, S., Zoccola, D. 2004. Biomineralisation in reef-building corals: from molecular mechanisms to environmental control. C. R., Palévol, 3: 453-467.

Alexander, C.S. 1953. The marine and stream terraces of the Capitola-Watsonville area. University of California Publications in Geography 10: 1-44.

Amiel, A.J., Miller, D.S., Friedman, G.M. 1973.Incorporation of uranium in modern corals. Sedimentology 20: 523-528.

Andersen, M.B., Stirling, C.H., Potter, E.-K., Halliday, A.N., Blake, S.G., McCulloch, M.T., Ayling, B.F., O'Leary, M.J. 2010. The timing of sea-level high-stands during Marine Isotope Stages 7.5 and 9: Constraints from the uranium-series dating of fossil corals from Henderson Island. Geochimica Cosmochimica Acta 74: 3598-3620. doi:10.1016/j.gca.2010.03.020.

Andersen, M. B., Stirling, C. H., Zimmerman, B., and Halliday, A. N., 2010b. Precise determination of the open ocean 234U/238U composition: Geochemistry, Geophysics, Geosystems 11(12): 1-8.

Andersen, M.B., Stirling, C.H., Potter, E-K., Halliday, A.N., Blake, S.G., McCulloch, M.T., Ayling, B.F., O'Leary, M. 2008. High-precision U-series measurements of more than 500,000 year old fossil corals. Earth and Planetary Science Latters 265: 229-245.

Andrews, J.C., Gentien, P. 1982. Upwelling as a source of nutrients for the Great Barrier Reef ecosystems: A solution to Darwin's question. Marine Ecology Progress Series 8: 257-269.f

Anthony, K.R.N. 2006. Enhanced energy status of corals on coastal, high-turbidity reefs. Marine Ecology Progress Series 319: 111-116. 
2217 Anthony, K.R.N, Kerswell, A.P. 2007. Coral mortality following extreme low tides and high solar 2218 radiation. Marine Biology 151: 1623-1631.

Anthony, K.R.N., Connolly, S.R. 2004. Environmental limits to growth: physiological niche boundaries of corals along turbidity-light gradients. Oecologia 141(3): 373-384.

Anthony, K.R.N., Fabricius, K.E. 2000. Shifting roles of heterotrophy and autotrophy in coral energetics under varying turbidity. Journal of Experimental Marine Biology and Ecology 252(2): 221253.

Anthony, K.R.N., Hoogenboom, M.O., Connolly, S.R. 2005. Adaptive variation in coral geometry and the optimization of internal colony light climates. Functional Ecology 19: 17-26.

Antonioli F., Chemello R., Improta S., Riggio S. 1999. Dendropoma lower intertidal reef formations and their palaeoclimatological significance, NW Sicily. Marine Geology 161: 155-170.

Armstrong, R.A., Singh, H., Torres, J., Nemeth, R.S., Can, A., Roman, C., Eustice, R., Riggs, L., GarciaMoliner, G. 2006. Characterizing the deep insular shelf coral reef habitat of the Hind Bank Marine Conservation District (US Virgin Islands) using the Seabed autonomous underwater vehicle. Continental Shelf Research 26: 194-205.

Aronson, R.B., Precht, W.F. 2001. White-band disease and the changing face of Caribbean coral reefs. Hydrobiologia 460: 25-38.

Atkinson, M.J., Bilger, R.W. 1992 Effects of water velocity on phosphate uptake on coral reefs. Limnology and Oceanography 37:273-279.

Atkinson, M.J., Kotler, E., Newton, P. 1994. Effects of water velocity on respiration, calcification and ammonium uptake in a Porites compressa community. Pacific Science 48:296-303.

Atkinson, M.J., Carlson, B., Crow, G.L. 1995. Coral growth in high-nutrient, low-pH seawater: A case study of corals cultured at the Waikiki Aquarium, Honolulu, Hawaii. Coral Reefs 14: 215-223.

Ayling, B.F., McCulloch, M.T., Gagan, M.K., Stirling, C.H., Andersen, M.B., Blake, S.G. 2006. Sr/Ca and d180 seasonality in a Porites coral from the MIS 9 (339-303 ka) interglacial. Earth and Planetary Science Letters 248: 462-475.

Bard, E., Hamelin, B. \& Delanghe-Sabatier, D. 2010. Deglacial Meltwater Pulse 1B and Younger Dryas Sea Levels Revisited with Boreholes at Tahiti. Science 327, 1235-1237, doi: 10.1126/Science.1180557.

Bard, E., Jouannic, C., Hamelin, B., Pirazzoli, P., Arnold, M., Faure, G., Sumosusastro, P., Syaefundin, 1996a. Pleistocene sea levels and tectonic uplift based on dating of corals from Sumba Island, Indonesia. Geophysical Research Letters 23(12): 1473-1476.

Bard, E., Hamelin, B., Arnold, M., Montaggioni, L., Cabioch, G., Faure, G., Rougerie, F. 1996b. Deglacial sea-level record from Tahiti corals and the timing of global meltwater discharge. Nature 382, 241-244. 
Bard, E., Fairbanks, R. G., Hamelin, B., 1992. How accurate are the U-Th ages obtained by mass spectrometry on coral terraces. In Kukla, G., Went, E. (Eds.), Start of a Glacial. Springer-Verlag, Berlin, pp. 15-21.

Bard, E., Fairbanks, R.G., Hamelin, B., Zindler, A., Huang, C.T. 1991. Uranium-234 anomalies in corals older than 150,000 years. Geochimica Cosmochimica Acta 55: 2385-2390.

Bard E, Hamelin B, Fairbanks R. G., Zindler A. 1990a. Calibration of the 14C timescale over the past 30,000 years using mass spectrometric U-Th ages from Barbados corals. Nature 345: 405-410.

Bard, E., Hamelin, B., Fairbanks, R.G. 1990b. U-Th ages obtained by mass spectrometry in corals from Barbados: sea level during the past 130,000 years. Nature 346: 456-458.

Bard, E., Hamelin, B., Fairbanks, R.G., Zindler, A., Mathieu, G., Arnold, M. 1990c. U/Th and 14C ages of corals from Barbados and their use for calibrating the $14 \mathrm{C}$ time scale beyond 9000 years BP. Nuclear Instruments and Methods in Physics Research B52: 461-468.

Barnes, D. J., Devereux, M. J. 1984. Productivity and calcification on a coral reef: a survey using pH and oxygen electrode techniques. Journal of Experimental Marine Biology and Ecology 79: 213-231.

Barnes and Hughes. 1999. An Introduction to Marine Ecology; Third edition. Oxford, UK: Blackwell Science Ltd. pp. 117-141.

Barnett, T.P. 1984. The estimation of "global" sea level change: A problem of uniqueness. Journal of Geophysical Research 89: 7980-7988.

Bassett, S.E., Milne, G.A., Mitrovica, J.X., Clark, P.U. 2005. Ice Sheet and Solid Earth Influences on Far-Field Sea-Level Histories. Science 309: 925-928.

Bellwood, D.R., Hughes, T.P., Folke, C. and Nyström, M., 2004. Confronting the coral reef crisis. Nature, 429(6994), pp.827-833.

Birkeland, C.E. 1977. The importance of rate of biomass accumulation in early successional stages of benthic communities to the survival of coral recruits. Proceedings of the 3rd International Coral Reef Symposium 1:15-21

Blake S. G. 1995. Late Quaternary history of Henderson Island, Pitcairn Group. Biological Journal of the Linnaean Society 56: 43-62.

Blanchon, P., Eisenhauer, A. 2001. Multi-stage reef development on Barbados during the Last Interglaciation. Quaternary Science Reviews 20: 1093-1112.

Blanchon, P., Shaw, J. 1995. Reef drowning during the last deglaciation: Evidence for catastrophic sea level rise and ice-sheet collapse. Geology 23: 4-8.

Blanchon, P., Eisenhauer, A., Fietzke, J., Liebetrau, V. 2009. Rapid sea-level rise and reef backstepping at the close of the last interglacial highstand. Nature 458: 881-885.

Blanchon, P., Jones, B. and Ford, D.C., 2002. Discovery of a submerged relic reef and shoreline off Grand Cayman: further support for an early Holocene jump in sea level. Sedimentary Geology, 147(3), pp.253-270. 
Blanchon, P., Jones, B., Kalbfleisch, W. 1997. Anatomy of a fringing reef around Grand Cayman:

Storm rubble, not coral framework. Journal of Sedimentary Research 67: 1-16.

Bloom, A.L., Jouannic, C., Taylor, F.W. Appendix to Ash, R.P., Carney N., Macfarlane A. 1978. Geology

Bloom A.L., Broecker W.S., Chappell, J.M.A., Matthews, R.K., Mesolella, K.J. 1974. Quaternary sea level fluctuations on a tectonic coast: new 230Th/234U dates from the Huon Peninsula, New Guinea. Quaternary Research 4: 185-205.

Bongaerts, P., Ridgway, T., Sampayo, E., Hoegh-Guldberg, O. 2010. Assessing the 'deep reef refugia' hypothesis: focus on Caribbean reefs. Coral Reefs, 29: 309-327.

Bradley, W.C., Griggs, G.B., 1976. Form, genesis, and deformation of central California wave-cut platforms. Geological Society of America Bulletin 87, 433-449.

Braithwaite, C.J.R., Montaggioni, L.F., Camoin, G.F., Dalmasso, H., Dullo, W.C., Mangini, A. 2000. Origins and development of Holocene coral reefs: A revisited model based on reef boreholes in the Seychelles, Indian Ocean. International Journal of Earth Sciences 89: 431-445.

Brancaccio, L., Capaldi, G., Cinque, A., Pece, R., Sgrosso, I., 1978. 230Th-238U dating of corals from a Tyrrhenian beach in Sorrentine Peninsula (southern Italy). Quaternaria 20: 175-183.

Brett, C.E. 1990. Destructive taphonomic processes and skeletal durability. In Briggs, D.E.G., Crowther, P.R. (Eds) Palaeobiology: a synthesis. Blackwell, Oxford, pp. 223-226.

Bridge, T.C.L., Hughes, T.P., Guinotte, J.M., Bongaerts, P. 2013. Call to protect all coral reefs. Nature Climate Change 3: 528-530.

Bridge, T.C.L., Fabricius, K.E., Bongaerts, P., Wallace, C.C., Muir, P.R., Done, T.J., Webster, J.M. 2012. Diversity of Scleractinia and Octocorallia in the mesophotic zone of the Great Barrier Reef, Australia. Coral Reefs 31: 179-189.

Broecker, W.S. 1963. A preliminary evaluation of uranium series inequilibrium as a tool for absolute age measurement on marine carbonates. Journal of Geophysical Research 68(9): 2817-2834.

Broecker, W.S., Thuber, D.L. 1965. Uranium-series dating of corals and oolites from Bahamian and Florida Key Limestones. Science 149: 58-60.

Broecker, W.S., Thurber, D.L., Goddard, J., Ku, T., Matthews, R.K., Mesolella, K.J. 1968. Milankovitch hypothesis supported by precise dating of coral reefs and deep-sea sediments. Science 159: 297300.

Bruckner and Radtke 1989.Fossile strande und korallenbanke auf Oahu, Hawaii. Essner Geogr. Arb. 17: 291-308 (in Hearty 2002)

Bruno, J.F., Selig, E.R., Casey, K.S., Page, C.A., Willis, B.L., Harvell, C.D., Sweatman, H., Melendy, A.M. 2007. Thermal stress and coral cover as drivers of coral disease outbreaks. PLoS Biology 5: 12201227 
Browne, N.K., Smithers, S.G., Perry, C.T. 2012. Corals reefs of the turbid inner-shelf of the Great Barrier Reef, Australia: An environmental and geomorphic perspective on their occurrence, composition and growth. Earth-Science Reviews 115: 1-20.

Bruckner and Radtke 1989.Fossile strande und korallenbanke auf Oahu, Hawaii. Essner Geogr. Arb.

Bruno, J.F., Petes, L.E., Harvell, C.D., Hettinger, A. 2003. Nutrient enrichment can increase the

Budd, A. F. 2000. Diversity and extinction in the Cenozoic history of Caribbean reefs. Coral Reefs 19: 25-35.

Budd, A.F., Stemann, T.A., Johnson, K.G. 1994. Stratigraphic distributions of genera and species of Neogene to recent Caribbean reef corals. Journal of Palaeontology 68(5): 951-977.

Budd, A.F., Johnson, K.G., Stemann, T.A. 1996. Plio-Pleistocene turnover and extinctions in the Caribbean reef coral fauna. Evolution and environment in tropical America p.168-204.

Burkepile, D.E., Hay, M.E. 2010. Impact of Herbivore Identity on Algal Succession and Coral Growth on a Caribbean Reef. PLOSONE

DOI: $10.1371 /$ journal.pone.0008963

Burkepile, D.E., Hay, M.E. 2008. Herbivore species richness and feeding complementarity affect community structure and function of a coral reef. Proceedings of the National Academy of Sciences of the United Sates of America (PNAS) 105(42): 16201-16206.

Burkepile, D.E., Hay, M.E. 2006. Herbivore vs. nutrient control of marine primary producers: Contextdependent effects. Ecology 87:3128-3139

Burns, T.P. 1985. Hard coral distribution and cold water disturbances in South Florida: Variation with depth and location. Coral Reefs 4:117-124.

Coral Reef Ecosystem Division (CRED), Pacific Island Fisheries Sciences Centre, NOAA National Marine Fisheries Service. 2011. CRED Rapid Ecological Assessment of Benthic Habitat Cover in the Pacific Ocean 2005-2010. Coral Reef Ecosystem Division, Honolulu, HI. Retrieved from http://www.usgs.gov/obis-usa/.

Cabioch, G., Montaggioni, L., Frank, N., Seard, C., Sallé, E., Payri, C., Pelletier, B. and Paterne, M. 2008. Successive reef depositional events along the Maquesas foreslopes (French Polynesia) since 26 ka. Marine Geology 254: 18-34.

Cabioch, G., Banks-Cutler, K.A., Beck, W.J., Burr, G.S., Corrège, T., Edwards, R.L. and Taylor, F.W., 2003. Continuous reef growth during the last 23calkyr BP in a tectonically active zone (Vanuatu, SouthWest Pacific). Quaternary Science Reviews, 22(15), pp.1771-1786.

Cabioch, G., Montaggioni, L. F., Faure, G. \& Ribaud-Laurenti, 1999. A. Reef coralgal assemblages as recorders of paleobathymetry and sea level changes in the Indo- Pacific province. Quaternary Science Reviews 18: 1681-1695. 
Cabioch, G., Montaggioni, L.F., Faure, G., Ribaud-Laurenti, A. 1999b. Reef coralgal assemblages as recorders of paleobathymetry and sea level changes in the Indo-Pacific province. Quaternary Science Reviews 18(14): 1681-1695.

Cabioch, G., Montaggioni, L.F., Faure, G. 1995. Holocene initiation and development of New Caledonian fringing reefs, SW Pacific. Coral Reefs 14: 131-140.

Camoin, G. and Webster, J., 2014. Coral Reefs and Sea-Level Change. In Earth and Life Processes Discovered from Subseafloor Environment-a Decade of Science Achieved by the Integrated Ocean Drilling Program (IODP). Series Developments in Marine Geology (pp. 395-441). Elsevier Amsterdam/New York.

Camoin, G., Seard, C., Deschamps, P, Webster, J.M., Abbey, E., Braga, J.C., Iryu, Y., Durand, N., Bard., E., Hamelin, B., Yokoyama, Y., Thomas, A.L., Henderson., G.M., Dussouillez, P. 2012. Reef response to sea-level and environmental changes during the last deglaciation: Integrated Ocean Drilling Program Expedition 310, Tahiti Sea Level. Geology 40: 643-646.

Camoin, G., Iryu, Y., McInroy, D. and the IODP Expedition 310 Scientists, E. 2007. IODP Expedition 310 reconstructs sea-Level, climatic and environmental changes in the South Pacific during the Last Deglaciation. Scientific Drilling 5: 4-12.

Camoin G.F., Montaggioni, L.F., Braithwaite, C.J.R. 2004. Late glacial to post glacial sea levels in the Western Indian Ocean. Marine Geology 206: 119-146.

Camoin, G.F., Ebren, P., Eisenhauer, A., Bard, E., Faure, G. 2001. A 300 000-yr coral reef record of sea level changes, Mururoa atoll (Tuamotu archipelago, French Polynesia). Palaeogeography, Palaeoclimatology, Palaeoecology 175: 325-341.

Camoin, G.F., Gautret, P., Montaggioni, L.F., and Cabioch, G., 1999. Nature and environmental significance of microbialites in Quaternary reefs: the Tahiti paradox. Sedimentary Geology 126:271304. doi:10.1016/S0037-0738(99)00045-7.

Camoin, G.F., Colonna, M., Montaggioni, L.F., Casanova, J., Faure, G., Thomassin, B.A. 1997. Holocene sea level changes and reef development in the southwestern Indian Ocean. Coral Reefs 16: 247-259

Cairns, S. D. 1999. Species richness of recent Scleractinia. Atoll Research Bulletin, Report Number 459, 46 pp.

Carpenter, R.C. 1986. Partitioning herbivory and its effects on coral reef algal communities. Ecological Monographs 56: 345-363.

Carpenter, K.E., Abrar, M., Aeby, G., Aronson, R.B., Banks, S., Bruckner, A., Chiriboga, A., Cortés, J., Delbeek, J.C., DeVantier, L., Edgar, G.J., Edwards, A.J., Fenner, D., Guzmán, H.M., Hoeksema, B.W., Hodgson, G., Johan, O., Licuanan, W.Y., Livingstone, S.R., Lovell, E.R, Moore, J.A., Obura, D.O., Ochavillo, D., Polidoro, B.A., Precht, W.F., Quibilan, M.C., Reboton, C., Richards, Z.T., Rogers, A.D., Sanciangco, J., Sheppard, A., Sheppard, C., Smith, J., Stuart, S., Turak, E., Veron, J.E.N., Wallace, C., Weil, E., Wood, E. 2008. One-Third of Reef-Building Corals Face Elevated Extinction Risk from Climate Change and Local Impacts. Science 321: 560-563. 
2468 Cervino, J., Goreau, T.J., Nagelkerken, I., Smith, G.W., Hayes, R. 2001. Yellow band and dark spot 2469 syndromes in Caribbean corals: distribution, rate of spread, cytology, and effects on abundance and division rate of zooxanthellae. Hydrobiologia 460: 53-63.

Chalker, B.E. 1981. Simulating Light-Saturation Curves for Photosynthesis and Calcification by ReefBuilding Corals. Marine Biology 63:135-141

Chappell, J.M. 1973. Geology of coral terraces on Huon Peninsula, New Guinea. PhD thesis, The Australian National University. Map.

Chappell, J. and Polach, H., 1991. Post-glacial sea-level rise from a coral record at Huon Peninsula, Papua New Guinea.

Chappell, J., Omura, A., Esat, T., McCulloch, M., Pandolfi, J., Ota, Y., Pillans, B. 1996. Reconciliation of late Quaternary sea levels derived from coral terraces at Huon Peninsula with deep sea oxygen isotope records. Earth and Planetary Science Letters 141: 227-236.

Chappell, J., 1974. Geology of coral terraces, Huon Peninsula, New Guinea: a study of Quaternary tectonic movements and sea-level changes. Geological Society of America Bulletin 85(4): 553-570.

Chave, K.E. 1962. Factors influencing the mineralogy of carbonate sediments. Limnology and Oceanography 7:218-233.

Chazottes, V., Le Campion-Alsumard, T., Peyrot-Clausade, N., Cuet, P. 2002. The effects of eutrophication-related alterations to coral reef communities on agents and rates of bio-erosion, Reunion Island, Indian Ocean. Coral Reefs 21: 375-390.

Chen, J.H., Curran, H.A., White, B., Wasserburg, G.J. 1991. Precise chronology of the last interglacial period: ${ }^{234} \mathrm{U}-{ }^{230} \mathrm{Th}$ data from fossil coral reefs from the Bahamas. Geological Society of America Bulletin 103: 82-97.

Chen, J.H., Edwards R.L., Wasserburg, G.J. $1986 .{ }^{238} \mathrm{U},{ }^{234} \mathrm{U}$ and ${ }^{232} \mathrm{Th}$ in seawater. Earth and Planetary Science Letters 80: 241-251.

Cheng, H., Edwards, R.L., Shen, C.-C., Polyak, V.J., Asmerom, Y., Woodhead, J., Hellstrom, J., Wang, Y., Kong, X., Spötl, C., Wang, X., Alexander Jr., E. 2013. Improvements in 230Th dating, 230Th and $234 \mathrm{U}$ half-life values, and U-Th isotopic measurements by multi-collector inductively coupled plasma mass spectrometry. Earth and Planetary Science Letters 371-317: 82-91.

Cheng, H., Edwards, R.L., Hoff, J., Gallup, C.D., Richards, D.A., Asmerom, Y. 2000. The half-lives of uranium-234 and thorium-230. Chemical Geology 169: 17-33.

Chisholm, J.R.M. 2003. Primary productivity of reef-building crustose coralline algae. Limnology and Oceanography 48:1376-387.

Chiu, T.-C., Fairbanks, R.G., Mortlock, R.A., Bloom, A.L. 2005. Extending the radiocarbon calibration beyond 26,000 years before present using fossil corals. Quaternary Science Reviews 24: 1797-1808.

Clark, P.U., Mitrovica, J.X., Milne, G.A., Tamisiea, M.E. 2002. Sea-Level Fingerprinting as a Direct Test for the Source of Global Meltwater Pulse IA. Science 295: 2438-2441. 
Cobb, M.M., Charles, D.D., Cheng, H., Kastner, M., Edwards, R.L. 2003a. U/Th-dating living and young corals from the central tropical Pacific. Earth and Planetary Science Letters 210: 91-103. Cobb, K.M., Charles, C.D., Cheng, H. and Edwards, R.L. 2003b. El Nino/Southern Oscillation and tropical Pacific climate during the last millennium. Nature 424: 271

Cohen, A.L., McConnaughey, T.A. 2003. Geochemical perspectives on coral mineralization. Reviews in Mineralogy and Geochemistry 54: 151-187.

Coles, S.L., Jokiel, P.L. 1992. Effects of salinity on corals. In Connell, D.W., Hawker, D.W. (Eds.) Pollution in tropical aquatic systems. CRC p. 147-166

Collier, R.L., Leeder, M.R., Rowe, P.J. and Atkinson, T.C., 1992. Rates of tectonic uplift in the Corinth and Megara basins, central Greece. Tectonics, 11(6), pp.1159-1167.

Collins L.B., Zhoa J.X., Freeman H. 2006. A high precision record of mid-late Holocene sea-level events from emergent coral pavements in the Houtman Abrolhos Islands, southwest Australia. Quaternary International 145-146: 78-85.

Collins, L.B., Zhu, Z.R., Wyrwoll, K.-H., Eisenhauer, A. 2003. Late Quaternary structure and development of the northern Ningaloo Reef, Australia. Sedimentary Geology 159: 81-94.

Colonna, M., Casanova, J., Dullo, W-C., Camoin, G. 1996. Sea-level changes and $\delta^{18}$ O record for the past 34,000 yr from Mayotte Reef, Indian Ocean. Quaternary Research 46: 335-339.

Connell, J.H. 1978. Diversity in tropical rain forests and coral reefs. Science 199: 1302-1310.

Cooper, T. F., Uthicke, S., Humphrey, C., Fabricius, K.E. 2007. Gradients in water column nutrients, sediment parameters, irradiance and coral reef development in the Whitsunday Region, central Great Barrier Reef. Estuarine, Coastal and Shelf Science 74(3): 458-470.

Cornell, H.V., Karlson, R.H. 2000. Coral species richness: ecological versus biogeographical influences. Coral Reefs 19: 37-49.

Coyne, M. K., Jones, B. \& Ford, D. 2006. Highstands during Marine Isotope Stage 5: evidence from the Ironshore Formation of Grand Cayman, British West Indies. Quaternary Science Reviews 26, 536-559, doi:10.1016/j.quascirev.2006.06.013.

Creveling, J.R., Mitrovica, J.X., Hay, C.C., Austermann, J., Kopp, R.E. 2015. Revisiting tectonic corrections applied to Pleistocene sea-level highstands. Quaternary Science Reviews 111: 72-80.

Cross and Cross, 1983. U, Sr and Mg in Holocene and Pleistocene corals. Journal of Sedimentary Petrology 53(2): 587-594.

Cutler K.B., Gray S.C., Burr G.S., Edwards R.L., Taylor F.W., Cabioch G., Beck J.W., Cheng H., Moor J. 2004. Radiocarbon calibration and comparison to $50 \mathrm{kyr}$ BP with paired $14 \mathrm{C}$ and 230Th dating of corals from Vanuatu and Papua New Guinea. Radiocarbon 46: 1127-1160.

Cutler, K. B., Edwards, R. L., Taylor, F.W., Cheng, H., Adkins, J., Gallup, C. D., Cutler, P. M., Burr, G. S., Bloom, A. L., 2003. Rapid sea level fall and deep ocean temperature change since the last interglacial period. Earth and Planetary Science Letters 206: 253-271. 
D'Elia, C.F., Wiebe, W.J.W. 1990. Biogeochemical nutrient cycles in coral-reef ecosystems, In

Darwin, C. 1874. The structure and distribution of coral reefs. Third edition. Appleton and Co., New York. pp. 344.

Delanghe, D., Bard, E., Hamelin, B. 2002. New TIMS constraints on the uranium-238 and uranium234 in seawaters from the main ocean basins and the Mediterranean Sea. Marine Chemistry 80: 7993.

Deschamps P., Durand N., Bard E., Hamelin B., Camoin G., Thomas A.L., Henderson G.M., Okuno J., Yokoyama Y. 2012. Ice-sheet collapse and sea-level rise at the Boling warming 14600 years age. Nature 483: 559-564.

DeVantier, L.M., De'ath, G., Turak, E., Done, T., Fabricius, K.E. 2006. Species richness and community structure of reef building corals on the near shore reefs of the Great Barrier Reef. Coral Reefs 25: $329-340$.

Dia, A.N., Cohen, A.S., O'nions, R.K. and Jackson, J.A., 1997. Rates of uplift investigated through 230 Th dating in the Gulf of Corinth (Greece). Chemical Geology, 138(3), pp.171-184.

Dia, A.N., Cohen, A.S., O'Nions, R.K. and Shackleton, N.J., 1992. Seawater Sr isotope variation over the past $300 \mathrm{kyr}$ and influence of global climate cycles. Nature, 356, pp.786-788.

Dickinson, W.R., 2001. Paleoshoreline record of relative Holocene sea levels on Pacific Islands. EarthScience Reviews 55, 191-234.

Dodge, R. E., Fairbanks, R. G., Benninger, L. K. \& Maurrasse, F. 1983. Pleistocene Sea Levels from Raised Coral Reefs of Haiti. Science 219: 1423-1425.

Done, T. 2011. Coral reef, definition. In Hopley, D. (Ed) Encyclopaedia of modern coral reefs: structure form and process. Springer, Berlin, pp 261-267.

Donovan, S.K., Harper, D.A.T. 2005. The geology of Barbados: a field guide. Caribbean Journal of Earth Science 38: 21-33.

Dullo, W.-C. 2005. Coral growth and reef growth: a brief review. Facies 51: 33-48.

Dullo, W.-C., Montaggioni, L.F. 1998. Modern Red Sea coral reefs: A review of their morphologies and zonation. In Purser, B.H., Bosence, D.W.J. (Eds), Sedimentation and tectonics in rift basins: Red Sea-Gulf of Aden. Chapman \& Hall, London. pp. 583-594.

Dunham, R.J. 1962. Classification of carbonate rocks according to depositional texture. Memoirs of the American Association of Petroleum Geologists 1:108-121.

Durand, N., Deschamps, P., Bard, E., Hamelin, B., Camoin, G., Thomas, A.L., Henderson, G.M., Yokoyama, Y. and Matsuzaki, H., 2013. Comparison of 14C and U-Th ages in corals from IODP\# 310 cores offshore Tahiti. Radiocarbon, 55(4), pp.1947-1974. 
Dustan, P. 1982. Depth-dependent photoadaptation by zooxanthellae of the reef coral Montastraea

Düsterhus, A., Rovere, A., Carlson, A. E., Barlow, N. L. M., Bradwell, T., Dutton, A., Gehrels, R., Hibbert, F. D., Hijma, M. P., Horton, B. P., Klemann, V., Kopp, R. E., Sivan, D., Tarasov, L. and Törnqvist, T. E. (2016) Palaeo sea-level and ice-sheet databases: problems, strategies and perspectives. Climate of the Past, 12: 1-11.

Dutton, A. 2015. Uranium-thorium dating. In Shennan, I., Long, A.J., Horton, B.P. Handbook of SeaLevel Research Wiley, London p. 386.

Dutton, A., Lambeck, K. 2012. Ice volume and sea level during the last interglacial. Science 337: 216219.

Edinger, E.N., Pandolfi, J.M., Kelley, R.A. 2001. Community structure of Quaternary coral reefs compared with Recent life and death assemblages. Paleobiology 27(4): 669-694.

Edinger, E.N., Burr, G.S., Pandolfi, J.M., Ortiz, J.C. 2007. Age accuracy and resolution of Quaternary corals used as proxies for sea level. Earth and Planetary Science Letters 253:37-49.

Edwards, R.L., Cutler, K.B., Cheng, H. \& Gallup, C.D. (2003a) Geochemical evidence for Quaternary sea-level changes. Treatise on Geochemistry. Elsevier, pp. 343-364.

Edwards, R.L., Gallup, C.D., Cheng, H., 2003b. Uranium-series dating of marine and lacustrine carbonates, in: Bourdon, B., Henderson, G.M., Lundstrom, C.C., Turner, S.P. (Eds.), Uranium-series geochemistry. Mineralogical Society of America, Washington, D.C., pp. 363-406

Edwards R.L., Beck J.W., Burr G.S., Donahue D.J., Chappell J.M.A., Bloom A.L., Druffel E.R.M., Taylor F.W. 1993. A large drop in atmospheric $14 \mathrm{C} / 12 \mathrm{C}$ and reduced melting in the Younger Dryas, documented with 230Th ages of corals. Science 260: 962-967.

Edwards, R. L., Cheng, H., Murrell, M. T., Goldstein, S. J., 1997. Protactinium-231 dating of carbonates by thermal ionization mass spectrometry: Implications for Quaternary climate change. Science 276: 782-786.

Edwards, R.L., Taylor, F.W., Wasserburg, G.J., 1988. Dating earthquakes with high-precision thorium230 ages of very young corals. Earth and Planetary Science Letters 90(4): 371-381.

Edwards, R.L., Chen, J.H., Ku, T.-L., Wasserburg, G.T. 1987b. Precise Timing of the Last Interglacial Period from Mass Spectrometric Determination of Thorium-230 in Corals. Science 236: 1547-1553.

Edwards, R.L., Chen, J.H., Wasserburg, G.J. 1987. 238U-234U-230Th-232Th systematics and the precise measurement of time over the past 500,000 years. Earth and Planetary Science Letters 81: 175-192.

Eggins S.M., Grun R., McCulloch M.T., Pike A.W.G., Chappell J., Kinsley L., Mortimer G., Shelley M., Murray-Wallace C.V., Spotl C., Taylor L. 2005. In situ U-series dating by laser-ablation multi-collector ICPMS: new prospects for Quaternary geochronology. Quaternary Science Reviews 24: 2523-2538. 

level change: new evidence from the Abrolhos islands, West Australia. Geologische Rundschau 85: 606-614.

Eisenhauer, A., Wasserburg, G.J., Chen, J.H., Bonani, G., Collins, L.B., Zhu, Z.R., and Wyrwoll, K.H., 1993. Holocene sea-level determination relative to the Australian continent: U/Th TIMS and ${ }^{14} \mathrm{C}$ (AMS) dating of corals from the Abrolhos Islands. Earth and Planetary Science Letters 114, 529-547.

Esat T.M, Yokoyama Y. 2006. Variability of uranium isotopic composition of the oceans over glacialinterglacial timescales. Geochimica et Cosmochimica Acta 70: 4140-4150.

Esat, T., McCulloch, M.T., Chappell, J., Pillans, B., Omura, A. 1999. Rapid fluctuations in sea level recorded at Huon Peninsula during the penultimate deglaciation. Science 283: 197-201.

Fadil, A., Sichoix, L., Barriot, J.P., Ortéga, P. and Willis, P., 2011. Evidence for a slow subsidence of the Tahiti Island from GPS, DORIS, and combined satellite altimetry and tide gauge sea level records. Comptes Rendus Geoscience, 343(5), pp.331-341.

Fairbanks, R. G. 1989. A 17,000-year glacio-eustatic sea level record: Influence of glacial melting rates on the Younger Dryas event and deep-ocean circulation. Nature 342: 637-642.

Fairbanks, R. G., Mortlock, R.A., Chiu, T.-C., Cao, L., Kaplan, A., Guilderson, T.P., Fairbanks, T.W., Bloom, A.L., Grootes, P.M., Nadeau, M.-KJ. 2005. Radiocarbon calibration curve spanning 0 to 50,000 years BP based on paired Th-230/U-234/U-238 and C-14 dates on pristine corals. Quaternary Science Reviews 24, 1781-1796, doi:10.1016/j.quascirev.2005.04.007.

Faichney, I.D.E., Webster, J.M., Clague, D.A., Paduan, J.B., Fullagar, P.D. 2010. Unravelling the tilting history of the submerged reefs surrounding Oahu and the Maui-Nui Complex, Hawaii. Geochemistry, Geophysics, Geosystems 11(7): DOI: 10.1029/2010GC003044

Farrell W.E., Clark J.A. 1976. On postglacial sea level, Geophysical Journal of the Royal Astronomical Society 46: 647-667.

Flor and Moore, 1977. Radium/calcium and uranium/calcium determinations for western Atlantic corals. Proc. 3rd International Coral reef symposium. Miami 2: 555-561.

Frank, N., Turpin, L., Cabioch, G., Blamart, D., Tressens-Fedou, M., Colin, C., Jean-Baptiste, P. 2006. Open system U-series ages of corals from a subsiding reef in New Caledonia: Implications for sea level changes, and subsidence rate. Earth and Planetary Science Letters 249: 274-289.

Fricke, H.W., Vareschi, E., Schlichter, D. 1987. Photoecology of the coral Leptoseris fragilis in the Red Sea twilight zone (an experimental study by submersible). Oecologia 73:371-381

Friedman, 1968. Geology and geochemistry of reefs, carbonate sediments and waters, Gulf of Aqaba. Journal of Sedimentary Petrology 38: 895-919.

Fruijtier, C., Elliott, T., Schlager, W. 2000. Mass-spectrometric 234U-230Th ages from the Key Largo Formation, Florida Keys, United States: Constraints on diagenetic age disturbance. Geological Society of America Bulletin 112: 267-277. 
2719

2720

2721

2722

2723

2724

2725

2726

2727

2728

2729

2730

2731

2732

2733

2734

2735

2736

2737

2738

2739

2740

2741

2742

2743

2744

2745

2746

2747

2748

2749

2750

2751

2752

2753

2754

2755

2756

2757

2758

2759

2760

2761

2762

2763

2764

2765

2766

2767

2768

2769
Galewsky, J., Silver, E.A., Gallup, C.D., Edwards, R.L. and Potts, D.C., 1996. Foredeep tectonics and carbonate platform dynamics in the Huon Gulf, Papua New Guinea. Geology, 24(9), pp.819-822.

Gallup, C. D., Cheng, H., Taylor, F.W., Edwards, R.L., 2002. Direct determination of the timing of sea level change during Termination II. Science 295: 310-313.

Gallup, C.D., Edwards, R.L., Johnson, R.G. 1994. The timing of high sea levels over the past 200,000 years. Science 263: 796-800.

Geister, J. 1977. The influence of wave exposure on the ecological zonation of Caribbean coral reefs. Proceedings of the Third International Coral Reef Symposium, Miami 1: 23-29.

Gerrodette, T. 1979. Equatorial submergence in a solitary coral, Balanophyllia elegans, and the critical life stage excluding the species from shallow water in the south. Marine Ecology Progress Series 1: 227-235.

Gischler, E., Hudson, J.H. 2004. Holocene development of the Belize Barrier Reef. Sedimentary Geology 164: 223-236.

Gong, S-Y., Wu, T-R., Siringan, F.P, Lin, K., Shen, C-C. 2013. An abrupt backreef infilling in a Holocene reef, Paraoir, Northwestern Luzon, Philippines. Coral Reefs 32: 293-303.

Goreau, T.F. 1959. The ecology of Jamaican coral reefs I. Species composition and zonation. Ecology 40:67-90.

Goreau, T.F., Wells, J.W. 1967. The shallow-water Scleractinia of Jamaica: revised list of species and their vertical distribution ranges. Bulletin of Marine Science 17: 442-453.

Greenstein, B.J., Pandolfi, J.M. 2008. Escaping the heat: rang shifts of reef coral taxa in coastal Western Australia. Global Change Biology 14: 513-528.

Greenstein, B.J., Pandolfi, J.M. 2003. Taphonomic alteration of reef corals: effects of reef environment and coral growth form II: The Florida Keys. Palaios 18: 495-509.

Greenstein, B.J., Harris, L.A., Curran, H.A. 1998a. Comparison of recent coral life and death assemblages to Pleistocene reef communities: Implications for rapid faunal replacement observed on modern reefs. Carbonates and Evaporites, 13, 23-31.

Greenstein, B.J., Curran, H.A., Pandolfi, J.M. 1998b. Shifting ecological baselines and the demise of Acropora cervicornis in the western North Atlantic and Caribbean province: a Pleistocene perspective. Coral Reefs 17: 249-261.

Grigg, R.W., 1998, Holocene coral reef accretion in Hawaii: a function of wave exposure and sea level history. Coral Reefs 17: 263-272.

Grossman, E.E., Fletcher, C.H. 2004. Holocene reef development where wave energy reduces accommodation space, Kailua Bay, Windward Oahu, Hawaii, U.S.A. Journal of Sedimentary Research 74: 49-63.

Grün, R., Radtke, U., Omura, A. 1992. ESR and U-series analyses on corals from Huon Peninsula, New Guinea. Quaternary Science Reviews 11: 197-202. 
Gvirtman et al., 1973. Control and distributions of uranium in coral reefs during diagenesis. Journal

Haapkyla, J., Unsworth, R.K.F., Flavell, M., Bourne, D.G., Schaffelke, B., Willis, B.L. 2011. Seasonal rainfall and runoff promote coral disease on an inshore reef. PLOS ONE 6(2): e16893.

Hallock, P. 1988. The role of nutrient availability in bioerosion: Consequences to carbonate buildups. Palaeogeography, Palaeoclimatology, Palaeoecology 63: 275-291.

Hallock, P., Schlager, W. 1986. Nutrient excess and the demise of coral reefs and carbonate platforms. Palaios 1:389-398.

Hamelin, B., Bard, E., Zindler, A., Fairbanks, R.G. 1991. 234U/238U mass spectrometry of corals: How accurate is the U-Th age of the last interglacial period? Earth and Planetary Science Letters 106: 169180.

Harmon R.S., Mitterer R.M., Kriausakul N., Land L.S., Schwarcz H.P, Garrett P., Larson G.J., Vacher H.L., Rowe M. 1983. U-series and amino-acid racemization geochronology of Bermuda: Implications for eustatic sea-level fluctuation over the past 250,000 years. Palaeogeography, Palaeoclimatology, Palaeoecology 44: 41-70.

Harriott, V.J., Banks, S.A. 2002. Latitudinal variation in coral communities in eastern Australia: A qualitative biophysical model of factors regulating coral reefs. Coral Reefs 21: 83-94.

Harvell, C.D., Jordan-Dahlgren, E., Merkel, S., Rosenberg, E., Raymundo, L., Smith, G., Weil, E., Willis, B.L. 2007. Coral disease, environmental drivers, and the balance between coral and microbial associates. Oceanography 20: 172-195.

Harvell, C.D., Mitchell, C.E., Ward, J.R., Altizer, S., Dobson, A.P., Ostfeld, R.S., Samuel, M.D. 2002. Ecology - Climate warming and disease risks for terrestrial and marine biota. Science 296: 21582162.

Hearn, C.J., Atkinson, M.J., Falter, J.L. 2001. A physical derivation of nutrient-uptake rates in coral reefs: effects of roughness and waves. Coral Reefs 20:347-356.

Hearty P.J. 2002. The Ka'ena Highstand of O'ahu, Hawai'i: Further evidence of Antarctic ice collapse during the Middle Pleistocene. Pacific Science 56(1): 65-81.

Hearty, P.J. 1997. Boulder deposits from large waves during the last interglaciation on North Eleuthera Island, Bahamas. Quaternary Research 48: 326-338.

Hearty, P.J., Hollin, J.T., Neumann, A.C., O'Leary, M.J., McCulloch, M. 2007. Global sea-level fluctuations during the Last Interglaciation. Quaternary Science Reviews 26: 2090-2112.

Hearty, P.J., Kindler, P., Cheng, H., Edwards, R.L. 1999. A +20 m middle Pleistocene sea-level highstand (Bermuda and the Bahamas) due to partial collapse of Antarctic ice. Geology 27(4): 375378.

Henderson, G.M. 2002. Seawater (234U/238U) during the last 800 thousand years. Earth and Planetary Science Letters 199: 97-110. 
Henderson, G.M., Cohen, A.S., O'Nions, R.K. $1993 .{ }^{234} \mathrm{U} /{ }^{238} \mathrm{U}$ ratios and ${ }^{230} \mathrm{Th}$ ages for Hateruma Atoll corals: implications for coral digenesis and seawater ${ }^{234} \mathrm{U} /{ }^{238} \mathrm{U}$ ratios. Earth and Planetary Science Letters 115: 65-73.

Hill, D.F., Griffiths, S.D., Peltier, W.R., Horton, B.P., Tornqvist T.E. 2011. High-resolution numerical modelling of tides in the western Atlantic, Gulf of Mexico, and Caribbean Sea during the Holocene. Journal of Geophysical Research-Oceans 116: C10.

Hinderstein, L.M., Marr, J.C.A., Martinez, F.A., Dowgiallo, M.J., Puglise, K.A., Pyle, R.L., Zawada, D.G., Appeldoorn, R. 2010. Theme section on "Mesophotic Coral Ecosystems: Characterization, Ecology, and Management". Coral Reefs 29: 247-251.

Hinton, A.C. 1996. Tides in the northeast Atlantic: considerations for modelling water depth changes. Quaternary Science Reviews 15: 873-894.

Hocking, R.M., Moors, H.T., van de Graaff, J.E. 1897. Geology of the Carnarvon Basin Western Australia. Geological Survey of Western Australian Bulletin 133. Department of Mines, Western Australia.

Hoffmann D.L., Spoetl C., Mangini A. 2009. Micromill and in-situ laser ablation sampling techniques for high spatial resolution MC-ICPMS U-Th dating of carbonates. Chemical Geology 259: 253-261.

Hopley, D. 1994. Continental Shelf reef systems. In Carter, R.W.G., Woodroffe, C.D. (Eds). Coastal Evolution: Late Quaternary Shoreline Morphodynamics. Combridge University Press pp 303-340.

Hopley, D., Smithers, S.G., Parnell, K.E. 2007. The geomorphology of the Great Barrier Reef: development, diversity and change. Cambridge University Press, Cambridge, United Kingdom

Hubbard, D.K. 1997. Reefs as Dynamic Systems. In Birkeland, C. (Ed) Life and Death of Coral Reefs. Chapman and Hall pp 43-67.

Hubbard, D.K. 1992. Hurricane-induced sediment transport in open-shelf tropical systems: An example from St. Croix, U.S Virgin Islands. Journal of Sedimentary Petrology 62: 946-960.

Hubbard, D.K., Miller, A.I., Scaturo, D. 1990. Production and cycling of calcium carbonate in a shelfedge reef system (St. Croix, US Virgin Islands): applications to the nature of reef systems in the fossil record. Journal of Sedimentary Petrology 60: 335-360.

Hughes, T.P., 1999. Off-reef transport of coral fragments at Lizard Island, Australia. Marine Geology, 157(1), pp.1-6.

Hughes, T.P., Tanner, J.E. 2000. Recruitment failure, life histories, and long-term decline of Caribbean corals. Ecology 81: 2250-2263.

Hughes, T.P., Baird, A.H., Bellwood, D.R., Card, M., Connollly, S.R., Folke, C., Grosberg, R., HoeghGuldberg, O., Jackson, J.B.C., Kleypas, J., Jough, J.M., Nyström, M., Palumbi, S.R., Pandolfi, J.M., Rosen, B., Roughgarden, J. 2003. Climate change, human impacts, and the resilience of coral reefs. Science 301: 929-933. 
Hughes, T.P., Rodrigues, M.J., Bellwood, D.R., Ceccarelli, D., Hoegh-Guldberg, O., McCook, L., Moltschaniwskyj, N., Pratchett, M.S., Steneck, R.S. and Willis, B., 2007. Phase shifts, herbivory, and

Hunter, I.G., Jones, B. 1996. Coral associations of the Pleistocene Ironshore formation, Grand Cayman. Coral Reefs 15: 249-267.

Huston, M.A. 1985. Patterns of Species Diversity on Coral Reefs. Annual Review of Ecology and Systematics 16: 149-177.

Hutchings, P.A. 1986. Biological destruction of coral reefs: a review. Coral Reefs 4: 239-252.

Iglesias-Prieto, R., Matta, J.L., Robbins, W.A., Trench, R.K. 1992. Photosynthetic response to elevated temperature in the symbiotic dinoflagellate Symbiodinium microadriaticum in culture. Proceedings of the National Academy of Sciences 89(21):10302-10305.

Insalaco, E. 1998. The descriptive nomenclature and classification of growth fabrics in fossil scleractinian reefs. Sedimentary Geology 118: 159-186.

Iryu, Y., Takahashi, Y., Fujita, K., Camoin, G., Cabioch, G., Matsuda, H., Sato, T., Sugihara, K., Webster, J.M., Westphal, H. 2010. Sea level history recorded in the Pleistocene carbonate sequence in IODP Hole 310-M0005D, off Tahiti. Island Arc 19: 690-706.

Israelson C, Wohlfarth B. 1999. Timing of the Last Interglacial high sea level on the Seychelles Islands, Indian Ocean. Quaternary Research 51: 306-316

Jackson, J.B.C. 1992. Pleistocene perspectives on coral reef community structure. American Zoologist 36(2): 719-731.

Jarrett, B.D., Hine, A.C., Halley, R.B., Naar, D.F., Locker, S.D., Neumann, A.C., Twichell, D., Hu, C., Donahue, B.T., Jaap, W.C., Palandro, D., Ciembronowicz, K. 2005. Strange bedfellows-a deep-water hermatypic coral reef superimposed on a drowned barrier island; southern Pulley Ridge, SW Florida platform margin. Marine Geology 214: 295-307.

Johannes, R.E., Wiebe, W.J., Crossland, C.J., Rimmer D.W., Smith, S.V. 1983. Latitudinal limits of coral growth. Marine Ecological Progress Series 11:105-111.

Jompa, J., McCook, L.J. 2002. Effects of competition and herbivory on interactions between a hard coral and a brown alga. Journal of Experimental Marine Biology and Ecology 271: 25-39.

Jouannic, C., Taylor, F.W., Bloom, A.L., Bernat, M., 1980. Late Quaternary uplift history from emerged reef terraces on Santo and Malekula, Central New Hebrides island arc. UN ESCAP, CCOP/ SOPAC Technical Bulletin 3, 91-108.

Kahng, S.E., Kelley, C.D. 2007. Vertical zonation of megabenthic taxa on a deep photosynthetic reef (50-140 m) in the Au'au Channel, Hawaii. Coral Reefs 26: 679-687.

Kahng, S.E., Maragos, J.E. 2006. The deepest zooxanthellate, scleractinian corals in the world? Coral Reefs 25:254. 
Kahng, S.E., Garcia-Sais, J.R., Spalding, H.L., Brokovich, E., Wagner, D., Weil, E., Hinderstein, L., Toonen, R.J. 2010. Community ecology of mesophotic coral ecosystems. Coral Reefs 29: 255-275.

Karlson, R.H., Cornall, H.V., Hughes, T.P. 2004. Coral communities are regionally enriched along an oceanic biodiversity gradient. Nature 429: 867-870.

Kayanne, H., Yamano, H., Randall, R.H. 2002. Holocene sea-level changes and barrier reef formation on an ocean island, Palau Islands, western Pacific. Sedimentary Geology 150: 47-60.

Keating, B.H., Helsey, C.E. 2002. The ancient shorelines of Lanai, Hawaii, revisited. Sedimentary Geology 150: 3-15.

Keith, S.A., Baird, A.H., Hughes, T.P., Madin, J.S., Connolly, S.R. 2013. Faunal breaks and species composition of Indo-Pacific corals: the role of plate tectonics, environment and habitat distribution. Proceedings of the Royal Society B 280: 20130818.

Kench, P., Smithers, S., McLean, R., Nichol, S. 2009. Holocene reef growth in the Maldives: Evidence of a mid-Holocene sea-level highstand in the central Indian Ocean. Geology 37: 455-458.

Kendall, R. A., Mitrovica, J. X. \& Milne, G. A. 2005. On post-glacial sea level - II. Numerical formulation and comparative results on spherically symmetric models. Geophysical Journal International 161: 679-706.

Kennedy, D., Woodroffe, C.D. 2004. Carbonate sediments of Elizabeth and Middleton Reefs close to the southern limits of reef growth in the southwest Pacific. Australian Journal of Earth Sciences 51: 847-857.

Kennedy D.M., Marsters, T.H., Woods J.L.D., Woodroffe C.D. 2012. Shore platform development on an uplifting limestone island over multiple sea-level cycles, Niue, South Pacific. Geomorphology 141142:170-182.

Kiessling, W., Simpson, C., Beck, B., Mewis, H., Pandolfi, J.M. 2012. Equatorial decline of reef corals during the last Pleistocene interglacial. PNAS 109(52): 21378-21383.

Kidwell, S.M., Flessa, K.W. 1995. The quality of the fossil record, Annual Review of Ecology, Evolution and Systematics 26: 269-299.

Kidwell S.M., Holland, S.M. 2002. The quality of the fossil record: implications for evolutionary analyses. Annual Review of Ecology, Evolution and Systematics 33: 561-588.

Kleypas, J.A. 1997. Modelled estimates of of global reef habitat and carbonate production since the last glacial maximum. Paleoceanography 12: 533-545.

Kleypas, J.A. 1996. Coral reef development under naturally turbid conditions: fringing reefs near Broad Sound, Australia. Coral Reefs 15: 153-167.

Kleypas, J.A., Danabasoglu, G., Lough, J.M. 2008. Potential role of the ocean thermostat in determining regional differences in coral reef bleaching events. Geophysical Research Letters 35: L03613, doi:10.1029/2007GL032257 
Kleypas, K.A., McManus, J.W., Menez, L.A.B. 1999. Environmental limits to coral reef development: where do we draw the line? American Zoology 39: 146-159.

Knowlton, N., Jackson, J.B.C. 1994. Taxonomy and niche partitioning on coral reefs: jack of all trades or master of some? Trends in Ecology and Evolution 9(1): 7-9.

Knowlton, N., Lang, J.C., Keller, B. 1990. Case study of natural population collapse: post-hurricane predation on Jamaica staghorn corals. Smithson Contributions to the Marine Sciences 31: 1-25.

Kopp, R.E., Simons, F.J., Mitrovica, J.X., Maloof, A.C., Oppenheimer, M. 2013. A probabilistic assessment of sea level within the last interglacial stage. Geophysical Journal International 193(2): 711-716.

Kopp, R.E., Simons, F.J., Mitrovica, J.X., Maloof, A.C., Oppenheimer, M. 2009. Probabilistic assessment of sea level during the last interglacial stage. Nature 462: 863-867.

Kowalewski, M. 1996. Time-averaging, overcompleteness, and the quality of the fossil record. Journal of Geology 104: 317-326.

Kowalewski, M., Bambach, R.K. 2003. The limits of paleontological resolution. In Harries, P.J. (Ed.), High Resolution Approaches in Stratigraphic Palaeontology, Topics in Geobiology Series, vol. 21, Plenum Press, New York, 2003, pp. 1-48.

Kuffner, I.B., Walters, L.J., Becerro, M.A., Paul, V.J., Ritson-Williams, R., K.S. Beach, K.S. 2006. Inhibition of coral recruitment by macroalgae and cyanobacteria. Marine Ecology Progress Series 323:107-117.

La Parguera, Puerto Rico Benthic Composition and Monitoring Data (2002 - Present) (NOAA-CCMA). National Oceanic and Atmospheric Association (NOAA)-National Ocean Service (NOS)-National Centres for Coastal Ocean Science (NCCOS)-Centre for Coastal Monitoring and Assessment (CCMA)Biogeography Team Publication_Date: 200703 Title: La Parguera, Puerto Rico Benthic Composition and Monitoring Data (2002 - Present) Publication_Information: Publication_Place: Silver Spring, MD Publisher: NOAAs Ocean Service, National Centers for Coastal Ocean Science (NCCOS)

Lambeck, K., Chappell, J. 2001. Sea level change through the Last Glacial cycle. Science 292: 679-686.

Lambeck, K., Rouby, H., Purcell, A., Sun, Y., Sambridge, M. 2014. Sea level and global ice volumes from the Last Glacial Maximum to the Holocene. Proceedings of the National Academy of Sciences of the United States of America 111(43): 15296-15303.

Larcombe, P., Costen, A., Woolfe, K.J. 2001. The hydrodynamic and sedimentary setting of nearshore coral reefs, central Great Barrier Reef shelf, Australia: Paluma Shoals, a case study. Sedimentology 48(4): 811-835.

3016 Lazar, B., Enmar, R., Schossberger, M., Bar-Matthews, M., Halicz, L., Stein, M., 2004. Diagenetic 3017 effects on the distribution of uranium in live and Holocene corals from the Gulf of Aqaba. 3018 Geochimica et Cosmochimica Acta 68(22): 4583-4593. 
Leeder, M.R., McNeill, L.C., Collier, R.E.L., Portman, C., Rowe, P.J., Andrews, J.E., Gawthorpe, R. 2003. Rift margin uplift: new evidence from late Quaternary marine shorelines, Corinth rift, Greece. Geophysical Research Letters 30: 1611-1614.

Leichter, J.J., Genovese, S.J. 2006. Intermittent upwelling and subsidised growth of the scleratinian coal madarcis mirabilis on the deep for-reef of Discovery Bay, Jamaica. Marine Ecology Progress Series 316: 95-103.

Leichter, J.J., Stwart, H.L., Miller, S.L. 2003. Episodic nutrient transport to Florida coral reefs. Limnology and Oceanography 48(4): 1394-1407.

Lesser, M.P., Slattery, M., Leichter, J.J. 2009. Ecology of mesophotic coral reefs. Journal of Experimental Marine Biology and Ecology 375: 1-8.

Liddell, W.D., Avery, W.B., Ohlhorst, S.L. 1997. Patterns of benthic community structure, 10-250 m, the Bahamas. Proceedings of the Eight International Coral Reef Symposium 1: 437-442.

Lidz, B.H., Shinn, E.A., Hine, A.C., Locker, S.D. 1997. Contrasts within an outlier reef system: Evidence for differential Quaternary evolution, South Florida windward margin, U.S.A. Journal of Coastal Research 13: 711-731.

Lighty, R.G., Macintyre, I.G., Stuckenrath, R. 1982. Acropora palmata reef framework: a reliable indicator of sea-level in the western Atlantic for the past 10,000 years. Coral Reefs 1: 125-130.

Lighty, R.G., Macintyre, I.G., Stuckenrath, R. 1978. Submerged early Holocene barrier reef, southeast Florida shelf. Nature 276: 59-60.

Lirman, D., Orlando, B., Maciá, S., Manzello, D., Kaufman, L., Biber, P., Jones, P. 2003. Coral communities of Biscayne Bay, Florida and adjacent offshore areas: diversity, abundance, distribution and environmental correlates. Aquatic Conservation: Marine and Freshwater Systems 13: 121-135.

Lisiecki, L. E., Raymo, M.E. 2005. A Pliocene-Pleistocene stack of 57 globally distributed benthic $\delta^{18} \mathrm{O}$ records. Palaeoceanography 20(1): PA1003, doi:10.1029/2004PA001071.

Littler, M.M., Littler, D.S., Blair, S.M., Norris, J.N. 1985. Deepest known plant life discovered on an uncharted seamount. Science 227: 57-59.

Littler, M.M., Littler, D.S., Blair, S.M., Norris, J.N. 1986. Deep-water plant communities from an uncharted seamount off San Salvador Island, Bahamas: distribution, abundance, and primary productivity. Deep Sea Research 33: 881-892.

Livingstone and Thompson, 1971. Trace element concentrations in some modern corals. Limnology and Oceanography 16: 786-796.

Loya, Y. 1972. Community structure and species diversity of hermatypic corals at Eilat, Red Sea. Marine Biology 13: 100-123

Loya, Y. 1976. Effects of water turbidity and sedimentation on the community structure of Puerto Rican corals. Bulletin of Marine Science 26: 450-466. 
3072 Ludwig, K. R. 2003. Isoplot: A Geochronological Toolkit for Microsoft Excel. Berkeley Geochronology 3073 Centre Special Publication No. 5.

Ludwig, K. R., Muhs, D. R., Simmons, K. R., Halley, R. B. \& Shinn, E. A. 1996. Sea-level records at 80

Ludwig, K.R., Szabo, B.J., Moore, J.G., Simmons, K.R. 1991. Crustal subsidence rate off Hawaii determined from 234U/238U ages of drowned coral reefs. Geology 19: 171-174.

Macintyre, I.G., Pilkey, O.H. 1969. Tropical reef corals: tolerance of low temperatures on the North Carolina Continental Shelf. Science 166: 374-375.

Macintyre, I.G., Glynn, P.W., Steneck, R.S. 2001. A classic Caribbean algal ridge, Holandes Cays, Panama: An algal coated storm deposit. Coral Reefs 20: 95-105.

Mallela, J., Perry, C.T. 2007. Calcium carbonate budgets for two coral reefs affected by different terrestrial runoff regimes, Rio Bueno, Jamaica. Coral Reefs 26: 129-145.

Maragos, J.E. 1974. Coral community on a seaward reef slope, Fanning Island. Pacific Science 28: 257-278.

Maragos, J.E., Jokiel, P.L. 1986. Reef corals of Johnston Atoll-one of the World's most isolated reefs. Coral Reefs 4: 141-150.

Marks, K.W. 2007. Atlantic and Gulf Rapid Reef Assessment - Benthic. AGRRA Database, version (05/2007). Australian Institute of Marine Science. http://www.aims.gov.au/index.html

Marshall, J.F., Davies, P.J. 1982. Internal structure and Holocene evolution of One Tree Reef, Southern Great Barrier Reef. Coral Reefs 1:21-28.

Marubini, F., Davies, P.S. 1996. Nitrate increases zooxanthellae population density and reduces skeletogenesis in corals. Marine Biology 127: 319-328.

Marubini F, Barnett H, Langdon C, Atkinson MJ. 2001. Dependence of calcification on light and carbonate ion concentration for the hermatypic coral Porites compressa Marine Ecology Progress Series 220:153-162.

Maxwell, W.G.H., Swinchatt, J.P. 1970. Great Barrier Reef: regional variation in a terrigenouscarbonate province. Geological Society of America Bulletin 81: 691-724.

McClanahan, T.R., Muthiga, N.A. 1988. Changes in Kenyan coral reef community structure and function due to exploitation. Hydrobiologia 166: 269-276.

McCook, L.J., Jompa, J., Diaz-Pulido, G. 2001. Competition between corals and algae on coral reefs: a review of evidence and mechanisms. Coral Reefs 19: 400-417.

McCulloch, M.T., Mortimer, G.E. 2008. Applications of the ${ }^{238} \mathrm{U}-{ }^{230}$ Th decay series to dating of fossil and modern corals using MC-ICPMS. Australian Journal of Earth Science 55(6): 955-965. 
McGregor, H.V. and Gagan, M.K., 2003. Diagenesis and geochemistry of Porites corals from Papua New Guinea: implications for paleoclimate reconstruction. Geochimica et Cosmochimica Acta, 67(12): 2147-2156.

McGregor, H.V., Hellstrom, J., Fink D., Hua Q., Woodroffe C.D. 2011. Rapid U-series dating of young

McMurtry G.M., Campbell J.F., Fryer G.J., Fietzke J. 2010. Uplift of Oahu, Hawaii, during the past 500 k.y. as recorded by elevated reef deposits. Geology 38(1): 27-30. (data - GSA data repository item 2010005, table DR1)

Medina-Elizalde, M. 2012. A global compilation of coral sea-level benchmarks: Implications and new challenges. Earth and Planetary Science Letters 362: 310-318.

Mesolella, K.J. 1967. Zonation of the uplifted Pleistocene coral reefs on Barbados, West Indies. Science 196: 638-640.

Mesolella, K.J. 1968. The Uplifted Reefs of Barbados: physical Stratigraphy, Facies Relationships and Absolute Chronology. Unpublished PhD Thesis, Brown University, Rhode Island.

Mesolella K J, Matthews R K, Broecker W S, Thurber D L. 1969, The astronomical theory of climatic change: Barbados data. The Journal of Geology 77: 250-274.

Miller, J., Muller, E., Rogers, C., Waara, R., Atkinson, A., Whelan, K.R.T., Patterson, M., Witcher, B. 2009. Coral disease following massive bleaching in 2005 causes $60 \%$ decline in coral cover on reefs in the US Virgin Islands. Coral Reefs 28: 925-937.

Milne, G.A., Mitrovica, J.X. 1998. Postglacial sea level change on a rotating Earth. Geophysical Journal International 133(1): 1-19.

Min, G.R., Edwards, R.L., Taylor, F.W., Recy, J., Gallup, C.D., Beck, J.W. 1995. Annual cycles of U/Ca in coral skeletons and U/Ca thermometry. Geochimica et Cosmochimica Acta 59: 2025-2042.

Mitrovica, J.X., Milne, G.A. 2003. On post-glacial sea level: I. General theory. Geophysical Journal International 154(2): 253-267.

Moberg F., Nystrom, M., Kautsky, N., Tedengren, M., Jarayabhand, P. 1997. Effects of reduced salinity on the rates of photosynthesis and respiration in the hermatypic corals Porites lutea and Pocillopora damicornis. Marine Ecology Progress Series 157: 53-59.

Montaggionii, L.F. 2005. History of Indo-Pacific coral reef systems since the last glaciation: Development patterns and controlling factors. Earth Science Reviews 71: 1-75.

Montaggioni, L.F., 1988. Holocene reef growth history in mid-plate high volcanic islands. Proceedings of the 6th International Coral Reef Symposium Vol. 3: 455-460.

Montaggioni L.F., Braithwaite, C.J.R. 2009. Quaternary Coral Reef Systems: History, Development Processes and Controlling Factors. Developments in Marine Geology v. 5: 1-532.

Montaggioni, L.F., Faure, G. 1997. Response of reef coral communities to sea-level rise: a Holocene model from Mauritius (Western Indian Ocean). Sedimentology 44(6): 1053-1070. 
Montaggioni LF, Hoang CT. 1988. The last interglacial high sea level in the granitic Seychelles, Indian

Montaggioni, L.F., Cabioch, G., Camoinau, G.F., Bard, E., Ribaud-Laurenti, A., Faure, G., Déjardin, P., Récy, J. 1997. Continuous record of reef growth over the past 14 k.y. on the mid-Pacific island of

Moore, J.G., Campbell, J.F. 1987. Age of tilted reefs, Hawaii. Journal of Geophysical Research 92:

Moore, J.G., Clague, D.A. 1992. Volcano growth and evolution of the island of Hawaii. Bulletin of the Geological Society of America 104(11): 1471-1484.

Moore, J.G., Moore, G.W., 1984. Deposit from a giant wave on the island of Lanai, Hawaii. Science 226: 1312-1314.

Moore, G.W., Moore, J.G., 1988. Large scale bed forms in boulder gravel produced by giant waves in Hawaii. Geological Society of America Special Papers 229: 101-110.

Morton, J.E., Chalis, D.A. 1969. The Biomorphology of Solomon Islands Shore with a Discussion of Zoning Patterns and Ecological Terminology. Philosophical Transactions of the Royal Society of London. Series B, Biological Sciences 255 (800): 459-516.

Moucha, R., Fortea, A. M., Mitrovica, J. X., Rowley, D. B., Quéré, S., Simmons, N. A., Grand, S. P. 2008. Dynamic topography and long-term sea-level variations: There is no such thing as a stable continental platform. Earth and Planetary Science Letters 271: 101-108.

Muhs, D.R., Szabo, B.J. 1994. New uranium-series ages of the Waimanalo Limestone, Oahu, Hawaii: Implications for sea level during the last interglacial period. Marine Geology 118: 315-326.

Muhs, D.R., Szabo, B.J. 1982. Uranium series age for the Eel Point terrace, San Clemente Island, California. Geology 10(1): 23-26.

Muhs, D.R., Simmons, K.R., Meco, J., Porat, N. 2015. Uranium-series ages of fossil corals from Mallorca, Spain: The "Neotyrrhenian" high stand of the Mediterranean Sea revisited. Palaeogeography, Palaeoclimatology, Palaeoecology 438: 408-424.

Muhs, D.R., Meco, J., Simmons, K.R. 2014. Uranium-series of coral, sea level history and palaeozoogeography, Canary Islands, Spain: An exploratory study for two Quaternary interglacial periods. Pelaeogeography, Palaeoclimatology; Palaeoecology 394: 99-118.

Muhs, D.R., Pandolfi, J.M., Simmons, K.R., Schumann, R.R. 2012a. Sea-level history of past interglacial periods from uranium-series dating of corals, Curaçao, Leeward Antilles islands. Quaternary Research 78: 157-169.

Muhs, D.R., Simmons, K.R., Schumann, R.R., Groves, L.T., Mitrovica, J.X., Laurel, D. 2012b. Sea-level history during the Last Interglacial complex on San Nicolas Island, California: Implications for glacial isostatic adjustment processes, paleozoogeography and tectonics. Quaternary Science Reviews 37: 125

3222 
Muhs, D.R., Simmons, K.R., Schumann, R.R., Halley, R.B. 2011. Sea-level history of the past two interglacial periods: new evidence from U-series dating of reef corals from south Florida. Quaternary

\begin{abstract}
Muhs, D.R., Simmons, K.R., Kennedy, G.L., Ludwig, K.R., Groves, L.T. 2006. A cool eastern Pacific Ocean at the close of the Last Interglacial complex. Quaternary Science Reviews 25: 235-262.
\end{abstract}

Muhs, D.R., Simmons, K.R., Steinke, B., 2002a. Timing and warmth of the Last Interglacial period: new U-series evidence from Hawaii and Bermuda and a new fossil compilation for North America. Quaternary Science Reviews 21: 1355-1383.

Muhs, D.R., Simmons, K.R., Kennedy, G.L., Rockwell, T.K. 2002b. The last interglacial period on the Pacific Coast of North America: Timing and paleoclimate. Geological Society of America Bulletin 114(5): 569-592.

Muhs DR, Kennedy GL, Rockwell TK. 1994. Uranium series ages of marine terrace corals from the Pacific coast of North America and implication for Last Interglacial sea level history. Quaternary Research 42: 72-87.

Muir, P.R., Wallace, C.C., Done, T., Aguirre, J.D. 2015. Limited scope for latitudinal extension of reef corals. Science 348: 1135-1138.

Multer, H.G., Gischler, E., Lundberg, J., Simmons, K.R., Shinn, E.A. 2002. Key Largo Limestone revisited: Pleistocene shelf-edge facies, Florida Keys, USA. Facies 46: 229-271.

Muthiga, N.A., Szmant, A.M. 1987. The effects of salinity stress on the rates of aerobic respiration and photosynthesis in the hermatypic coral S. sidereal. Biological Bulletin 173: 539-551.

Mylroie, J.E. 2007. Late Quaternary sea-level position: Evidence from Bahamian carbonate deposition and dissolution cycles. Quaternary International 183: 61-75.

Neumann, A.C., Macintyre, I.G. 1985. Reef response to sea level rise: Keep-up, catch-up or give-up. Proceedings of the 5th International Coral Reef Congress, Tahiti 3: 105-110.

Nugues, M.M., Smith, G.W., van Hooidonk, R.J., Seabra, M.I., Bak, R.P.M. 2004. Algal contact as a trigger for coral disease. Ecology Letters 7(10): 919-923.

Nunn PD, Ollier C, Hope G, Rodda P, Omura A, Peltier WR. 2002. Late Quaternary sea-level and tectonic changes in northeast Fiji. Marine Geology 187: 299-311.

OBIS (2014). Data from the Ocean Biogeographic Information System. Intergovernmental Oceanographic Commission of UNESCO. Web. http://www.iobis.org (last consulted on 2014/03/21).

O'Leary, M.J., Hearty, P.J., Thompson, W.J., Raymo, M.E., Mitrovica, J.X., Webster, J.M. 2013. Ice sheet collapse following a prolonged period of stable sea level during the last interglacial. Nature Geoscience 6: 796-800.

O'Leary, M.J., Hearty, P.J., McCulloch, M.T. 2008a. U-series evidence for widespread reef development in Shark Bay during the last interglacial. Palaeogeography, Palaeoclimatology, Palaeoecology 259: 424-435. 
3274

3275

3276

3277

3278

3279

3280

3281

3282

3283

3284

3285

3286

3287

3288

3289

3290

3291

3292

3293

3294

3295

3296

3297

3298

3299

3300

3301

3302

3303

3304

3305

3306

3307

3308

3309

3310

3311

3312

3313

3314

3315

3316

3317

3318

3319

3320

3321

3322

3323

3324
O'Leary, M.J., Hearty, P.J., McCulloch, M.T. 2008b. Geomorphic evidence of major sea-level fluctuations during marine isotope substage-5e, Cape Cuvier, Western Australia. Geomorphology 102: 595-602.

Ortlieb,L.,1987,Néotectoniqueet variations duniveau marin au Quaternaire dans la région du Golfe de Californie, Méxique: Paris, Institut Français de Recherche Scientifique pour le Dévelopement en Coopération, Collection Études et Thèses, 1036 p.

Ortiz, J.C., Gomez-Cabrera, M.C., Hoegh-Guldberg, O. 2009. Effect of colony size and surrounding substrate on corals experiencing a mild bleaching effect on Heron Island reef flat (southern Great Barrier Reef, Australia). Coral Reefs 28: 999-1003.

Ota, Y., Chappell, J. 1996. Late Quaternary coseismic uplift events on the Huon Peninsula, Papua New Guinea, deduced from coral terrace data. Journal of Geophysical Research: Solid Earth 101(B3): 6071-6082.

Ota, Y., Chappell, J., Kelley, R., Yonekura, N., Matsumoto, E., Nishimura, T., Head, J. 1993. Holocene Coral Reef Terraces and Coseismic Uplift of Huon Peninsula, Papua New Guinea. Quaternary Research 40(2): 177-188.

Ota, Y., Matsushima Y, Moriwaki H. 1983. Notes on the Holocene sea-level study in Japan. Quat. Res. (Daiyonki-Kenkyu), 21 (1982), pp. 133-143

Page, C.A., Willis, B.L. 2008. Epidemiology of skeletal eroding band on the Great Barrier Reef and the role of injury in the initiation of this widespread coral disease. Coral Reefs 27:257-272.

Pandolfi, J.M. 1992. A review do the tectonic history of New Guinea and its significance for marine biogeography. Proceedings of the Seventh International Coral Reef Symposium (Guam) 2: 718-728.

Pandolfi, J.M. 1996. Limited membership in Pleistocene reef coral assemblages from the Huon Peninsula, Papua New Guinea: constancy during global change. Paleobiology 22: 152-176.

Pandolfi, J.M. 1999. Response of Pleistocene coral reefs to environmental change over long temporal scales. American Zoologist 39: 113-130.

Pandolfi, J.M. 2007. A new, extinct Pleistocene reef coral from the Montastraea "annularis"' species complex. Journal of Paleontology 81(3): 472-282.

J. Pandolfi and J. Chappell, in: Study on Coral Reef Terraces of the Huon Peninsula. Papua New Guinea, Y. Ota, ed., pp.119-139, Geography Dept., Senshu Univ., Kawasaki, Japan, 1994

Pandolfi, J.M., Michin, P.R. 1995. A comparison of taxonomic diversity between reef coral life and death assemblages in Madang Lagoon, Papua, New Guinea. Palaeogeogeography, Palaeoclimatology, Palaeoecology 119: 321-341.

Pandolfi, J.M., Greenstein, B.J. 1997a. Taphonomic alteration of reef corals: effects of reef environment and coral growth form. I. The Great Barrier Reef. Palaios 12: 27-42.

Pandolfi, J.M., Jackson, J.B.C. 2007. Broad-scale patterns in Pleistocene coral reef communities from the Caribbean: Implications for ecology and management. In Aronson, R.B. (Ed.), Geological approaches to coral reef ecology. Springer, New York, pp. 201-236. 
Pandolfi, J.M., Jackson, J.B.C. 2006. Ecological persistence interrupted in Caribbean coral reefs. Ecology Letters 9: 818-826.

Pandolfi, J.M., Jackson, J.B.C. 2001. Community structure of Pleistocene coral reefs of Curaçao, Netherlands Antilles. Ecological Monographs 71: 49-67.

Pandolfi, J.M., Jackson, J.B.C., Geister, J. 2001. Geologically sudden natural extinction of two widespread Late Pleistocene Caribbean reef corals. In Jackson, J.B.C., Lidgard, S., McKinney, F.K. (eds) Process from Pattern in the Fossil Record. University of Chicago Press p. 120-158.

Panuska, B.C., Boardman, M.R., Carew, J.L., Mylroie, J.E., Sealey, N.E., Voegeli, V. 2002. Eleuthera Island field trip Guide, 11th Symposium on the Geology of the Bahamas and Other Carbonate Regions. Gerace Research Center, San Salvador Island, Bahamas pp 20.

Peltier, W.R. 2004. Global glacial isostasy and the surface of the ice-age earth: The ICE-5G (VM2) model and GRACE. Annual Review of Earth and Planetary Sciences 32: 111-149.

Peltier W.R., Fairbanks, R.G. 2006. Global ice volume and Last Glacial Maximum duration from an extended Barbados sea-level record. Quaternary Science Reviews 25: 3322-3337.

Perrin, C., Bosence, D., Rosen, B. 1995. Quantitative approaches to palaeozonation and palaeobathymetry of corals and coralline algae in Cenozoic reefs. Marine Palaeoenvironmental Analysis from Fossils, Geological Society Special Publication No. 83, pp. 181-229.

Perry, C.T., Smithers, S.G. 2011. Cycles of coral reef 'turn-on', rapid growth and 'turn-off' over the past 8500 years: a context for understanding modern ecological states and trajectories. Global Change Biology 17(1): 76-86.

Perry, C.T., Smithers, S.G., Palmer, S.E., Larcombe, P., Johnson K.G. 2008. 1200 year paleoecological record of coral community development from the terrigenous inner shelf of the Great Barrier Reef. Geology 36: 691-694.

Pineda, J. 1991. Predictable upwelling and the shoreward transport of planktonic larvae by internal tidal bores. Science 253: 548-559.

Pirazzoli, P.A. and Montaggioni, L.F., 1988. Holocene sea-level changes in French Polynesia.

Palaeogeography, Palaeoclimatology, Palaeoecology, 68(2-4), pp.153-175.

Pirazzoli P.A., Radtke U., Hantoro W.S., Jouannic C., Hoang C.T., Causse C., and Borel Best M. 1993. A one million-year-long sequence of marine terraces on Sumba Island, Indonesia. Marine Geology 109:221-236.

Pirazzoli, P. A., U. Radtke, W. S. Hantoro, C. Jouannic, C. T. Hoang, C. Causse, M. Borel Best. 1991. Quaternary raised coral reef terraces on Sumba island, Indonesia. Science, 252, 1834-1836.

Plaziat, J.C., Baltzer, F., Choukri, A., Conchon, O., Freytet, P., Orszag-Sperber, F., Raguideau, A., Reyss, J.-L. 1998. Quaternary marine and continental sedimentation in the northern Red Sea and Gulf of Suez (Egyptian coast): Influences of rift tectonics, climatic changes and sea-level fluctuations. In Purser, B.H., Bosence, D.W.J. (Eds), Sedimentation and tectonics in Rift Basins: Red Sea-Gulf of Aden. Chapman \& Hall, London. pp. 537-573. 
Poole, A.J., Shimmield, G.B., Roberston, A.H.F., 1990. Late Quaternary uplift of the Toodos ophiolite,

Cyprus: uranium-series dating of Pleistocene coral. Geology 18: 894-897.

Porter, J.W., Lewis, S.K., Porter, K.G. 1999. The effect of multiple stressors on the Florida Keys coral reef ecosystem: A landscape hypothesis and a physiological test.

3381

\begin{abstract}
Potter E-K., Esat T.M., Schellmann G., Radtke U., Lambeck K., McCulloch M.T. 2004. Suborbitalperiod sea-level oscillations during marine isotope substages $5 \mathrm{a}$ and $5 \mathrm{c}$. Earth and Planetary Science Letters 225: 191-204.
\end{abstract}

Purdy, E.G., 1974, Karst-determined facies patterns in British Honduras: Holocene carbonate sedimentation model: American Association of Petroleum Geologists, Bulletin 58: 825-855

Purdy, E.G., Gischler, E., Lomando, A.J. 2003. The Belize margin revisited. 2. Origin

of Holocene antecedent topography. International Journal of Earth Sciences 92: 552-572.

Radtke, U., Schellmann, G. 2006 Uplift history along the Clermont Nose traverse on the west coast of Barbados during the last 500,000 years-implications for paleo-sea level reconstructions. Journal of Coastal Research 22: 350-356.

Radtke, U., Grün, R., Omura, A., Mangini, A. 1996 The Quaternary coral reef tracts of Hateruma, Ryuku Islands, Japan. Quaternary International 31: 61-70.

Rasser, M.W., Riegl, B. 2002. Holocene coral reef rubble and its binding agents. Coral Reefs 21: 5772

Reed J.K. 2006. Deep-water Oculina reefs of Florida: summary of the state of knowledge of the habitat, fauna, geology, and physical processes of the ecosystem. A Report to the South Atlantic Fishery Management Council, Oculina Evaluation Team Workshop, August 21-23, 2006. Port Canaveral, Florida.

Reed, J.K. 2002. Deep-water Oculina coral reefs of Florida: biology, impacts, and management. Hydrobiologia, 471: $43-55$

Reed, J.K. 1985. Deepest distribution of Atlantic hermatypic corals discovered in the Bahamas. In: Proceedings of the 5th international coral reef symposium, vol 6, pp 249-254.

Reed, J.K. 1980. Distribution and Structure of Deep-water Oculina varicosa Coral Reefs Off Central Eastern Florida. Bulletin of Marine Science, 30(3): 667-677.

Reimer, P.J., Bard, E., Bayliss, A., Beck, J. W., Blackwell, P. G., Bronk Ramsey, C., Brown, D. M., Buck, C. E., Edwards, R. L., Friedrich, M., Grootes, P. M., Guilderson, T. P., Haflidason, H., Hajdas, I., Hatté, C., Heaton, T. J., Hogg, A. G., Hughen, K. A., Kaiser, K. F., Kromer, B., Manning, S. W., Reimer, R. W., Richards, D. A., Scott, M. E., Southon, J. R., Turney, C. S. M., van der Plicht, J. 2013. Selection and treatment of data for radiocarbon calibration: An update to the International Calibration (IntCal) criteria. Radiocarbon 55(4): 1923-1945.

Reynaud S, Ferrier-Pagès C, Boisson F, Allemand D, Fairbanks RG. 2004. Effect of light and temperature on calcification and strontium uptake in the scleractinian coral 
Richmond, RH. 1993. Effects of coastal runoff on coral reproduction. In Ginsburg, R.N. (Ed.). Global Aspects of Coral Reefs. Health, Hazards, and History. Miami, pp. 360-364.

Riker-Coleman K E, Gallup C D, Wallace L M, Webster J M, Cheng H, Edwards R L. 2006. Evidence of Holocene uplift in east New Britain, Papua New Guinea. Geophysical Research Letters 33: L18612.

Roberts, H.H., Rouse, L.J., Walker, N.D., Hudson, J.H. 1982. Cold water stress in Florida Bay and northern Bahamas: a product of winter cold-air outbreaks. Journal of Sedimentary Petrology 52(1): 145-155.

Robinson, L.F., Adkins, J.F., Fernandez, D.P., Burnett, D.S., Wang, S.L., Gagnon, A.C. and Krakauer, N., 2006. Primary $U$ distribution in scleractinian corals and its implications for $U$ series dating. Geochemistry, Geophysics, Geosystems, 7(5).

Robinson, L.F., Belshaw, N.S., Henderson, G.M. 2004. U and Th concentrations and isotope ratios in modern carbonates and waters from the Bahamas. Geochimica et Cosmochimica Acta 68(8): 17771789.

Rockwell, T.K., Muhs, D.R., Kennedy, G.L., Hatch, M.E., Wilson, S.H., and Klinger, R.E., 1989, Uraniumseries ages, faunal correlations and tectonic deformation of marine terraces within the Agua Blanca fault zone at Punta Banda, northern Baja California, Mexico, in Abbott, P.L., ed., Geologic studies in Baja California: Los Angeles, Pacific Section, Society of Economic Paleontologists and Mineralogists, p. 1-16.

Rogers, C.S. 1993. Hurricanes and coral reefs - the intermediate disturbance hypothesis revisited. Coral Reefs 12:127-137.

Rogers, C.S. 1990. Responses of coral reefs and reef organisms to sedimentation. Marine Ecology Progress Series 62: 185-202.

Rosholt, J.N. 1967. Open system model for uranium-series dating of Pleistocene samples. In Radioactive dating and methods of low level counting. International Atomic Agency, Vienna. Proc. Ser., Pub. SM-87/50.p 299.

Romaniello et al., 2013. Uranium concentrations and $238 \mathrm{U} / 235 \mathrm{U}$ isotope ratios in modern carbonates from the Bahamas: Assessing a novel paleoredox proxy. Chemical Geology 362: 305-316.

Rosenberg, E., Ben-Haim, Y. 2002. Microbial diseases of corals and global warming. Environmental Microbiology 4:318-326.

Rotjan, R.D. 2007. The patterns, causes, and consequences of parrotfish corallivory in Belize. PhD thesis, Tufts University, Boston, MA, USA.

Rotjan, R.D., Lewis, S.M. 2008. Impact of coral predators on tropical reefs. Marine Ecology Progress Series 367: 73-91.

Rotjan, R.D., Lewis, S.M. 2005. Selective predation by parrotfishes on the reef coral Porites asteroides. Marine Ecology Progress Series 305: 193-201. 

2006. Chronic parrotfish grazing impedes coral recovery after bleaching. Coral Reefs 25: 361-368.

Rowe, M.P., Bristow, C.S. 2015. Sea-level controls on carbonated beaches and coastal dunes (eolianite): Lessons from Pleistocene Bermuda. Geological Society of America Bulletin 127: 16451665.

Rowe, M.P., Wainer, K.I., Bristow, C.S., Thomas, A.L. 2014. Anomalous MIS 7 sea level recorded on Bermuda. Quaternary Science Reviews 90: 47-59.

Sackett and Portratz, 1963. Dating of carbonate rocks by ionium-uranium ratios. USGS Prof Papers No 260-BB.

Safriel, U.N. 1974. Vermetid Gastropods and Intertidal Reefs in Israel and Bermuda. Science 186: 1113-1115.

Sagawa, N., Nakamori, T. and Iryu, Y., 2001: Pleistocene reef development in the southwest Ryukyu Islands, Japan. Palaeogeography Palaeoclimatology Palaeoecology 175: 303-323.

St. Croix, USVI Benthic Composition and Monitoring Data (2002 - Present). 2007. National Oceanic and Atmospheric Association (NOAA); National Ocean Service (NOS)National Centers for Coastal Ocean Science (NCCOS), Center for Coastal Monitoring and Assessment.

Sammarco P.W., Lirette, A., Tung, Y.F., Bolan, G.S., Genazzio, M., Sinclair, J. 2014. Coral communities on artificial reefs in the Gulf of Mexico: standing vs. toppled oil platforms. ICES Journal of Marine Science 71(2): 417-426. doi:10.1093/icesjms/fst140.

Sanders, D., Baron-Szabo, R.C. 2005. Scleractinian assemblages under sediment input: Their characteristics and relation to the nutrient input concept. Palaeogeography, Palaeoclimatology, Palaeoecology 216: 139-181.

Sammarco, P.W. 1996. Comments on coral reef regeneration, bioerosion, biogeography, and chemical ecology: future directions. Journal of Experimental Marine Biology and Ecology 200: 135168.

Schellmann, G., Radtke, U. 2004. A revised morpo- and chronostrtigraphy of the Late and Middle Pleistocene coral reef terraces on Southern Barbados (West Indies). Earth-Science Reviews 64: 157187.

Schellmann G, Radtke U, Potter E-K, Esat TM, McCulloch MT. 2004. Comparison of ESR and TIMS $\mathrm{U} /$ Th dating of marine isotope stage (MIS) $5 \mathrm{e}, 5 \mathrm{c}$ and $5 \mathrm{a}$ coral from Barbados - implications for paleo sea-level changes in the Caribbean. Quaternary International 120: 41-50.

Schiaparelli, S. Albertelli, G., Cattaneo-Vietti, R. 2008. Phenotypic plasticity of Vermetidae suspension feeding: a potential bias in their use as Biological Sea-Level Indicators. Marine Ecology 27: 44-53.

Schlacher, T.A., Stark, J., Fischer, A.B.P. 2007. Evaluation of artificial light regimes and substrate types for aquaria propagation of the staghorn coral Acropora solitaryensis. Aquaculture 269:278-289 
Schmidt, G.M., Phongsuwan, N., Jantzen, C., Roder, C., Khokaittiwong, S., Richter, C. 2012. Coral community composition and reef development at the Similan Islands, Andaman Sea, in response to strong environmental variations. Marine Ecology Progress Series 456: 113-126.

Schneider, K., Erez, J. 2006. The effect of carbonate chemistry on calcification and photosynthesis in the hermatypic coral Acropora eurystoma. Limnology and Oceanography 51(3):1284-1293.

Scholz, D., Mangini, A., 2006. Estimating the uncertainty of coral isochron U-Th ages. Quaternary Geochronology 1(4): 279-288.

Scholz D, Mangini A, Meichner D. 2009. U-redistribution in fossil reef corals from Barbados, West Indies, and sea-level reconstruction for MIS 6.

Scholz, D., Mangini, A., Felis, T., 2004. U-series dating of diagenetically altered fossil reef corals. Earth and Planetary Science Letters 218: 163-178.

Schroeder, J.H., Miller, D.S. and Friedman, G.M., 1970. Uranium distributions in recent skeletal carbonates. Journal of Sedimentary Research 40(2).

Schutter, S., van Velthoven, B., Janse, M., Osinga, R., Janssen, M., Wijffels, R., Verreth, J. 2008. The effect of irradiance on long-term skeletal growth and net photosynthesis in Galaxea fascicularis under four light conditions. Journal of Experimental Marine Biology and Ecology 367:75-80.

Scoffin, T.P. 1992. Taphonomy of coral reefs: a review. Coral Reefs 11: 57-77.

Scoffin, T.P. 1993. The geological effects of hurricanes on coral reefs and the interpretation of storm deposits. Coral Reefs 12:203-221.

Scoffin, T.P., Steam, C.W., Boucher, D., Frydl, P., Hawkins, C.M., Hunter, I.G., McGeachy, J.K. 1980. Calcium carbonate budget of a fringing reef on the west coast of Barbados: Part II - Erosion, sediments and internal structure. Bulletin of Marine Science 302: 457-508.

Scopélitis, J., Andréfouët, S., Phinn, S., Done, T., Chabanet, P. 2011. Coral colonisation of a shallow reef flat in response to rising sea level: quantification from 35 years of remote sensing data at Heron Island, Australia. Coral Reefs 30: 951-965.

Sherman C.E., Fletcher C.H., Rubin K.H. 1999. Marine and meteoric diagenesis of Pleistocene carbonates from a nearshore submarine terrace, Oahu, Hawaii. Journal of Sedimentary Research 69(5): 1083-1097.

Shen, G.T. and Dunbar, R.B., 1995. Environmental controls on uranium in reef corals. Geochimica et Cosmochimica Acta, 59(10), pp.2009-2024.

Shen, C.C., Li, K.S., Sieh, K., Natawidjaja, D., Cheng, H., Wang, X., Edwards, R.L., Lam, D.D., Hsieh, Y.T., Fan, T.Y., Meltzner, A.J., 2008. Variation of initial $230 \mathrm{Th} / 232 \mathrm{Th}$ and limits of high precision U-Th dating of shallow-water corals. Geochimica et Cosmochimica Acta 72(17): 4201-4223.

Shinn, E.A. 1966. Coral growth-rate, an environmental indicator. Journal of Paleontology 40:233240. 
Shinn, E.A., Smith, G.W., Prosper, J.M., Betzer, P., Hayes, M.L., Garrison, V., Barber, R.T. 2000. African dust and the demise of Caribbean coral reefs. Geophysical Research Letters 27: 3029-3032.

E.A. Shinn, B.H. Lidz, J.L. Kindinger, J.H. Hudson, R.B. Halley. 1989. Reefs of Florida and the Dry Tortugas: a Guide to the Modern Carbonate Environments of the Florida Keys and the Dry Tortugas. U.S. Geological Survey, St. Petersburg, Florida (1989) 53 pp.

Sieh, K., Natawidjaja, D.H., Meltzner, A.J., Shen, C.C., Cheng, H., Li, K.S., Suwargadi, B.W., Galetzka, J., Philibosian, B., Edwards R.L. 2008. Earthquake supercycles inferred from sea-level changes recorded in the corals of west Sumatra. Science 322: 1674-1678.

Smithers, S.G., Woodroffe, C.D. 2001. Coral microatolls and $20^{\text {th }}$ century sea level in the eastern Indian Ocean. Earth Planet Science Letters 191:173-184

Speed, R.C., with Speed, C., and Sedlock, R. (editors), 2013., Geology and Geomorphology of Barbados: A Companion Text to Maps with Accompanying Cross Sections, Scale 1:10,000: Geological Society of America Special Paper 491, 63 p., doi:10.1130/2012.2491

Speed, R.C., 2001, Geological and geomorphological map of Barbados and accompanying text: Government of Barbados, Ministry of Environment, Energy, and Natural Resources, scale 1:10,000, 1 sheet.

Speed RC, Cheng H. 2004. Evolution of marine terraces and sea level in the last interglacial, Cave Hill, Barbados. GSA Bulletin, 116(1-2), 219-232

Spooner, P.T., Chen, T., Robinson, L.F., Coath, C.D. 2016. Rapid uranium-series age screening of carbonates by laser ablation mass spectrometry. Quaternary Geochronology 31: 28-39.

Stafford-Smith, M.G., Ormond, R.F.G. 1992. Sediment-rejection mechanisms of 42 species of Australian scleratinian corals. Australian Journal of Marine and Freshwater Research 43: 683-705.

Stanford, J.D., Hemingway, R., Rohling, E.J., Challenor, P.G., Medina-Elizalde, M., Lester, A.C. 2011. Sea-level probability for the last deglaciation: A statistical analysis of far-field records. Global and Planetary Change 79(3): 193-203.

Stearn, C.W., Scoffin, T.P., Martindale, W. 1977. Calcium carbonate budget of a fringing reef on the west coast of Barbados: Part II - Zonation and productivity. Bulletin of Marine Science 27: 479-510.

Stehli, F.G., Wells, J.W. 1971. Diversity and age patterns in hermatypic corals. Systematic Zoology 20: $115-126$

Stein, M., Wasserburg, G.J., Aharon, P., Chen, J.H., Zhu, Z.R., Bloom, A., Chappell, J. 1993. TIMS Useries dating and stable isotopes of the last interglacial event in Papua New Guinea. Geochimica et Cosmochimica Acta 57: 2541-2554.

Stein, M., Wasserburg, G.J., Lajoie, K.R., Chen, J.H. 1991. U-series ages of solitary corals from the California coast by mass spectrometry. Geochimica et Cosmochimica Acta 5: 3709-3722.

Stirling, C.H. 1996. High-precision U-series dating of corals from Western Australia: implications for Last Interglacial sea levels PhD Thesis, The Australian National University. 
Stirling, C.H., Andersen, M.B., 2009. Uranium-series dating of fossil coral reefs: extending the sealevel record beyond the last glacial cycle. Earth and Planetary Science Letters 284: 269-283.

Stirling, C. H., Esat, T. M., Lambeck, K., McCulloch, M.T., 1998. Timing and duration of the Last Science Letters 160: 745-762.

Stirling, C. H., Esat, T.M., McCulloch, M. T., Lambeck, K., 1995. High-precision U-series dating of corals from Western Australia and implications for the timing and duration of the Last Interglacial. Earth and Planetary Science Letters 135: 115-130.

Strasser, A., Strohmenger, C., Davaud, E., Bach, A. 1992. Sequential evolution and diagenesis of Pleistocene coral reefs (South Sinai, Egypt). Sedimentary Geology 78: 59-79.

Sugihara, K., Yamada, T., Iryu, Y. 2006. Contrasts of coral zonation between Ishigaki Island (Japan, northwest Pacific) and Tahiti Island (French Polynesia, central Pacific), and its significance in Quaternary reef growth histories. SEALAIX'06 Meeting. (eds G. Camoin, A. Droxler, C. Fulthorpe, \& K Miller) 179-180 (Association des Sedimentologistes Français) In Deschamps et al., 2012. Nature 483: 559-564.

Sumich, J.L. 1996. An Introduction to the Biology of Marine Life, sixth edition. Dubuque, IA: Wm. C. Brown. pp. 255-269.

Sun, D., Gagan, M.K., Cheng, H., Scott-Gagan, H., Dykoski, C.A., Edwards, R.L., Su, R. 2005. Seasonal and interannual variability of the Mid-Holocene East Asian monsoon in coral $\delta^{18} \mathrm{O}$ records from the South China Sea. Earth and Planetary Science Letters 237: 69-84.

Swart and Hubbard, 1982. Uranium in scleractinian coral skeletons. Coral Reefs 1: 13-19.

Szabo, B.J., Moore, J.G. 1986. Age of $-360 \mathrm{~m}$ reef terrace, Hawaii and the rate of late Pleistocene subsidence of the island. Geology 6: 713-715.

Szabo, B.J., Vedder, J.G. 1971. Uranium-series dating of some Pleistocene marine deposits in southern California. Earth and Planetary Science Letters 11: 282-290.

Szabo, B.J., Ludwig, K.R., Muhs, D.R., Simmons, K.R. 1994. Thorium-230 Ages of Corals and Duration of the Last Interglacial Sea-Level High Stand on Oahu, Hawaii. Science 266: 93-96.

Szmant, A.M. 2002. Nutrient enrichment on coral reefs: Is it a major cause of coral reef decline? Estuaries 25: 743-766.

Tager, D., Webster, J.W., Potts, D.C., Renema, W., Braga, J.C., Pandolfi, J.M. 2010. Community dynamics of Pleistocene coral reefs during alternative climatic regimes. Ecology 91: 191-200.

Tanner, J.E. 1995. Competition between scleractinian corals and macroalgae - an experimental investigation of coral growth, survival and reproduction. Journal of Experimental Marine Biology and Ecology 190: 151-168. 
Taylor, F.W., Mann, P. 1991. Late Quaternary folding of coral reef terraces, Barbados. Geology 19: 103-196.

Taylor, F.W., Mann, P., Bevis, M.G., Edwards, R.L., Cheng, H., Cutler, K.B., Gray, S.C., Burr, G.S., Beck, 3684 J.W., Phillips, D.A. and Cabioch, G., 2005. Rapid forearc uplift and subsidence caused by impinging

Taylor, F.W., Frohlich, C., Lecolle, J., Strecker, M., 1987. Analysis of partially emerged corals and reef terraces in the central Vanuatu arc: comparison of contemporary coseismic and nonseismic with Quaternary vertical movements. Journal of Geophysical Research 92, 4905-4933.

Taylor, F.W., Jouannic, C., Bloom, A.L. 1985. Quaternary Uplift of the Torres Islands, Northern New Hebrides Frontal Arc: Comparison with Santo and Melekula Islands, Central New Hebrides Frontal Arc. Journal of Geology 93: 419-438.

Taylor, F.W., Isacks, B.L., Jouannic, C., Bloom, A.L., Dubois, J., 1980. Coseismic and Quaternary vertical tectonic movements, Santo and Malekula Islands, new Hebrides island arc. Journal of Geophysical Research 85, 5367-5381.

Thomas, A.L., Fujita, K., Iryu, Y., Bard, E., Cabioch, G., Camoin, G., Cole, J.E., Deschamps P., Durand N., Hamelin B., Heindel K., Henderson G.M., Mason A.J., Matsuda H., Menabreaz L., Omori A., Quinn T., Sakai S., Sato T., Sugihara K., Takahashi Y., Thouveny N., Tudhope A.W., Webster J., Westphal H., Yokoyama, Y. 2012. Assessing subsidence rates and paleo water-depths for Tahiti reefs using U-Th chronology of altered corals. Marine Geology 295-298: 86-94.

Thomas, A.L., Henderson, G.M., Deschamps, P., Yokoyama, Y., Mason, A.J., Bard, E., Hamelin, B., Durand, N., Camoin, G. 2009. Penultimate Deglacial Sea-Level Timing from Uranium/Thorium Dating of Tahitian Corals. Science 324, 1186-1189, doi:10.1126/science.1168754.

Thompson, G., Livingston, H.D., 1970. Strontium and uranium concentrations in aragonite precipitated by some modern corals. Earth and Planetary Science Letters 8(6): 439-442.

Thompson, W. G. \& Goldstein, S. L. 2005. Open-system coral ages reveal persistent suborbital sealevel cycles. Science 308, 401-404, doi:10.1126/science.1104035.

Thompson W.G., Curran H.A., Wilson M.A., White B. 2011. Sea-level oscillations during the last interglacial highstand recorded by Bahamas corals. Nature Geoscience 4: 684-687.

Thompson, W. G., Spiegelmann, M.W., Goldstein, S. L., Speed, R. C., 2003. An open-system model for U-series age determinations of fossil corals. Earth and Planetary Science Letters 210: 365-381.

Titlyanov, E.A., Titlyanova, T.V., Yamazato, K., Van Woesik, R. 2001. Photo-acclimation dynamics of the coral Stylophora pistillata to low and extremely low light. Journal of Experimental Marine Biology and Ecology 263:211-225.

Tomascik, T.R., Sander, F. 1987. Effects of eutrophication on reef-building corals II. Structure of Scleractinian coral communities on fringing reefs, Barbados, West Indies. Marine Biology 94: 53-75.

Toscano, M. A. \& Lundberg, J. 1999. Submerged Late Pleistocene reefs on the tectonically-stable SE Florida margin: high-precision geochronology, stratigraphy, resolution of Substage 5 a sea-level elevation, and orbital forcing. Quaternary Science Reviews 18: 753-767. 
Toscano, M.A., Macintyre, I.G. 2003. Corrected western Atlantic sea-level curve for the last 11,000 years based on calibrated $14 \mathrm{C}$ dates from Acropora palmate framework and intertidal mangrove

Toscano, M.A., Macintyre, I.G., Lundberg, J. 2012. Last interglacial reef limestones, northeastern St. Croix, US Virgin Islands-evidence of tectonic tilting and subsidence since MIS 5.5. Coral Reefs 31:27-38.

Trichet, J., Repellin, P., Oustrière, P. 1984. Stratigraphy and subsidence of the Mururoa atoll (French Polynesia). Marine Geology 56: 241-257.

Tudhope, A.W., Buddemeir, R.W., Chilcott, C.P., Berryman, K.R., Fautin, D.G., Jebb, M., Lipps, J.H., Pearce, R.G. Scoffin, T.P., Shimmield, G.B. 2000. Alternating seismic uplift and subsidence in the late Holocene at Madang, Papua New Guinea: Evidence from raised reefs. Journal of Geophysical Research: Solid Earth 105(B6): 13797-13807.

Uehara, K., Scourse, J.D., Horsburgh, K.J., Lambeck, K., Purcell A.P. 2006. Tidal evolution of the northwest European shelf seas from the Last Glacial Maximum to the present. Journal of Geophysical Research-Oceans 111: C9.

Van Oppen, M.J.H., Bongaerts, P.I.M., Underwood, J.N., Peplow, L.M., Cooper, T.F. 2011. The role of deep reefs in shallow reef recovery: an assessment of vertical connectivity in a brooding coral from west and east Australia. Molecular Ecology 20(8): 1647-1660.

Van Woesik, R., Done, T.J. 1997. Coral communities and reef growth in the southern Great Barrier Reef. Coral Refs 16: 103-115.

Vacher, H.L., Hearty, P., 1989. History of stage 5 sea level in Bermuda: review with new evidence of a brief rise to present sea level during substage 5a. Quaternary Science Reviews 8: 159-168.

Vacher, H.L., Rowe, M., Garrett, P., 1989. The Geological Map of Bermuda, Scale 1: 25,000. Public Works Department, Hamilton, Bermuda.

Vedder, J.G., Norris R.M. 1963. Geology of San Nicolas Island California. U.S. Geological Survey Professional Paper 369: 1-65.

Veeh, H.H, Turekian, K.K. 1968. Cobalt, silver and uranium concentrations of reef building corals in the Pacific. Limnology and Oceanography 13(2): 304-308.

Veron, J.E.N. 2000. Corals of the world (3 vols). Australian Institute of Marine Science, Townsville.

Veron J.E.N. 1995. Corals in Space and Time: The Biogeography and Evolution of the Scleractinia. University of New South Wales Press, Sydney.

Veron, J.E.N. 1993. A biogeographic database of hermatypic corals: species of the central IndoPacific, genera of the world. Australian Institute of Marine Science Monograph Series 9

Veron J.E.N. 1992. Environmental control of Holocene changes to the world's most northern hermatypic coral outcrop. Pacific Science 46(4): 405-425. 
3782

3783

3784

3785

3786

3787

3788

3789

3790

3791

3792

3793

3794

3795

3796

3797

3798

3799

3800

3801

3802

3803

3804

3805

3806

3807

3808

3809

3810

3811

3812

3813

3814

3815

3816

3817

3818

3819

3820

3821

3822

3823

3824

3825

3826

3827

3828

3829

3830

3831

3832

Veron, J.E.N., Minchin, P.R. 1992. Correlations between sea surface temperature, circulation patterns and the distribution of hermatypic corals of Japan. Continental Shelf Research 12: 835-857.

Veron, J.E.N., Devantier, L.M., Turak, E., Green, A.L., Kininmonth, S., Stafford-Smith, M., Peterson, N. 2009. Delineating the Coral Triangle. Glalaxea, Journal of Coral Reef Studies 11: 91-100.

Vezina J, Jones B., Ford D. 1999. Sea-level highstands over the last 500,000 years: Evidence from the Ironshore Formation on Grand Cayman, British West Indies. Journal of Sedimentary Research 69(2): 317-327.

Villemant, B., Feuillet, N., 2003. Dating open systems by the 238U-234U-230Th method: application to Quaternary reef terraces. Earth and Planetary Science Letters 210: 105-118.

Wallace, A.R. 1863. On the physical geography of the Malay Archipelago. Journal of the Royal Geographical Society 33: 217-234.

Walter, R.C., Buffler, R.T., Bruggemann, H., Guillaume, M.M.M., Berhe, S.M., Negassi, B., Libsekal, Y., Cheng, H., Edwards, R.L., von Cosel, R., Néraudeau, D., Gagnon, M. 2000. Early human occupation of the Red Sea coast of Eritrea during the last interglacial. Nature 405: 65-69.

Webster, J.M., Davies, P.J. 2003. Coral variation in two deep drill cores: significance for the Pleistocene development of the Great Barrier Reef. Sedimentary Geology 159: 61-80.

Webster, J.M., Wallace, L., Silver, E., Potts, D., Braga, J.C., Renema, W., Riker-Coleman, K., Gallup, C. 2004. Coralgal composition of drowned carbonate platforms in the Huon Gulf, Papua New Guinea; implications for lowstand reef development and drowning. Marine Geology 204: 59-89.

Webster, J.M., Brage, J.C., Clague, D.A., Gallup, C., Hein, J.R., Potts, D.C., Renema, W., Riding, R., Riker-Coleman, K., Silver, E., Wallace, L.M. 2009. Coral reef evolution on rapidly subsiding margins. Global and Planetary Change 66: 129-148.

Wei B L. 2001. Characteristics of Seismic Activities on the Southeast Coast of China (in Chinese). Beijing: Seismological Press, 2001

Wells, J.W. 1954. Recent corals of the Marshall Islands. US Geological Survey Professional Papers 260: 385-486.

White B, Curran H A, Wilson. 2001. A sea level lowstand (Devil's Point Event) recorded in Bahamian Reefs: Comparison with other last interglacial climate proxies. In Greenstein and Carney (Eds) Proceeding of the 10th symposium on the geology of the Bahamas and other carbonate regions, Gerace Research Centre, San Salvador, Bahamas.

Whitney, B.B. and Hengesh, J.V., 2015. Geomorphological evidence of neotectonic deformation in the Carnarvon Basin, Western Australia. Geomorphology, 228, pp.579-596.

Williams, I.D., Polunin, N.V.C. 2001. Large-scale associations between macroalgal cover and grazer biomass on mid-depth reefs in the Caribbean. Coral Reefs 19: 358-366.

Willis BL, Page CA, Dinsdale EA (2004) Coral disease on the Great Barrier Reef. In: Rosenberg E, Loya $Y$ (eds) Coral health and disease. Springer-Verlag, Berlin, pp 69-104. 
3833

3834

3835

3836

3837

3838

3839

3840

3841

3842

3843

3844

3845

3846

3847

3848

3849

3850

3851

3852

3853

3854

3855

3856

3857

3858

3859

3860

3861

3862

3863

3864

3865

3866

3867

3868

3869

3870
Wilson, M.E. and Rosen, B.R., 1998. Implications of paucity of corals in the Paleogene of SE Asia: plate tectonics or centre of origin. In Hall, R and Holloway (Eds) Biogeography and geological evolution of SE Asia, Backhuys Publishers, Leiden. pp.165-195.

Woodroffe, C.D., Webster, J.M. 2014. Coral reefs and sea-level change. Marine Geology 352: 248267.

Woolfe K.J., Larcombe, P. 1998. Terrigenous sediment accumulation as a regional control upon the distribution of reef carbonates. In: Camoin G. F. \& Davies P. J. eds. Reefs and Carbonate Platforms in the Pacific and Indian Oceans, pp. 295-310. IAS Special Publication 25.

Yamano, H., Kayanne, H., Yonekura, N. 2001. Anatomy of a modern coral reef flat: a recorder of storms and uplift in the Late Holocene. Journal of Sedimentary Research 71: 295-304.

Yao, Y-T., Zhan, W-H., Sun, J-L., Sun, J. 2013. Emerged fossil corals on the coast of northwestern Hianan Island, China: Implications for mid-Holocene sea level change and tectonic uplift. Chinese Science Bulletin 58(23): 2869-2876.

Yokoyama, Y., Esat, T. M. \& Lambeck, K. 2001. Coupled climate and sea-level changes deduced from Huon Peninsula coral terraces of the last ice age. Earth and Planetary Science Letters 193: 579-587.

Yu, K.-F., Zhao, J.-X., Done, T., Chen, T.-G. 2009. Microatoll record for large century-scale sea-level fluctuations in the mid-Holocene. Quaternary Research 71: 354-360.

Zachariasen, J., Sieh, K., Taylor, F.W., Edwards, R.L., Hantoro, W.S. 1999. Submergence and uplift associated with the giant 1833 Sumatran subduction earthquake: Evidence from coral microatolls. Journal of Geophysical Research 104: 895-919.

Zazo, C., Goy, J.L., Dabrio, C.J., Soler, V., Hillaire-Marcel, C., Ghaleb, B., González-Delgado, J.A., Bardají, T. and Cabero, A., 2007. Quaternary marine terraces on Sal Island (Cape Verde archipelago). Quaternary Science Reviews, 26(7), pp.876-893.

Zhao, J., Yu, K. 2002. Timing of Holocene sea-level highstands by mass spectrometric U-series ages of a coral reef from Leizhou Peninsula, South China Sea. Chinese Science Bulletin 47: 348-352.

Zhu, Z.R., Wyrwoll, K.-H., Collins, L.B., Chen, J.H., Wasserburg, G.J., Eisenhauer, A. 1993. Highprecision U-series dating of Last Interglacial events by mass spectrometry: Houtman Abrolhos Islands, western Australia. Earth \& Planetary Science Letters 118: 281-293. 


\section{Table 1:}

† uncertainty derived from mapping (i.e., half contour spacing) and assigned $\pm 1 \mathrm{~m}$ measurement uncertainty

* assigned $\pm 1 \mathrm{~m}$ uncertainty (none quoted in original reference)

$\S$ elevation uncertainty derived from half the elevation range plus an assigned $\pm 1 \mathrm{~m}$ measurement uncertainty (as this was not given in the original reference)

$\ddagger$ rates recalculated using Equation 1

\begin{tabular}{|c|c|c|c|c|c|c|c|c|}
\hline Location & $\begin{array}{l}\text { Max. elevation } \\
\text { LIG terrace }(\mathrm{m})\end{array}$ & Error & $\begin{array}{l}\text { How elevation } \\
\text { determined }\end{array}$ & $\begin{array}{l}\text { Reference for } \\
\text { the max. } \\
\text { elevation }\end{array}$ & $\begin{array}{l}\text { Recalculated uplift }(+) \\
/ \text { subsidence }(-) \text { rate } \\
\left(\mathrm{m} \mathrm{ka}^{-1}\right)^{\ddagger}\end{array}$ & $\begin{array}{l}\text { Uncertainty } \\
(2 \sigma)\end{array}$ & $\begin{array}{l}\text { Reported uplift }(+) \text { and } \\
\text { subsidence }(-) \text { rates }\left(\mathrm{m} \mathrm{ka}^{-1}\right)\end{array}$ & Refs \\
\hline \multicolumn{9}{|l|}{ BARBADOS (west) } \\
\hline \multirow[t]{2}{*}{$\begin{array}{l}\text { Clermont Nose } \\
\text { anticline (traverse) }\end{array}$} & +61 & $4^{\dagger}$ & $\begin{array}{l}\text { Mapping of First } \\
\text { High Cliff }\end{array}$ & $\begin{array}{l}\text { Taylor and } \\
\text { Mann, } 1991\end{array}$ & +0.44 & 0.04 & +0.44 & $\begin{array}{l}\text { Gallup et al., } 2004 \text { (citing } \\
\text { Taylor and Mann, 1991) }\end{array}$ \\
\hline & +57.4 & 1 & $\begin{array}{l}\text { Back calculated } \\
\text { (elevation } \\
\text { resurveyed?) }\end{array}$ & $\begin{array}{l}\text { Thompson } \\
\text { and } \\
\text { Goldstein, } \\
2005\end{array}$ & +0.41 & 0.02 & $\begin{array}{l}+0.45 \text { (back calculated using age } \\
122 \mathrm{ka} \text { and Last Interglacial sea } \\
\text { level of }+2.5 \mathrm{~m} \text { ) }\end{array}$ & $\begin{array}{l}\text { Thompson and } \\
\text { Goldstein, 2005; } \\
\text { Thompson et al., } 2003\end{array}$ \\
\hline \multirow[t]{3}{*}{ Cave Hill } & +70 & 2 & Shoreline angle & $\begin{array}{l}\text { Speed and } \\
\text { Cheng, 2004; } \\
\text { Speed, 2013 }\end{array}$ & +0.51 & 0.03 & $\begin{array}{l}+0.53 \pm 0.04 \text { (using elevation of } \\
\text { shoreline angle and age of } 120 \pm 2 \\
\text { ka) }\end{array}$ & Speed and Cheng, 2004 \\
\hline & & & & & & & $\begin{array}{l}+0.49 \pm 0.06 \text { (average of values } \\
\text { from Taylor and Mann, } 1991 \\
(+0.44) ; \text { Gallup et al., } 2002(0.45 \pm \\
0.01) ; \text { Speed and Cheng, } 2004 \\
(0.53 \pm 0.04) \text { and; Thompson and } \\
\text { Goldstein, } 2005(0.45 \pm 0.01))\end{array}$ & Scholz et al., 2009 \\
\hline & +70 & 1 & $\begin{array}{l}\text { Mapping of } \\
\text { Rendezvous Hill } \\
\text { terrace }\end{array}$ & Speed, 2013 & +0.51 & 0.03 & +0.53 & Speed, 2013 \\
\hline \multirow[t]{2}{*}{ Batts Rock Bay } & $\sim+61.5$ & 1 & Back calculated & $\begin{array}{l}\text { Potter et al., } \\
2004\end{array}$ & +0.44 & 0.03 & $\begin{array}{l}+0.45 \pm 0.03 \text { (calculated using an } \\
\text { age of } 128 \pm 3 \text { ka and Last } \\
\text { Interglacial sea level of } 4 \pm 2 \mathrm{~m} \text { ) }\end{array}$ & Potter et al., 2004. \\
\hline & $\begin{array}{l}+29 \text { (reported } \\
\text { max elevation } \\
\text { correlated to } \\
\text { MIS 5c) }\end{array}$ & 0.5 & Reef crest elevation & $\begin{array}{l}\text { Potter et al., } \\
2004\end{array}$ & $n / a$ & $\mathrm{n} / \mathrm{a}$ & & Potter et al., 2004 \\
\hline \multirow[t]{2}{*}{$\begin{array}{l}\text { University of West } \\
\text { Indies (UWI) transect }\end{array}$} & +61 & $4^{+}$ & $\begin{array}{l}\text { Mapping of First } \\
\text { High Cliff }\end{array}$ & $\begin{array}{l}\text { Taylor and } \\
\text { Mann, } 1991\end{array}$ & +0.44 & 0.04 & +0.44 & $\begin{array}{l}\text { Gallup et al., } 2002 \text { (citing } \\
\text { Taylor and Mann, 1991) }\end{array}$ \\
\hline & +57.8 & $1^{*}$ & Back calculated & $\begin{array}{l}\text { Cutler et al., } \\
2003\end{array}$ & +0.41 & 0.02 & +0.44 & Cutler et al., 2003 \\
\hline St Stephens School & $\mathrm{n} / \mathrm{a}$ & $\mathrm{n} / \mathrm{a}$ & $\mathrm{n} / \mathrm{a}$ & $\mathrm{n} / \mathrm{a}$ & $\begin{array}{l}\text { Assumed similar rate to } \\
\text { UWI transect transect } \\
\text { (cf. Cutler et al., 2003) }\end{array}$ & $\mathrm{n} / \mathrm{a}$ & +0.44 & Cutler et al., 2003 \\
\hline Guinea Quarry & $\mathrm{n} / \mathrm{a}$ & $\mathrm{n} / \mathrm{a}$ & $\mathrm{n} / \mathrm{a}$ & $\mathrm{n} / \mathrm{a}$ & $\begin{array}{l}\text { Assumed similar rate to } \\
\text { UWI transect transect } \\
\text { (cf. Cutler et al., 2003) }\end{array}$ & $\mathrm{n} / \mathrm{a}$ & +0.44 & Cutler et al., 2003 \\
\hline \multirow[t]{2}{*}{ Holders Hill transect } & +46 & $4^{+}$ & $\begin{array}{l}\text { Mapping of First } \\
\text { High Cliff }\end{array}$ & $\begin{array}{l}\text { Taylor and } \\
\text { Mann, } 1991\end{array}$ & +0.32 & 0.04 & $\begin{array}{l}\text { Not reported (use the values of } \\
\text { Taylor and Mann, 1991) }\end{array}$ & Gallup et al., 1994 \\
\hline & +44.6 & $1^{*}$ & Back calculated & $\begin{array}{l}\text { Cutler et al., } \\
2003\end{array}$ & +0.30 & 0.02 & $\begin{array}{l}+0.33 \text { (calculated using an age of } \\
120 \text { ka and Last Interglacial sea } \\
\text { level of }+5 \mathrm{~m} \text { ) }\end{array}$ & Cutler et al., 2003 \\
\hline \multicolumn{9}{|l|}{ BARBADOS (south) } \\
\hline \multirow[t]{2}{*}{ Southern Barbados } & 35 to 40 & $3.5^{5}$ & $\begin{array}{l}\text { Reef crest elevation } \\
\text { Rendezvous Hill } \\
\text { terrace }\end{array}$ & $\begin{array}{l}\text { Schellmann } \\
\text { and Radtke, } \\
2004\end{array}$ & +0.25 & 0.03 & Not reported & $\begin{array}{l}\text { Schellmann and Radtke, } \\
2004\end{array}$ \\
\hline & $\sim+38.5$ & 1 & Back calculated & $\begin{array}{l}\text { Potter et al., } \\
2004\end{array}$ & +0.26 & 0.02 & $\begin{array}{l}+0.27 \pm 0.03 \text { (calculated using an } \\
\text { age of } 128 \pm 3 \text { ka and Last } \\
\text { Interglacial sea level of } 4 \pm 2 \mathrm{~m} \text { ) }\end{array}$ & Potter et al., 2004. \\
\hline \multirow[t]{2}{*}{ South Point } & +38 & 1 & $\begin{array}{l}\text { Back calculated } \\
\text { (elevation } \\
\text { resurveyed?) }\end{array}$ & $\begin{array}{l}\text { Thompson } \\
\text { and } \\
\text { Goldstein, } \\
2005\end{array}$ & +0.25 & 0.02 & $\begin{array}{l}+0.29 \text { (back calculated using age } \\
122 \mathrm{ka} \text { and Last Interglacial sea } \\
\text { level of }+2.5 \mathrm{~m} \text { ) }\end{array}$ & $\begin{array}{l}\text { Thompson and } \\
\text { Goldstein, 2005; } \\
\text { Thompson et al., } 2003\end{array}$ \\
\hline & $\mathrm{n} / \mathrm{a}$ & $\mathrm{n} / \mathrm{a}$ & $\mathrm{n} / \mathrm{a}$ & $\mathrm{n} / \mathrm{a}$ & & & $\begin{array}{l}+0.27 \pm 0.03 \text { (value for southern } \\
\text { Barbados) }\end{array}$ & Potter et al., 2004. \\
\hline
\end{tabular}




\begin{tabular}{|c|c|c|c|c|c|c|c|c|}
\hline & +40 & $4+$ & $\begin{array}{l}\text { Mapping of First } \\
\text { High Cliff }\end{array}$ & $\begin{array}{l}\text { Taylor and } \\
\text { Mann, } 1991\end{array}$ & +0.27 & 0.04 & Not reported & Taylor and Mann, 1991 \\
\hline \multirow[t]{4}{*}{ Salt Cave Point } & +34 & 1 & $\begin{array}{l}\text { Back calculated } \\
\text { (elevation } \\
\text { resurveyed?) }\end{array}$ & $\begin{array}{l}\text { Thompson } \\
\text { and } \\
\text { Goldstein, } \\
2005\end{array}$ & +0.22 & 0.02 & $\begin{array}{l}+0.26 \text { (back calculated using age } \\
122 \mathrm{ka} \text { and Last Interglacial sea } \\
\text { level of }+2.5 \mathrm{~m} \text { ) }\end{array}$ & $\begin{array}{l}\text { Thompson and } \\
\text { Goldstein, 2005; } \\
\text { Thompson et al., } 2003\end{array}$ \\
\hline & & & & & & & $\begin{array}{l}+0.27 \pm 0.03 \text { (value for southern } \\
\text { Barbados) }\end{array}$ & Potter et al., 2004. \\
\hline & $\sim+33$ & $4^{+}$ & $\begin{array}{l}\text { Mapping of First } \\
\text { High Cliff }\end{array}$ & $\begin{array}{l}\text { Taylor and } \\
\text { Mann, } 1991\end{array}$ & +0.21 & 0.04 & Not reported & Taylor and Mann, 1991 \\
\hline & +36 & 0.5 & $\begin{array}{l}\text { Mapping of } \\
\text { Rendezvous Hill } \\
\text { terrace }\end{array}$ & Speed, 2013 & +0.24 & 0.02 & +0.25 & Speed, 2013. \\
\hline \multirow[t]{2}{*}{ Kendall Fort } & $\mathrm{n} / \mathrm{a}$ & $\mathrm{n} / \mathrm{a}$ & $\mathrm{n} / \mathrm{a}$ & $\mathrm{n} / \mathrm{a}$ & $\mathrm{n} / \mathrm{a}$ & $\mathrm{n} / \mathrm{a}$ & $\begin{array}{l}+0.27 \pm 0.03 \text { (value for southern } \\
\text { Barbados) }\end{array}$ & Potter et al., 2004. \\
\hline & $\sim+37$ to +40 & $4^{+}$ & $\begin{array}{l}\text { Mapping of First } \\
\text { High Cliff }\end{array}$ & $\begin{array}{l}\text { Taylor and } \\
\text { Mann, } 1991\end{array}$ & +0.26 & 0.04 & Not reported & Taylor and Mann, 1991 \\
\hline \multirow[t]{2}{*}{ Pepperpot } & $\mathrm{n} / \mathrm{a}$ & $\mathrm{n} / \mathrm{a}$ & $\mathrm{n} / \mathrm{a}$ & $\mathrm{n} / \mathrm{a}$ & $\mathrm{n} / \mathrm{a}$ & $\mathrm{n} / \mathrm{a}$ & $\begin{array}{l}+0.27 \pm 0.03 \text { (value for southern } \\
\text { Barbados) }\end{array}$ & Potter et al., 2004. \\
\hline & $\sim+37$ & $4+$ & $\begin{array}{l}\text { Mapping of First } \\
\text { High Cliff }\end{array}$ & $\begin{array}{l}\text { Taylor and } \\
\text { Mann, } 1991\end{array}$ & +0.24 & 0.04 & Not reported & Taylor and Mann, 1991 \\
\hline \multirow[t]{2}{*}{ Inch Marlowe Point } & $\mathrm{n} / \mathrm{a}$ & $\mathrm{n} / \mathrm{a}$ & $\mathrm{n} / \mathrm{a}$ & $\mathrm{n} / \mathrm{a}$ & $\mathrm{n} / \mathrm{a}$ & $\mathrm{n} / \mathrm{a}$ & $\begin{array}{l}+0.27 \pm 0.03 \text { (value for southern } \\
\text { Barbados) }\end{array}$ & Potter et al., 2004. \\
\hline & +40 & $4+$ & $\begin{array}{l}\text { Mapping of First } \\
\text { High Cliff }\end{array}$ & $\begin{array}{l}\text { Taylor and } \\
\text { Mann, } 1991\end{array}$ & +0.27 & 0.04 & Not reported & Taylor and Mann, 1991 \\
\hline \multirow[t]{2}{*}{ Paragon Point } & $\mathrm{n} / \mathrm{a}$ & $\mathrm{n} / \mathrm{a}$ & $\mathrm{n} / \mathrm{a}$ & $\mathrm{n} / \mathrm{a}$ & $\mathrm{n} / \mathrm{a}$ & $\mathrm{n} / \mathrm{a}$ & $\begin{array}{l}+0.27 \pm 0.03 \text { (value for southern } \\
\text { Barbados) }\end{array}$ & Potter et al., 2004. \\
\hline & $\sim+31$ & $4^{+}$ & $\begin{array}{l}\text { Mapping of First } \\
\text { High Cliff }\end{array}$ & $\begin{array}{l}\text { Taylor and } \\
\text { Mann, } 1991\end{array}$ & +0.20 & 0.04 & Not reported & Taylor and Mann, 1991 \\
\hline \multirow[t]{2}{*}{$\begin{array}{l}\text { Gibbons transect } \\
\text { (south coast) }\end{array}$} & $\mathrm{n} / \mathrm{a}$ & $\mathrm{n} / \mathrm{a}$ & $\mathrm{n} / \mathrm{a}$ & $\mathrm{n} / \mathrm{a}$ & $\mathrm{n} / \mathrm{a}$ & $\mathrm{n} / \mathrm{a}$ & Not reported & $\begin{array}{l}\text { Blanchon and } \\
\text { Eisenhauer, } 2001\end{array}$ \\
\hline & +41 & 0.5 & $\begin{array}{l}\text { Mapping of } \\
\text { Rendezvous Hill } \\
\text { terrace }\end{array}$ & Speed, 2013 & +0.28 & 0.02 & +0.29 & Speed, 2013 \\
\hline $\begin{array}{l}\text { Erol Barrow transect } \\
\text { (south coast) }\end{array}$ & $\mathrm{n} / \mathrm{a}$ & $\mathrm{n} / \mathrm{a}$ & $\mathrm{n} / \mathrm{a}$ & $\mathrm{n} / \mathrm{a}$ & $\begin{array}{l}\text { Used south coast value } \\
\text { (location unknown) }\end{array}$ & & Not reported & $\begin{array}{l}\text { Blanchon and } \\
\text { Eisenhauer, } 2001\end{array}$ \\
\hline St George's Valley & No LIG terrace & $\mathrm{n} / \mathrm{a}$ & $\mathrm{n} / \mathrm{a}$ & $\mathrm{n} / \mathrm{a}$ & $\mathrm{n} / \mathrm{a}$ & $\mathrm{n} / \mathrm{a}$ & Not reported & Edwards et al., 1987 \\
\hline $\begin{array}{l}\text { Core - "off south } \\
\text { coast" }\end{array}$ & $\mathrm{n} / \mathrm{a}$ & $\mathrm{n} / \mathrm{a}$ & $\mathrm{n} / \mathrm{a}$ & $\mathrm{n} / \mathrm{a}$ & $\begin{array}{l}\text { +0.34 Location } \\
\text { unknown: used the } \\
\text { same uplift rate as } \\
\text { Fairbanks, } 1989\end{array}$ & 0.02 & +0.34 & $\begin{array}{l}\text { Fairbanks, 1989; Bard et } \\
\text { al., 1990a, b; Fairbanks } \\
\text { et al., 2005, Peltier and } \\
\text { Fairbanks, } 2006\end{array}$ \\
\hline \multicolumn{9}{|l|}{ CAPE VERDE } \\
\hline $\begin{array}{l}\text { ARCHIPELAGO } \\
\text { Sal Island }\end{array}$ & +2.5 & $1^{*}$ & Shoreline angle & $\begin{array}{l}\text { Zazo et al., } \\
2007\end{array}$ & -0.03 & 0.02 & $\begin{array}{l}\text { Not reported (based on U-series } \\
\text { dating of marine terraces Sal } \\
\text { Island "stable, or slightly } \\
\text { subsiding, at least since the Last } \\
\text { Interglacial", although older } \\
\text { terraces between } 600 \text { ka and } 300 \\
\text { ka suggest uplift) }\end{array}$ & Zazo et al 2007 \\
\hline \multicolumn{9}{|l|}{ CHINA } \\
\hline Hainan Island & $\mathrm{n} / \mathrm{a}$ & $\mathrm{n} / \mathrm{a}$ & $\mathrm{n} / \mathrm{a}$ & $\mathrm{n} / \mathrm{a}$ & $\begin{array}{l}\text { Used estimate from } \\
\text { literature (non volcanic } \\
\text { zone (Wei, 2001) }\end{array}$ & $\mathrm{n} / \mathrm{a}$ & $\begin{array}{l}\text { Volcanic zone (north of island): } 0 \\
\text { to }+1 \text {; non volcanic zone } 0 \text { to }-1\end{array}$ & $\begin{array}{l}\text { Wei } 2001 \text { (in Chinese) in } \\
\text { Yao et al., } 2013\end{array}$ \\
\hline \multicolumn{9}{|l|}{ COMORO } \\
\hline $\begin{array}{l}\text { ARCHIPELAGO } \\
\text { Mayotte Island }\end{array}$ & -20 & $1^{*}$ & Drill core & & -0.21 & 0.02 & -0.13 to -0.25 & Camoin et al., 1997 \\
\hline \multicolumn{9}{|l|}{ CURACAO } \\
\hline Boca Cortalein & +12.4 & $1 *$ & $\begin{array}{l}\text { Maximum elevation } \\
\text { of inner edge of } \\
\text { Hato unit }\end{array}$ & $\begin{array}{l}\text { Muhs et al., } \\
2012 a\end{array}$ & +0.05 & 0.02 & & Muhs et al., 2012a \\
\hline Boca Labadero & $\mathrm{n} / \mathrm{a}$ & $\mathrm{n} / \mathrm{a}$ & $\mathrm{n} / \mathrm{a}$ & $\mathrm{n} / \mathrm{a}$ & $\begin{array}{l}\text { Used Boca Cortalein } \\
\text { rate }\end{array}$ & $\mathrm{n} / \mathrm{a}$ & +0.26 to +0.054 & Muhs et al., 2012a \\
\hline Boca Mansalina & $\mathrm{n} / \mathrm{a}$ & $\mathrm{n} / \mathrm{a}$ & $n / a$ & $\mathrm{n} / \mathrm{a}$ & $\begin{array}{l}\text { Used Boca Cortalein } \\
\text { rate }\end{array}$ & $\mathrm{n} / \mathrm{a}$ & +0.26 to +0.054 & Muhs et al., 2012a \\
\hline
\end{tabular}




\begin{tabular}{|c|c|c|c|c|c|c|c|c|}
\hline Boca Santu Pretu & $\mathrm{n} / \mathrm{a}$ & $\mathrm{n} / \mathrm{a}$ & $\mathrm{n} / \mathrm{a}$ & $n / a$ & $\begin{array}{l}\text { Used Boca Cortalein } \\
\text { rate }\end{array}$ & $\mathrm{n} / \mathrm{a}$ & +0.26 to +0.054 & Muhs et al., 2012a \\
\hline Knipbai & $\mathrm{n} / \mathrm{a}$ & $\mathrm{n} / \mathrm{a}$ & $\mathrm{n} / \mathrm{a}$ & $n / a$ & $\begin{array}{l}\text { Used Boca Cortalein } \\
\text { rate }\end{array}$ & $n / a$ & +0.26 to +0.054 & Muhs et al., 2012a \\
\hline Kust Van Hato & $\mathrm{n} / \mathrm{a}$ & $n / a$ & $\mathrm{n} / \mathrm{a}$ & $n / a$ & $\begin{array}{l}\text { Used Boca Cortalein } \\
\text { rate }\end{array}$ & $n / a$ & +0.26 to +0.054 & Muhs et al., 2012a \\
\hline Punta Halvedag & $\mathrm{n} / \mathrm{a}$ & $\mathrm{n} / \mathrm{a}$ & $\mathrm{n} / \mathrm{a}$ & $\mathrm{n} / \mathrm{a}$ & $\begin{array}{l}\text { Used Boca Cortalein } \\
\text { rate }\end{array}$ & $\mathrm{n} / \mathrm{a}$ & +0.26 to +0.054 & Muhs et al., 2012a \\
\hline Rif Baai & $\mathrm{n} / \mathrm{a}$ & $\mathrm{n} / \mathrm{a}$ & $\mathrm{n} / \mathrm{a}$ & $\mathrm{n} / \mathrm{a}$ & $\begin{array}{l}\text { Used Boca Cortalein } \\
\text { rate }\end{array}$ & $\mathrm{n} / \mathrm{a}$ & +0.26 to +0.054 & Muhs et al., 2012a \\
\hline Westpuntbai & $n / a$ & $\mathrm{n} / \mathrm{a}$ & $\mathrm{n} / \mathrm{a}$ & $\mathrm{n} / \mathrm{a}$ & $\begin{array}{l}\text { Used Boca Cortalein } \\
\text { rate }\end{array}$ & $n / a$ & +0.26 to +0.054 & Muhs et al., 2012a \\
\hline Un Boca & $\mathrm{n} / \mathrm{a}$ & $n / a$ & $\mathrm{n} / \mathrm{a}$ & $n / a$ & $\begin{array}{l}\text { Used Boca Cortalein } \\
\text { rate }\end{array}$ & $n / a$ & +0.26 to +0.054 & Muhs et al., 2012a \\
\hline \multicolumn{9}{|l|}{ ERITREA } \\
\hline Red Sea coast & 14 & $1^{*}$ & & $\begin{array}{l}\text { Walter et al., } \\
2000\end{array}$ & +0.06 & 0.018 & Not given & Walter et al., 2000 \\
\hline \multirow[t]{2}{*}{ Mururoa Atoll } & $\mathrm{n} / \mathrm{a}$ & $\mathrm{n} / \mathrm{a}$ & $\mathrm{n} / \mathrm{a}$ & $\mathrm{n} / \mathrm{a}$ & $\begin{array}{l}\mathrm{n} / \mathrm{a} \text { (used mid point of } \\
\text { range from Trichet et } \\
\text { al., 1984) }\end{array}$ & $\mathrm{n} / \mathrm{a}$ & $\begin{array}{l}-0.07 \text { to }-0.08 \text { (K-Ar dating } \\
\text { basaltic basement) }\end{array}$ & Trichet et al., 1984 \\
\hline & & & & & & & Not reported & Bard et al., 1991 \\
\hline \multirow[t]{4}{*}{ Tahiti } & $\mathrm{n} / \mathrm{a}$ & $\mathrm{n} / \mathrm{a}$ & $\mathrm{n} / \mathrm{a}$ & $\mathrm{n} / \mathrm{a}$ & $\begin{array}{l}\mathrm{n} / \mathrm{a} \text { (used mid point of } \\
\text { range from Deschamps } \\
\text { et al., 2012) }\end{array}$ & $\mathrm{n} / \mathrm{a}$ & $\begin{array}{l}-0.21 \text { and }-0.25 \\
\text { (radiometric dating lava flows) } \\
-0.15 \text { and }-0.3 \text { to }-0.4 \text { (Holocene } \\
\text { shoreline) }\end{array}$ & $\begin{array}{l}\text { Bard et al 1996; Le Roy, } \\
1994 \\
\text { Pirazzoli and } \\
\text { Montaggioni, 1988; } \\
\text { Pirazzoli et al., 1985; } \\
\text { Montaggioni, } 1988\end{array}$ \\
\hline & & & & & & & -0.39 (Maximum) & Thomas et al., 2012 \\
\hline & & & & & & & $\begin{array}{l}-0.2 \text { to }-0.4 \\
\text { (range based on approaches } \\
\text { above) }\end{array}$ & Deschamps et al., 2012 \\
\hline & & & & & & & $\begin{array}{l}-0.3 \pm 0.4 \text { (geodetic } \\
\text { measurement) }\end{array}$ & Fadil et al., 2011 \\
\hline $\begin{array}{l}\text { GREECE (Gulf of } \\
\text { Corinth) }\end{array}$ & & & & & & & +0.3 (mean for area) & Dia et al., 1997 \\
\hline \multirow[t]{2}{*}{$\begin{array}{l}\text { Alepohori-Magara } \\
\text { basin }\end{array}$} & $\mathrm{n} / \mathrm{a}$ & $\mathrm{n} / \mathrm{a}$ & $\mathrm{n} / \mathrm{a}$ & $\mathrm{n} / \mathrm{a}$ & $\begin{array}{l}\text { Used estimate from } \\
\text { literature (average for } \\
\text { Gulf of Corinth and } \\
\text { Isthmus region; Dia et } \\
\text { al., 1997; Collier et al } \\
\text { 1992) }\end{array}$ & $\mathrm{n} / \mathrm{a}$ & $\begin{array}{l}+0.3 \text { to }+0.5 \text { (based on correlation } \\
\text { of corals to highstands and } \\
\text { assumed past sea levels) }\end{array}$ & Dia et al., 1997 \\
\hline & & & & & & & $\begin{array}{l}+0.3 \text { (based on correlation of } \\
\text { corals to highstands and assumed } \\
\text { past sea levels) }\end{array}$ & Collier et al., 1992 \\
\hline Canal & $n / a$ & $n / a$ & $\mathrm{n} / \mathrm{a}$ & $\mathrm{n} / \mathrm{a}$ & $\begin{array}{l}\text { Used estimate from } \\
\text { literature (average for } \\
\text { Gulf of Corinth and } \\
\text { Isthmus region; Dia et } \\
\text { al., 1997; Collier et al } \\
\text { 1992) }\end{array}$ & $\mathrm{n} / \mathrm{a}$ & $\begin{array}{l}+0.3(+0.2 \mathrm{NW} \text { part of the canal) } \\
\text { (based on correlation of corals to } \\
\text { highstands and assumed past sea } \\
\text { levels) }\end{array}$ & Dia et al., 1997 \\
\hline Examilia & $\mathrm{n} / \mathrm{a}$ & $\mathrm{n} / \mathrm{a}$ & $\mathrm{n} / \mathrm{a}$ & $\mathrm{n} / \mathrm{a}$ & $\begin{array}{l}\text { Used estimate from } \\
\text { literature (average for } \\
\text { Gulf of Corinth and } \\
\text { Isthmus region; Dia et } \\
\text { al., 1997; Collier et al } \\
\text { 1992) }\end{array}$ & $\mathrm{n} / \mathrm{a}$ & $\begin{array}{l}+0.3 \text { (based on correlation of } \\
\text { corals to highstands and assumed } \\
\text { past sea levels) }\end{array}$ & Dia et al., 1997 \\
\hline \multirow[t]{2}{*}{$\begin{array}{l}\text { Perakora Peninsula } \\
\text { (SW shore) }\end{array}$} & $\mathrm{n} / \mathrm{a}$ & $\mathrm{n} / \mathrm{a}$ & $\mathrm{n} / \mathrm{a}$ & $\mathrm{n} / \mathrm{a}$ & $\begin{array}{l}\text { Used estimate from } \\
\text { literature (average for } \\
\text { Gulf of Corinth and } \\
\text { Isthmus region; Dia et } \\
\text { al., 1997; Collier et al } \\
\text { 1992) }\end{array}$ & $\mathrm{n} / \mathrm{a}$ & $\begin{array}{l}+0.2 \text { to }+0.5 \text { (based on correlation } \\
\text { of corals to highstands and } \\
\text { assumed past sea levels) }\end{array}$ & Dia et al., 1997 \\
\hline & & & & & & & $\begin{array}{l}+0.17 \text { to }+0.7 \text { (based on } \\
\text { correlation of corals to } \\
\text { highstands and assumed past sea } \\
\text { levels) }\end{array}$ & Dia et al., 1997 \\
\hline
\end{tabular}




\begin{tabular}{|c|c|c|c|c|c|c|c|c|}
\hline & & & & & & & $\begin{array}{l}+0.3 \text { (based on correlation of } \\
\text { corals to highstands and assumed } \\
\text { past sea levels) }\end{array}$ & Dia et al., 1997 \\
\hline \multicolumn{9}{|l|}{ HAITI } \\
\hline & +52 & $1 *$ & $\begin{array}{l}\text { Aerial photographs, } \\
\text { topographic maps, } \\
\text { plane table and } \\
\text { alidade mapping }\end{array}$ & $\begin{array}{l}\text { Dodge et al., } \\
1983\end{array}$ & +0.36 & 0.11 & +0.35 & $\begin{array}{l}\text { Dodge et al., } 1983 \text { in } \\
\text { Bard et al., 1990a }\end{array}$ \\
\hline \multicolumn{9}{|l|}{ INDONESIA } \\
\hline \multirow[t]{3}{*}{$\begin{array}{l}\text { Sumba Island (Cape } \\
\text { Lundi) }\end{array}$} & $\mathrm{n} / \mathrm{a}$ & $\mathrm{n} / \mathrm{a}$ & $\mathrm{n} / \mathrm{a}$ & $\mathrm{n} / \mathrm{a}$ & $\begin{array}{l}\mathrm{n} / \mathrm{a} \text { (used mid point of } \\
\text { range from literature) }\end{array}$ & $\mathrm{n} / \mathrm{a}$ & +0.2 to +0.5 & Bard et al., 1996 \\
\hline & & & & & & & $<0.3$ (Holocene, microatoll) & Bard et al., 1996 \\
\hline & & & & & & & +0.5 (last 1Ma) & $\begin{array}{l}\text { Pirazzoli et al., 1991, } \\
1993\end{array}$ \\
\hline \multicolumn{9}{|l|}{ MADAGASCAR } \\
\hline Toliara & -13 & $1 *$ & $\begin{array}{l}\text { Elevation of LIG } \\
\text { terrace in drill cores }\end{array}$ & $\begin{array}{l}\text { Camoin et al., } \\
2004\end{array}$ & -0.16 & 0.02 & -0.16 & Camoin et al., 2004 \\
\hline \multicolumn{9}{|l|}{$\begin{array}{l}\text { MEXICO (Baja } \\
\text { California) }\end{array}$} \\
\hline Cabo Pulmo & +6 & $1^{*}$ & Shoreline angle & Ortleib, 1987 & 0 & 0.02 & Not reported & Muhs et al., 2002b \\
\hline Isla de Guadalupe & $n / a$ & $\mathrm{n} / \mathrm{a}$ & $\mathrm{n} / \mathrm{a}$ & $\mathrm{n} / \mathrm{a}$ & 0 & 0.02 & Not reported & Muhs et al., 2002b \\
\hline Punta Banda & $\begin{array}{l}+34 \text { to }+40 \mathrm{~m} \\
\text { (Sea Cave } \\
\text { terrace) }\end{array}$ & $4^{\S}$ & Shoreline angle & $\begin{array}{l}\text { Rockwell et } \\
\text { al., } 1989\end{array}$ & +0.24 & 0.04 & $\begin{array}{l}\text { Not reported (give shoreline } \\
\text { angle elevation) }\end{array}$ & Muhs et al., 2002b \\
\hline \multicolumn{9}{|l|}{ NEW CALEDONIA } \\
\hline Amedee Inlet & -12 & 1 & $\begin{array}{l}\text { LIG corals in drill } \\
\text { core }\end{array}$ & $\begin{array}{l}\text { Frank et al., } \\
2006\end{array}$ & -0.15 & 0.02 & $-0.16 \pm 0.4$ & Frank et al., 2006 \\
\hline \multicolumn{9}{|l|}{ NIUE } \\
\hline Niue Island & $\mathrm{n} / \mathrm{a}$ & $\mathrm{n} / \mathrm{a}$ & $\mathrm{n} / \mathrm{a}$ & $\mathrm{n} / \mathrm{a}$ & $\begin{array}{l}\mathrm{n} / \mathrm{a} \text { (used mid point of } \\
\text { range from literature) }\end{array}$ & $\mathrm{n} / \mathrm{a}$ & $\begin{array}{l}+0.13 \text { to }+0.16 \\
\text { (derived from elevation of } \\
\text { emerged post mid-Holocene } \\
\text { shoreline) }\end{array}$ & $\begin{array}{l}\text { Dickinson, } 2001 \text { (in } \\
\text { Kennedy et al., 2012) }\end{array}$ \\
\hline \multicolumn{9}{|l|}{$\begin{array}{l}\text { PAPUA NEW GUINEA } \\
\text { (Huon Peninsula) }\end{array}$} \\
\hline $\begin{array}{l}\text { Bobongara (aka } \\
\text { Fortification Point) }\end{array}$ & +403 & $1 *$ & $\begin{array}{l}\text { Max. elevation of } \\
\text { Last Interglacial } \\
\text { terrace (reef crest of } \\
\text { terrace VII) - } \\
\text { resurveyed by } \\
\text { authors }\end{array}$ & $\begin{array}{l}\text { Chappell et } \\
\text { al., } 1996\end{array}$ & +3.17 & 0.13 & $\begin{array}{l}+3.3 \pm 0.1 \text { (elevation resurveyed } \\
\text { by the authors, used an age of } \\
122 \pm 4 \mathrm{ka} \text { ) }\end{array}$ & $\begin{array}{l}\text { Chappell et al 1996; } \\
\text { Yokoyama et al., } 2001\end{array}$ \\
\hline Gagidu Point & $n / a$ & $\mathrm{n} / \mathrm{a}$ & $\mathrm{n} / \mathrm{a}$ & $\mathrm{n} / \mathrm{a}$ & $\begin{array}{l}\text { n/a (used rate from } \\
\text { literature; Cutler et al., } \\
\text { 2003) }\end{array}$ & $\mathrm{n} / \mathrm{a}$ & $\begin{array}{l}+2.1 \text { (derived from elevations of } \\
\text { deglacial samples) }\end{array}$ & Cutler et al., 2003 \\
\hline Kanomi & +317 & $1 *$ & $\begin{array}{l}\text { Back calculated from } \\
\text { Cutler et al., } 2003\end{array}$ & $\begin{array}{l}\text { Cutler et al., } \\
2003\end{array}$ & +2.48 & 0.10 & $\begin{array}{l}+2.6 \text { (no elevation quoted by } \\
\text { Cutler et al., 2003; used age of } \\
120 \mathrm{ka} \text { ) }\end{array}$ & Cutler et al., 2003 \\
\hline \multirow[t]{4}{*}{ Kanzarua } & +350 & $1^{*}$ & $\begin{array}{l}\text { Elevation terrace } \\
\text { VIllb }\end{array}$ & $\begin{array}{l}\text { Chappell, } \\
1973\end{array}$ & +2.74 & 0.11 & Not reported & Chappell, 1973 \\
\hline & +330 & $1^{*}$ & $\begin{array}{l}\text { Elevation of terrace } \\
\text { VIllb }\end{array}$ & $\begin{array}{l}\text { Bloom et al., } \\
1974\end{array}$ & +2.59 & 0.11 & $\begin{array}{l}+2.62 \text { (calculated using elevation } \\
\text { and an age of } 124 \mathrm{ka} \text { ) }\end{array}$ & Bloom et al., 1974 \\
\hline & +320 & $1^{*}$ & $\begin{array}{l}\text { Elevation reef crest } \\
\text { of terrace VII } \\
\text { (resurveyed by } \\
\text { authors) }\end{array}$ & $\begin{array}{l}\text { Chappell et } \\
\text { al., } 1996\end{array}$ & +2.05 & 0.10 & $\begin{array}{l}+2.8 \pm 0.1 \text { (use elevation and an } \\
\text { age of } 122 \pm 4 \mathrm{ka} \text { ) }\end{array}$ & $\begin{array}{l}\text { Chappell et al., 1996; } \\
\text { Yokoyama et al., } 2001\end{array}$ \\
\hline & +341 & $1^{*}$ & $\begin{array}{l}\text { Back calculated from } \\
\text { Cutler et al., } 2003\end{array}$ & $\begin{array}{l}\text { Cutler et al., } \\
2003\end{array}$ & +2.68 & 0.10 & $\begin{array}{l}+2.8 \text { (no elevation quoted by } \\
\text { Cutler et al., 2003; used age of } \\
120 \mathrm{ka} \text { ) }\end{array}$ & $\begin{array}{l}\text { Esat et al., 1999; Cutler } \\
\text { et al., } 2003\end{array}$ \\
\hline Kilasairo & $\mathrm{n} / \mathrm{a}$ & $\mathrm{n} / \mathrm{a}$ & $\mathrm{n} / \mathrm{a}$ & $\mathrm{n} / \mathrm{a}$ & $\begin{array}{l}\text { Used the rate for } \\
\text { Kwambu (cf. Cutler et } \\
\text { al., } 2003 \text { due to } \\
\text { proximity of sites) }\end{array}$ & $\mathrm{n} / \mathrm{a}$ & +1.85 & Cutler et al., 2003 \\
\hline Kwambu & +230 and +223 & $1^{*}$ & $\begin{array}{l}\text { Max (?) elevation } \\
\text { LIG terrace (terrace } \\
\text { VIIa) }\end{array}$ & $\begin{array}{l}\text { Stein et al., } \\
1993\end{array}$ & $\begin{array}{l}+1.79 \\
\text { (using } 230 \mathrm{~m} \text { ) }\end{array}$ & 0.07 & $\begin{array}{l}\text { +1.9 (used elevation and age of } \\
\text { two samples KAM-A-1 }(230 \mathrm{~m} \text {; } \\
118.7 \mathrm{ka}) \text { and HP-47 ( } 223 \mathrm{~m} \text {; } \\
118.1 \mathrm{ka}) \text { ) }\end{array}$ & $\begin{array}{l}\text { Stein et al., 1993; Esat et } \\
\text { al., } 1999\end{array}$ \\
\hline
\end{tabular}




\begin{tabular}{|c|c|c|c|c|c|c|c|c|}
\hline & +227 & $1^{*}$ & $\begin{array}{l}\text { Back calculated from } \\
\text { Cutler et al., } 2003\end{array}$ & $\begin{array}{l}\text { Cutler et al., } \\
2003 \text { using } \\
\text { values of } \\
\text { Stein et al., } \\
1993\end{array}$ & +1.76 & 0.07 & $\begin{array}{l}+1.85 \text { (Cutler et al., } 2003 \text { appear } \\
\text { to have used the mid point of the } \\
\text { elevation of two samples from } \\
\text { Stein et al., 1993: KAM-A-1 ( } 230 \\
\mathrm{~m} ; 118.7 \mathrm{ka} \text { ) and HP- } 47(223 \mathrm{~m} ; \\
118.1 \mathrm{ka} \text { ) and an age of } 120 \mathrm{ka})\end{array}$ & Cutler et al., 2003 \\
\hline & +215 & $1^{*}$ & $\begin{array}{l}\text { Max. elevation of } \\
\text { terrace Vllb }\end{array}$ & $\begin{array}{l}\text { Bloom et al., } \\
1974\end{array}$ & +1.67 & 0.07 & $\begin{array}{l}+1.69 \text { (calculated using elevation } \\
\text { and an age of } 124 \mathrm{ka} \text { ) }\end{array}$ & Bloom et al., 1974 \\
\hline Kwangam & +188 & $1^{*}$ & $\begin{array}{l}\text { Back calculated } \\
\text { using age of } 118.1 \\
\text { (cf. Stein et al., } \\
\text { 1993) }\end{array}$ & $\mathrm{n} / \mathrm{a}$ & +1.45 & 0.06 & +1.6 & Esat et al., 1999. \\
\hline Nanda & $\mathrm{n} / \mathrm{a}$ & $\mathrm{n} / \mathrm{a}$ & $\mathrm{n} / \mathrm{a}$ & $\mathrm{n} / \mathrm{a}$ & $\begin{array}{l}\text { Used the rate for } \\
\text { Kanomi (Cutler et al., } \\
\text { 2003) due to proximity } \\
\text { of sites }\end{array}$ & $\mathrm{n} / \mathrm{a}$ & +2.8 & Esat et al., 1999 \\
\hline \multirow[t]{4}{*}{ Sialum } & +195 & $1^{*}$ & $\begin{array}{l}\text { Elevation of reef } \\
\text { crest terrace VIIb }\end{array}$ & $\begin{array}{l}\text { Chappell, } \\
1973\end{array}$ & +1.51 & 0.06 & Not reported & Chappell, 1973 \\
\hline & +226 & $1^{*}$ & $\begin{array}{l}\text { Elevation of reef } \\
\text { crest terrace VIIb }\end{array}$ & $\begin{array}{l}\text { Chappell and } \\
\text { Polach, } 1991 .\end{array}$ & +1.76 & 0.07 & $\begin{array}{l}+1.9 \text { (calculated using elevation } \\
\text { and an age of } 118 \mathrm{ka} \text { ) }\end{array}$ & $\begin{array}{l}\text { Chappell and Polach, } \\
1991\end{array}$ \\
\hline & +243 & $1^{*}$ & $\begin{array}{l}\text { Elevation of terrace } \\
\text { VIIb }\end{array}$ & $\begin{array}{l}\text { Edwards et } \\
\text { al., } 1993\end{array}$ & +1.89 & 0.08 & $\begin{array}{l}+1.9 \text { (calculated using elevation } \\
\text { and an age of } 125 \mathrm{ka} \text { ) }\end{array}$ & Edwards et al., 1993 \\
\hline & $\mathrm{n} / \mathrm{a}$ & $\mathrm{n} / \mathrm{a}$ & $\mathrm{n} / \mathrm{a}$ & $\mathrm{n} / \mathrm{a}$ & & & $\begin{array}{l}+1.85 \text { (Cutler et al., } 2003 \text { used the } \\
\text { rate for Kwambu due to } \\
\text { proximity of sites) }\end{array}$ & Cutler et al., 2003 \\
\hline Drill core (unspecified) & +243 & $1^{*}$ & $\begin{array}{l}\text { Max. elevation of } \\
\text { terrace VIlb }\end{array}$ & $\begin{array}{l}\text { Edwards et } \\
\text { al., } 1993\end{array}$ & +1.89 & 0.08 & $\begin{array}{l}+1.9 \text { (calculated using elevation } \\
\text { and an age of } 125 \mathrm{ka} \text { ) }\end{array}$ & Edwards et al., 1993 \\
\hline $\begin{array}{l}\text { Surface exposure } \\
\text { (unspecified) }\end{array}$ & $\mathrm{n} / \mathrm{a}$ & $\mathrm{n} / \mathrm{a}$ & $n / a$ & $\mathrm{n} / \mathrm{a}$ & $\mathrm{n} / \mathrm{a}$ & $\mathrm{n} / \mathrm{a}$ & +1.9 & Edwards et al., 1993 \\
\hline \multicolumn{9}{|l|}{$\begin{array}{l}\text { PAPUA NEW GUINEA } \\
\text { (Huon Gulf) }\end{array}$} \\
\hline Southern Huon Gulf & $\mathrm{n} / \mathrm{a}$ & $\mathrm{n} / \mathrm{a}$ & $\mathrm{n} / \mathrm{a}$ & $\mathrm{n} / \mathrm{a}$ & $\begin{array}{l}\text { n/a (used estimate } \\
\text { from literature; } \\
\text { Galewsky et al., 1996) }\end{array}$ & $\mathrm{n} / \mathrm{a}$ & $\begin{array}{l}-5.7 \text { (average derived from } \\
\text { subsidence of the Huon Gulf by } \\
2,000 \mathrm{~m} \text { in } 348 \mathrm{ka} \text { ) }\end{array}$ & Galewskey et al., 1996 \\
\hline \multicolumn{9}{|l|}{$\begin{array}{l}\text { PAPUA NEW GUINEA } \\
\text { (New Britain Island) }\end{array}$} \\
\hline Jacquinot Bay & $\mathrm{n} / \mathrm{a}$ & $\mathrm{n} / \mathrm{a}$ & $\mathrm{n} / \mathrm{a}$ & $\mathrm{n} / \mathrm{a}$ & $\begin{array}{l}\text { n/a (used estimate } \\
\text { from literature; Riker- } \\
\text { Coleman et al., 2006) }\end{array}$ & $\mathrm{n} / \mathrm{a}$ & $\begin{array}{l}+1.6 \pm 0.4 \\
\text { (dating Holocene coral reefs) }\end{array}$ & $\begin{array}{l}\text { Riker-Coleman et al., } \\
2006\end{array}$ \\
\hline \multicolumn{9}{|l|}{ PITCAIRN ISLANDS } \\
\hline Henderson Island & $\mathrm{n} / \mathrm{a}$ & $\mathrm{n} / \mathrm{a}$ & $\mathrm{n} / \mathrm{a}$ & $\mathrm{n} / \mathrm{a}$ & $\begin{array}{l}\text { Used estimate from } \\
\text { literature (Anderson et } \\
\text { al., 2008) }\end{array}$ & $\mathrm{n} / \mathrm{a}$ & $\begin{array}{l}+0.09 \pm 0.02 \text { ( } 55 \mathrm{~m} \text { of uplift in } \\
\text { approx. } 600 \text { ka determined using } \\
\text { fossil lagoon at }+25 \pm 5 \mathrm{~m} \text { and } \\
\text { reef growth at } 615 \mathrm{ka} \text { ) }\end{array}$ & $\begin{array}{l}\text { Anderson et al., } 2008 \text { in } \\
\text { Anderson et al., } 2010 .\end{array}$ \\
\hline & & & & & & & $\begin{array}{l}+0.093 \text { to }+0.1 \text { Erosional notches } \\
\text { at }+10.7 \text { and }+15.5 \mathrm{~m} \text { (elevation } \\
\text { error } \pm 5 \mathrm{~cm} \text { ) }\end{array}$ & $\begin{array}{l}\text { Blake, } 1995 \text { in Stirling et } \\
\text { al., } 2001 \text { (quoted as } \\
<+0.1 \text { in 42) }\end{array}$ \\
\hline \multicolumn{9}{|l|}{ USA (California) } \\
\hline Cayucos Pt & $\sim+7$ to +8 & $1.5^{\S}$ & Shoreline angle & $\begin{array}{l}\text { Muhs et al., } \\
2002 b\end{array}$ & +0.01 & 0.02 & $\begin{array}{l}\text { Not reported (give shoreline } \\
\text { angle elevation) }\end{array}$ & Muhs et al., 2002b \\
\hline Point Loma & $\sim+23$ to +24 & $1.5^{\S}$ & Shoreline angle & $\begin{array}{l}\text { Muhs et al., } \\
2002 b\end{array}$ & +0.14 & 0.02 & $\begin{array}{l}\text { Not reported (give shoreline } \\
\text { angle elevation) }\end{array}$ & Muhs et al., 2002b \\
\hline Point Arena & $\sim+40$ to +45 & $3.5^{\S}$ & Shoreline angle & $\begin{array}{l}\text { Muhs et al., } \\
2006\end{array}$ & +0.29 & 0.02 & $\begin{array}{l}\text { Not reported (give shoreline } \\
\text { angle elevation) }\end{array}$ & Muhs et al., 2006 \\
\hline San Clemente Island & $\begin{array}{l}\sim+21(\text { Eel } \\
\text { terrace aka } \\
\text { terrace } 2 b)\end{array}$ & $1^{*}$ & $\begin{array}{l}\text { Shoreline angle (Eel } \\
\text { Point) }\end{array}$ & $\begin{array}{l}\text { Muhs et al., } \\
2002\end{array}$ & +0.12 & 0.02 & $\begin{array}{l}\text { Not reported (give shoreline } \\
\text { angle elevation) }\end{array}$ & Muhs et al, 2002 \\
\hline San Nicholas Island & $\sim+34$ & $1^{*}$ & Shoreline angle & $\begin{array}{l}\text { Muhs et al., } \\
2012 b\end{array}$ & +0.22 & 0.02 & $\begin{array}{l}+0.25 \text { to }+0.27 \text { (elevation of LIG } \\
\text { platform, assumed sea level }+6 \mathrm{~m} \\
\text { and age of } 120 \text { ka) (Note, Muhs et } \\
\text { al., } 2012 \mathrm{~b} \text { measurement } \\
\text { uncertainty of } \pm 0.3 \text { ) }\end{array}$ & Muhs et al., 2012b \\
\hline
\end{tabular}




\begin{tabular}{|c|c|c|c|c|c|c|c|c|}
\hline & $\begin{array}{l}\sim+33 \\
\text { (northern, } \\
\text { northeastern } \\
\text { and eastern } \\
\text { side of the } \\
\text { island, to }+36 \\
\text { (near Vizcaino } \\
\text { Point) }\end{array}$ & $1^{*}$ & Shoreline angle & $\begin{array}{l}\text { Muhs et al., } \\
2006\end{array}$ & +0.22 & 0.03 & $\begin{array}{l}\text { Not reported (give shoreline } \\
\text { angle elevation) }\end{array}$ & Muhs et al., 2006 \\
\hline $\begin{array}{l}\text { Green Oaks Creek } \\
\text { area, San Mateo } \\
\text { County }\end{array}$ & $\begin{array}{l}\text { Uncertain }- \text { no } \\
\text { age constraint } \\
\text { (Greyhound } \\
\text { terrace } \sim+50 \\
\text { to } \sim+44 \mathrm{~m} \text {; } \\
\text { Highway } 1 \\
\text { terrace at } \sim+26 \\
\text { to } \sim+29 \mathrm{~m} \text { ) }\end{array}$ & $n / a$ & $\begin{array}{l}\text { Shoreline angles } \\
\text { elevation }\end{array}$ & $\begin{array}{l}\text { Bradley and } \\
\text { Griggs, 1976; } \\
\text { Muhs et al., } \\
2006\end{array}$ & Can't calculate & $n / a$ & $\begin{array}{l}\text { Not reported (report the } \\
\text { shoreline angles for both the } \\
\text { Greyhound and Highway } 1 \\
\text { terraces) }\end{array}$ & Muhs et al., 2006 \\
\hline $\begin{array}{l}\text { Palos Verdes Hills, Los } \\
\text { Angeles County }\end{array}$ & $\begin{array}{l}+70 \text { to }+80 \\
\text { (Gaffey } \\
\text { terrace) }\end{array}$ & $6^{5}$ & $\begin{array}{l}\text { Shoreline angle not } \\
\text { found - inferred }\end{array}$ & $\begin{array}{l}\text { Muhs et al., } \\
2006\end{array}$ & +55 & 0.06 & $\begin{array}{l}\text { Not reported (inferred shoreline } \\
\text { angle elevation) }\end{array}$ & Muhs et al., 2006 \\
\hline \multirow[t]{9}{*}{$\begin{array}{l}\text { USA (Hawaii) } \\
\text { O'ahu }\end{array}$} & $n / a$ & n/a & $n / a$ & n/a & $\begin{array}{l}\text { Used estimate from } \\
\text { literature (McMurty et } \\
\text { al., 2010) }\end{array}$ & $n / a$ & $\begin{array}{l}+0.028 \text { to }+0.052 \text { (based on }+8.5 \\
\text { m elevation of growth position } \\
\text { corals of Waimanalo deposits at } \\
\text { Mokapu Point) }\end{array}$ & Muhs and Szabo, 1994 \\
\hline & $n / a$ & $\mathrm{n} / \mathrm{a}$ & n/a & $\mathrm{n} / \mathrm{a}$ & $n / a$ & $\mathrm{n} / \mathrm{a}$ & $\begin{array}{l}-2 \text { to }-3 \text { (based on submerged } \\
\text { reef terraces) }\end{array}$ & $\begin{array}{l}\text { Szabo and Moore, 1986; } \\
\text { Moore and Campbell, } \\
\text { 1987; Ludwig et al., 1991 }\end{array}$ \\
\hline & $n / a$ & $\mathrm{n} / \mathrm{a}$ & $n / a$ & $\mathrm{n} / \mathrm{a}$ & $n / a$ & $\mathrm{n} / \mathrm{a}$ & +1.6 (from tide gauge data) & Barnett, 1984 \\
\hline & $n / a$ & $n / a$ & n/a & $n / a$ & $n / a$ & $n / a$ & $\begin{array}{l}+0.036 \text { to } 0.070 \text { (using age } 600 \pm \\
100 \mathrm{ka} \text { Sterns, } 1973 \text { and elevation } \\
\text { of }+30 \mathrm{~m} \mathrm{Sterns,}, 1978 \text { ) }\end{array}$ & Muhs and Szabo, 1994 \\
\hline & $n / a$ & $\mathrm{n} / \mathrm{a}$ & $n / a$ & $\mathrm{n} / \mathrm{a}$ & $n / a$ & $\mathrm{n} / \mathrm{a}$ & $\begin{array}{l}+0.05 \text { to }+0.06(\text { based on }+24.4 \mathrm{~m} \\
\text { coral from the Kaena Limestone } \\
\text { and an age of } 532+130 /-70 \mathrm{ka})\end{array}$ & $\begin{array}{l}\text { Szabo et al., 1994; } \\
\text { Sherman et al., } 1999\end{array}$ \\
\hline & & & & & & & $\begin{array}{l}\sim+0.05 \text { (based on coral from } \\
\text { Black Point Limestone at } \sim+17 \mathrm{~m} \\
\text { and K-Ar of overlying basalt and } \\
\text { dyke }(480 \pm 160 \text { ka and } 410 \pm 80 \\
\text { ka respectively) }\end{array}$ & \\
\hline & $\mathrm{n} / \mathrm{a}$ & $\mathrm{n} / \mathrm{a}$ & $n / a$ & $\mathrm{n} / \mathrm{a}$ & $n / a$ & $\mathrm{n} / \mathrm{a}$ & $\begin{array}{l}0.025 \pm 0.005 \text { (last } 120 \mathrm{ka} \text { ); } 0.024 \\
\pm 0.003 \text { (last } 125 \mathrm{ka} \text { ); } 0.020 \pm 0.003 \\
\text { (last } 400 \mathrm{ka} \text { ); } 0.015 \pm 0.001 \text { (last } \\
410 \mathrm{ka} \text { ); } 0.012 \pm 0.005 \text { (last } 420 \\
\text { ka) (based on comparison to } \\
\text { other MIS } 11 \text { terraces of } \\
\text { Bahamas and Bermuda) }\end{array}$ & Hearty, 2002 \\
\hline & $n / a$ & $n / a$ & $n / a$ & $n / a$ & $n / a$ & $n / a$ & $\begin{array}{l}+0.060 \pm 0.001 \text { (rate over the last } \\
500 \text { ka from emerged reef } \\
\text { elevation of }+21 \mathrm{~m} \text { and mean } \mathrm{U} \text { - } \\
\text { series age of } 335 \pm 22 \mathrm{ka} \text { ) }\end{array}$ & McMurty et al., 2010 \\
\hline & $n / a$ & $\mathrm{n} / \mathrm{a}$ & $n / a$ & $\mathrm{n} / \mathrm{a}$ & $\mathrm{n} / \mathrm{a}$ & $n / a$ & +0.02 & $\begin{array}{l}\text { Muhs and Szabo, 1994; } \\
\text { Hearty et al., } 2000 \text { (in } \\
\text { Hearty et al., 2007) }\end{array}$ \\
\hline $\begin{array}{l}\text { USA (Oregon) } \\
\text { Coquille Point }\end{array}$ & $n / a$ & $n / a$ & $n / a$ & $n / a$ & $\begin{array}{l}\mathrm{n} / \mathrm{a} \text { (used mid point of } \\
\text { range from literature) }\end{array}$ & $\mathrm{n} / \mathrm{a}$ & $\begin{array}{l}+0.45 \text { to }+1.05 \text { (based on the } \\
\text { elevation of the Whiskey Run } \\
\text { terrace, corrected for landward } \\
\text { tilt; an age of } 80 \text { ka and; } \\
\text { assumptions regarding sea level } \\
\text { at } 80 \mathrm{ka} \text { ) }\end{array}$ & Muhs et al., 1990 \\
\hline \multicolumn{9}{|l|}{$\begin{array}{l}\text { US VIRGIN ISLANDS } \\
\text { (St Croix) }\end{array}$} \\
\hline West End & +1.5 & $1^{*}$ & $\begin{array}{l}\text { Mapped beach } \\
\text { facies }\end{array}$ & $\begin{array}{l}\text { Hubbard et } \\
\text { al., } 1989\end{array}$ & -0.04 & 0.02 & -0.03 & Toscano et al., 2012 \\
\hline $\begin{array}{l}\text { Long Reef (east of } \\
\text { island) }\end{array}$ & -5.8 & $1^{*}$ & $\begin{array}{l}\text { Maximum elevation } \\
\text { for LIG reef }\end{array}$ & $\begin{array}{l}\text { Toscano et } \\
\text { al., } 2012\end{array}$ & -0.10 & 0.02 & -0.07 & Toscano et al., 2012 \\
\hline Tague Reef & -7.75 & $1^{*}$ & $\begin{array}{l}\text { Maximum elevation } \\
\text { for LIG reef }\end{array}$ & $\begin{array}{l}\text { Toscano et } \\
\text { al., } 2012\end{array}$ & -0.11 & 0.02 & -0.08 & Toscano et al., 2012 \\
\hline
\end{tabular}




\begin{tabular}{|c|c|c|c|c|c|c|c|c|}
\hline Efate Island & $\mathrm{n} / \mathrm{a}$ & $\mathrm{n} / \mathrm{a}$ & $\mathrm{n} / \mathrm{a}$ & $n / a$ & $\begin{array}{l}\text { Used estimate from } \\
\text { literature (Bloom et al., } \\
\text { 1978; Edwards et al., } \\
\text { 1987b, 1988)) }\end{array}$ & $n / a$ & +1 & $\begin{array}{l}\text { Bloom et al., 1978; } \\
\text { Edwards et al., 1987b, } \\
1988\end{array}$ \\
\hline Espiritu Santo Island & $\mathrm{n} / \mathrm{a}$ & $\mathrm{n} / \mathrm{a}$ & $\mathrm{n} / \mathrm{a}$ & $n / a$ & $\mathrm{n} / \mathrm{a}$ & $n / a$ & Not reported & Edwards et al., $1987 a$ \\
\hline Tasmaloum & $\mathrm{n} / \mathrm{a}$ & $\mathrm{n} / \mathrm{a}$ & $\mathrm{n} / \mathrm{a}$ & $\mathrm{n} / \mathrm{a}$ & $\begin{array}{l}\text { Used estimate from } \\
\text { literature (Cutler et al., } \\
\text { 2004) }\end{array}$ & $n / a$ & $\begin{array}{l}+4.6 \text { (no details on derivation } \\
\text { provided) }\end{array}$ & Cutler et al., 2004 \\
\hline Tangoa & $\mathrm{n} / \mathrm{a}$ & $n / a$ & $n / a$ & $n / a$ & $n / a$ & $\mathrm{n} / \mathrm{a}$ & Not reported & Edwards et al., 1987a \\
\hline \multirow[t]{3}{*}{ Urelapa Island } & $\mathrm{n} / \mathrm{a}$ & $n / a$ & $\mathrm{n} / \mathrm{a}$ & $n / a$ & $\begin{array}{l}\text { Used estimate from } \\
\text { literature (Cabioch et } \\
\text { al., 2003) }\end{array}$ & $n / a$ & $\begin{array}{l}+3.4 \text { (no details on derivation } \\
\text { provided) }\end{array}$ & Cutler et al., 2004 \\
\hline & & & & & & & $\begin{array}{l}+3 \pm 0.3 \text { (mean late Holocene } \\
\text { rate) }\end{array}$ & $\begin{array}{l}\text { Jouannic et al 1990; } \\
\text { Taylor et al., 1980, } 1987 \\
\text { in Cabioch et al., } 2003\end{array}$ \\
\hline & & & & & & & $\begin{array}{l}\sim+2.5 \text { (average for last } 100 \mathrm{ka} \\
\text { based on dating of terraces) }\end{array}$ & $\begin{array}{l}\text { Cabioch et al., } 2003 \text { (and } \\
\text { references therein) }\end{array}$ \\
\hline \multirow[t]{2}{*}{ Araki Island } & $n / a$ & $n / a$ & $\mathrm{n} / \mathrm{a}$ & $n / a$ & $\begin{array}{l}\text { Used estimate from } \\
\text { literature (Cabioch et } \\
\text { al., 2003) }\end{array}$ & $n / a$ & Not reported & Fairbanks et al., 2005 \\
\hline & & & & & & & $\begin{array}{l}\sim+2.5 \text { (average for last } 100 \mathrm{ka} \\
\text { based on dating of terraces) }\end{array}$ & $\begin{array}{l}\text { Cabioch et al., } 2003 \text { (and } \\
\text { references therein) }\end{array}$ \\
\hline
\end{tabular}


Table 2:

\begin{tabular}{|l|l|l|}
\hline Location & Site(s) & $\begin{array}{l}\text { Modern tidal } \\
\text { range (min and } \\
\text { max) (m) (3dp) }\end{array}$ \\
\hline Bahamas & & \\
Barbados & Abaco, Great Inagua and San Salvador Islands & 1.005 to 1.284 \\
Bermuda & various & 0.906 to 1.29 \\
China & various & 1.249 to 1.258 \\
Comoro Islands & Leizhou Peninsula & 4.628 \\
Curacao & Mayotte Island & 4.160 \\
Eritrea & various & 0.450 to 0.501 \\
French Polynesia & Red Sea coast & 1.391 \\
French Polynesia & Mururoa atoll & 0.899 \\
Grand Cayman & Tahiti & 0.394 to 0.427 \\
Haiti & various & 0.441 to 0.443 \\
Indonesia & N.W. Peninsula & 0.811 \\
Madagascar & Sumba Island & 3.621 \\
Mexico & Toliara & 3.289 \\
Mexico & Baja California: various & 0.958 to 2.710 \\
New Caledonia & Yucatan Peninsula & 0.396 \\
Niue & Amdee Inlet & 1.570 \\
Papua New Guinea & Niue Island & 1.276 to 1.542 \\
Pitcairn Islands & Huon Peninsula: various & 1.186 to 1.225 \\
Seychelles & Henderson Island & 1.036 to 1.233 \\
USA & various & 1.554 to 1.787 \\
USA & California: various & 2.667 to 2.876 \\
USA & Florida: various & 0.737 to 1.129 \\
USA & Hawaii: various & 0.892 to 1.044 \\
Vanuatu & Oregon - Coquille Point & 3.597 \\
Western Australia & various & 1.499 to 2.158 \\
\hline
\end{tabular}


Table 3:

* too few modern observations $(<50)$ to enable a depth preference to be assigned - used genus information (where available) for the fossil database;

¥ depth preference based on few $(<200)$ observations - treat with caution

\# widened depth precision (depth precision $\leq 5 \mathrm{~m}$ )

† no modern observations (but some museum collection specimens); used the study of Gerrodette, 1979

$\S$ numbers in brackets are the number of species used to determine the genus depth range

$\zeta$ Maximum depth observed from study of Muir et al., 2015 using the Worldwide Acropora Collection, Queensland Museum. This collection comprises 23,000 specimens and included SCUBA collection (to base of reef or the regulated diving limit)

\begin{tabular}{|c|c|c|c|c|c|c|c|c|c|c|c|c|}
\hline Species & $\begin{array}{l}\text { Number in } \\
\text { fossil } \\
\text { database }\end{array}$ & $\begin{array}{l}\text { Number of } \\
\text { observations } \\
\text { used to } \\
\text { determine } \\
\text { depth } \\
\text { distribution }\end{array}$ & $\begin{array}{l}\text { Depth range } \\
\text { (m) (1dp) } \\
(95 \% \\
\text { confidence) }\end{array}$ & $\begin{array}{l}\text { Depth range } \\
\text { (m) (1dp) } \\
(68 \% \\
\text { confidence) }\end{array}$ & $\begin{array}{l}\text { Max. depth } \\
\text { recorded in } \\
\text { OBIS } \\
\text { database } \\
\text { (m) (1dp) }\end{array}$ & $\begin{array}{l}\text { Median depth } \\
\text { (m) ( } 95 \% \\
\text { confidence) }\end{array}$ & $\begin{array}{l}\text { Uerror } \\
(95 \%) \\
(\mathrm{m}) \\
(1 \mathrm{dp})\end{array}$ & $\begin{array}{l}\text { Lerror } \\
(95 \%) \\
(\mathrm{m}) \\
(1 \mathrm{dp})\end{array}$ & $\begin{array}{l}\text { Uerror } \\
(68 \%) \\
(\mathrm{m}) \\
(1 \mathrm{dp})\end{array}$ & $\begin{array}{l}\text { Lerror } \\
(68 \%) \\
(\mathrm{m}) \\
(1 \mathrm{dp})\end{array}$ & $\begin{array}{l}\text { ICUN Red } \\
\text { List } \\
\text { (Carpenter } \\
\text { et al., 2008) } \\
\text { depth range } \\
\text { (m) § }\end{array}$ & $\begin{array}{l}\text { Muir et } \\
\text { al., } 2015 \\
\text { maximum } \\
\text { observed } \\
\text { depth (m) } \\
\text { (Acropora } \\
\text { only) } \zeta\end{array}$ \\
\hline Acropora sp. & 154 & 13,598 & 0 to -18 & 0 to -7 & -91 & -2.4 & 2.4 & 15.6 & 1.8 & 4.6 & $\begin{array}{l}0 \text { to }-70 \\
\text { (169; some } \\
\text { species } \\
\text { depth range } \\
\text { unknown) }\end{array}$ & \\
\hline $\begin{array}{l}\text { Acropora } \\
\text { abrotanoides } \ddagger\end{array}$ & 0 & $50 \ddagger$ & 0 to -39 & 0 to -6 & -49.5 & -3 & 3 & 36 & 3 & 3 & 0 to -15 & -26 \\
\hline Acropora cervicornis & 15 & 788 & -0.5 to -16.4 & -1.8 to -10.5 & -48 & -4.6 & 4.1 & 11.8 & 2.818 & 5.959 & -0.5 to -60 & -10 \\
\hline Acropora danai* & 24 & No info* & & & & & & & & & Not listed & \\
\hline $\begin{array}{l}\text { Acropora gr. danai- } \\
\text { robusta* }\end{array}$ & 8 & No info* & & & & & & & & & Not listed & \\
\hline Acropora humilis & 37 & 280 & 0 to -40 & -0.1 to -7 & -46 & -3 & 3 & 37 & 2.86 & 4 & 0 to -11 & -20 \\
\hline Acropora hyacinthus & 41 & 322 & 0 to -10 & -2 to -7 & -11 & -3 & 3 & 7 & 1 & 4 & -5 to -20 & -26 \\
\hline Acropora palmata & 515 & 4,761 & -0.4 to -9.4 & -0.7 to -3 & -22 & -1.5 & 1.2 & 7.9 & 0.8 & 1.5 & -0.1 to -40 & -3 \\
\hline Acropora pharaonis* & 0 & No info* & & & & & & & & & -5 to -25 & -12 \\
\hline Acropora robusta $\ddagger$ & 3 & $63 \ddagger$ & 0 to -8 & -1 to -8 & -8 & -4 & 4 & 4 & 3 & 4 & -1 to -8 & -17.5 \\
\hline Agaricia sp. & 0 & 5,495 & -1.1 to -20 & -3 to -14 & -86 & -9.8 & 8.7 & 10.3 & 6.8 & 4.3 & $\begin{array}{l}-0.5 \text { to }-115 \\
\text { (7) }\end{array}$ & $\mathrm{n} / \mathrm{a}$ \\
\hline Agaricia agaricites & 1 & 2,136 & -2 to -20.5 & -6.8 to -15 & -86 & -11.25 & 9.3 & 9.3 & 4.5 & 3.8 & -0.5 to -75 & $\mathrm{n} / \mathrm{a}$ \\
\hline Alveopora sp. $\neq$ & 5 & $70 \ddagger$ & -2 to -48.2 & -2 to -36.9 & -50 & -5 & 3 & 43.2 & 3 & 31.9 & $\begin{array}{l}-1 \text { to }-50 \\
(14)\end{array}$ & $\mathrm{n} / \mathrm{a}$ \\
\hline Astreopora sp. & 0 & 1,245 & 0 to -46 & 0 to -42 & -66 & -34 & 34 & 12 & 34 & 8 & $\begin{array}{l}-1 \text { to }-20 \\
(13)\end{array}$ & $\mathrm{n} / \mathrm{a}$ \\
\hline Balanophyllia elegans $^{+}$ & 235 & $n / a$ & -12 to -20 & -13 to -18 & & -15 & 3 & 5 & 2 & 3 & Not listed & $\mathrm{n} / \mathrm{a}$ \\
\hline $\begin{array}{l}\text { Colpophyllia sp. (NB } \\
\text { only based on C. natans } \\
\text { data) }\end{array}$ & 1 & 1,170 & -2.3 to -22 & -4.8 to -15 & -81 & -10 & 8 & 12 & 3.9 & 5 & $\begin{array}{l}-0.5 \text { to }-55 \\
\text { (1) }\end{array}$ & $\mathrm{n} / \mathrm{a}$ \\
\hline Colpophyllia natans & 8 & 1,170 & -2 to -22 & -6.1 to -15 & -81 & -10 & 8 & 12 & 3.9 & 5 & -0.5 to -55 & $\mathrm{n} / \mathrm{a}$ \\
\hline Cyphastrea sp. & 0 & 408 & -1 to -33.1 & -2 to -8 & -69.7 & -5 & 4 & 28 & 3 & 3 & 0 to $-50(8)$ & $\mathrm{n} / \mathrm{a}$ \\
\hline $\begin{array}{l}\text { Cyphastrea } \\
\text { chalcidium } \ddagger\end{array}$ & 0 & $91 \ddagger$ & -0.8 to -13 & -2 to -7.1 & -15 & -5 & 4.3 & 8 & 3 & 2.1 & 0 to -50 & $\mathrm{n} / \mathrm{a}$ \\
\hline Cyphastrea serailia & 1 & 202 & -1 to -11.48 & -2 to -8 & -15 & -5 & 4 & 6.5 & 3 & 3 & 0 to -50 & $\mathrm{n} / \mathrm{a}$ \\
\hline $\begin{array}{l}\text { Diploastrea sp. } \neq \text { (NB } \\
\text { only based on } D . \\
\text { heliopora data) }\end{array}$ & 5 & $162 \ddagger$ & 0 to -12 & -3 to -8 & -16 & -6 & 6 & 6 & 3 & 2 & 0 to $-30(1)$ & $\mathrm{n} / \mathrm{a}$ \\
\hline Diploastrea heliopora $\ddagger$ & 2 & $162 \ddagger$ & 0 to -12 & -3 to -8 & -16 & -6 & 6 & 6 & 3 & 2 & 0 to -30 & $\mathrm{n} / \mathrm{a}$ \\
\hline Diploria sp. & 31 & 4,525 & -0.6 to -23.4 & -1.5 to -13 & -81 & -7.3 & 6.75 & 16.1 & 5.8 & 5.7 & 0 to $-55(3)$ & $\mathrm{n} / \mathrm{a}$ \\
\hline Diploria clivosa & 23 & 853 & -0.4 to -16 & -1 to -9.1 & -66 & -3.65 & 3.3 & 12.4 & 2.7 & 5.4 & 0 to -15 & $\mathrm{n} / \mathrm{a}$ \\
\hline $\begin{array}{l}\text { Diploria } \\
\text { labyrinthiformis }\end{array}$ & 2 & 894 & -1.3 to -19.32 & -5.25 to -14 & -9.32 & -10 & 8.7 & 9.32 & 4.75 & 4 & & $\mathrm{n} / \mathrm{a}$ \\
\hline Diploria strigosa & 28 & 2,763 & -0.6 to -27 & -1.5 to -13.4 & -81 & -7.675 & 7.1 & 19.3 & 6.2 & 5.7 & -0.5 to -55 & $\mathrm{n} / \mathrm{a}$ \\
\hline Echinopora sp. & 1 & 451 & 0 to -21 & -2 to -8 & -52 & -5 & 5 & 16 & 3 & 3 & 0 to -40 (14) & $\mathrm{n} / \mathrm{a}$ \\
\hline $\begin{array}{l}\text { Echinopora } \\
\text { gemmacea } \neq\end{array}$ & 1 & $95 \ddagger$ & -2 to -13.2 & -2 to -8.5 & -15 & -6 & 4 & 7.2 & 4 & 2.5 & 0 to -40 & $n / a$ \\
\hline Favia sp. & 12 & 747 & 0 to -48 & 0 to -42 & -66 & -34 & 34 & 14 & 34 & 8 & 0 to -50 (21) & $\mathrm{n} / \mathrm{a}$ \\
\hline Favia fragum $\ddagger$ & 4 & 91 & 0 to -51.9 & -2 to -31 & -66 & -6.1 & 6.1 & 45.83 & 4.1 & 24.9 & & $\mathrm{n} / \mathrm{a}$ \\
\hline Favia laxa* & 1 & $\mathrm{n} / \mathrm{a}$ & & & & & & & & & & \\
\hline Favia maxima* & 3 & 39 & & & & & & & & & & $\mathrm{n} / \mathrm{a}$ \\
\hline Favia pallida & 6 & 445 & 0 to -46.2 & -3 to -40 & -53 & -8 & 8 & 38.2 & 5 & 32 & 0 to -50 & $\mathrm{n} / \mathrm{a}$ \\
\hline Favia speciosa & 0 & $89 \ddagger$ & -0.7 to -10.3 & -2 to -8 & -47 & -5 & 4.3 & 5.3 & 3 & 3 & 0 to -40 & $\mathrm{n} / \mathrm{a}$ \\
\hline Favia stelligera & 8 & 503 & 0 to -46 & 0 to -43 & -65 & -3 & 3 & 43 & 3 & 40 & 0 to -20 & $\mathrm{n} / \mathrm{a}$ \\
\hline Faviidae (family) & 211 & 7,769 & -0.8 to -37 & -2.55 to -14 & -183 & -7.6 & 5.2 & 31 & 3.45 & 8 & & $\mathrm{n} / \mathrm{a}$ \\
\hline Favites sp. & 1 & 1,269 & 0 to -17.6 & -2 to -8 & -69.4 & -4 & 4 & 13.6 & 2 & 4 & 0 to -40 (14) & $n / a$ \\
\hline Fungia $s p$. & 1 & 1,015 & 0 to -51 & 0 to -40 & -66.9 & -3 & 3 & 48 & 3 & 37 & $\begin{array}{l}-1 \text { to }-85 \\
(25)\end{array}$ & $\mathrm{n} / \mathrm{a}$ \\
\hline Galaxea sp. & 0 & 846 & 0 to -46 & -2 to -37 & -52 & -7 & 7 & 39 & 5 & 30 & -1 to $-30(7)$ & $\mathrm{n} / \mathrm{a}$ \\
\hline Galaxea fascicularis & 2 & 598 & 0 to -46 & -2 to -40 & -52 & -7 & 7 & 39 & 5 & 33 & -1 to -15 & $\mathrm{n} / \mathrm{a}$ \\
\hline
\end{tabular}




\begin{tabular}{|c|c|c|c|c|c|c|c|c|c|c|c|c|}
\hline Gardineroseris sp.* & 2 & $28^{*}$ & & & & & & & & & $\begin{array}{l}-2 \text { to }-30(1 ; \\
\text { G. } \\
\text { planulata) }\end{array}$ & $\mathrm{n} / \mathrm{a}$ \\
\hline $\begin{array}{l}\text { Gardineroseris } \\
\text { planulata* }\end{array}$ & 7 & $27^{*}$ & & & & & & & & & -2 to -30 & $\mathrm{n} / \mathrm{a}$ \\
\hline Goniastrea sp. & 20 & 1,970 & 0 to -46 & -2 to -40 & -59.8 & -5 & 5 & 41 & 3 & 35 & 0 to -40 (13) & $\mathrm{n} / \mathrm{a}$ \\
\hline Goniastrea parvistella* & 0 & No info* & & & & & & & & & Not listed & $\mathrm{n} / \mathrm{a}$ \\
\hline Goniastrea pectinata & 1 & 314 & 0 to -44 & -2 to -15.4 & -51 & -5 & 5 & 39 & 3 & 10.42 & 0 to -40 & $\mathrm{n} / \mathrm{a}$ \\
\hline Goniastrea retiformis & 2 & 571 & 0 to -46 & -2 to -42 & -51 & -23 & 23 & 23 & 21 & 19 & 0 to -20 & $\mathrm{n} / \mathrm{a}$ \\
\hline Goniopora sp. & 2 & 737 & 0 to -45 & -2 to -10 & -69.7 & -5 & 5 & 40 & 3 & 5 & $\begin{array}{l}-0.5 \text { to }-30 \\
(24)\end{array}$ & $\mathrm{n} / \mathrm{a}$ \\
\hline Goniopora lobata* & 1 & $15^{*}$ & & & & & & & & & -0.5 to -30 & $\mathrm{n} / \mathrm{a}$ \\
\hline Hydnophora sp. & 0 & 554 & 0 to -40 & -1 to -8 & -65 & -3 & 3 & 37 & 2 & 5 & 0 to $-40(6)$ & $\mathrm{n} / \mathrm{a}$ \\
\hline Hydnophora exesa & 1 & 228 & 0 to -38.8 & -2 to -8 & -47 & -4 & 4 & 34.8 & 2 & 4 & -1 to -30 & $\mathrm{n} / \mathrm{a}$ \\
\hline $\begin{array}{l}\text { Hydnophora } \\
\text { microconos } \neq\end{array}$ & 1 & $117 \ddagger$ & 0 to -46.2 & 0 to -6 & -65 & -2 & 2 & 44.2 & 2 & 4 & -1 to -35 & $\mathrm{n} / \mathrm{a}$ \\
\hline Leptastrea sp. & 3 & 1,791 & 0 to -46 & 0 to -41 & -86 & -5 & 5 & 41 & 5 & 36 & 0 to $-40(7)$ & $\mathrm{n} / \mathrm{a}$ \\
\hline Leptoria sp. & 0 & 216 & 0 to -45 & -2 to -10 & -50 & -5 & 5 & 40 & 3 & 5 & 0 to $-30(2)$ & $\mathrm{n} / \mathrm{a}$ \\
\hline Leptoria phrygiaf & 2 & $183 \ddagger$ & 0 to -12 & -2 to -8 & -45 & -4 & 4 & 8 & 2 & 4 & 0 to -30 & $\mathrm{n} / \mathrm{a}$ \\
\hline Leptoseris sp. $\neq$ & 1 & 228 & 0 to -65 & 0 to -46 & $\begin{array}{ll}-69.4 \\
\end{array}$ & -9 & 9 & 56 & 9 & 37 & $\begin{array}{l}-1 \text { to }-150 \\
\text { (14) }\end{array}$ & $\mathrm{n} / \mathrm{a}$ \\
\hline Lobophyllia sp. & 0 & 692 & 0 to -12 & -2 to -8 & -48 & -5 & 5 & 7 & 3 & 3 & -1 to $-50(9)$ & $\mathrm{n} / \mathrm{a}$ \\
\hline $\begin{array}{l}\text { Lobophyllia } \\
\text { corymbosa }\end{array}$ & 0 & $132 \ddagger$ & -2 to -13.2 & -3 to -8 & -15 & -6 & 4 & 7.2 & 3 & 2 & -2 to -40 & $\mathrm{n} / \mathrm{a}$ \\
\hline Millepora sp. & 3 & 3,801 & -0.3 to -40 & -1 to -11.2 & -92 & -3 & 2.75 & 37 & 2 & 8.2 & 0 to $-40(16)$ & $\mathrm{n} / \mathrm{a}$ \\
\hline Montastraea sp. & 19 & 18,520 & -1.1 to -39 & -5.5 to -15 & -85 & -10 & 8.9 & 29 & 4.5 & 5 & $\begin{array}{l}0 \text { to }-113 \\
\text { (12) }\end{array}$ & $\mathrm{n} / \mathrm{a}$ \\
\hline Montastraea annularis & 233 & 6,733 & -1.1 to -17 & -4.8 to -12.7 & -65 & -9.7 & 8.6 & 7.3 & 5 & 3 & -0.5 to 82 & $\mathrm{n} / \mathrm{a}$ \\
\hline Montastraea cavernosa & 8 & 3,437 & -1.8 to -23 & -6 to 14.6 & -85 & -10 & 8.2 & 13 & 4 & 4.6 & -0.5 to -113 & $\mathrm{n} / \mathrm{a}$ \\
\hline $\begin{array}{l}\text { Montastraea } \\
\text { annuligera* }\end{array}$ & 2 & 5* & & & & & & & & & 0 to -20 & $\mathrm{n} / \mathrm{a}$ \\
\hline Montipora sp. & 14 & 25,751 & 0 to -56 & 0 to -45 & -98 & 0 & 0 & 56 & 0 & 45 & 0 to -40 (74) & $\mathrm{n} / \mathrm{a}$ \\
\hline $\begin{array}{l}\text { Oculina sp. } \# \# \\
\text { (NB includes } \\
\text { museum/collection } \\
\text { specimens) }\end{array}$ & 29 & 248 & -7 to -237.8 & -18 to -77 & $-1,050$ & -42.5 & 33.5 & 195.3 & 24.5 & 34.5 & $\begin{array}{l}-0.5 \text { to }-152 \\
\text { (3, some } \\
\text { species } \\
\text { depth range } \\
\text { unknown) }\end{array}$ & $\mathrm{n} / \mathrm{a}$ \\
\hline $\begin{array}{l}\text { Oulophyllia sp. } ¥ \# \\
\text { (NB includes } \\
\text { museum/collection } \\
\text { specimens) }\end{array}$ & 1 & 239 & -1.5 to -49.3 & -3 to -42.5 & -70.5 & -7 & 5.5 & 42.3 & 4 & 35.5 & -1 to $-30(3)$ & $\mathrm{n} / \mathrm{a}$ \\
\hline Oulophyllia crispa \#\# & 4 & $136 \ddagger$ & -1.9 to -18 & -3 to -8 & -40 & -5 & 3.1 & 13 & 2 & 3 & -2 to -30 & $\mathrm{n} / \mathrm{a}$ \\
\hline Pachyseris sp. & 0 & 296 & -2 to -13 & -3 to -10 & -18 & -6 & 4 & 7 & 3 & 4 & -3 to $-25(5)$ & $\mathrm{n} / \mathrm{a}$ \\
\hline Pachyseris foliosa* & 3 & 4* & & & & & & & & & -10 to -25 & $\mathrm{n} / \mathrm{a}$ \\
\hline Pavona sp. & 4 & 3,347 & 0 to -51 & 0 to -43 & -75 & -5 & 5 & 46 & 5 & 38 & $\begin{array}{l}-0.5 \text { to }-80 \\
(16)\end{array}$ & $\mathrm{n} / \mathrm{a}$ \\
\hline Pavona clavus & 4 & $30 *$ & & & & & & & & & -2 to -15 & $\mathrm{n} / \mathrm{a}$ \\
\hline Platygyra sp. & 7 & 1183 & 0 to -42 & -2 to -8 & -50 & -5 & 5 & 37 & 3 & 3 & 0 to -30 (11) & $\mathrm{n} / \mathrm{a}$ \\
\hline Platygyra daedalea* & 1 & No info* & & & & & & & & & 0 to -30 & $\mathrm{n} / \mathrm{a}$ \\
\hline Platygyra lamellina & 2 & $179 \ddagger$ & 0 to -10.1 & -2 to -8 & -16 & -4.5 & 4.5 & 5.6 & 2.5 & 3.5 & -1 to -30 & $\mathrm{n} / \mathrm{a}$ \\
\hline Platygyra sinensis $\neq$ & 1 & $169 \ddagger$ & 0 to -12.3 & -2 to -8 & -16 & -5 & 5 & 7.3 & 3 & 3 & 0 to -30 & $\mathrm{n} / \mathrm{a}$ \\
\hline Plesiastrea sp. $¥$ & 0 & $84 \ddagger$ & -2 to -43.7 & -2 to -8.2 & -45 & -5 & 3 & 38.655 & 3 & 3.22 & 0 to $-40(2)$ & $\mathrm{n} / \mathrm{a}$ \\
\hline $\begin{array}{l}\text { Plesiastrea curta (can't } \\
\text { assign depth } \\
\text { distribution) }\end{array}$ & 1 & No info & & & & & & & & & Not listed & $\mathrm{n} / \mathrm{a}$ \\
\hline Pocillopora sp. & 81 & 14,439 & 0 to -64 & 0 to -43 & -98 & 0 & 0 & 64 & 0 & 43 & $\begin{array}{l}-0.5 \text { to }-54 \\
\text { (18; some } \\
\text { species } \\
\text { depth range } \\
\text { unknown) }\end{array}$ & $\mathrm{n} / \mathrm{a}$ \\
\hline Pocillopora eydouxi & 0 & 401 & 0 to -49 & 0 to -34 & -65 & 0 & 0 & 49 & 0 & 34 & -2 to -20 & $\mathrm{n} / \mathrm{a}$ \\
\hline $\begin{array}{l}\text { Pocillopora } \\
\text { guadalupensis }\end{array}$ & 4* & No info* & & & & & & & & & Not listed & $\mathrm{n} / \mathrm{a}$ \\
\hline Pocillopora meandrina & 2 & 8,227 & 0 to -56 & 0 to -43 & -98 & 0 & 0 & 56 & 0 & 43 & -1 to -27 & $\mathrm{n} / \mathrm{a}$ \\
\hline Pocillopora verrucosa & 5 & 455 & 0 to -45.2 & 0 to -33 & -54 & 0 & 0 & 45.2 & 0 & 33 & -1 to -54 & $\mathrm{n} / \mathrm{a}$ \\
\hline Porites $s p$. & 350 & 50,936 & 0 to -66 & 0 to -45 & -98 & -4 & 4 & 62 & 4 & 41 & $\begin{array}{l}0 \text { to }-50 \text { (61; } \\
\text { some } \\
\text { species } \\
\text { depth range } \\
\text { unknown) }\end{array}$ & $\mathrm{n} / \mathrm{a}$ \\
\hline Porites asteroides & 17 & 6,133 & -0.7 to -20.5 & -2 to -12.7 & -84 & -6.8 & 6.1 & 13.7 & 4.8 & 5.9 & -0.2 to -70 & $\mathrm{n} / \mathrm{a}$ \\
\hline Porites brighami & 1 & 428 & 0 to -87 & 0 to -75 & -87 & -17 & 17 & 70 & 17 & 58 & "Unknown" & $\mathrm{n} / \mathrm{a}$ \\
\hline Porites lobata & 12 & 29,941 & 0 to -67 & 0 to -45 & -98 & 0 & 0 & 67 & 0 & 45 & 0 to -30 & $\mathrm{n} / \mathrm{a}$ \\
\hline Porites lutea & 9 & 804 & 0 to -45 & 0 & -52 & 0 & 0 & 45 & 0 & 0 & 0 to -30 & $\mathrm{n} / \mathrm{a}$ \\
\hline Porites nigrescens $\ddagger$ & 1 & $59 \ddagger$ & -2 to- 12 & -3 to -8 & -12 & -6 & 4 & 6 & 3 & 2 & -2 to -15 & $\mathrm{n} / \mathrm{a}$ \\
\hline Porites solida & 0 & $127 \ddagger$ & 0 to -47 & 0 & -87 & 0 & 0 & 47 & 0 & 0 & -1 to -30 & $\mathrm{n} / \mathrm{a}$ \\
\hline Porites solida lobata* & 1 & no info* & & & & & & & & & Not listed & $\mathrm{n} / \mathrm{a}$ \\
\hline Pseudosiderastrea sp. ${ }^{*}$ & 0 & $38^{*}$ & & & & & & & & & -8 to $-20(1)$ & $\mathrm{n} / \mathrm{a}$ \\
\hline $\begin{array}{l}\text { Pseudosiderastrea } \\
\text { tayami* }\end{array}$ & 0 & $34^{*}$ & & & & & & & & & -8 to -20 & $\mathrm{n} / \mathrm{a}$ \\
\hline Siderastrea sp. & 44 & 4,393 & -1.2 to -32 & -4.3 to -14 & -85 & -10 & 8.8 & 22 & 5.8 & 4 & $\begin{array}{l}0 \text { to }-70(5 ; \\
\text { some } \\
\text { species }\end{array}$ & $\mathrm{n} / \mathrm{a}$ \\
\hline
\end{tabular}




\begin{tabular}{|c|c|c|c|c|c|c|c|c|c|c|c|c|}
\hline & & & & & & & & & & & $\begin{array}{l}\text { depth range } \\
\text { unknown) }\end{array}$ & \\
\hline Siderastrea radians $\neq$ & 12 & 276 & -0.1 to -64.9 & -3 to -32 & -79 & -10.45 & 10.3 & 54.4 & 7.5 & 21.6 & 0 to -3 & $\mathrm{n} / \mathrm{a}$ \\
\hline Siderastrea siderea & 16 & 4,098 & -1.2 to -23 & -4.3 to -14 & -85 & -10 & 8.8 & 13 & 5.8 & 4 & 0 to -70 & $\mathrm{n} / \mathrm{a}$ \\
\hline Stylophora sp. & 2 & 601 & 0 to -44 & -2 to -36 & -50 & -8 & 8 & 36 & 6 & 28 & 0 to $-40(7)$ & $\mathrm{n} / \mathrm{a}$ \\
\hline Symphyllia sp. & 0 & 343 & 0 to -10 & -2 to -8 & -16 & -4 & 4 & 6 & 2 & 4 & 0 to $-45(7)$ & $\mathrm{n} / \mathrm{a}$ \\
\hline Symphyllia mobilis & 0 & No info* & & & & & & & & & Not listed & $\mathrm{n} / \mathrm{a}$ \\
\hline Turbinaria sp. & 1 & 985 & 0 to -45.3 & -2 to -8 & -66.6 & -5 & 5 & 40.3 & 3 & 3 & $\begin{array}{l}-0.5 \text { to }-25 \\
\text { (11) }\end{array}$ & $\mathrm{n} / \mathrm{a}$ \\
\hline
\end{tabular}


Table 4:

(a) assumed that where uranium concentration was reported as [U], that this $\left[{ }^{238} \mathrm{U}\right]$.

(b) indicates where uranium concentration determinations were made on differing parts of the coral skeleton (work of Veeh and Turekian, 1968 and; Schroeder et al., 1970), both are included in the range of values quoted.

\begin{tabular}{|c|c|c|c|c|}
\hline Species & $\begin{array}{l}\text { Number } \\
\text { of } \\
\text { analyses }\end{array}$ & $\begin{array}{l}\left.\text { Range of }{ }^{238} \mathrm{U}\right] \\
\text { reported } \\
(\mathrm{ppm})^{(\mathrm{a})}\end{array}$ & Sample location & References \\
\hline Acropora cervicornis ${ }^{(b)}$ & 3 & 3.27 to $5.8^{(b)}$ & Bahamas, Barbados & Schroeder et al., 1970; Cross and Cross, 1983 \\
\hline Acropora cuneata & 3 & 1.56 to 1.96 & Australia & Swart and Hubbard, 1982. \\
\hline Acropora palmata & 32 & 3.03 to 3.86 & $\begin{array}{l}\text { Bahamas, } \quad \text { Barbados, } \\
\text { Cayman Islands }\end{array}$ & $\begin{array}{l}\text { Flor and Moore, 1977; Cross and Cross 1983; } \\
\text { Hamelin et al., 1991; }\end{array}$ \\
\hline Acropora squamosa & 2 & 1.84 to 1.85 & Australia & Swart and Hubbard, 1982 \\
\hline Acropora sp. & 53 & 1.3 to 4.005 & $\begin{array}{l}\text { ibid, Australia, Red Sea, } \\
\text { Samoa, Tahiti }\end{array}$ & $\begin{array}{l}\text { ibid, Veeh and Turekian, 1968; Gvirtman et al., } \\
\text { 1973; Zhu et al., 1993; }\end{array}$ \\
\hline Agaricia agaricites & 1 & 2.76 & Cayman Islands & Flor and Moore, 1977. \\
\hline $\begin{array}{l}\text { Bathycyathus } \\
\text { maculatus }\end{array}$ & 1 & 3.0 & Brazil (St Peter's Rocks) & Livingston and Thompson, 1971. \\
\hline Cladocora patriaca & 1 & 3.6 & Brazil (St Peter's Rocks) & Livingston and Thompson, 1971. \\
\hline Colpophyllia natans & 1 & 3.16 & Barbados & Cross and Cross, 1983. \\
\hline Dendrophyllia sp. & 1 & 4.6 & Brazil (St Peter's Rocks) & Livingston and Thompson, 1971. \\
\hline $\begin{array}{l}\text { Diploria } \\
\text { labyrinthiformis }^{(\mathrm{b})}\end{array}$ & 3 & 2.1 to $3.4^{(b)}$ & Barbados, Bermuda & Schroeder et al., 1970; Cross and Cross, 1983 \\
\hline Diploria strigosa $^{(\mathrm{b})}$ & 6 & 2.5 to $4.2^{(b)}$ & Barbados, & $\begin{array}{l}\text { Schroeder et al., 1970; Cross and Cross, 1983; } \\
\text { Muhs et al., 2011; Romaniello et al., } 2013 .\end{array}$ \\
\hline Favia cavernosa & 1 & 2.24 & Gulf of Aqaba & Freidman, 1968. \\
\hline Favia sp. & 6 & 1.60 to 2.24 & $\begin{array}{l}\text { ibid, Vanuatu, Christmas } \\
\text { Island, Tuamotu }\end{array}$ & $\begin{array}{l}\text { ibid, Sackett and Portratz, 1968; Veeh and } \\
\text { Turekian, 1968; Edwards et al., 1988; }\end{array}$ \\
\hline Fungia sp. ${ }^{(b)}$ & 5 & 1.96 to $2.39^{(b)}$ & Tuamotu & Veeh and Turekian, 1968. \\
\hline Goniastrea retiformis & 7 & 2.17 to 2.69 & Vanuatu & Edwards et al., 1988 \\
\hline Goniastrea sp. & 8 & 2.17 to 2.681 & ibid, Japan & ibid, Henderson et al., 1993. \\
\hline Leptastrea sp. & 3 & 2.59 to 3.18 & Hawaii & Veeh and Turekian, 1968. \\
\hline Leptoria sp. & 3 & 1.80 to 2.24 & Samoa & Veeh and Turekian, 1968. \\
\hline Madacis asperula & 1 & 4.5 & Brazil (St Peter's Rocks) & Livingston and Thompson, 1971. \\
\hline Madracis mirabilis & 2 & 3.5 & Jamaica & Livingston and Thompson, 1971. \\
\hline Madracis sp. & 5 & 2.63 to 4.5 & ibid, Barbados, Brazil & ibid, Cross and Cross 1983. \\
\hline Meandrina areolata & 1 & 2.7 & Florida Bay & Livingston and Thompson, 1971. \\
\hline Meandrina braziliensis & 3 & 2.47 to 4.8 & Barbados, Brazil & $\begin{array}{l}\text { Livingston and Thompson, 1971; Cross and Cross, } \\
1983 .\end{array}$ \\
\hline Meadrina meandrites & 1 & 2.77 & Barbados & Cross and Cross, 1983. \\
\hline Millipora dichotoma & 4 & 7.5 to 12.5 & Gulf of Aqaba & Abu-Hilal, 1994. \\
\hline Montastraea annularis & 23 & 2.19 to 3.13 & $\begin{array}{l}\text { Bahamas, Barbados, Grand } \\
\text { Cayman, Jamaica }\end{array}$ & $\begin{array}{l}\text { Livingston and Thompson, 1971.; Flor and Moore, } \\
\text { 1977; Cross and Cross, 1983; Chen et al., 1991; } \\
\text { Muhs et al., } 2011 .\end{array}$ \\
\hline Montastraea cavernosa & 2 & 2.1 to 3.5 & Bermuda & Schroeder et al 1970. \\
\hline Montastraea sp. & 24 & 2.1 to 3.5 & ibid & ibid \\
\hline Oculina diffusa & 2 & 1.9 to $3.6^{(b)}$ & Bermuda & Schroeder et al 1970. \\
\hline Oculina sp. & 4 & 1.9 to $3.14^{(b)}$ & Bermuda & ibid, Ludwig et al., 1996 \\
\hline Pavona clavus & 4 & 2.90 to 3.08 & Galapagos & Hamelin et al., 1991. \\
\hline Platygra lamellina & 4 & 6.7 to 10.0 & Gulf of Aqaba & Abu-Hilal, 1994. \\
\hline Platygra sinensis & 1 & 2.57 & Vanuatu & Edwards et al., 1988. \\
\hline Platygra sp. & 8 & 1.44 to 10.0 & ibid, Hong Kong & ibid, Edwards et al., 1987b \\
\hline Plerogyra sinuosa & 4 & 7.0 to 12.5 & Gulf Aqaba & Abu-Hilal, 1994. \\
\hline Pocillopora damicornis & 2 & 1.736 to 1.807 & Australia (Heron Island) & Swart and Hubbard, 1982. \\
\hline Pocillopora sp. & 8 & 1.736 to 2.51 & ibid, Hawaii, Tahiti & ibid, Veeh and Turekian, 1968; Szabo et al., 1994 \\
\hline Porites asteroids ${ }^{(b)}$ & 6 & 2.7 to 4.2 & $\begin{array}{l}\text { Bahamas, Barbados, } \\
\text { Bermuda, Curacao, Grand } \\
\text { Cayman }\end{array}$ & $\begin{array}{l}\text { Flor and Moore, 1977; Schroeder et al., 1977; } \\
\text { Cross and Cross, 1983; Muhs et al., 2012a; } \\
\text { Romaniello et al., 2013. }\end{array}$ \\
\hline Porites australiensis & 1 & 2.4 & $\begin{array}{l}\text { Marshall Islands (Enewetak } \\
\text { Atoll) }\end{array}$ & Sackett and Portratz, 1963. \\
\hline Porites divaricata & 1 & 2.55 & Bahamas & Romaniello et al., 2013. \\
\hline Porites lutea & 13 & 2.46 to 2.595 & Vietnam & Shen et al., 2008 \\
\hline Porites porites & 2 & 2.76 to 2.91 & Bahamas, Barbados & Cross and Cross, 1983; Muhs et al., 2011. \\
\hline
\end{tabular}




\begin{tabular}{|c|c|c|c|c|}
\hline Porites sp. & 89 & 1.3 to 4.2 & $\begin{array}{l}\text { ibid, Taiwan, China, Gulf } \\
\text { Aqaba, Hawaii, Marquesas } \\
\text { Islands }\end{array}$ & $\begin{array}{l}\text { ibid, Gvirtman et al., 1973, Szabo et al., 1994; } \\
\text { Zhao and Ku, 2002, Lazar et al., 2004; Scholz et al., } \\
\text { 2004; Cabioch et al., } 2008\end{array}$ \\
\hline Scolmia cubensis & 2 & 2.6 to 2.7 & Jamaica & Livingston and Thompson, 1971. \\
\hline Siderastrea radians & 1 & 2.79 & Bahamas & Romaniello et al., 2013. \\
\hline Siderastrea siderea & 1 & 2.58 & Barbados & Cross and Cross, 1983. \\
\hline Siderastrea sp. & 5 & 2.58 to 2.87 & ibid, Bermuda, Florida & Ibid, Ludwig et al., 1996. \\
\hline Stylophora pistillata & 5 & 2.46 to 11.3 & Gulf of Aqaba & Friedman, 1968; Abu-Hilal, 1994. \\
\hline $\begin{array}{l}\text { Unidentified } \\
\text { (hermatypic) }\end{array}$ & 54 & 1.3 to 4.7 & $\begin{array}{l}\text { Bermuda, Brazil (St Paul's } \\
\text { Rocks), Brazil, Florida Keys, } \\
\text { Gulf of Aqaba, Marshall } \\
\text { Islands (Enewetak Atoll), } \\
\text { Palmyra Island (Northern } \\
\text { Line Islands) }\end{array}$ & $\begin{array}{l}\text { Broecker, 1963; Broecker and Thuber, 1965; } \\
\text { Friedman, 1968; Livingston and Thompson, 1971; } \\
\text { Amiel et al., 1973; Gvirtman et al., 1973; Cobb et } \\
\text { al., 2003b. }\end{array}$ \\
\hline $\begin{array}{l}\text { Unidentified } \\
\text { (ahermatypic) }\end{array}$ & 9 & 4.06 to 4.16 & $\begin{array}{l}\text { Unidentified and shallow } \\
\text { waters around St Peter and } \\
\text { St Paul's Rocks }\end{array}$ & Thompson and Livingston, 1970. \\
\hline ALL (hermatypic) & 254 & 1.28 to 12.5 & ibid & ibid \\
\hline
\end{tabular}




\section{Figure's}

\section{Figure 1}

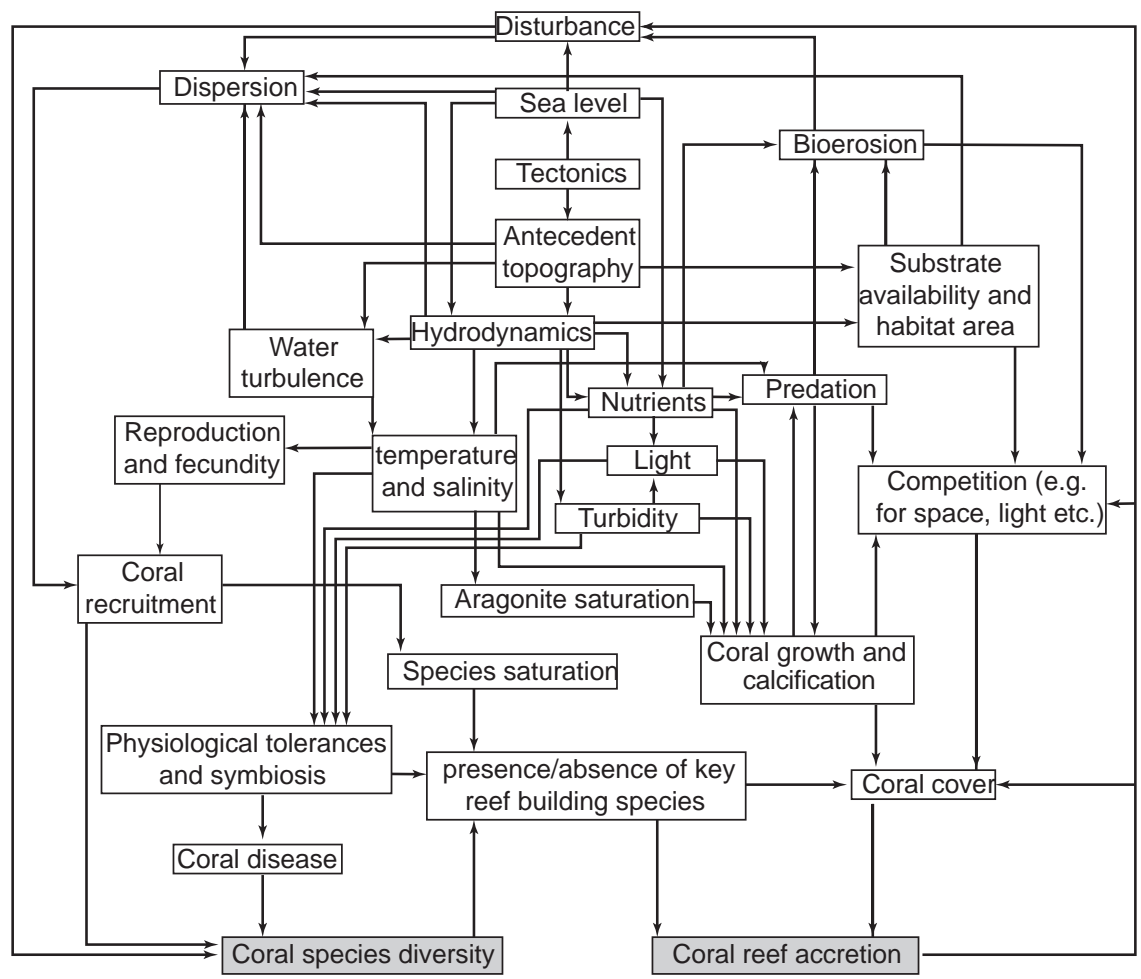


Figure 2

(A)

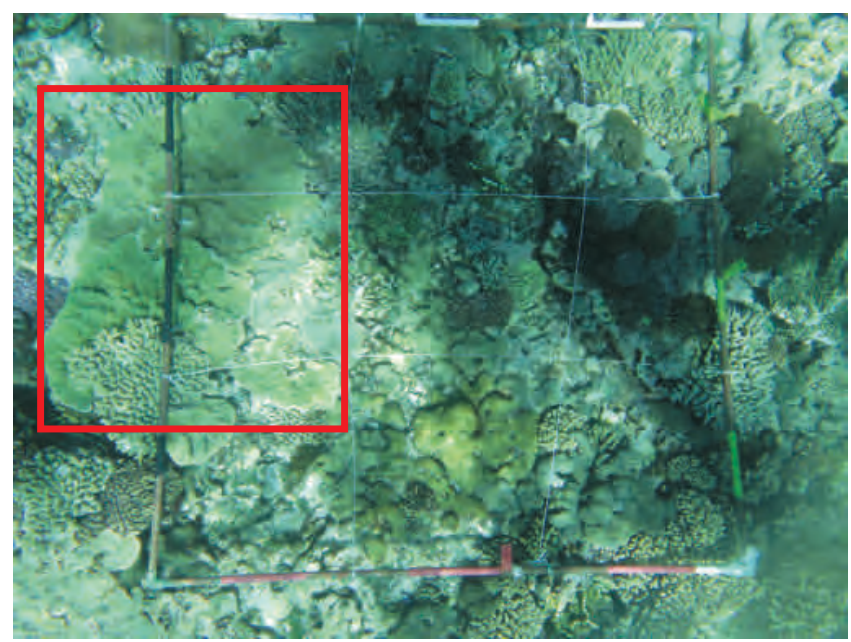

(B)

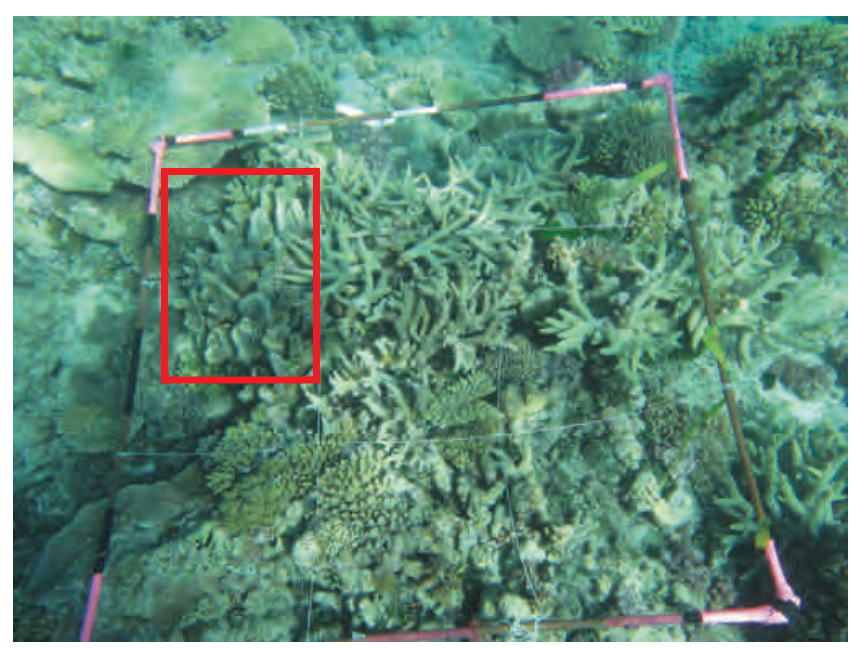

(C)

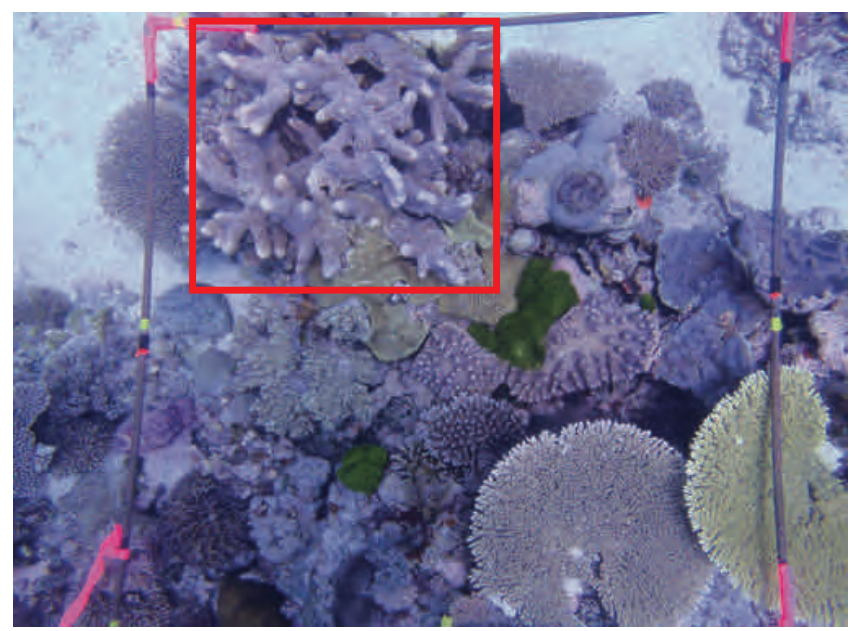


Figure 3

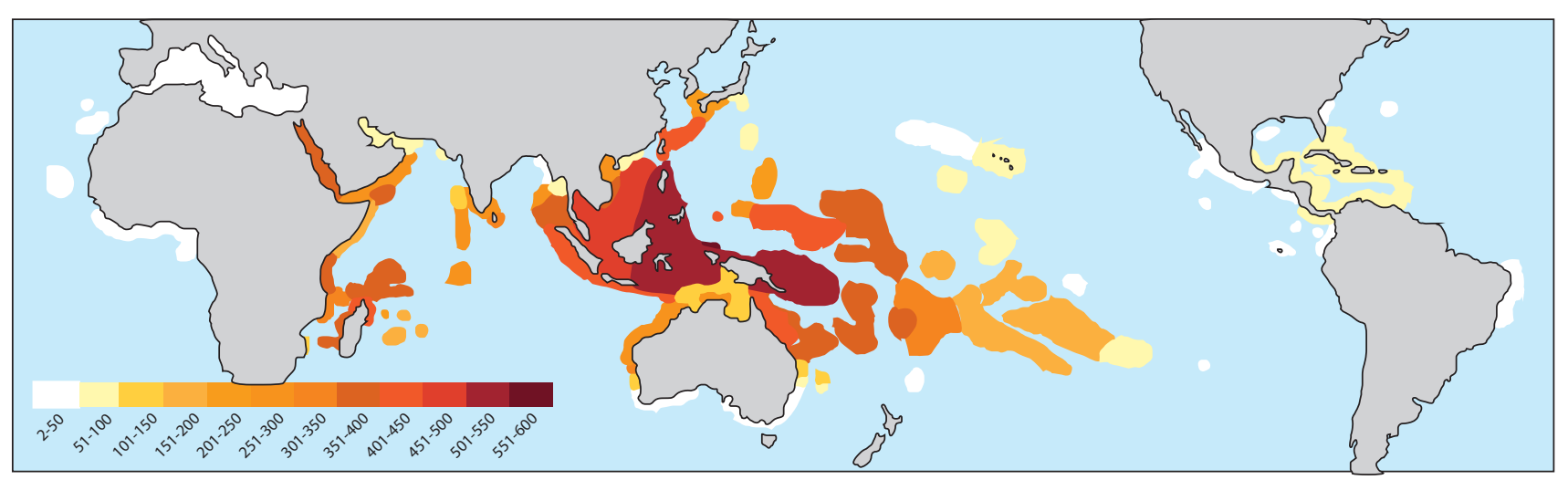


Figure 4

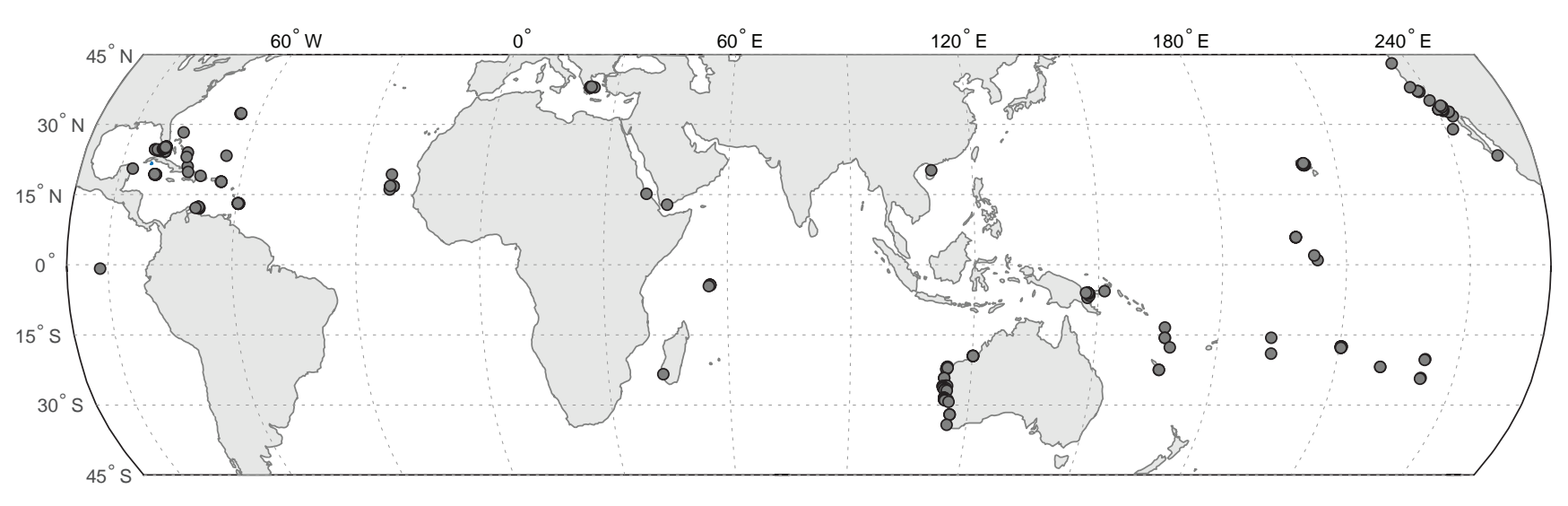




\section{Figure 5a}
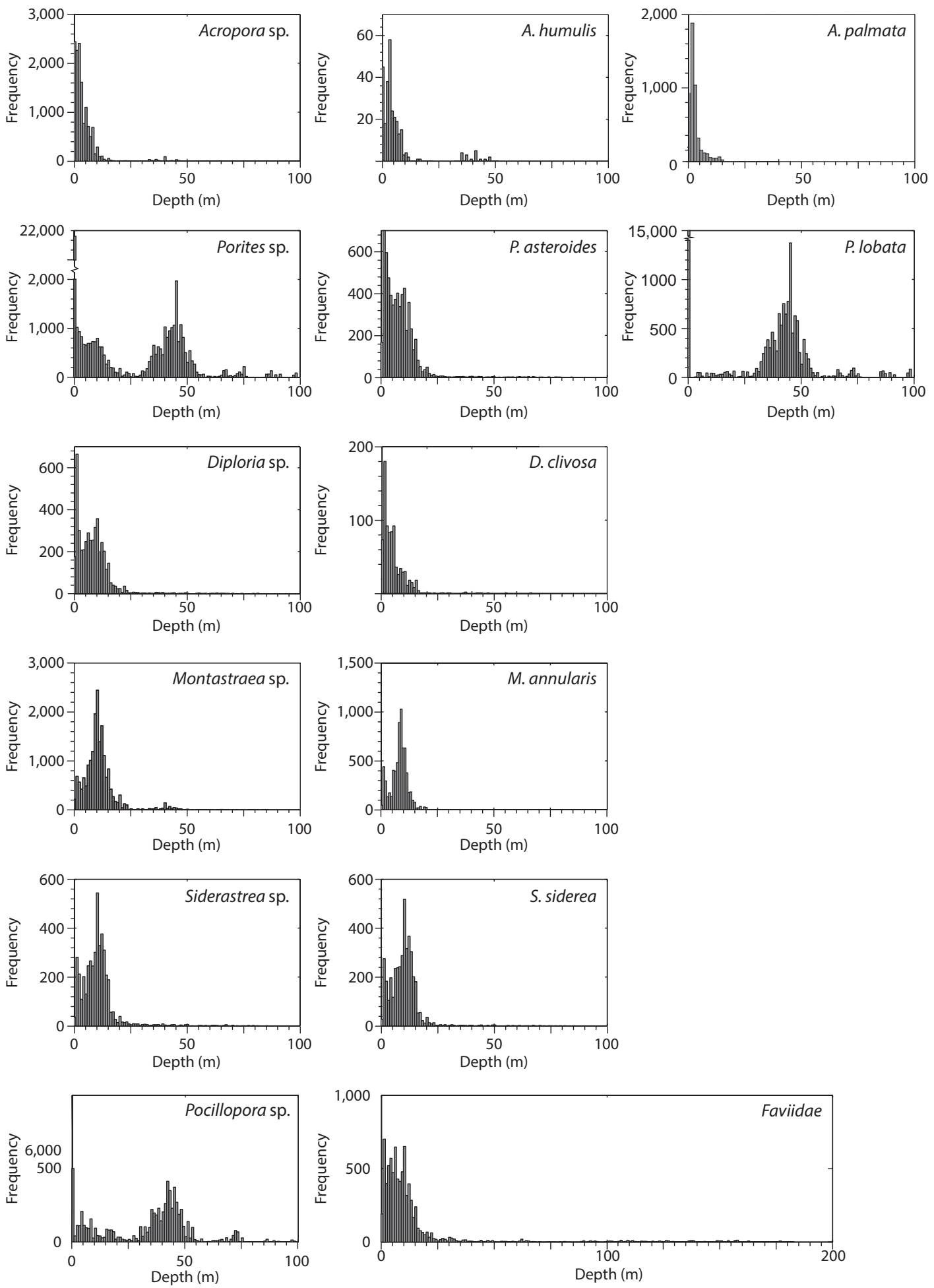


\section{Figure 5b}
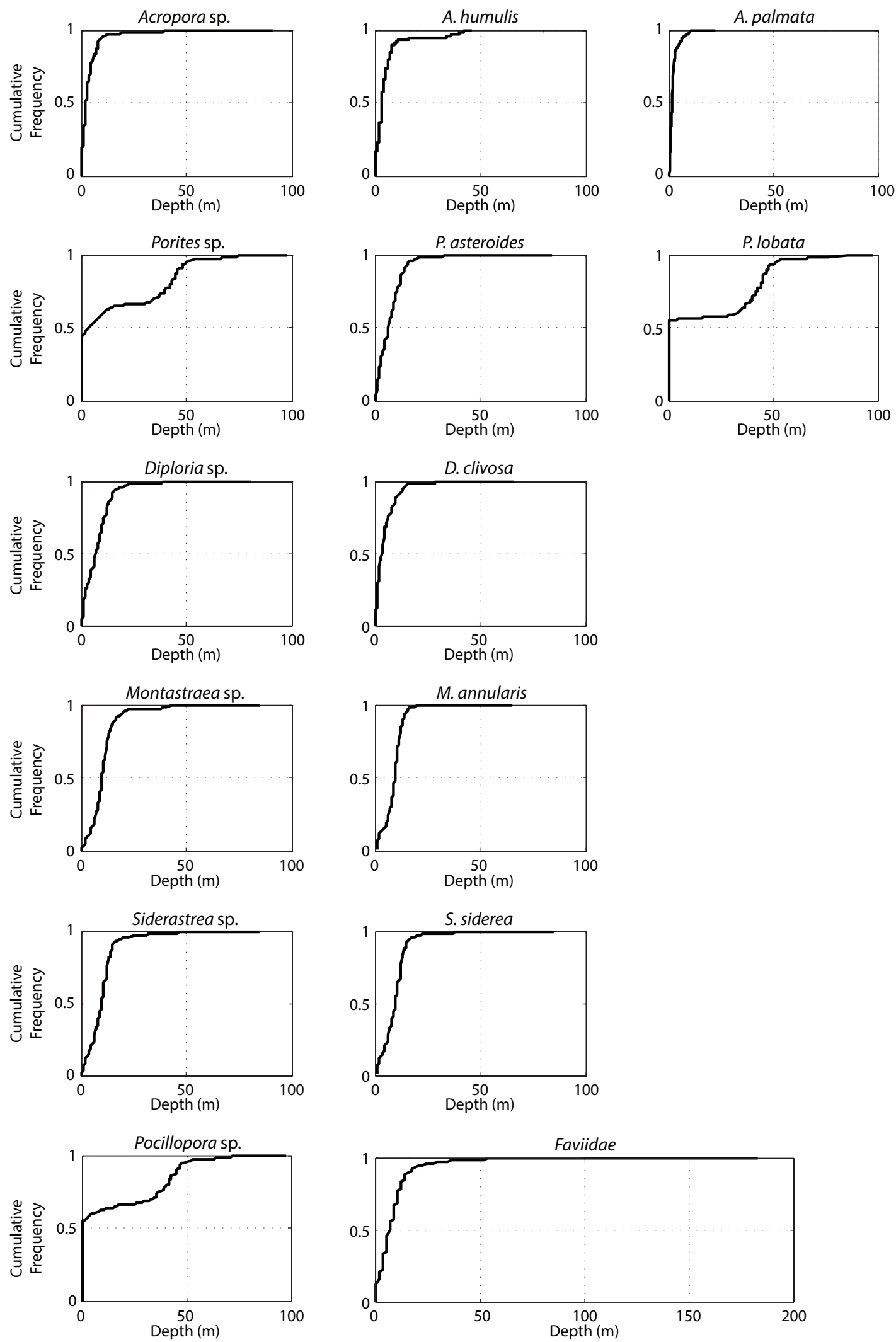


\section{Figure 6}

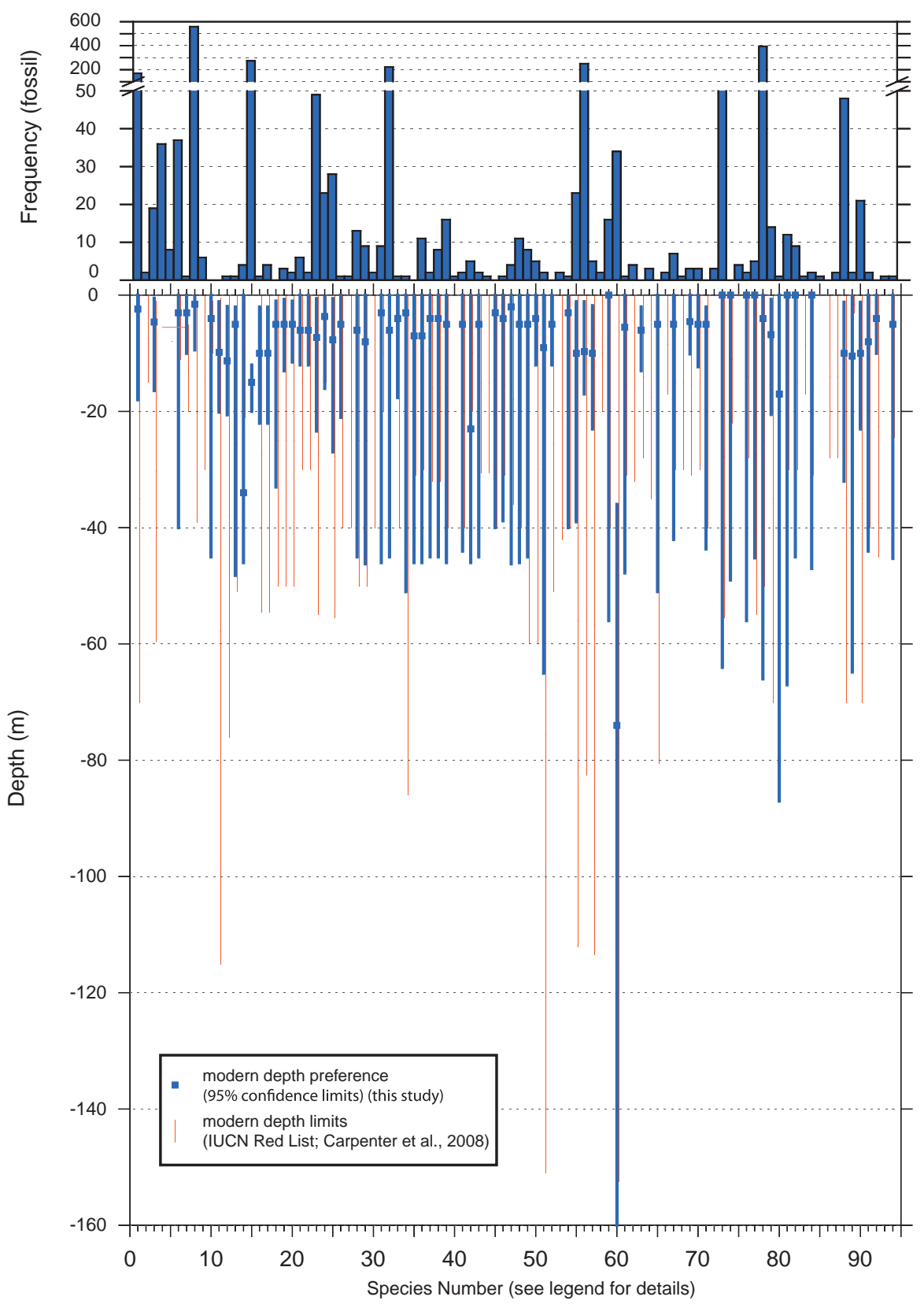


Figure 7

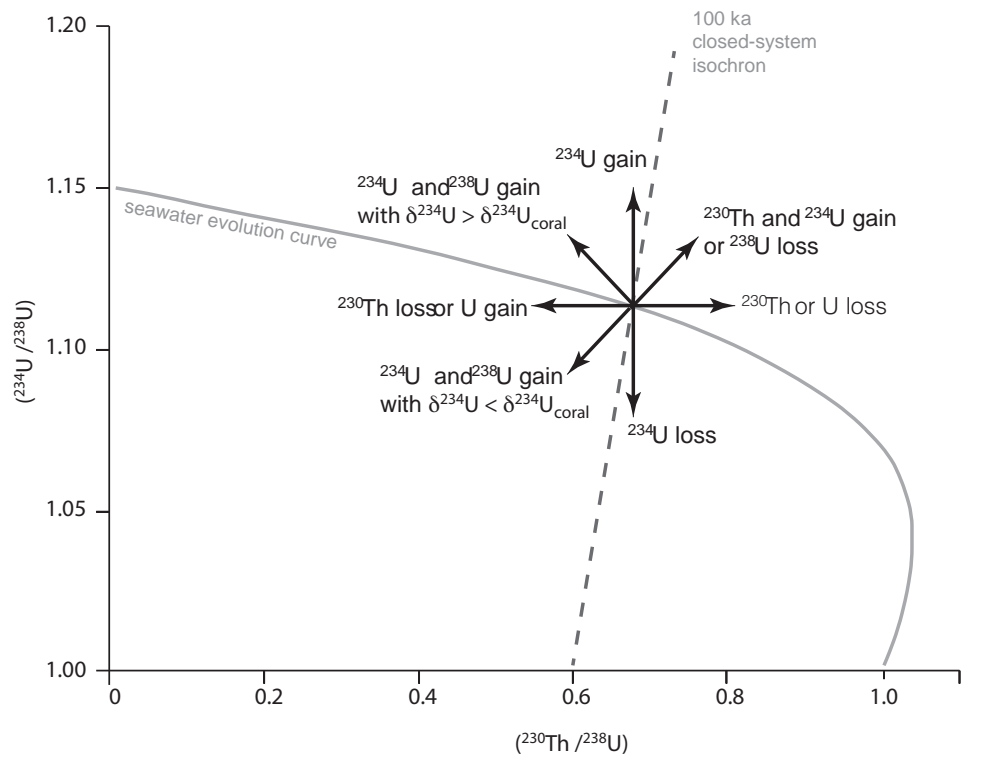




\section{Figure 8}

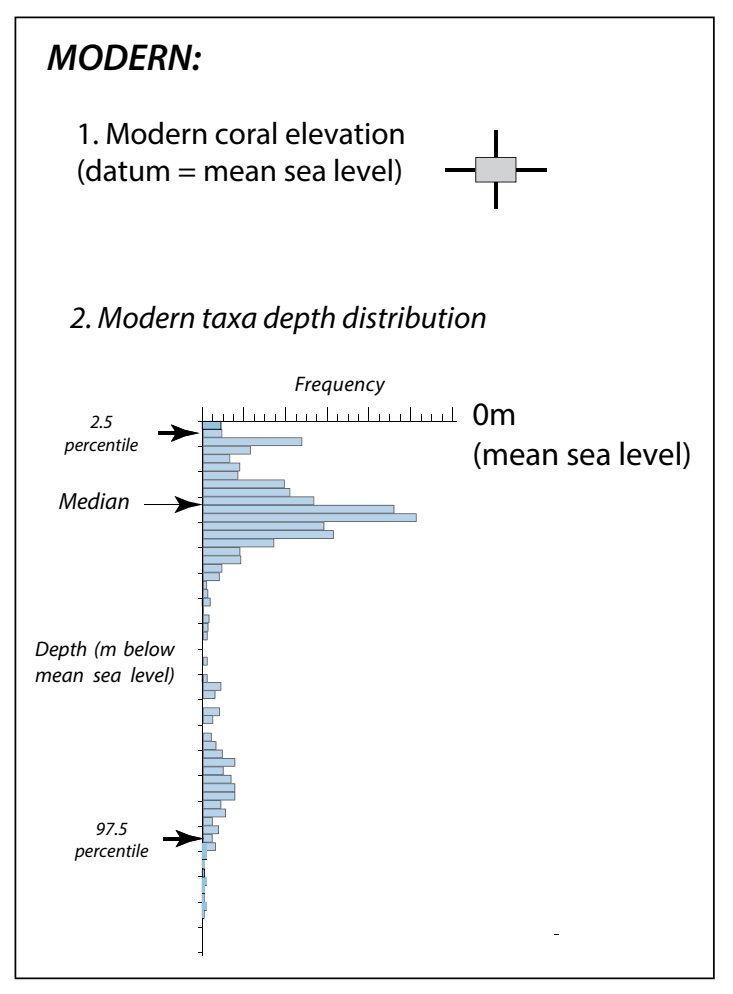

PAST:

1. Corrected coral position

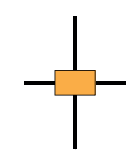

$Z c p$

(frame of reference $=0 \mathrm{~m}$, mean sea level)

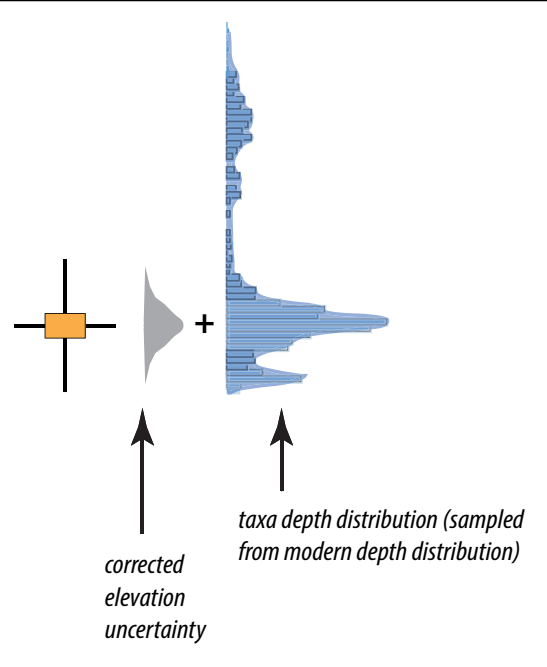

2. Probability of RSL $\left(P_{R S L}\right)=$ Combination of elevation error AND depth distribution

(frame of reference $=$ coral position) 


\section{Figure 9}

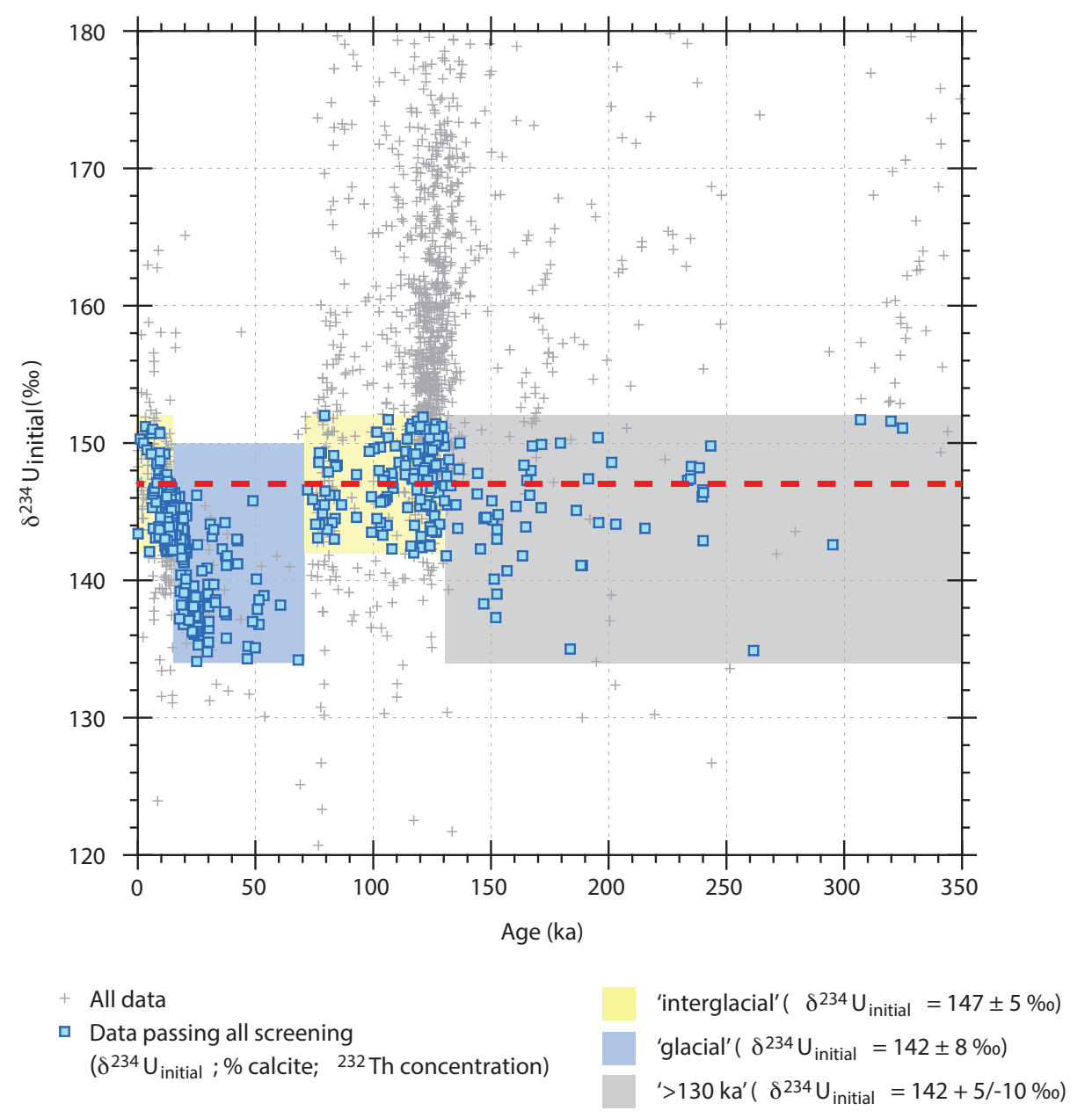




\section{Figure 10}

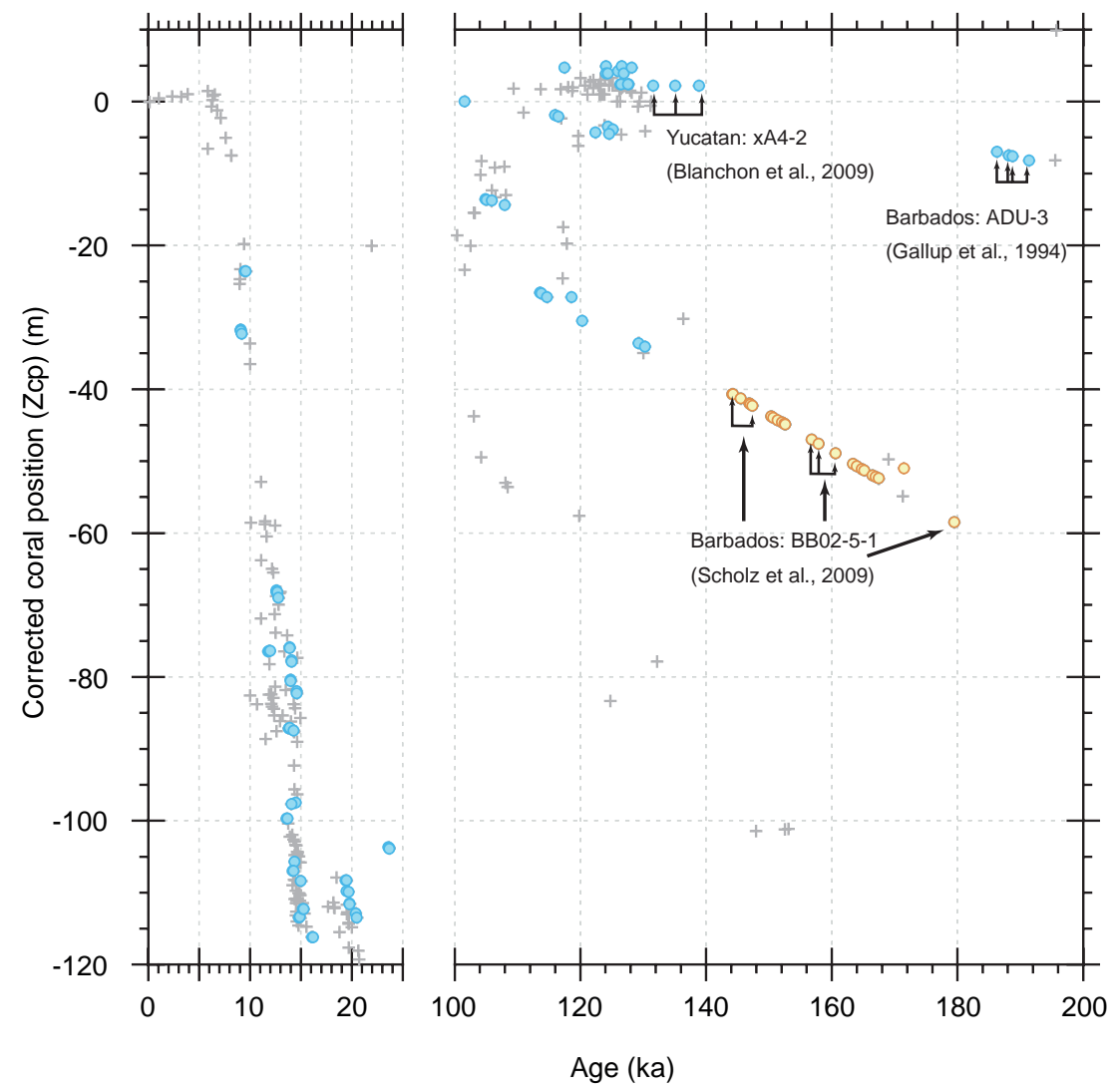

\footnotetext{
Samples passing ${ }^{234} \mathrm{U}_{\text {inital }}, \%$ calcite, ${ }^{232} \mathrm{Th}$ concentration screening

Replicate samples passing screening

- Scholz et al., 2009 samples passing screening
} 


\section{Figure 11}
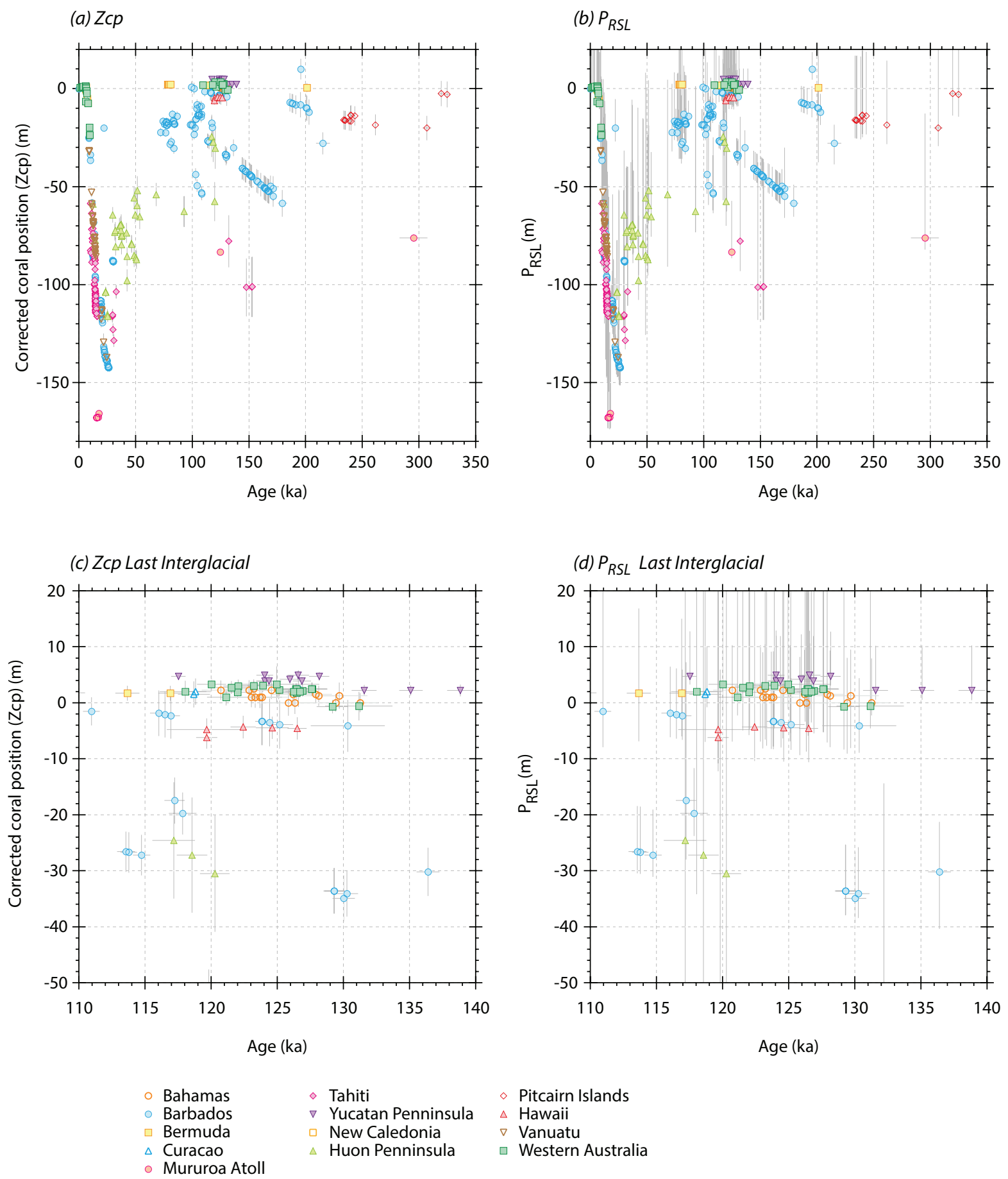


\section{Figure 12}
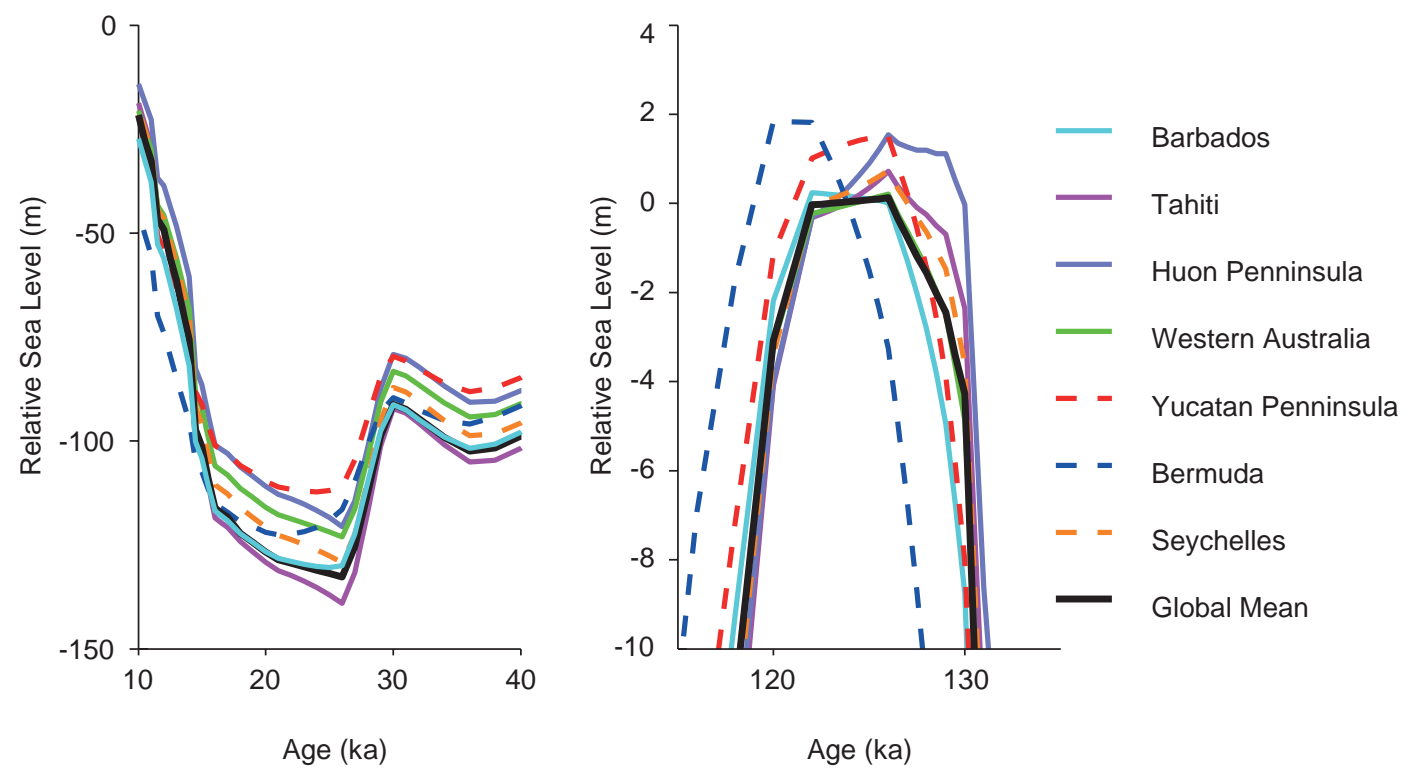


\section{Figure 13}
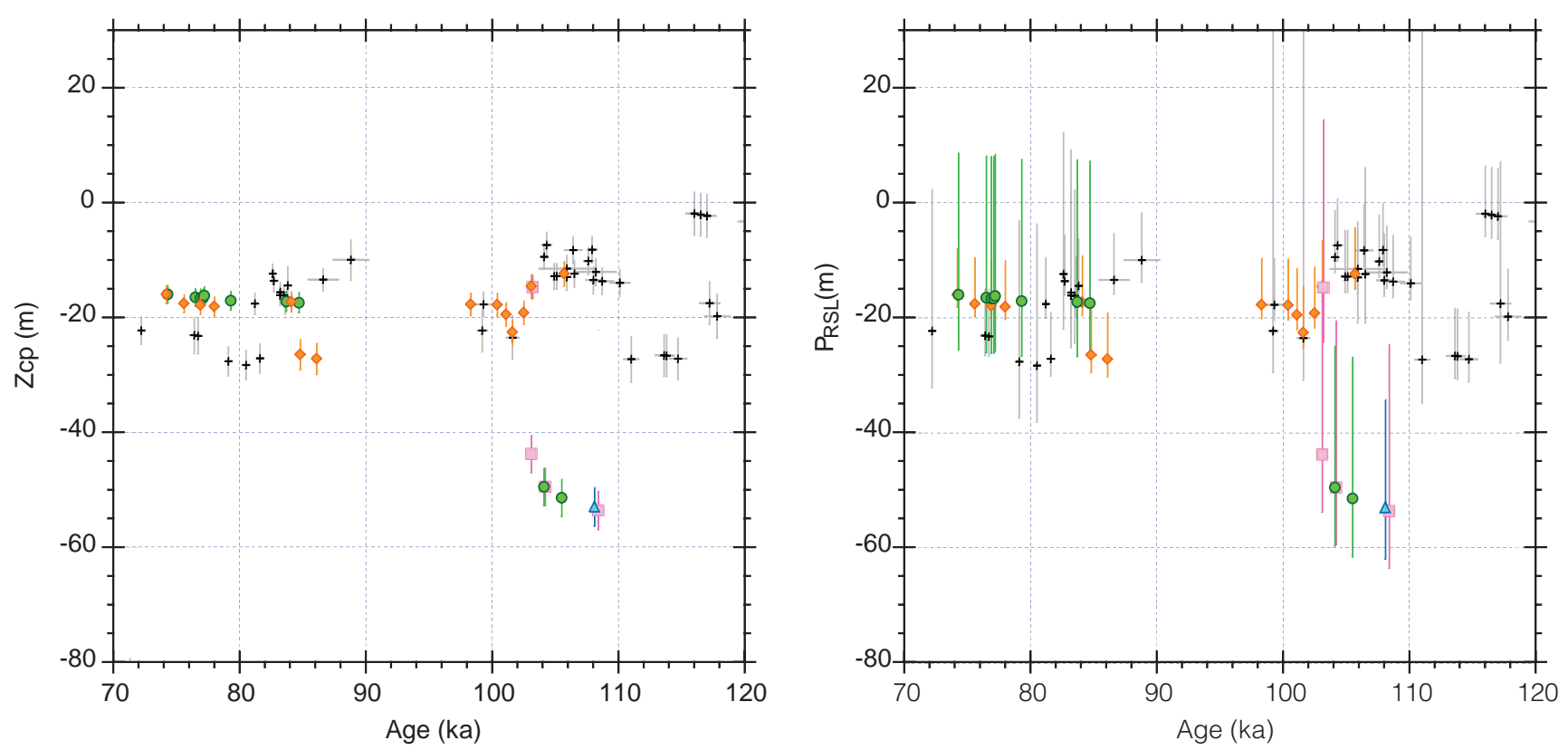

\footnotetext{
+ AllBarbados samples passing screening Reef crest- A. palmata

$\left(\delta^{234} \mathrm{U}_{\text {initial }}, \%\right.$ calcite, ${ }^{232} \mathrm{Th}$ concentration $) \Delta$ Reef crest - Diploria sp.

$\square$ Reef crest - Montastraea sp.

- Reef crest - Siderastreasp.
} 
Figure 14

(A)

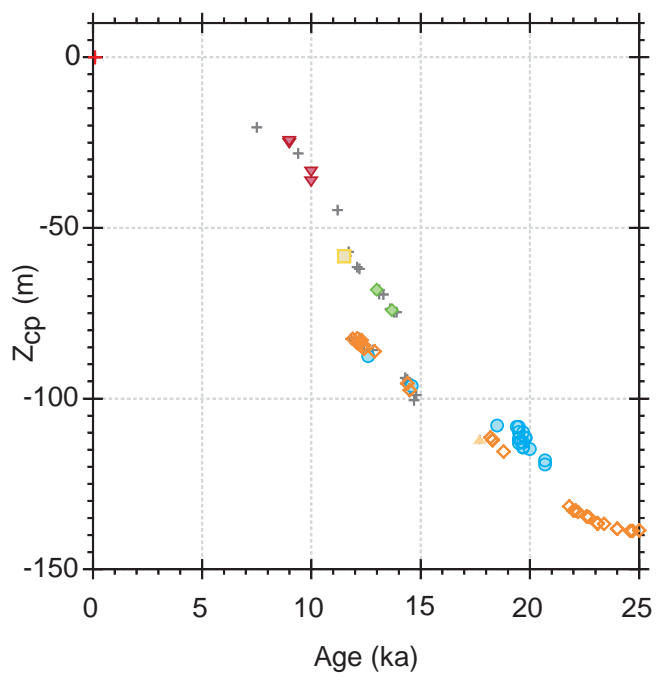

(B)

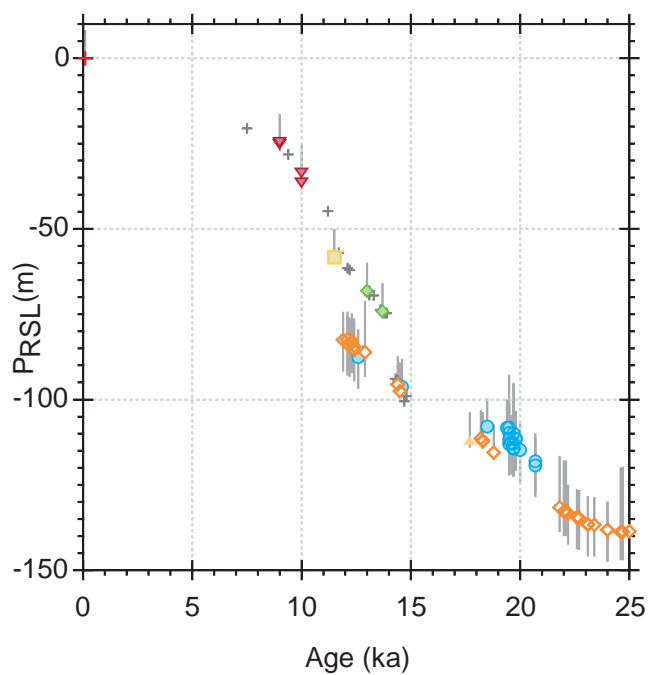

(C)

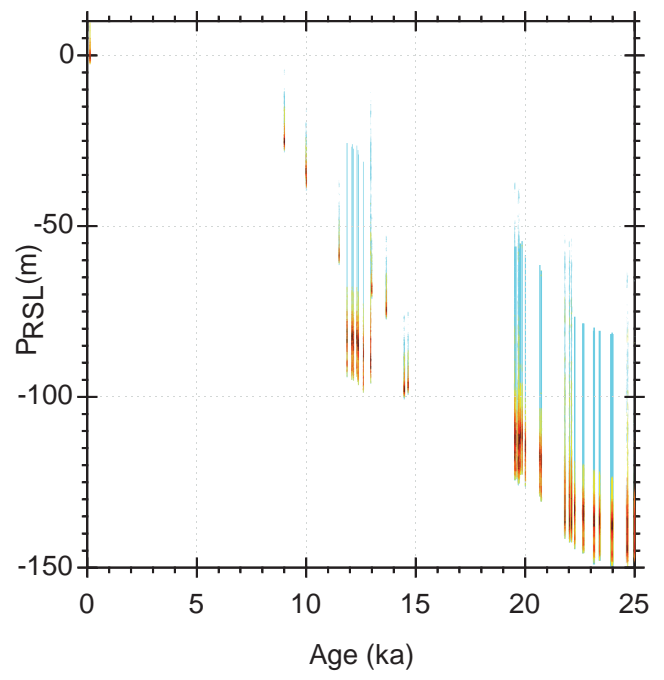

Drill core samples:

$\nabla$ RGF 7

$\diamond$ RGF 9

$\diamond$ RGF 12

$\triangle$ RGF 13

$+\begin{aligned} & \text { Barbados samples NOT passing screening } \\ & \left(\delta^{234} U_{\text {initial }}, \% \text { calcite, } 232 T h \text { concentration }\right)\end{aligned}$

- RGF 15

+ Barbados samples passing screening -

ㅁ RGF 16

99th percentile

$95^{\text {th }}$ percentile

$80^{\text {th }}$ percentile

$70^{\text {th }}$ percentile

$50^{\text {th }}$ percentile 
Figure 15

(A)

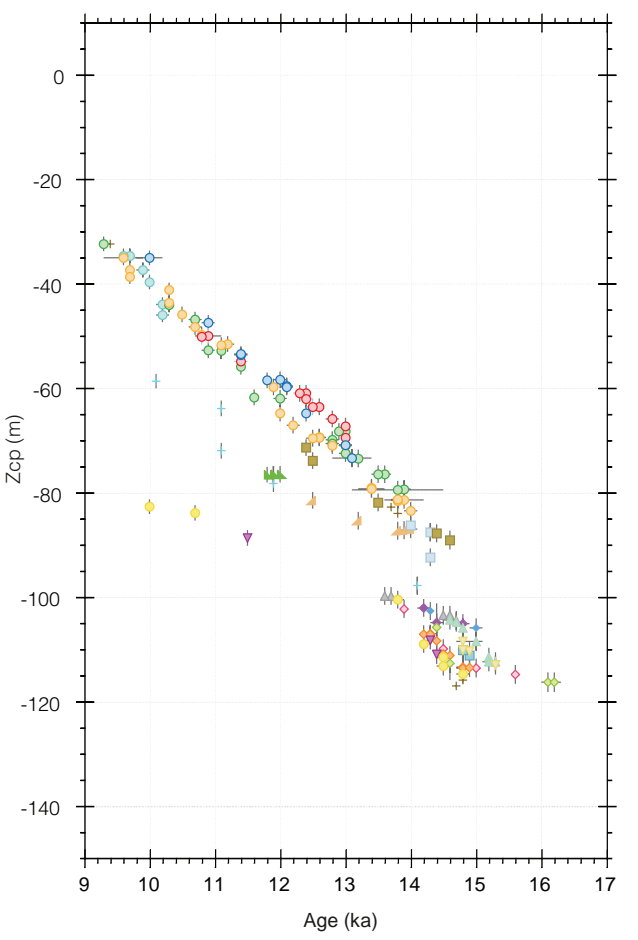

(B)

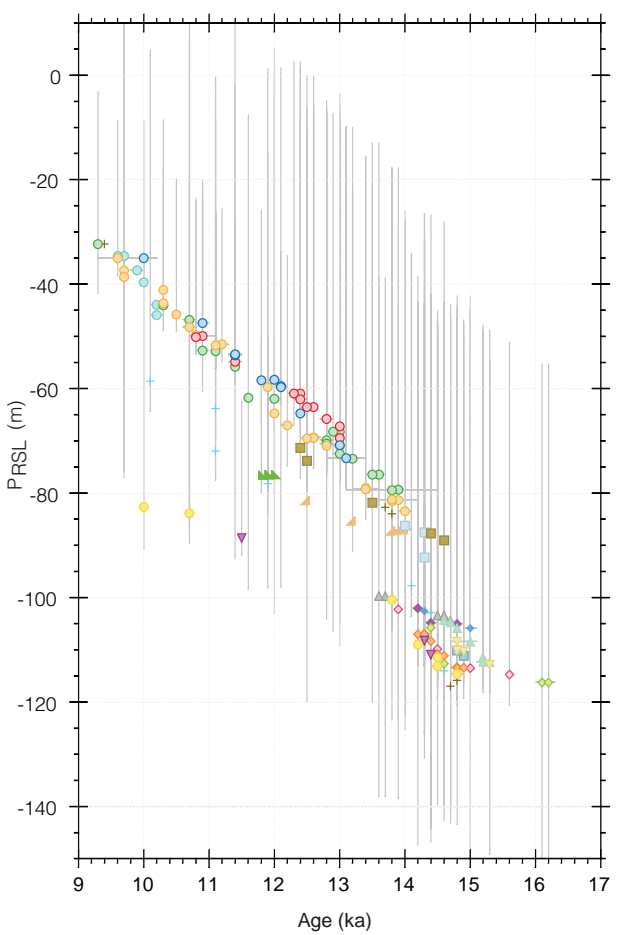

Papeete harbour

(note, no ${ }^{232} \mathrm{Th}$ concentrations

Samples passing screening
( $88^{34} \mathrm{U}$ initial \% calcite, , 32 Th concentration)

+ Tahiti samples NOT passing screening listed for these samples)

Ta-P6
T. Tap7

$\circ$ Ta-P7
$\circ$ Ta-P8
0 TaPg

$\circ$ Ta-P9
(C)

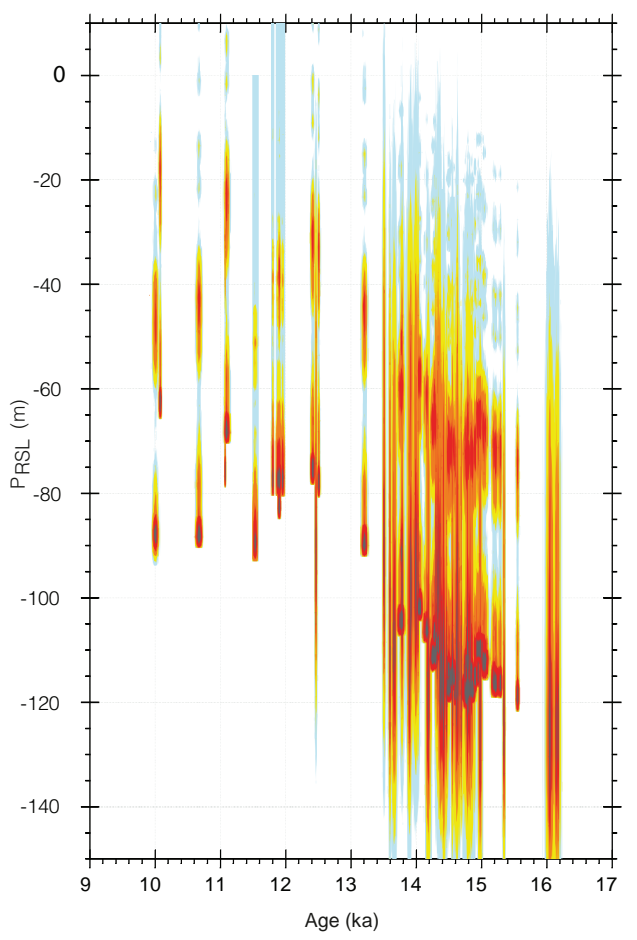

99th percentile

95th percentile

$80^{\text {th }}$ percentile

$70^{\text {th }}$ percentile

$50^{\text {th }}$ percentile 


\section{Figure 16}

(A)
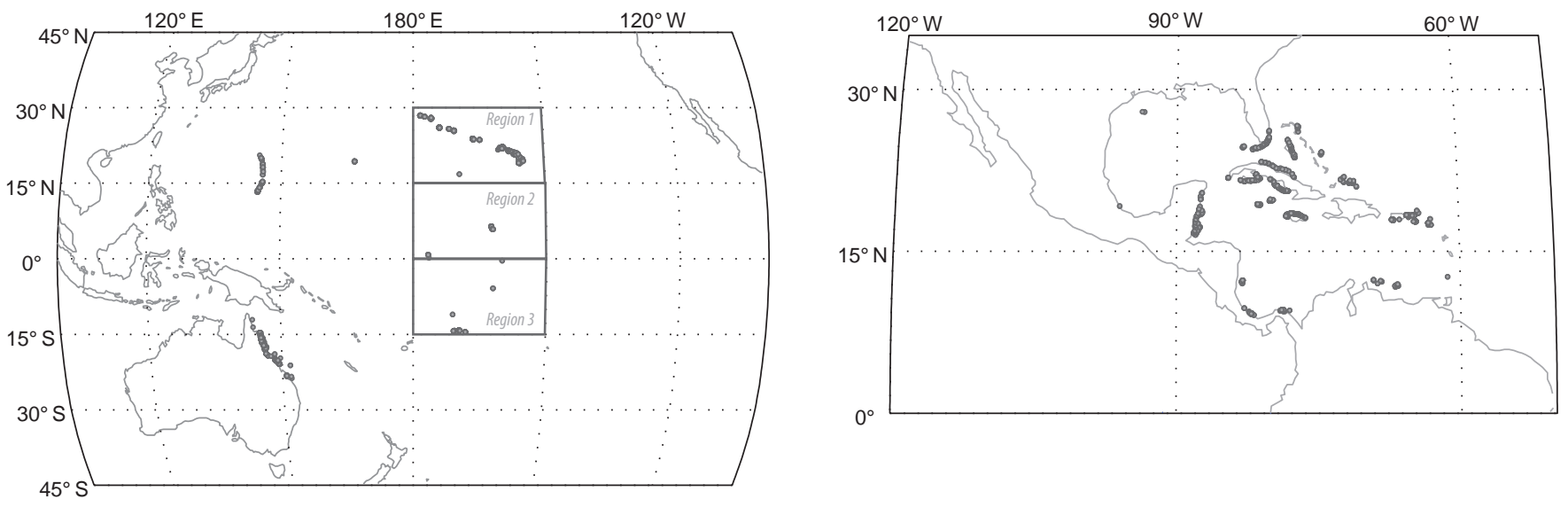

(B)
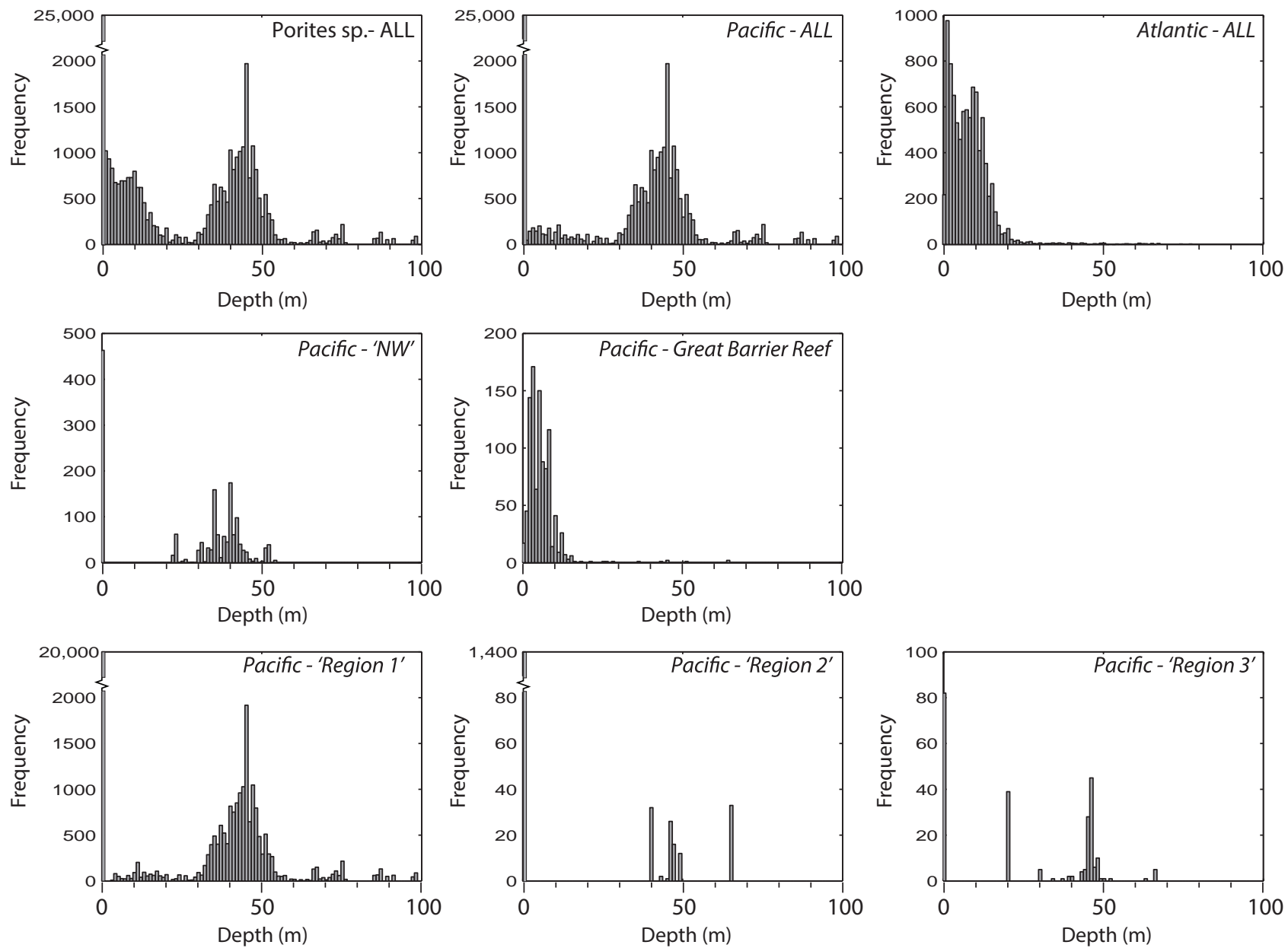


\section{Figure 17}

(A)
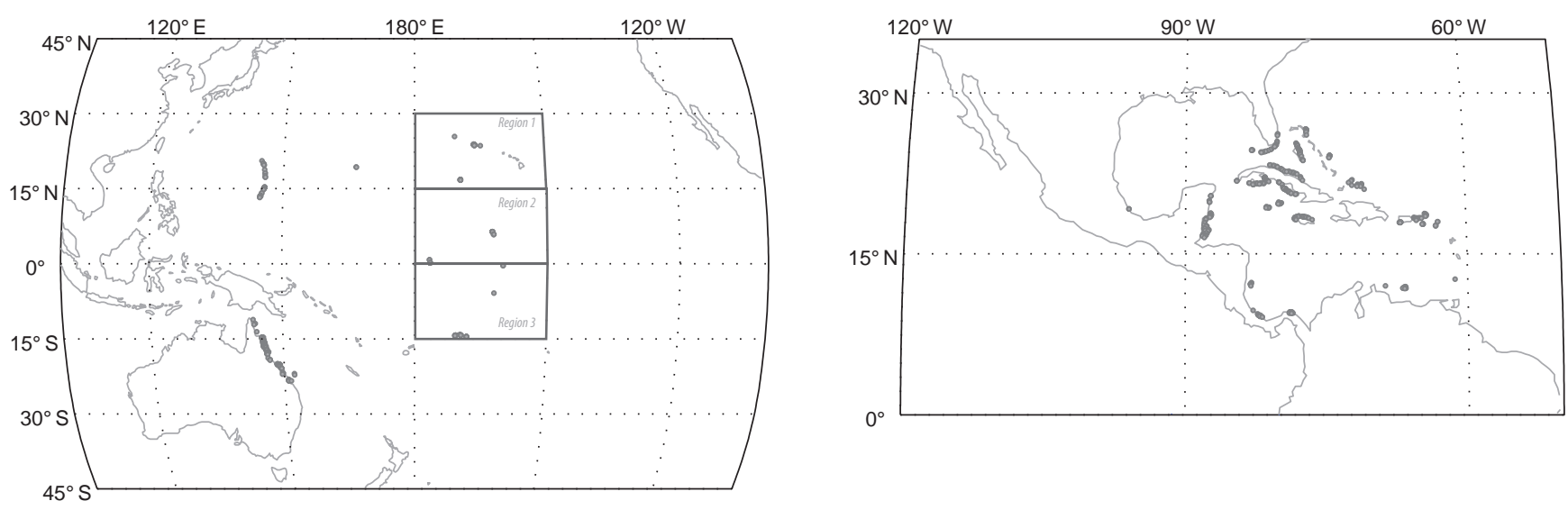

(B)
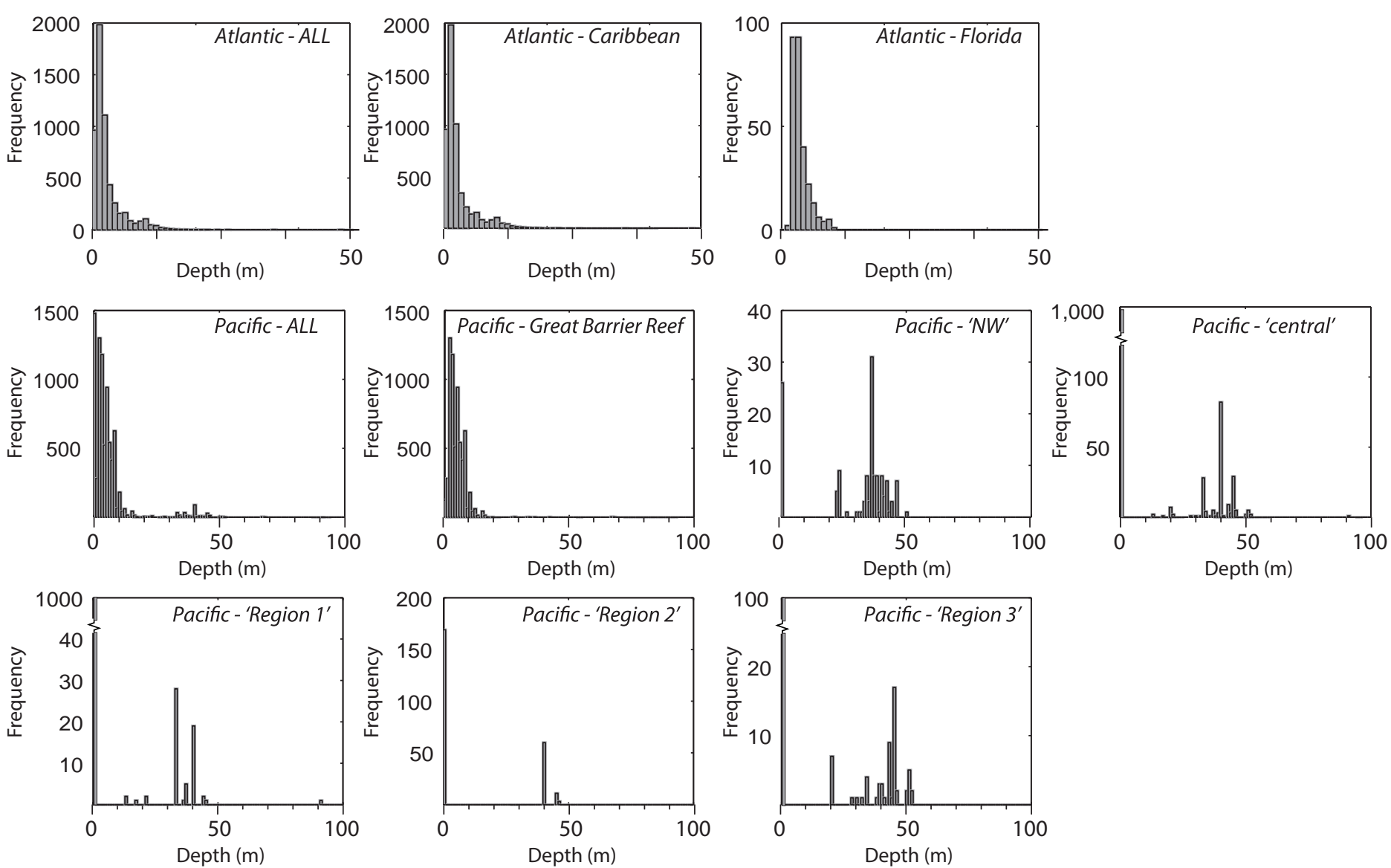


\section{Figure 18}

(A)
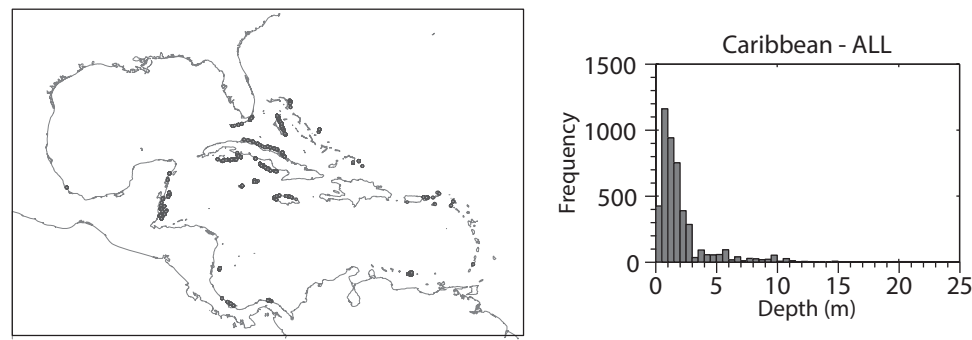

(B)
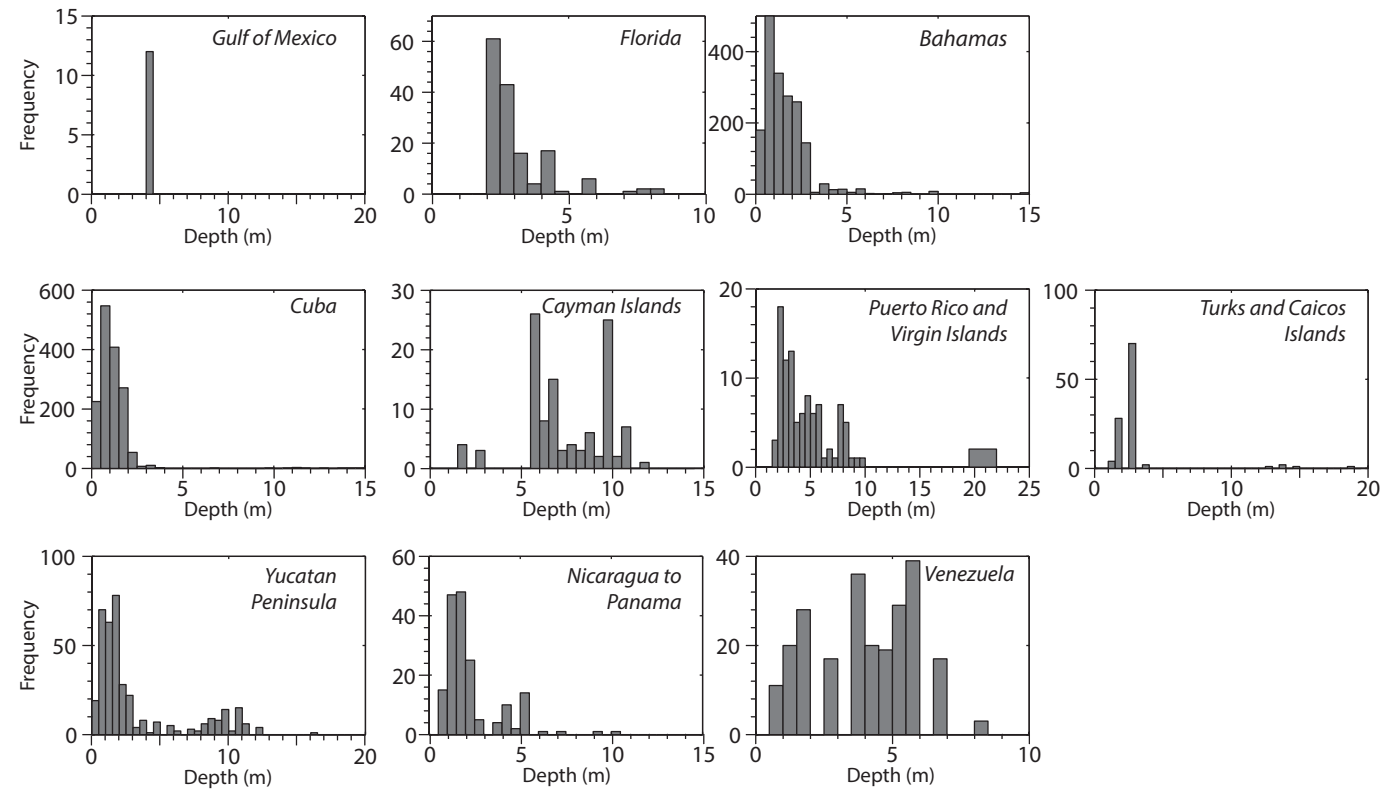

(C)
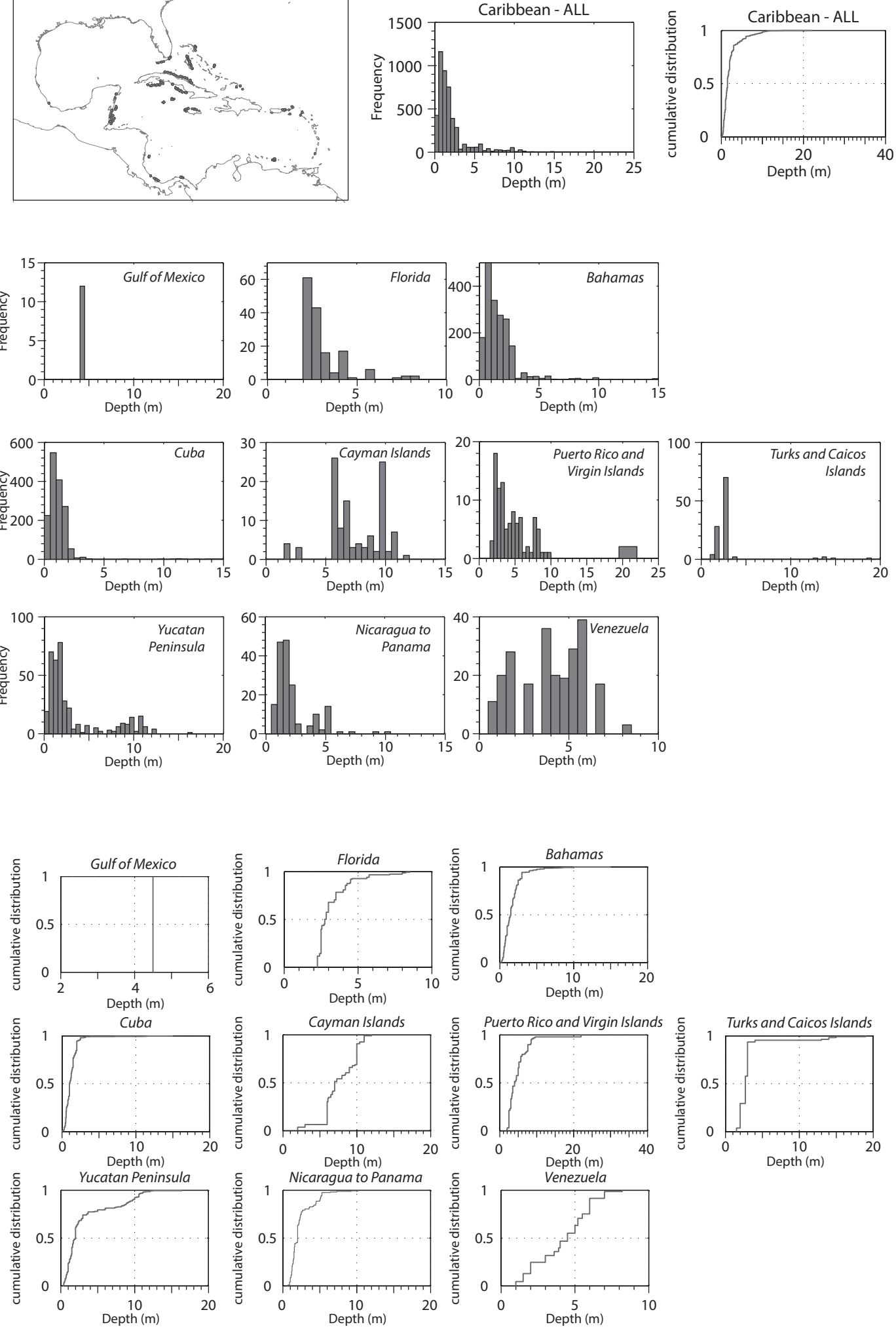

$$
\text { . }
$$

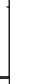




\section{Figure 19}

(A) Zcp

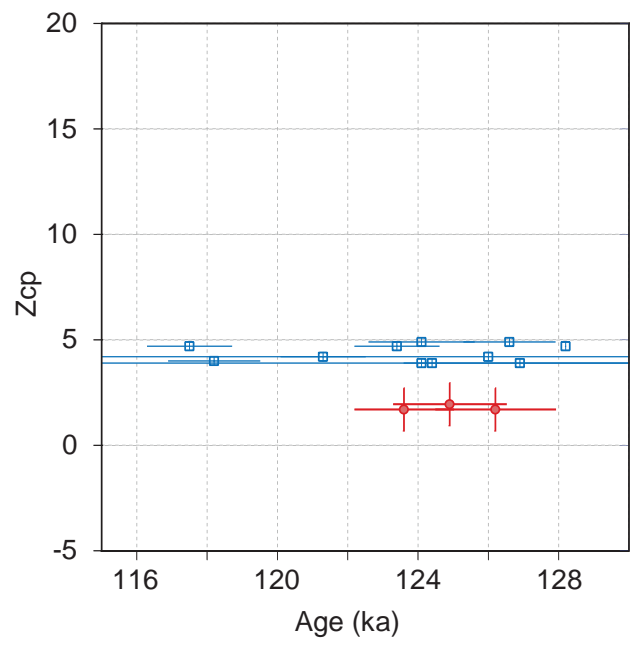

$\begin{array}{ll}\square \text { Yucatan Peninsula } & - \text { Bahamas } \\ 99^{\text {th }} \text { percentile } & 99^{\text {th }} \text { percentile } \\ 95^{\text {th }} \text { percentile } & 95^{\text {th }} \text { percentile } \\ 80^{\text {th }} \text { percentile } & 80^{\text {th }} \text { percentile } \\ 70^{\text {th }} \text { percentile } & 70^{\text {th }} \text { percentile } \\ 50^{\text {th }} \text { percentile } & 50^{\text {th }} \text { percentile }\end{array}$

(B) $\mathrm{P}_{\mathrm{RSL}}$

(i) 'global' depth distribution

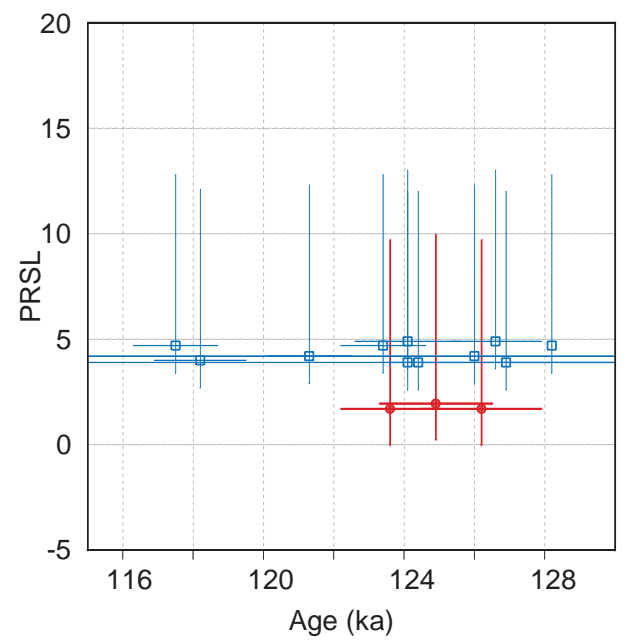

(ii) 'sub-regional' depth distribution

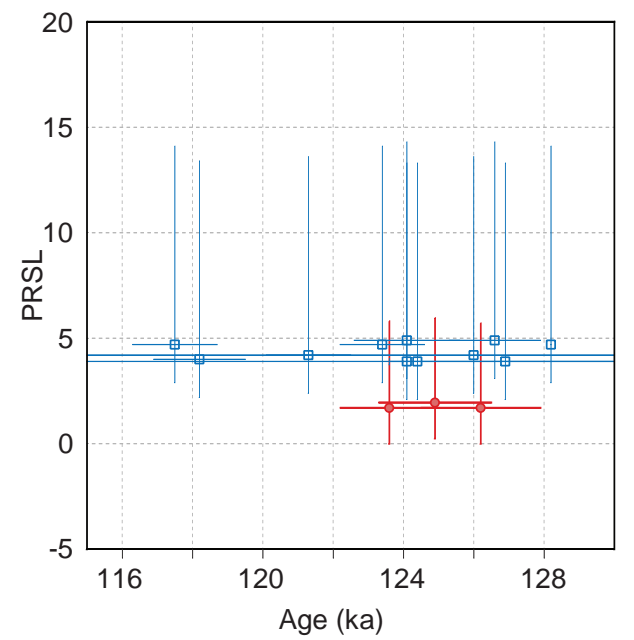

(iii) 'sub-regional' depth distribution

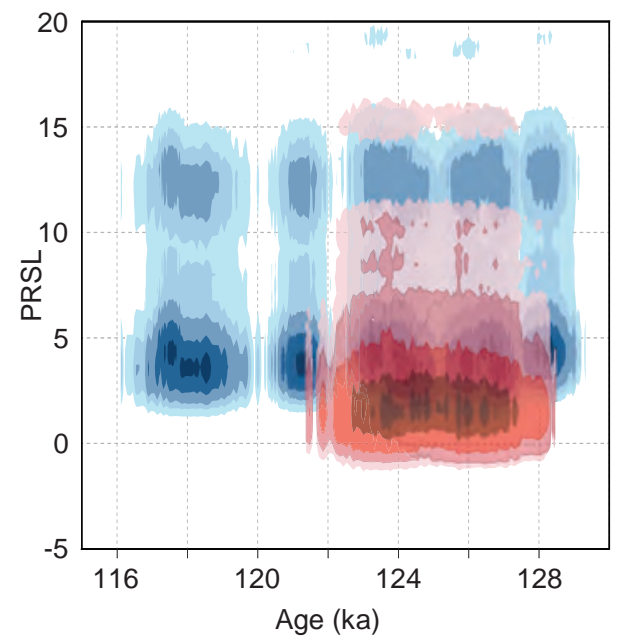


Figure 20

(A)

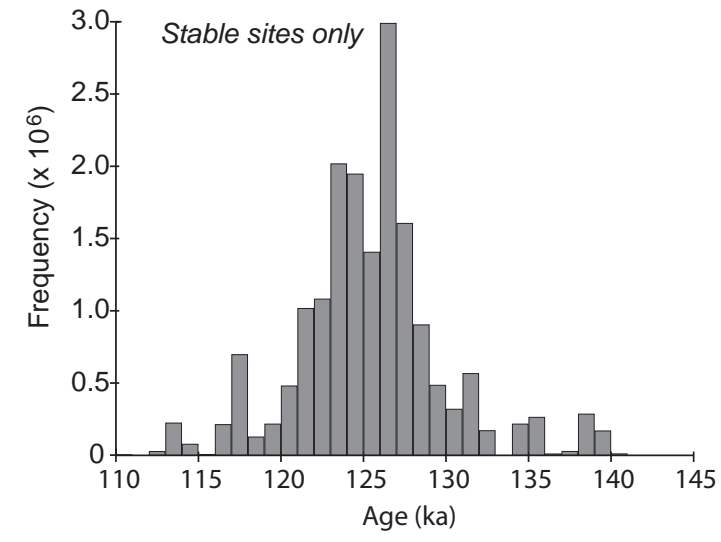

(B)

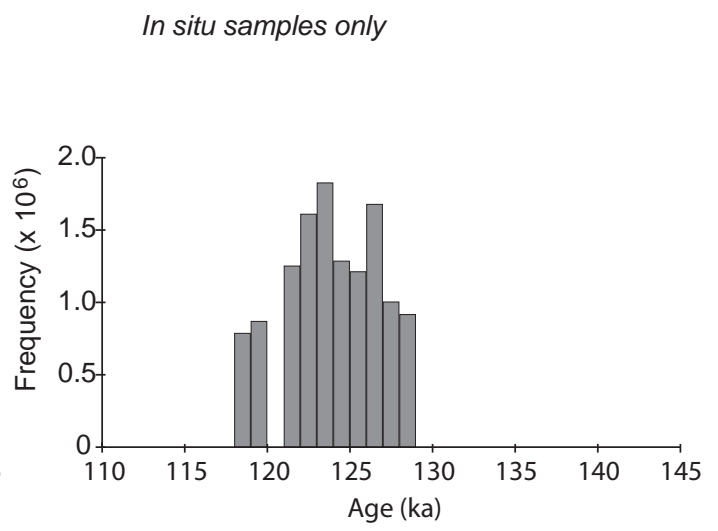

